UNIVERSIDADE DE SÃO PAULO

INSTITUTO DE ASTRONOMIA, GEOFÍSICA E CIÊNCIAS ATMOSFÉRICAS DEPARTAMENTO DE CIÊNCIAS ATMOSFÉRICAS

LÍVIA MÁRCIA MOSSO DUTRA

Ciclones subtropicais sobre o Atlântico Sul: análise da estrutura dinâmica de eventos 



\section{Ciclones subtropicais sobre o Atlântico Sul: análise da estrutura dinâmica de eventos}

Dissertação apresentada ao Departamento de Ciências atmosféricas do Instituto de Astronomia, Geofísica e Ciências Atmosféricas da Universidade de São Paulo como requisito parcial para obtenção do título de Mestre em Ciências.

Área de concentração: Meteorologia

Orientador: Prof. Dr. Rosmeri Porfírio da Rocha

Versão corrigida. A versão original se encontra arquivada no Serviço de PósGraduação do IAG. 
Ao meu namorado, Jean Peres, por todo o incentivo, paciência e amor imensurável ao longo dos últimos anos. 


\section{AGRADECIMENTOS}

- À professora Rosmeri Porfírio da Rocha, pela orientação, confiança e paciência nos meus momentos de desespero;

- Ao professor Ricardo de Camargo, pelo enorme incentivo, sugestões e envolvimento com o trabalho de pesquisa desenvolvido;

- Ao meu namorado, Jean Peres, por todo o incentivo, paciência e amor imensurável ao longo dos últimos anos. Sem sua ajuda, companheirismo, amizade e apoio desde o início da minha graduação, eu certamente não seria a pessoa feliz e completa que sou hoje;

- Aos meus pais, Nanci e Silvio, por todo o apoio incondicional e compreensão;

- Aos meus avós maternos, Carmela (in memoriam) e Silvio, por sempre acreditarem e torcerem por mim;

- À minha avó paterna, Cenira, por todo o carinho e apoio;

- Aos membros da banca do Exame de Qualificação, profs. Ricardo de Camargo e Carlos Frederico Mendonça Raupp, pelas sugestões e críticas construtivas que contribuíram para o desenvolvimento deste trabalho;

- À todos os professores do IAG-USP que contribuíram para a minha formação;

- À todos os funcionários do IAG-USP, sempre muito atenciosos e prestativos;

- Aos meus amigos e colegas do IAG-USP, que me proporcionaram inúmeros bons momentos ao longo dos últimos anos;

- À minha amiga Paula, que sempre torceu verdadeiramente por mim, por sua inestimável amizade;

- Ao meu amigo Stefano, por sempre me ajudar e dar dicas em todos os momentos que preciso de sua ajuda;

- À todos aqueles que me ajudaram e incentivaram;

- Ao grupo do laboratório GREC, em especial à Michelle Reboita, Luiz Kruger e Bruce Pontes por toda a ajuda nas etapas iniciais deste trabalho;

- Aos meus amigos Luiz Felippe e João Rafael, pelo companheirismo e troca de idéias pertinentes ao estudo desenvolvido neste trabalho; 
- Ao IAG-USP pela oportunidade de realização do curso de Mestrado;

- À CAPES (Coordenação de Aperfeiçoamento de Pessoal de Nível Superior) e à FAPESP (Fundação de Amparo à Pesquisa do Estado de São Paulo) pela concessão da bolsa de Mestrado e pelo apoio financeiro;

- À $F A P E S P$ e à $C P q$ do IAG pelo apoio financeiro para apresentar parte deste trabalho no CMOS Congress 2011 em Victoria, Canadá;

- À Pró Reitoria de Pós Graduação da USP pelo apoio financeiro para apresentar parte deste trabalho no WCRP (World Climate Research Programme) Open Science Conference 2011 em Denver, Estados Unidos;

- Ao meu colega John Saxton pela ajuda na revisão dos abstracts escritos em inglês para participação nas conferências internacionais;

- Ao meu amigo Robert Lee pela ajuda na revisão do abstract em inglês. 
"A mente que se abre a uma nova idéia jamais voltará ao seu tamanho original." 


\section{RESUMO}

\section{DUTRA, L. M. M. Ciclones subtropicais sobre o Atlântico Sul: análise da estrutura}

dinâmica de eventos, 2012. 144 f. Dissertação (Mestrado) - Instituto de Astronomia, Geofísica e Ciências Atmosféricas, Universidade de São Paulo, São Paulo, 2012.

Neste trabalho, o objetivo geral é investigar os processos sinóticos, dinâmicos e termodinâmicos de dois ciclones subtropicais ocorridos no Atlântico Sul. Utilizou-se um algoritmo de rastreamento de máximos de vorticidade ciclônica e o algoritmo Cyclone Phase Space (CPS), que permite classificar o ciclo de vida dos ciclones. Desenvolveu-se um processo de automatização destes algoritmos, que possibilitou a análise dos diagramas de fase de todos os ciclones ocorridos no Atlântico Subtropical durante 2008, 2009 e março de 2010. As condições sinóticas para dois eventos foram analisadas desde o período prévio à formação até o decaimento dos sistemas, e as equações do balanço de vorticidade e de calor foram utilizadas para investigar os processos dinâmicos e termodinâmicos. Embora com fraca intensidade em termos de pressão central, os ciclones tiveram impacto importante nas condições de tempo sobre suas regiões de atuação, e os ventos máximos superaram $15 \mathrm{~m} \mathrm{~s}^{-1}$ em $925 \mathrm{hPa}$ por várias horas. Ambos os ciclones apresentaram, ao menos em algum tempo de sua fase subtropical, um pico de advecção horizontal quente em altos níveis, enquanto a advecção horizontal quente em baixos níveis apresentou fraca intensidade. Nos estágios de fase híbrida, o termo diabático foi responsável pelas tendências de aquecimento em baixos níveis. Já durante a fase de transição extratropical ocorrida em um dos ciclones, o sentido dos fluxos turbulentos em superfície se inverteu e o termo diabático passou a contribuir para tendências de resfriamento em baixos níveis. Em altos níveis, foram encontradas regiões em que altos valores positivos do termo diabático da equação da termodinâmica correspondem a regiões de intenso resíduo negativo da equação da vorticidade. Nestas regiões, os processos convectivos podem explicar os "imbalanços" de vorticidade. Nas demais regiões e níveis em que esta relação não ocorreu, sugere-se que a convecção influencia as variações locais de vorticidade de uma forma mais distribuída na coluna atmosférica, assim como a divergência associada aos movimentos verticais pode ocorrer de forma distribuída ao longo da troposfera.

Palavras-chave: ciclone subtropical, Atlântico Sul, balanço de calor, balanço de vorticidade, rastreamento de ciclones, diagrama de fase de ciclones. 


\begin{abstract}
DUTRA, L. M. M. Subtropical cyclones over the South Atlantic: analysis of the dynamic structure of some events, 2012. 144 p. Master Dissertation - Institute of Astronomy, Geophysics and Atmospheric Sciences, University of São Paulo, São Paulo, 2012.
\end{abstract}

This work aims to investigate the synoptic and dynamic processes of a sample of subtropical cyclones that occurred near the east coast of South America. A cyclonic vorticity maximum tracking algorithm and the Cyclone Phase Space (CPS) algorithm are used to track and to classify the life cycle evolution of the cyclones. By automating these algorithms, it was possible to perform the analysis of the phase diagrams of all the cyclones occurred in the Subtropical Atlantic during 2008, 2009 and March 2010. The synoptic conditions for two events were analyzed from the period prior to the genesis until the decay of the systems, and the heat and vorticity balance equations were used to investigate the thermodynamic and dynamic processes. Although with low intensity in terms of central pressure, the cyclones had a major impact on the weather conditions in their regions of occurrence, and the $925 \mathrm{hPa}$ maximum sustained winds exceeded $15 \mathrm{~m} \mathrm{~s}^{-1}$ for several hours. Both selected cyclones, at least at a time of its subtropical phase, had a peak of warm horizontal advection at higher levels, whilst the warm horizontal advection at lower levels showed weak intensity. In the hybrid stages of both cyclones, the diabatic term was responsible for warming trends at low levels. However, during the extratropical transition in one of the cyclones, the direction of the near-surface turbulent fluxes reversed and the diabatic term began to contribute to cooling trends at low levels. In the upper troposphere, it was found that in some regions that featured large positive values of the thermodynamic equation diabatic term, there was also a significant negative residual of the vorticity equation. In these regions, the convective processes can explain the observed vorticity imbalances. For other regions and levels, at which there was no direct relationship between the residual fields, it is suggested here that convection influences the local variations of vorticity in a more distributed way in the atmospheric column, as well as the divergence associated with the vertical velocities can be more distributed throughout the troposphere, without being concentrated at only some levels.

Keywords: subtropical cyclone, South Atlantic, heat balance, vorticity balance, cyclone tracking, cyclone phase space. 


\section{LISTA DE FIGURAS}

Fig. 1.1. Densidade de ciclogêneses no Atlântico Sul, no período de 1990 a 1999 , que se iniciaram com vorticidade menor ou igual a $-1,5 \times 10^{-5} \mathrm{~s}^{-1}$ e que tiveram tempo de vida maior ou igual à 24 horas na reanálise do NCEP (National Centers for Environmental Prediction). Na escala de cor da figura, o valor 1,5 corresponde a aproximadamente 37,5 sistemas. Adaptado de Reboita et al. (2010). . . . . . . . . . . . . . . . . . .

Fig. 1.2. Circulação ciclônica em baixos níveis. As correntes de ar frio são ilustradas pelas linhas grossas, e as correntes de ar quente pelas linhas finas duplas.

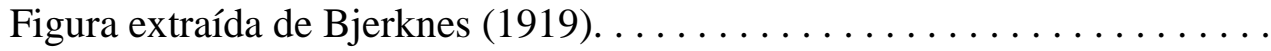

Fig. 1.3. (a) Tracking e (b) localização do início da ventania em superfície das tempestades subtropicais na climatologia ERA-40 de Guishard (2006). O ponto e a caixa vermelha em (b) indicam respectivamente a posição média e o domínio do desvio padrão de todas as localizações de iníxio da ventania

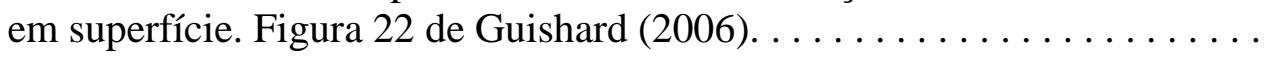

Fig. 1.4. Imagem de satélite do GOES-8 no canal IR do ciclone Michael na fase (a) subtropical e (b) tropical de seu ciclo de vida. As setas amarelas e vermelhas indicam a extensão das nuvens associadas à circulação ciclônica durante sua fase subtropical e tropical, respectivamente. Adaptado de Guishard (2006) . . . . . . . . . . . . . . . . . . . . . . .

Fig. 1.5. Cyclone Phase Space (Hart, 2003) para o ciclone Catarina, ocorrido em março de 2004. Figura extraída de Gozzo (2011). . . . . . . . . . . . . . . . .

Fig. 2.1. Esquematização para o $\mathrm{HN}$ : (a) Semicírculos de raio $500 \mathrm{~km}$ que compreendem a região do ciclone analisada pelo CPS e (b) valores esperados do parâmetro $B$ para diferentes estágios de um ciclone tropical convencional (topo) e de um ciclone extratropical convencional (abaixo). $\mathrm{Na}$ figura, $L$ indica a posição do centro do sistema de baixa pressão e a barra que delimita os semicírculos é definida de acordo com o movimento do distúrbio. Adaptado de

(http://moe.met.fsu.edu/cyclonephase/index.html)...........

Fig. 2.2. Esquematização das localizações de $Z_{\max }$ e $Z_{\min }$ para um dado nível de pressão. Adaptado de (http://moe.met.fsu.edu/cyclonephase/index.html). . .

Fig. 2.3. Exemplo das saídas gráficas do CPS, para um caso idealizado de um ciclone extratropical (trajetória em verde). (a) parâmetro $B$ versus $-\left|V_{T}^{L}\right| \mathrm{e}$ (b) $-\left|V_{T}^{U}\right|$ versus $-\left|V_{T}^{L}\right|$. Adaptado de

(http://moe.met.fsu.edu/cyclonephase/index.html). . . . . . . . .

Fig. 2.4. Região na qual foi realizado o rastreamento dos máximos de vorticidade ciclônica (área do contorno azul), e região dos dados de entrada fornecidos ao algoritmo de rastreamento (área do pontilhado vermelho). . . . . . . . .

Fig. 2.5. Esquematização do efeito da divergência na vorticidade, para um fluido 
ciclônico no HN. A área que o fluido abrange num instante inicial é a colorida pelo tom de cinza claro, e a área após algum tempo é a colorida pelo tom de cinza escuro. (a) ilustra o efeito da divergência e (b) o efeito da convergência. Adaptado de Martin (2006). . . . . . . . . . . . . . . . .

Fig. 3.1. Ocorrência (a) anual (para 2008 e 2009) e (b) mensal (para março de 2010) dos ciclones em parte da região subtropical do Atlântico Sul, encontrados através do algoritmo que rastreia máximos de vorticidade ciclônica com limiar de $-1,0 \times 10^{-5} \mathrm{~s}^{-1}$ (azul) e $-2,5 \times 10^{-5} \mathrm{~s}^{-1}$ (vermelho). As barras preenchidas referem-se aos sistemas híbridos encontrados. . . . . . . . .

Fig. 3.2. Trajetórias da posição central de três ciclones de março de 2010, obtidas pelo algoritmo que rastreia máximos de vorticidade ciclônica, com limiar de $-1.0 \times 10^{-5} \mathrm{~s}^{-1}$. Cada ciclone está representado por uma cor diferente, e o círculo sem preenchimento indica a posição inicial do sistema. . . . . . . .

Fig. 3.3. Trajetória (indicada a cada $6 \mathrm{~h}$ ) da posição central do ciclone subtropical ocorrido em a) abril de 2009 e b) março de 2010. A trajetória em preto foi obtida pela inspeção visual dos campos de PNMM, e a trajetória em azul refere-se à rastreada pelo algoritmo de Sugahara (2000), com limiar de $-1,0$

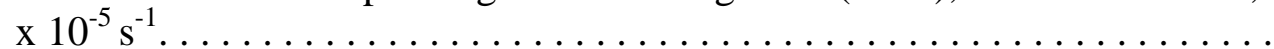

Fig. 3.4. Cyclone Phase Space para o ciclone de (a)-(b) abril de 2009 e (c)-(d) março de 2010. O algoritmo foi iniciado com o rastreamento visual dos campos de PNMM. . . . . . . . . . . . . . . . . .

Fig. 4.1. Pressão central $(\mathrm{hPa})$ do ciclone em superfície. Os estágios do ciclo de vida do ciclone de abril de 2009 (início, maduro, enfraquecimento, dissipação) estão identificados e marcados na figura. . . . . . . . . . . . . . .

Fig. 4.2. (a) Intensidade média e máxima do vento em $925 \mathrm{hPa}\left(\mathrm{m} \mathrm{s}^{-1}\right)$, (b) VR média e mínima em $925 \mathrm{hPa}\left(10^{-5} \mathrm{~s}^{-1}\right)$ e perfil vertical (c) do vento máximo $\left(\mathrm{m} \mathrm{s}^{-1}\right)$ e $(\mathrm{d})$ da VR mínima $\left(10^{-5} \mathrm{~s}^{-1}\right)$ na região de atuação do ciclone de abril de 2009. A análise foi feita com os dados do NCEP e considerando os pontos de grade dentro de uma caixa de $10^{\circ} \times 10^{\circ}$ centrada no ciclone em

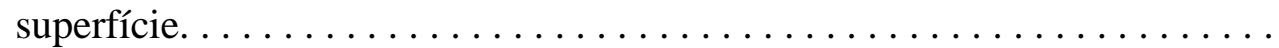

Fig. 4.3. 00 UTC do dia 23/04/2009 (início): (a) PNMM (hPa, linha preta), altura geopotencial em $500 \mathrm{hPa}$ (metros geopotencial, pontilhado vermelho) e VR em $925 \mathrm{hPa}\left(10^{-5} \mathrm{~s}^{-1}\right)$; (b) temperatura $\left({ }^{\circ} \mathrm{C}\right.$, sombreado) e vento horizontal $\left(\mathrm{m} \mathrm{s}^{-1}\right.$, vetor) em $925 \mathrm{hPa}$; (c) linhas de corrente e isotacas $\left(\mathrm{m} \mathrm{s}^{-1}\right.$, sombreado) em $200 \mathrm{hPa}$; (d) imagem de satélite no canal do IR. . . . . . . .

Fig. 4.4. Idem à Fig. 4.3, mas para o dia 23/04/2009 às 12 UTC (maduro). . . . . . 70

Fig. 4.5. Idem à Fig. 4.3, mas para o dia 24/04/2009 às 12 UTC (enfraquecimento). . 71

Fig. 4.6. Idem à Fig. 4.3, mas para o dia 25/04/2009 às 12 UTC (dissipação). . . . . 72

Fig. 4.7. Precipitação acumulada diária $\left(\mathrm{mm} \mathrm{dia}^{-1}\right)$ para cada dia de atuação do ciclone de abril de 2009: dia (a) 23 (início e maduro), (b) 24 (enfraquecimento) e (c) 25 (dissipação). A caixa de $10^{\circ} \times 10^{\circ} \mathrm{em}$ cada figura 
está centralizada no ciclone em superfície às 12 UTC de cada dia. . . . . . . .

Fig. 4.8. Temperatura $\left({ }^{\circ} \mathrm{C}\right.$, sombreado) e vento $\left(\mathrm{m} \mathrm{s}^{-1}\right)$ em $200 \mathrm{hPa}$, para as (a) 00 UTC do dia 23 (início), (b) 12 UTC do dia 23 (maduro), (c) 12 UTC do dia 24 (enfraquecimento) e (e) 12 UTC do dia 25 (dissipação) de abril de 2009.

Fig. 4.9. Altura geopotencial (linhas contínuas, metros geopotencial) e termos do balanço de calor (sombreado; termo diabático, variação local, advecção horizontal e termo relacionado ao movimento vertical Sw, $\mathrm{K} \mathrm{dia}^{-1}$ ) em 925 hPa para as (a) 00 UTC do dia 23 (início), (b) 12 UTC do dia 23 (maduro), (c) 12 UTC do dia 24 (enfraquecimento) e (e) 12 UTC do dia 25

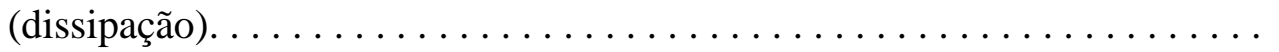

Fig. 4.10. Idem à Fig. 4.9, mas para $500 \mathrm{hPa} \ldots \ldots \ldots \ldots \ldots \ldots \ldots \ldots \ldots \ldots$

Fig. 4.11. Idem à Fig. 4.9, mas para 300 hPa. . . . . . . . . . . . . . . . . .

Fig. 4.12. Altura geopotencial (linhas contínuas, metros geopotencial) e termos do balanço de vorticidade (sombreado; resíduo, variação local, advecção horizontal e termo de divergência, $10^{-10} \mathrm{~s}^{-2}$ ) em $925 \mathrm{hPa}$ para as (a) 00 UTC do dia 23 (início), (b) 12 UTC do dia 23 (maduro), (c) 12 UTC do dia 24 (enfraquecimento) e (e) 12 UTC do dia 25 (dissipação) . . . . . . . . . . .

Fig. 4.13. Idem à Fig. 4.12, mas para $300 \mathrm{hPa} \ldots \ldots \ldots \ldots \ldots \ldots \ldots \ldots \ldots$

Fig. 4.14. Altura geopotencial (linhas contínuas, metros geopotencial) e termos diabático e Sw do balanço de calor (sombreado; painel superior; tons em amarelo indicam aquecimento, e tons em azul claro indicam resfriamento, $\mathrm{K} \mathrm{dia}^{-1}$ ) e termos residual e de divergência do balanço de vorticidade (sombreado; painel inferior; tons em vermelho indicam diminuição de vorticidade ciclônica, e tons em azul escuro indicam aumento de vorticidade ciclônica, $10^{-10} \mathrm{~s}^{-2}$ ) em $300 \mathrm{hPa}$ para (a) 00 UTC do dia 23/04/2009 (início) e (b) 12 UTC do dia 23/04/2009 (maduro). A posição central do ciclone em superfície é marcada pelo ponto preto, e os círculos pretos delimitam as regiões em que foram observadas associações entre os campos residuais (ver o texto para mais detalhes) . . . . . . . . . .

Fig. 4.15. Perfis verticais médios de (a) VR $\left(10^{-5} \mathrm{~s}^{-1}\right)$, (b) divergência $\left(10^{-5} \mathrm{~s}^{-1}\right)$ e (c) pseudo-velocidade vertical Omega $\left(\mathrm{Pa} \mathrm{s}^{-1}\right)$, centrados no ciclone em superfície de abril de 2009. Cada cor representa um diferente estágio do

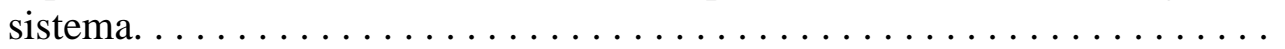

Fig. 4.16. Perfil vertical médio na área em torno do ciclone em superfície (a) da variação local de temperatura $\left(\mathrm{K} \mathrm{dia}^{-1}\right)$, (b) da advecção horizontal de temperatura $\left(\mathrm{K} \mathrm{dia}^{-1}\right)$, (c) da advecção vertical de temperatura $\left(\mathrm{K} \mathrm{dia}^{-1}\right),(\mathrm{d})$ do termo adiabático $\left(\mathrm{K} \mathrm{dia}^{-1}\right)$, (e) do termo relacionado ao movimento vertical $\left(\mathrm{K} \mathrm{dia}^{-1}\right)$ e (f) do resíduo da equação da termodinâmica $\left(\mathrm{K} \mathrm{dia}^{-1}\right)$, para cada estágio do ciclone de abril de $2009 \ldots \ldots \ldots \ldots \ldots \ldots$

Fig. 4.17. Perfil vertical dos termos de maior contribuição do balanço de calor (resíduo ou termo diabático, variação local de temperatura, advecção horizontal de temperatura e termo relacionado ao movimento vertical $\mathrm{Sw}$, 
Fig. 4.18. Perfil vertical médio na área em torno do ciclone em superfície (a) da variação local de vorticidade relativa $\left(10^{-10} \mathrm{~s}^{-2}\right)$, (b) da advecção horizontal de vorticidade relativa $\left(10^{-10} \mathrm{~s}^{-2}\right)$, (c) do termo de divergência $\left(10^{-10} \mathrm{~s}^{-2}\right),(\mathrm{d})$ do resíduo do balanço de vorticidade $\left(10^{-10} \mathrm{~s}^{-2}\right)$, (e) da advecção vertical de vorticidade relativa $\left(10^{-10} \mathrm{~s}^{-2}\right)$, (f) da advecção de vorticidade planetária (10$\left.{ }^{10} \mathrm{~s}^{-2}\right)$ e $(\mathrm{g})$ do termo de inclinação $\left(10^{-10} \mathrm{~s}^{-2}\right)$, para cada estágio do ciclone de abril de $2009 . \ldots \ldots \ldots \ldots \ldots \ldots \ldots$. . . . . . . . . . . . . . . . . . .

Fig. 4.19. Perfil vertical do resíduo do balanço de vorticidade $\left(10^{-10} \mathrm{~s}^{-2}\right.$, preto $)$ e do resíduo calculado desprezando-se os termos de menor contribuição $\left(10^{-10} \mathrm{~s}\right.$ ${ }^{2}$, azul), para cada estágio do ciclone de abril de $2009 . \ldots \ldots \ldots \ldots \ldots$. . . . .

Fig. 5.1. Pressão central (hPa) do ciclone em superfície. Os estágios do ciclo de vida do ciclone de março de 2010 (início, intensificação 1, maduro, enfraquecimento, intensificação 2) estão identificados e marcados na

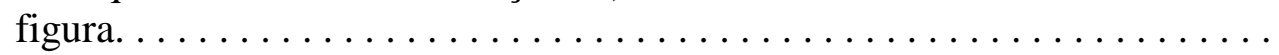

Fig. 5.2. (a) Intensidade média e máxima do vento em $925 \mathrm{hPa}\left(\mathrm{m} \mathrm{s}^{-1}\right)$, (b) VR média e mínima em $925 \mathrm{hPa}\left(10^{-5} \mathrm{~s}^{-1}\right)$ e perfil vertical (c) do vento máximo $\left(\mathrm{m} \mathrm{s}^{-1}\right)$ e (d) da VR mínima $\left(10^{-5} \mathrm{~s}^{-1}\right)$ na região de atuação do ciclone de março de 2010. A análise foi feita com os dados do NCEP e considerando os pontos de grade dentro de uma caixa de $10^{\circ} \times 10^{\circ}$ centrada no ciclone em

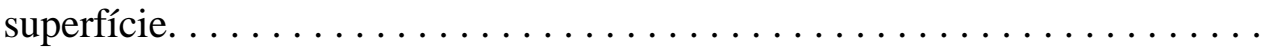

Fig. 5.3. 12 UTC do dia 04/03/2010 (início): (a) PNMM (hPa, linha preta), altura geopotencial em $500 \mathrm{hPa}$ (metros geopotencial, pontilhado vermelho) e VR em $925 \mathrm{hPa}\left(10^{-5} \mathrm{~s}^{-1}\right.$, sombreado); (b) temperatura $\left({ }^{\circ} \mathrm{C}\right.$, sombreado) e vento horizontal ( $\mathrm{m} \mathrm{s}^{-1}$, vetor) em $925 \mathrm{hPa}$; (c) linhas de corrente e isotacas (m s ${ }^{1}$, sombreado) em $200 \mathrm{hPa}$ e (d) imagem de satélite no canal do IR. . . . . . 96

Fig. 5.4. Idem à Fig. 5.3, mas para o dia 07/03/2010 às 12 UTC (intensificação 1). . 97

Fig. 5.5. Idem à Fig. 5.3, mas para o dia 09/03/2010 às 12 UTC (maduro). . . . . . . 98

Fig. 5.6. Idem à Fig. 5.3, mas para o dia 10/03/2010 às 12 UTC (enfraquecimento). . 99

Fig. 5.7. Idem à Fig. 5.3, mas para o dia 11/03/2010 às 12 UTC (intensificação 2). . 100

Fig. 5.8. Imagens de satélite no canal do visível sobre a região de atuação do ciclone, às (a) 17:09 UTC do dia 08, (b) 17:39 UTC do dia 09, (c) 17:09 UTC do dia 10 e (d) 17:09 UTC do dia 11. Fonte: comunicação pessoal

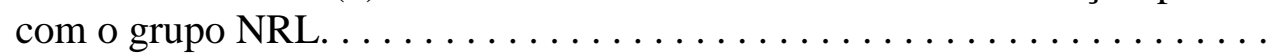

Fig. 5.9. Precipitação acumulada diária $\left(\mathrm{mm} \mathrm{dia}^{-1}\right)$ para cada dia de atuação do ciclone de março de 2010: dia (a) 04 (início), (b) 05, (c) 06, (d) 07 (intensificação 1), (e) 08, (f) 09 (maduro), (g) 10 (enfraquecimento) e (h) 11 (intensificação 2). A caixa de $10^{\circ} \times 10^{\circ} \mathrm{em}$ cada figura está centralizada no ciclone em superfície às 12 UTC de cada dia. . . . . . . . . . . . . . .

Fig. 5.10. Temperatura $\left({ }^{\circ} \mathrm{C}\right.$, sombreado) e vento $\left(\mathrm{m} \mathrm{s}^{-1}\right)$ em $200 \mathrm{hPa}$, para às $12 \mathrm{UTC}$ 
do dia (a) 04 (início), (b) 07 (intensificação 1), (c) 09 (maduro), (d) 10 (enfraquecimento) e (e) 11 (intensificação 2) de março de 2010 . . . . . . 104

Fig. 5.11. Altura geopotencial (linhas contínuas, metros geopotencial) e termos do balanço de calor (sombreado; termo diabático, variação local, advecção horizontal e termo relacionado ao movimento vertical $\mathrm{Sw}, \mathrm{K} \mathrm{dia}^{-1}$ ) em 925 hPa para às 12 UTC do dia (a) 04 (início), (b) 07 (intensificação 1), (c) 09 (maduro), (d) 10 (enfraquecimento) e (e) 11 (intensificação 2) . . . . . . . . .

Fig. 5.12. Idem à Fig. 5.11, mas para 500 hPa. . . . . . . . . . . . . . . . 108

Fig. 5.13. Idem à Fig. 5.11, mas para $300 \mathrm{hPa} \ldots \ldots \ldots \ldots \ldots \ldots \ldots \ldots \ldots$

Fig. 5.14. Altura geopotencial (linhas contínuas, metros geopotencial) e termos do balanço de vorticidade (sombreado; resíduo, variação local, advecção horizontal e termo de divergência, $10^{-10} \mathrm{~s}^{-2}$ ) em $925 \mathrm{hPa}$ para às 12 UTC do dia (a) 04 (início), (b) 07 (intensificação 1), (c) 09 (maduro), (d) 10 (enfraquecimento) e (e) 11 (intensificação 2) . . . . . . . . . . . . .

Fig. 5.15. Idem à Fig. 5.14, mas para $300 \mathrm{hPa} \ldots \ldots \ldots \ldots \ldots \ldots \ldots \ldots \ldots$

Fig. 5.16. Altura geopotencial (linhas contínuas, metros geopotencial) e termos diabático e $\mathrm{Sw}$ do balanço de calor (sombreado; painel superior; tons em amarelo indicam aquecimento, e tons em azul claro indicam resfriamento, $\mathrm{K} \mathrm{dia}^{-1}$ ) e termos residual e de divergência do balanço de vorticidade (sombreado; painel inferior; tons em vermelho indicam diminuição de vorticidade ciclônica, e tons em azul escuro indicam aumento de vorticidade ciclônica, $10^{-10} \mathrm{~s}^{-2}$ ) em $300 \mathrm{hPa}$ para 12 UTC de (a) 04/03/2010 (início), (b) 09/03/2010 (maduro) e (c) 11/03/2010 (intensificação 2). A posição central do ciclone em superfície é marcada pelo ponto preto, e os círculos pretos delimitam as regiões em que foram observadas associações entre os campos residuais (ver o texto para mais detalhes). . . . . . . . . . .

Fig. 5.17. Perfis verticais médios de (a) VR $\left(10^{-5} \mathrm{~s}^{-1}\right)$, (b) divergência $\left(10^{-5} \mathrm{~s}^{-1}\right)$ e (c) pseudo-velocidade vertical Omega $\left(\mathrm{Pa} \mathrm{s}^{-1}\right)$, centrados no ciclone em superfície de março de 2010. Cada cor representa um diferente estágio do

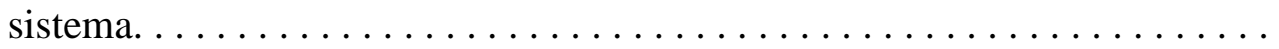

Fig. 5.18. Perfil vertical (a) da variação local de temperatura $\left(\mathrm{K} \mathrm{dia}{ }^{-1}\right)$, (b) da advecção horizontal de temperatura $\left(\mathrm{K} \mathrm{dia}^{-1}\right)$, (c) da advecção vertical de temperatura $\left(\mathrm{K} \mathrm{dia}^{-1}\right)$, (d) do termo adiabático $\left(\mathrm{K} \mathrm{dia}{ }^{-1}\right)$, (e) do termo relacionado ao movimento vertical $\left(\mathrm{K} \mathrm{dia}^{-1}\right)$ e (f) do resíduo da equação da termodinâmica $\left(\mathrm{K} \mathrm{dia}^{-1}\right)$, para cada estágio do ciclo de vida do ciclone de

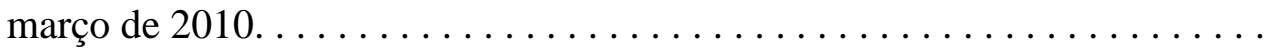

Fig. 5.19. Perfil vertical dos termos de maior contribuição do balanço de calor (variação local, resíduo, advecção horizontal de temperatura e termo relacionado ao movimento vertical, $\mathrm{K} \mathrm{dia}^{-1}$ ), para cada estágio do ciclo de

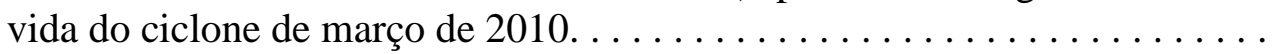

Fig. 5.20. Perfil vertical (a) da variação local de vorticidade relativa $\left(10^{-10} \mathrm{~s}^{-2}\right)$, (b) da advecção horizontal de vorticidade relativa $\left(10^{-10} \mathrm{~s}^{-2}\right)$, (c) do termo de 
xviii

divergência $\left(10^{-10} \mathrm{~s}^{-2}\right)$, (d) do resíduo do balanço de vorticidade $\left(10^{-10} \mathrm{~s}^{-2}\right)$, (e) da advecção vertical de vorticidade relativa $\left(10^{-10} \mathrm{~s}^{-2}\right)$, (f) da advecção de vorticidade planetária $\left(10^{-10} \mathrm{~s}^{-2}\right)$ e $(\mathrm{g})$ do termo de inclinação $\left(10^{-10} \mathrm{~s}^{-2}\right)$, para cada estágio do ciclo de vida do ciclone de março de 2010 . . . . . . . .

Fig. 5.21. Perfil vertical do resíduo do balanço de vorticidade (preto, $10^{-10} \mathrm{~s}^{-2}$ ) e do resíduo calculado desprezando-se os termos de menor contribuição (advecção de vorticidade planetária, advecção vertical de vorticidade relativa e termo de inclinação - azul, $10^{-10} \mathrm{~s}^{-2}$ ), para cada estágio do ciclo

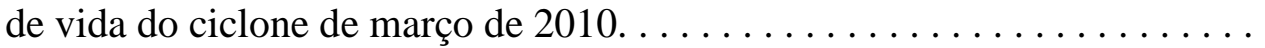

Fig. 5.22. Perfil vertical do resíduo do balanço de vorticidade para diferentes regiões de composites de ondas de leste (ver o texto para mais explicações). Figura extraída de Reed e Johnson (1974) . . . . . . . . . . . . . . . . . . . . . 


\section{LISTA DE TABELAS}

Tabela 2.1. Valores esperados dos parâmetros do CPS para ciclones tropicais, subtropicais e extratropicais. Baseado em Guishard (2006). . . . . . . . 50

Tabela 3.1. Datas de início e fim de cada distúrbio selecionado, obtidas através da inspeção visual dos campos de PNMM e do rastreamento pelos núcleos de

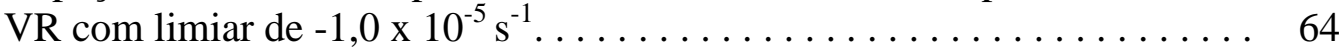




\section{LISTA DE ABREVIATURAS E SIGLAS}

AMS

APR2009

AVN

CAPES

CNPq

CPS

CPTEC-INPE

ECMWF

ERA-40

FAPESP

GFS

GOES-8

GOES-12

HN

HS

IAG

MAR2010

NCEP

NCEP FNL

NHC

NRL

PNMM

TRMM

TSM
American Meteorological Society

Ciclone de abril de 2009

AViatioN model

Coordenação de Aperfeiçoamento de Pessoal de Nível Superior

Conselho Nacional de Desenvolvimento Científico e Tecnológico

Cyclone Phase Space

Centro de Previsão de Tempo e Estudos Climáticos do Instituto Nacional de Pesquisas Espaciais

European Centre for Medium-Range Weather Forecasts

ECMWF 40 Years Reanalysis

Fundação de Amparo à Pesquisa do Estado de São Paulo

Global Forecast System

Geostationary Operational Environmental Satellite 8

Geostationary Operational Environmental Satellite 12

Hemisfério Norte

Hemisfério Sul

Instituto de Astronomia, Geofísica e Ciências Atmosféricas

Ciclone de março de 2010

National Centers for Environmental Prediction

National Centers for Environmental Prediction final Operational Model Global Tropospheric Analyses

National Hurricane Center

United States Naval Research Laboratory

Pressão reduzida ao Nível Médio do Mar

Tropical Rainfall Measuring Mission

Temperatura da Superfície do Mar 
xxii

UR

USP

UTC

VCAN

WMO
Umidade Relativa

Universidade de São Paulo

Universal Time Coordinated

Vórtice Ciclônico de Altos Níveis

World Meteorological Organization 


\section{LISTA DE SÍMBOLOS}

o

$\mathbf{S}$

RG1 Região 1: costa sul/sudeste do Brasil

RG2 Região 2: costa do Uruguai

RG3 Região 3: costa sudeste da Argentina

$\mathbf{S}$

hPa hectopascais

$\mathbf{m m}$

$\mathbf{r}_{\mathbf{0}}$

km

B

$-\left|\mathbf{V}_{\mathbf{T}}^{\mathbf{L}}\right|$

$-\left|\mathbf{V}_{\mathbf{T}}^{\mathbf{U}}\right|$

$\mathbf{Z}$

m

$\mathbf{Z}_{\max }$

$\mathbf{Z}_{\text {min }}$

$\mathbf{c}_{\mathbf{p}}$

$\mathbf{J}$

$\mathbf{T}$

$\mathbf{t}$

$\alpha$

p

o

graus

Sul

segundos

milímetros pelo método de Cressman

quilômetros

parâmetro do vento térmico em baixos níveis

parâmetro do vento térmico em altos níveis

Altura Geopotencial

metros

calor específico à pressão constante

Joules

temperatura

tempo

volume específico

pressão

operador derivada local

raio constante pré-estabelecido para suavizar os valores dos pontos de grade

parâmetro de simetria térmica ou de espessura do ciclone

Altura Geopotencial na borda do círculo de raio $500 \mathrm{~km}$ centrado no ciclone

Altura Geopotencial no centro do círculo de raio $500 \mathrm{~km}$ centrado no ciclone 
D operador derivada total

J taxa de aquecimento diabático

H fontes diabáticas de calor

K Kelvin

kg kilogramas

( $\quad$ pseudo-velocidade vertical

$\mathbf{u}$ componente zonal do vento

$\mathbf{v} \quad$ componente meridional do vento

$\mathbf{x} \quad$ medida de comprimento zonal

y medida de comprimento meridional

$\mathbf{S}_{\mathbf{p}} \quad$ parâmetro de estabilidade estática no sistema isobárico

R constante dos gases

$\overrightarrow{\mathbf{V}}_{\mathbf{H}} \quad$ vento horizontal

$\vec{\nabla}_{\mathbf{p}} \quad$ operador nabla horizontal calculado sobre uma superfície de pressão constante

$\mathbf{S}_{\mathbf{w}} \quad$ soma do termo de expansão/compressão adiabática e da advecção vertical de temperatura

$\mathbf{F}_{\mathbf{T}}$ resíduo do balanço de calor ou termo diabático

a raio da Terra

$\lambda \quad$ longitude

$\varphi \quad$ latitude

$\zeta \quad$ componente vertical da vorticidade relativa

$\overrightarrow{\mathbf{\omega}} \quad$ vetor vorticidade

$\vec{\nabla} \quad$ operador nabla

$\overrightarrow{\mathbf{V}} \quad$ vetor vento

f vorticidade planetária

$\boldsymbol{\beta} \quad$ variação meridional de vorticidade planetária 
$\mathbf{F}_{\zeta} \quad$ resíduo da equação da vorticidade

${ }^{\mathbf{O}} \mathrm{g} \quad$ graus Celsius

W Oeste (West)

Pa Pascal

$\mathbf{A}_{\mathbf{T}}$ advecção horizontal de temperatura

$\overrightarrow{\mathbf{V}}_{\mathrm{g}} \quad$ vento geostrófico

$\sigma$

parâmetro de estabilidade estática da atmosfera padrão em coordenadas isobáricas

$\mathbf{f}_{\mathbf{0}} \quad$ parâmetro de coriolis constante

$\Phi$

geopotencial 


\section{SUMÁRIO}

CAPÍTULO 1: Introdução. .................................... 29

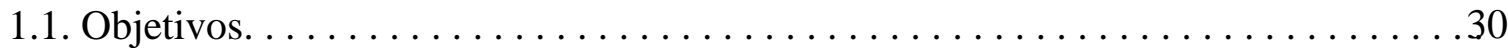

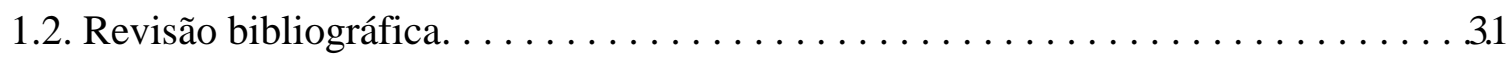

a. Ciclones e ciclogêneses no Atlântico Sul. . . . . . . . . . . . . . . 31

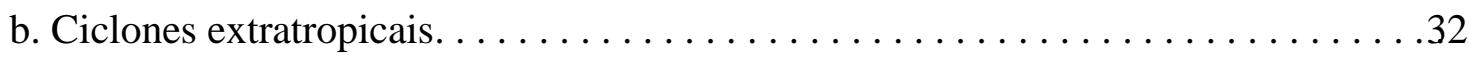

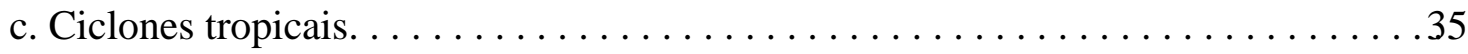

d. Ciclones subtropicais e de transição. . . . . . . . . . . . . . . . 3.6

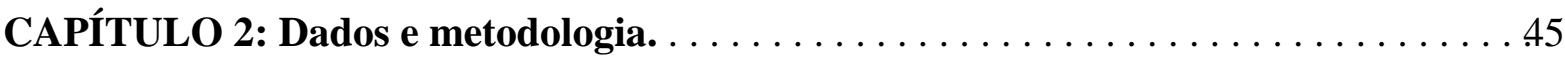

2.1. Dados. . . . . . . . . . . . . . . . . . . . . . . . . . . . . . 45

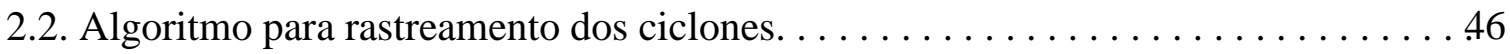

2.3. Algoritmo para avaliar a estrutura dos ciclones. . . . . . . . . . . 48

2.4. Automatização do rastreamento e do CPS . . . . . . . . . . . . . . . 50

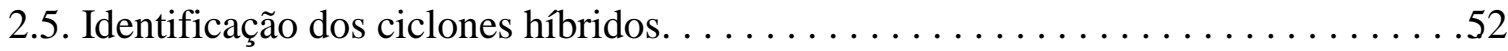

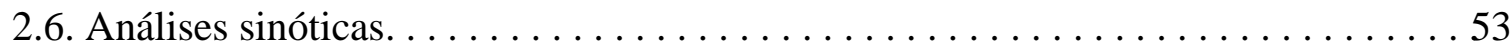

2.7. Balanço de calor. . . . . . . . . . . . . . . . . . . . . 53

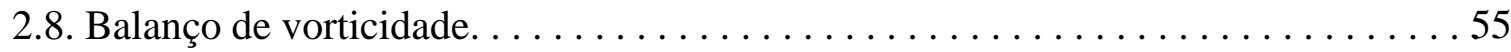

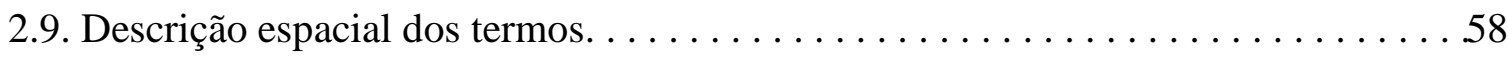

2.10. Perfis verticais médios. . . . . . . . . . . . . . . . . . . . . . 59

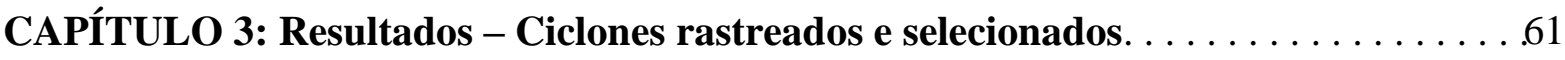

3.1. Ciclones rastreados. . . . . . . . . . . . . . . 61

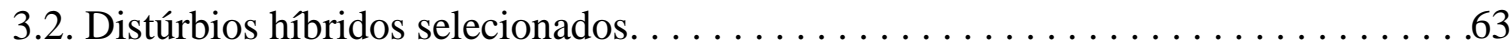

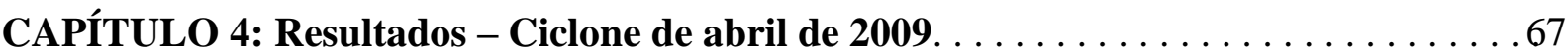

4.1. Discussão sinótica. . . . . . . . . . . . . . . . . . . . . . . . . . . . .67

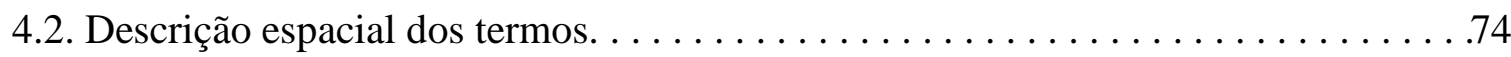

a. Balanço de calor. . . . . . . . . . . . . . . . . . . . . .

b. Balanço de vorticidade. . . . . . . . . . . . . . . . . . . . . 78

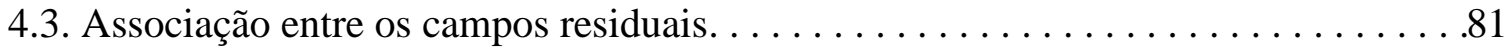

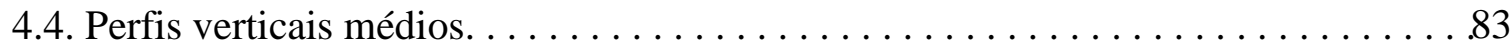

a. Vorticidade, divergência e Omega. ......................... 83

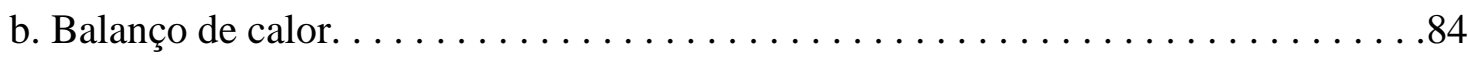

c. Balanço de vorticidade. . . . . . . . . . . . . . . . . . . 88

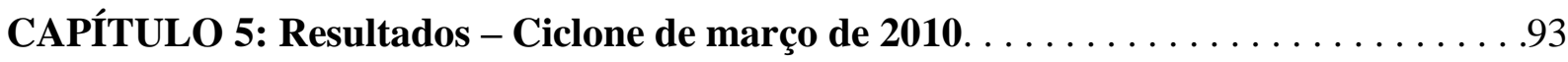

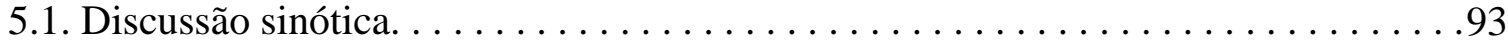


5.2. Descrição espacial dos termos. . . . . . . . . . . . . . . . . . . . . 105

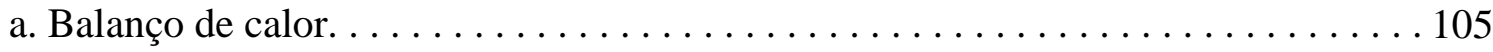

b. Balanço de vorticidade. . . . . . . . . . . . . . . . . . . . . 110

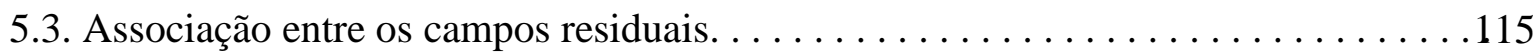

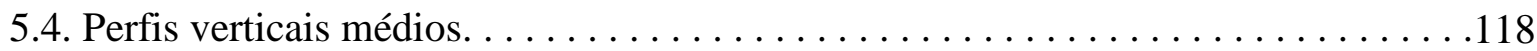

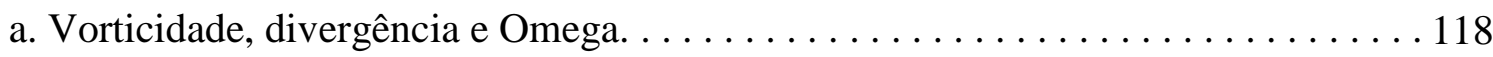

b. Balanço de calor. . . . . . . . . . . . . . . . . . . . . . 119

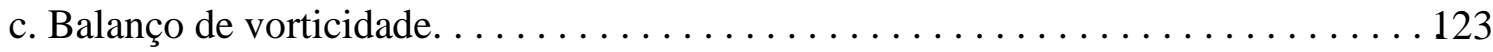

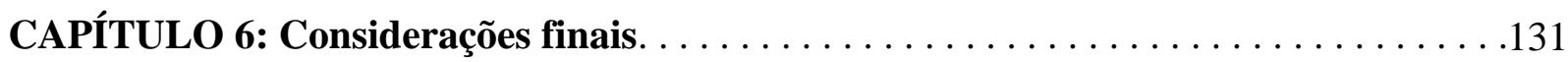

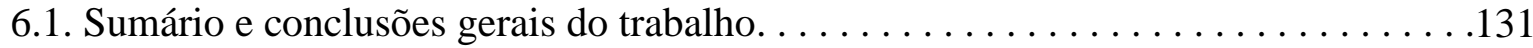

6.2. Sugestões para pesquisas futuras. . . . . . . . . . . . . . . . $\ldots \ldots \ldots$

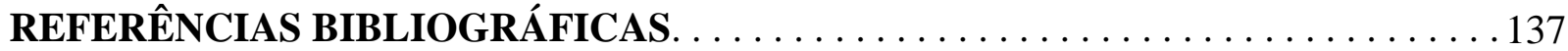




\section{CAPÍTULO 1}

\section{Introdução}

Os ciclones fazem parte do grupo dos fenômenos severos da escala sinótica, e representam um mecanismo importante no balanço de energia e vapor de água na atmosfera, sendo responsáveis pelo transporte de calor e umidade. Os ciclones também desempenham um papel fundamental no sistema climático da Terra, pois regulam os contrastes de temperatura entre os pólos e o equador e mantém os ventos de oeste nas latitudes médias contra a dissipação friccional (HAKIM, 2003). Isto se deve ao processo de transferência de energia cinética dos distúrbios para o escoamento médio durante a fase de dissipação dos mesmos.

Até a década de 1950, a classificação do ciclo de vida dos ciclones considerava somente dois tipos distintos: os ciclones tropicais e os extratropicais, caracterizados então por uma única fase definida e distinta durante o ciclo de vida. Os tropicais possuem núcleo quente e são simétricos, com formação fortemente associada à transferência de calor latente na interface ar-mar; o enfraquecimento e dissipação geralmente ocorrem quando esta fonte de energia cessa, ao atingir águas mais frias ou o continente (CHARNEY e ELIASSEN, 1964). Os ciclones extratropicais possuem núcleo frio, são assimétricos e se formam em latitudes médias onde os gradientes horizontais de temperatura e o consequente cisalhamento vertical do vento horizontal são mais intensos; estes sistemas possuem frentes associadas e decaem quando a instabilidade baroclínica enfraquece (BJERKNES e SOLBERG, 1922; CHARNEY, 1947; EADY, 1949).

Nas décadas seguintes, esta separação rígida entre os tipos de ciclones começou a ser reavaliada em trabalhos que verificaram a existência de sistemas que passavam por processos de transição, apresentando estrutura híbrida entre os dois tipos de ciclones previamente conhecidos (BEVEN, 1997). Hart (2003) desenvolveu um diagrama de fase que descreve a estrutura dos ciclones e permite classificá-los em um contínuo de possibilidades de estruturas e ciclos de vida. Este diagrama permite identificar a fase híbrida dos ciclones que passam por processos de transição, como casos de ciclones tropicais que fazem transição para extratropicais ou ciclones frontais que fazem transição para tropicais. Além disso, o diagrama 
de fase possibilita ainda identificar casos de ciclones híbridos que se formam in situ, ou seja, que não se desenvolveram de outros ciclones pré-existentes.

Os ciclones subtropicais, ou híbridos, apresentam combinações dos ciclos de vida convencionais, com núcleos frios em altos níveis e quentes em baixos níveis, e possuem dinâmica de desenvolvimento distinta da dos ciclones tropicais e extratropicais. Sua formação no Hemisfério Norte $(\mathrm{HN})$ é baroclínica na presença de vorticidade ciclônica sobre temperatura da superfície do mar quente (GUISHARD et al. 2007).

Apesar da existência de alguns trabalhos que investigam e propõem teorias para os processos de formação de ciclones subtropicais, ainda não existe um modelo conceitual amplamente aceito, e o estudo das características destes distúrbios ainda não foi completamente explorado na literatura. Além disso, diferentes mecanismos dinâmicos e termodinâmicos podem estar associados à formação destes ciclones, dependendo da região do globo. Dado seu potencial de transição para outras categorias de ciclones, como os tropicais, o estudo mais detalhado destes sistemas híbridos é de extrema importância. Guishard (2006) demonstrou que uma fração considerável das tempestades subtropicais no Atlântico Norte durante a estação quente realiza transição para ciclones tropicais.

No Atlântico Sul, o desenvolvimento de ciclones pode afetar diretamente as condições de tempo das regiões costeiras da América do Sul, causando diversos danos tais como enchentes e desabamentos. Além disso, as chuvas intensas, ventos fortes e a consequente agitação marítima associada aos sistemas ciclônicos também podem afetar negativamente as atividades portuárias e de navegação. Desta forma, estudos detalhados das áreas atingidas e da evolução típica destes sistemas nesta região são de extrema importância. Levando em conta a necessidade de explorar mais profundamente as características dos distúrbios ciclônicos híbridos e a relevância do desenvolvimento de ciclones no Atlântico Sul, que podem afetar a região costeira do continente sul-americano, este trabalho investigar os processos dinâmicos e termodinâmicos durante o desenvolvimento de ciclones subtropicais originados no Oceano Atlântico Sul. Uma descrição completa dos objetivos específicos do trabalho é apresentada no item 1.1 a seguir.

\subsection{Objetivos}

O objetivo deste trabalho é investigar a evolução sinótica e dinâmica de dois eventos de ciclones subtropicais ocorridos próximo à costa leste da América do sul, procurando compreender o ambiente característico e os mecanismos dinâmicos e termodinâmicos associados aos desenvolvimentos. Entre os objetivos específicos têm-se: 
- Desenvolver algoritmos que permitam a identificação de ciclones subtropicais através do Cyclone Phase Space desenvolvido por Hart (2003);

- Identificar e selecionar dois eventos de ciclones subtropicais para análise sinótica;

- Caracterizar o ambiente sinótico nos quais os sistemas se desenvolveram;

- Utilizar as equações de balanço de calor e vorticidade, a fim de identificar os principais processos termodinâmicos e dinâmicos relacionados a estes sistemas;

- Contribuir no melhor entendimento da estrutura e evolução dos ciclones subtropicais que ocorrem no Atlântico Sul.

\subsection{Revisão bibliográfica}

A seguir é apresentada uma breve revisão bibliográfica sobre as regiões favoráveis ao desenvolvimento de ciclones no Atlântico Sul e sobre as principais características de cada tipo de sistema ciclônico (extratropical, tropical, subtropical e sistemas que passam por processos de transição).

\section{a. Ciclones e ciclogêneses no Atlântico Sul}

A ciclogênese representa o processo de abaixamento da pressão atmosférica em superfície com conseqüente circulação ciclônica. Estudos sobre a climatologia de ciclones extratropicais tiveram início a partir de técnicas visuais de identificação de suas posições e trajetórias, que utilizavam, por exemplo, cartas sinóticas de pressão à superfície (van LOON, 1965; TALJAARD, 1967) ou imagens de satélite (STRETEN e TROUP, 1973). Posteriormente, desenvolveram-se esquemas automáticos para a identificação e rastreamento de ciclones, que possibilitam a análise de uma grande quantidade de dados em pouco tempo. Tais esquemas automáticos podem utilizar dados de pressão em superfície (MURRAY e SIMMONDS, 1991b), altura geopotencial (LIM e SIMMONDS, 2007) ou vorticidade relativa (SINCLAIR, 1994) para rastrear os ciclones.

Gan e Rao (1991) definem a ciclogênese como o aparecimento da primeira isóbara fechada nas cartas sinóticas de pressão ao nível médio do mar (PNMM), sendo que a isóbara fechada deveria persistir por pelo menos 24 horas. Com esta metodologia, os autores encontraram duas regiões preferenciais para a ciclogênese sobre a costa leste da América do Sul: uma na costa sudeste da Argentina e outra na costa do Uruguai.

Posteriormente, estudos realizados no Hemisfério Sul (SINCLAIR 1996; HOSKINS e HODGES, 2005; REBOITA et al. 2010) que utilizam vorticidade relativa ao invés de PNMM 
mostraram que a frequência de ciclones na América do Sul é máxima em três diferentes setores próximos à costa leste (Fig. 1.1): costa sul/sudeste do Brasil $\left(\sim 25^{\circ} \mathrm{S}-\mathrm{RG} 1\right)$; costa do Uruguai $\left(\sim 35^{\circ} \mathrm{S}-\mathrm{RG} 2\right)$; e costa sudeste da Argentina $\left(\sim 45^{\circ} \mathrm{S}-\mathrm{RG}\right.$ ). Reboita (2008) verificou que na RG1 a atividade ciclogenética é maior mesmo quando os distúrbios em níveis superiores são mais fracos (verão), porém na época de maior disponibilidade de umidade, o que sugere que a umidade é fundamental para as ciclogêneses nesta região. Reboita (2008) também verificou que as ciclogêneses nas três regiões sofrem influência da topografia: nas RG1 e RG2, o cavado transiente em níveis médios torna-se mais intenso quando interage com o cavado da onda estacionária produzida pelo efeito dos Andes.

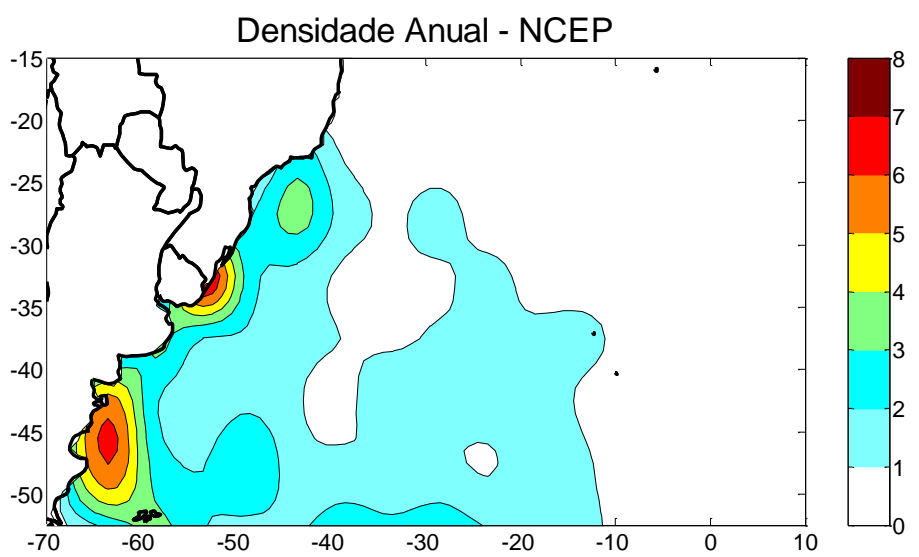

Fig. 1.1. Densidade de ciclogêneses no Atlântico Sul, no período de 1990 a 1999, que se iniciaram com vorticidade menor ou igual a $-1,5 \times 10^{-5} \mathrm{~s}^{-1}$ e que tiveram tempo de vida maior ou igual à 24 horas na reanálise do NCEP (National Centers for Environmental Prediction). $\mathrm{Na}$ escala de cor da figura, o valor 1,5 corresponde a aproximadamente 37,5 sistemas. Adaptado de Reboita et al. (2010).

\section{b. Ciclones extratropicais}

De acordo com Petterssen (1956) e Cavalcanti et al. (2009), modelos conceituais de ciclones extratropicais vêm sendo desenvolvidos desde o século XIX, com os trabalhos pioneiros de FitzRoy (1863) e Shaw (1911), que abordavam conceitos de ciclone termal. O modelo de FitzRoy (1863) ilustrava as correntes de ar em superfície dos ciclones extratropicais e propunha que estes sistemas se formam em uma zona de interação de massas de ar com diferentes propriedades, que se originam em regiões subtropicais e polares (PALMÉN e NEWTON, 1969). Segundo Schultz (2001), princípios básicos para a construção e interpretação das trajetórias das parcelas de ar foram estabelecidos por Shaw (1911), e diagramas esquemáticos similares de correntes de ar foram apresentados em Bjerknes (1919). É importante destacar que os modelos descritos acima não representavam os escoamentos em alturas muito afastadas da superfície. Apesar disso, as ideias descritas em Bjerknes (1919) e 
mais tarde aprofundadas em Bjerknes e Solberg (1922) representam o primeiro modelo conceitual mais realístico de ciclones extratropicais, e continuam aceitas até hoje.

O modelo conceitual de Bjerknes (1919) e Bjerknes e Solberg (1922), também conhecido como o modelo da escola norueguesa de Bergen ou Teoria da Frente Polar, propõe que os ciclones se formam em uma região denominada frente polar, que separa massa de ar fria de origem polar de massa de ar mais quente de latitudes tropicais. Nesta região de formação, o contraste de temperatura entre as diferentes massas de ar concentra-se em uma estreita faixa de transição (PALMÉN e NEWTON, 1969). O modelo descrito em Bjerknes e Solberg (1922) engloba diferentes estágios do ciclo de vida dos ciclones extratropicais, desde a amplificação da perturbação até sua dissipação. Neste modelo, existe uma instabilidade entre a massa de ar frio/mais densa e a massa de ar quente/menos densa, que força o ar frio sob o ar quente, e a circulação gera as frentes fria e quente; a frente fria é mais intensa e avança mais rapidamente em torno do centro de baixa pressão, alcançando e ultrapassando a frente quente, num processo denominado oclusão. A Fig. 1.2, retirada de Bjerknes (1919), ilustra as correntes de ar frio e quente em um ciclone extratropical no $\mathrm{HN}$, cuja circulação resulta do efeito combinado da força de Coriolis, pelo movimento de rotação da Terra, e da queda de pressão associada ao distúrbio, através da ascensão do ar quente que diminui o peso da coluna atmosférica.

Pettersen e Smebye (1971) classificaram os ciclones em dois diferentes grupos (tipo A e tipo B), de acordo com o tipo de desenvolvimento inicial e a partir de análises de ciclones ocorridos no Oceano Atlântico Norte. Dentre as características dos dois tipos de ciclones, detaca-se que, para os ciclones do tipo A inicialmente não existe um cavado em altos níveis, enquanto para os ciclones do tipo B têm-se um cavado de ar superior pré-existente. Mais tarde, Radinovic (1986) propôs a existência de ciclones do tipo C, associados a efeitos orográficos e também conhecidos como ciclones a sotaventos de montanhas. Locais montanhosos perturbam o escoamento zonal de oeste e contribuem para a formação de cavado a sotavento da montanha (CAVALCANTI et al., 2009).

Shapiro e Keyser (1990) propuseram um modelo conceitual de ciclones extratropicais que levaram a uma revisão/atualização do modelo da escola norueguesa e cujas características podem ser observadas em alguns ciclones oceânicos (NEIMAN e SHAPIRO, 1993). Dentre as principais características dos ciclones descritas em Shapiro e Keyser (1990), destacam-se: 1) a frente fria se move praticamente perpendicular à frente quente (padrão T-bone); 2) em um dos estágios a frente quente se estende a oeste do centro, no setor frio do ciclone (padrão bentback front); 3) no estágio maduro, a circulação próxima à superfície no setor frio aprisiona 
região de ar mais quente, configurando uma seclusão quente. Uma ilustração adaptada para o Hemisfério Sul (HS) do modelo de Shapiro e Keyser (1990) pode ser encontrada em Gozzo (2010).

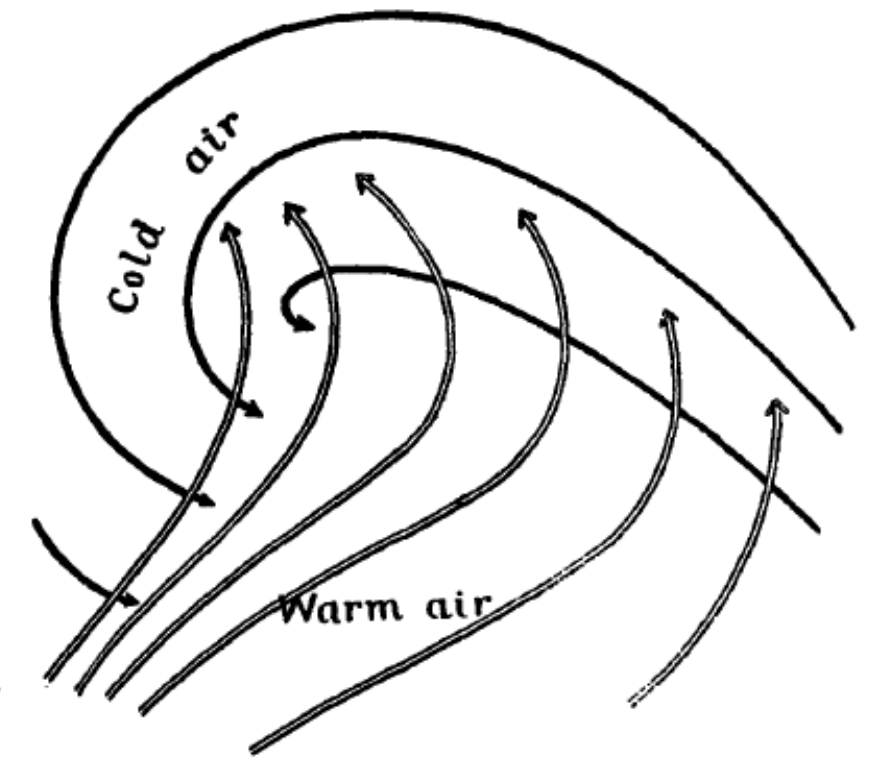

Fig. 1.2. Circulação ciclônica em baixos níveis. As correntes de ar frio são ilustradas pelas linhas grossas, e as correntes de ar quente pelas linhas finas duplas. Figura extraída de Bjerknes (1919).

A instabilidade baroclínica é um dos mecanismos de formação dos ciclones extratropicais. Tal instabilidade está associada ao cisalhamento vertical do escoamento horizontal e cresce a partir da conversão de energia potencial disponível da perturbação em energia cinética da perturbação (CHARNEY, 1947; EADY, 1949). A variabilidade atmosférica na região extratropical numa escala de tempo de vários dias é associada à instabilidade baroclínica, sendo os sistemas ciclônicos e anticiclônicos manifestações desta variabilidade.

De forma geral, os ciclones extratropicais são sistemas de baixa pressão com frentes associadas, e que derivam sua energia principalmente dos gradientes horizontais de temperatura existentes na atmosfera. Os ventos mais intensos em um ciclone extratropical ocorrem próximos à tropopausa, em função de possuírem núcleo quente na estratosfera e núcleo frio na troposfera (MARKS, 2003). Tal núcleo frio na troposfera significa que o sistema de baixa pressão possui menores temperaturas que o ambiente ao seu redor, para um dado nível de pressão. Assim, nos diagramas de fase de Hart (2003), ciclones extratropicais apresentam valores negativos para os parâmetros do vento térmico (ver item 2.3). 


\section{c. Ciclones tropicais}

Os ciclones tropicais podem receber diferentes denominações de acordo com a região do globo em que ocorrem: furacões (do inglês, hurricanes), no Atlântico Norte e Caribe; tufões (do inglês, typhoons) no Pacífico; e simplesmente ciclones nos Oceanos Índico e Pacífico Sul (ALLABY, 2009). Tais nomeações referem-se aos sistemas que possuem ventos sustentados em superfície maior que $33 \mathrm{~m} \mathrm{~s}^{-1}$ por um minuto. Caso os ventos sustentados em superfície situem-se entre 17 e $32 \mathrm{~m} \mathrm{~s}^{-1}$ (maiores que $33 \mathrm{~m} \mathrm{~s}^{-1}$ ) por um minuto, os distúrbios ciclônicos recebem o nome de tempestade tropical (grande furacão, major hurricane, ou super tufão, super typhoon). Nos Oceanos Atlântico e Pacífico Leste, os ciclones tropicais também são classificados de acordo com os danos causados, em uma escala de 1 a 5 (escala Saffir-Simpson; ver tabela 1 de MARKS, 2003). Destaca-se que os motivos pelos quais alguns ciclones tropicais se intensificam para categorias mais destrutivas enquanto outros permanecem com o status de depressão tropical ainda não são completamente entendidos na literatura.

Ao contrário dos sistemas ciclônicos de latitudes médias, os ciclones tropicais se desenvolvem em regiões de fraco cisalhamento vertical do vento horizontal. São sistemas de baixa pressão não frontais, associados a nuvens convectivas próximas de seu centro e que derivam sua energia principalmente da evaporação do mar. Os ventos mais fortes nos ciclones tropicais ocorrem próximos à superfície, como consequência do núcleo quente associado (MARKS, 2003). A expressão "núcleo quente" refere-se ao fato de os ciclones tropicais serem mais quentes que o ambiente em uma mesma superfície de pressão. A região interna de uma tempestade tropical é caracterizada por bandas espirais de precipitação, com um "olho" no centro do sistema com diâmetro típico de 20-50 km, visível em imagens de satélite e em radares meteorológicos. De acordo com Marks (2003), a frequência anual de ciclones tropicais em todo o globo é de 80 a 90 eventos, sendo que a maior parte ocorre no HN com pico nos meses de verão.

A temperatura da superfície do mar (TSM) alta é de grande importância para o desenvolvimento de tempestades tropicais, como indicam estudos teóricos como os de Emanuel (1988) e Holland (1997), que verificaram uma relação direta entre a máxima intensidade de uma tempestade tropical e a TSM (BENGTSSON et al., 2007). Brand (1971) mostrou que um tufão pode enfraquecer caso se desloque sobre uma região por onde previamente havia passado outro tufão que tenha gerado TSM mais fria devido à ressurgência. Gray (1979) sugere que TSM maior que $26^{\circ} \mathrm{C}$ é uma condição necessária (porém não 
suficiente) para o desenvolvimento de furacões. Entretanto, Gray (1979) destaca algumas condições atmosféricas que podem afetar negativamente o desenvolvimento de ciclones tropicais, tais como: baixa umidade relativa, alta estabilidade estática e alto cisalhamento vertical do vento horizontal na baixa e alta troposfera. Além disso, Marks (2003) destaca que uma condição necessária para o desenvolvimento de ciclones tropicais é uma grande profundidade da camada de mistura oceânica, com águas quentes entendendo-se por até aproximadamente 50 metros de profundidade. Valores não nulos do parâmetro de Coriolis (vorticidade planetária $f$ ) também parecem ser condição necessária para o desenvolvimento destes sistemas tropicais, já que observações mostram que tais eventos não ocorrem numa faixa de latitude de 3 graus em torno do Equador ( $f$ é nulo no Equador e adquire valores máximos nos pólos). No Atlântico Norte em anos de El Niño ocorre uma redução do número de furacões, devido ao aumento do cisalhamento vertical do vento e aos movimentos descendentes que ocorrem nas regiões em que os furacões normalmente ocorrem no Atlântico Norte (WU e LAU, 1992).

\section{d. Ciclones subtropicais e de transição}

Segundo a definição da WMO (World Meteorological Organization), ciclones subtropicais são sistemas de baixa pressão não-frontais que possuem características tanto de ciclones extratropicais quanto tropicais. O tipo mais comum de ciclone subtropical possui uma baixa fria em altos níveis com circulação estendendo-se até a superfície, sendo que os ventos mais intensos geralmente ocorrem em um raio de cerca de $160 \mathrm{~km}$ ou mais do centro. Em comparação com os ciclones tropicais, os subtropicais apresentam uma região relativamente ampla de ventos intensos localizada longe do centro, e tanto o campo de vento como o de convecção são tipicamente menos simétricos. O segundo tipo de ciclone subtropical possui tempo de vida mais curto, pode ter núcleo frio ou quente e corresponde a uma baixa pressão de mesoescala que se origina em ou próxima a uma zona de frontólise do cisalhamento do vento horizontal, com os ventos mais fortes encontrados geralmente a menos de $50 \mathrm{~km}$ do centro do sistema e com a circulação inicial podendo ter diâmetro menor do que $160 \mathrm{~km}$. De acordo com a WMO, se o vento máximo sustentado em superfície do ciclone subtropical for igual ou maior (menor) que $17,5 \mathrm{~m} \mathrm{~s}^{-1}$, o sistema recebe o nome de tempestade subtropical (depressão subtropical) (WMO, 2005).

De acordo com o glossário de Meteorologia da AMS (American Meteorological Society; GLICKMAN, 2000), ciclones subtropicais são sistemas que ocorrem em latitudes 
tropicais e subtropicais (do equador até $50^{\circ} \mathrm{N}$ - o glossário não menciona as latitudes do Hemisfério Sul) e possuem uma área com ventos fortes maior do que a observada nos ciclones tropicais, porém o vento máximo não excede $32,0 \mathrm{~m} \mathrm{~s}^{-1}$. O glossário enfatiza que os ciclones subtropicais possuem características tanto de ciclones de latitudes médias (ou extratropicais) quanto de ciclones tropicais: se desenvolvem em regiões onde o gradiente horizontal de temperatura varia de fraco a moderado e extraem energia potencial disponível do escoamento médio (da mesma forma que os ciclones extratropicais baroclínicos); e recebem parte ou quase toda energia da redistribuição convectiva de calor adquirido do mar (da mesma forma como ocorre nos ciclones tropicais). Além disso, segundo o glossário, os ciclones subtropicais podem fazer transição para tropicais, e vice-versa. Assim como proposto pela WMO, a AMS também propõe que, na bacia do Atlântico Norte, de acordo com a intensidade do vento sustentado, os ciclones subtropicais podem ser classificados como depressões subtropicais (ventos em superfície $<18,0 \mathrm{~m} \mathrm{~s}^{-1}$ ) ou tempestades subtropicais (ventos em superfície $\geq \mathrm{a}$ $\left.18,0 \mathrm{~m} \mathrm{~s}^{-1}\right)$.

Ambas as definições para ciclones subtropicais acima mencionadas (WMO e AMS) são vagas e de forma alguma representam de forma clara e fiel as principais características e processos de formação destes sistemas. Não existe na literatura uma definição oficial precisa e amplamente aceita para ciclones híbridos, e, além disso, suas características e mecanismos físicos podem ser diferentes dependendo da região de formação.

(a)

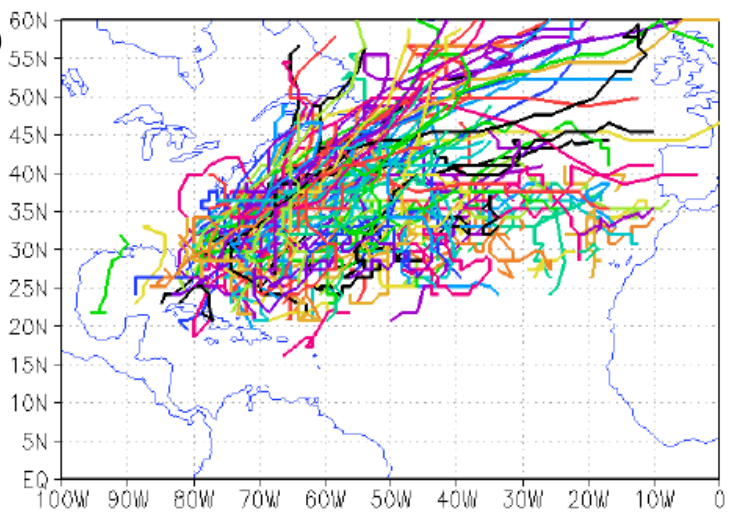

(b)

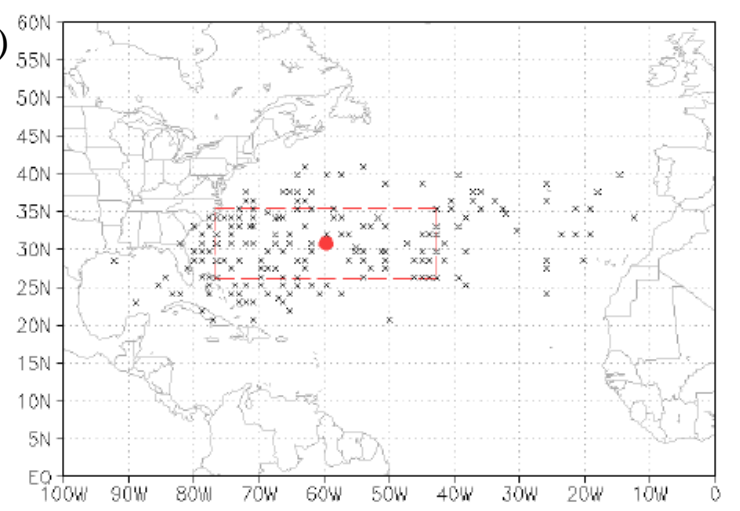

Fig. 1.3. (a) Tracking e (b) localização do início da ventania em superfície das tempestades subtropicais na climatologia ERA-40 de Guishard (2006). O ponto e a caixa vermelha em (b) indicam respectivamente a posição média e o domínio do desvio padrão de todas as localizações de início da ventania em superfície. Figura 22 de Guishard (2006).

Guishard (2006) investigou os ciclones subtropicais na bacia do Atlântico Norte, e encontrou uma média de quatro sistemas por ano em sua climatologia de 45 anos (1957 a 2002, Fig. 1.3a) com a reanálise ERA-40 (ECMWF 40 Years Reanalysis) do ECMWF (European Centre for Medium-Range Weather Forecasts; UPPALA et al. 2004). Os ciclones 
subtropicais incluídos nesta climatologia desenvolveram-se entre $20^{\circ}$ e $40^{\circ} \mathrm{N}$ (o que reduz a possibilidade de sistemas tropicais e extratropicais terem sido incluídos no conjunto de dados) e apresentaram núcleo quente em baixos níveis e frio em altos níveis dentro de 24 horas a partir do início do ciclone e por no mínimo 36 horas durante seu ciclo de vida. O autor argumenta que a condição imposta de que a estrutura híbrida devesse ser verificada dentro de 24 horas a partir do início do ciclone seleciona apenas a formação in situ de ciclones subtropicais, excluindo, portanto, sistemas híbridos que evoluíram de diferentes estruturas pré-existentes (tropicais ou extratropicais). Além disso, ventos fortes (ou ventania) com velocidades iguais ou superiores a $17,0 \mathrm{~m} \mathrm{~s}^{-1}$ em $925 \mathrm{hPa}$ deveriam ser registradas em algum horário durante a fase híbrida. A localização do ciclone no início da ventania em $925 \mathrm{hPa}$ foi considerada como sendo a posição de gênese das tempestades subtropicais (Fig. 1.3b). A análise de Guishard (2006) foi realizada somente sobre o oceano, uma vez que fatores como a fricção na superfície e a topografia complicam o entendimento dos processos que governam a ciclogênese subtropical.

Os resultados obtidos na climatologia da ERA-40 de Guishard (2006) mostraram que a temperatura da superfície do mar (TSM) é um fator importante na ciclogênese subtropical, já que pode sustentar a convecção profunda ao ser associada com alta umidade relativa (UR) da baixa e média troposfera. Entretanto, o autor argumenta que a TSM quente não é condição suficiente para prever e/ou analisar a gênese dos ciclones subtropicais, uma vez que $12 \%$ destes sistemas se formaram sobre águas mais frias que $20^{\circ} \mathrm{C}$, com mínimo de $15^{\circ} \mathrm{C}$. Guishard (2006) utilizou também as análises operacionais do GFS (Global Forecast System - antigo AVN - AViatioN model) do NCEP (National Centers for Environmental Prediction) e restringiu sua análise para 18 ciclones subtropicais ocorridos em 5 anos (1999 a 2004). Com isso, o autor observou a presença de um cavado em níveis superiores nos ventos de oeste como característica dominante para o desenvolvimento de tais sistemas, assim como discutido em trabalhos como os de Morrisson e Bussinger (2001) e Caruso e Businger (2006) para os ciclones subtropicais que se desenvolvem no Oceano Pacífico Norte. Assim, Guishard (2006) propõe que a presença de um cavado em altos níveis ou de uma cutoff low fornece o suporte dinâmico para o desenvolvimento dos ciclones subtropicais. Os resultados sugeriram também que o cavado em níveis superiores tende a mover-se para regiões de TSM elevadas, permitindo o aumento do cisalhamento vertical do vento e o início de uma baixa baroclínica e quente em superfície. Entre as principais características dos ciclones subtropicais na bacia do Atlântico Norte destacam-se: cisalhamento vertical do vento horizontal (V200hPa V900hPa) maior do que $10 \mathrm{~m} \mathrm{~s}^{-1}$; parâmetro de Coriolis suficientemente grande comparado 
com ciclogêneses tropicais, ou seja, os ciclones subtropicais ocorrem preferencialmente entre $20^{\circ} \mathrm{N}$ e $35^{\circ} \mathrm{N}$; se desenvolvem em ambiente de anomalia de vorticidade ciclônica em baixos níveis pré-existente, que pode resultar de uma zona frontal velha ligada ao cavado em nível superior que força a ciclogênese.

A Fig. 1.4, retirada do trabalho de Guishard (2006), mostra a extensão de nebulosidade associada ao ciclone subtropical Michael, em duas diferentes fases. Este ciclone foi denominado "garoto propaganda" por Guishard (2006), e teve seu início com características subtropicais e posteriormente fez transição para tropical. Pela Fig. 1.4, nota-se que a área de nebulosidade durante a fase subtropical é maior do que durante a fase tropical.

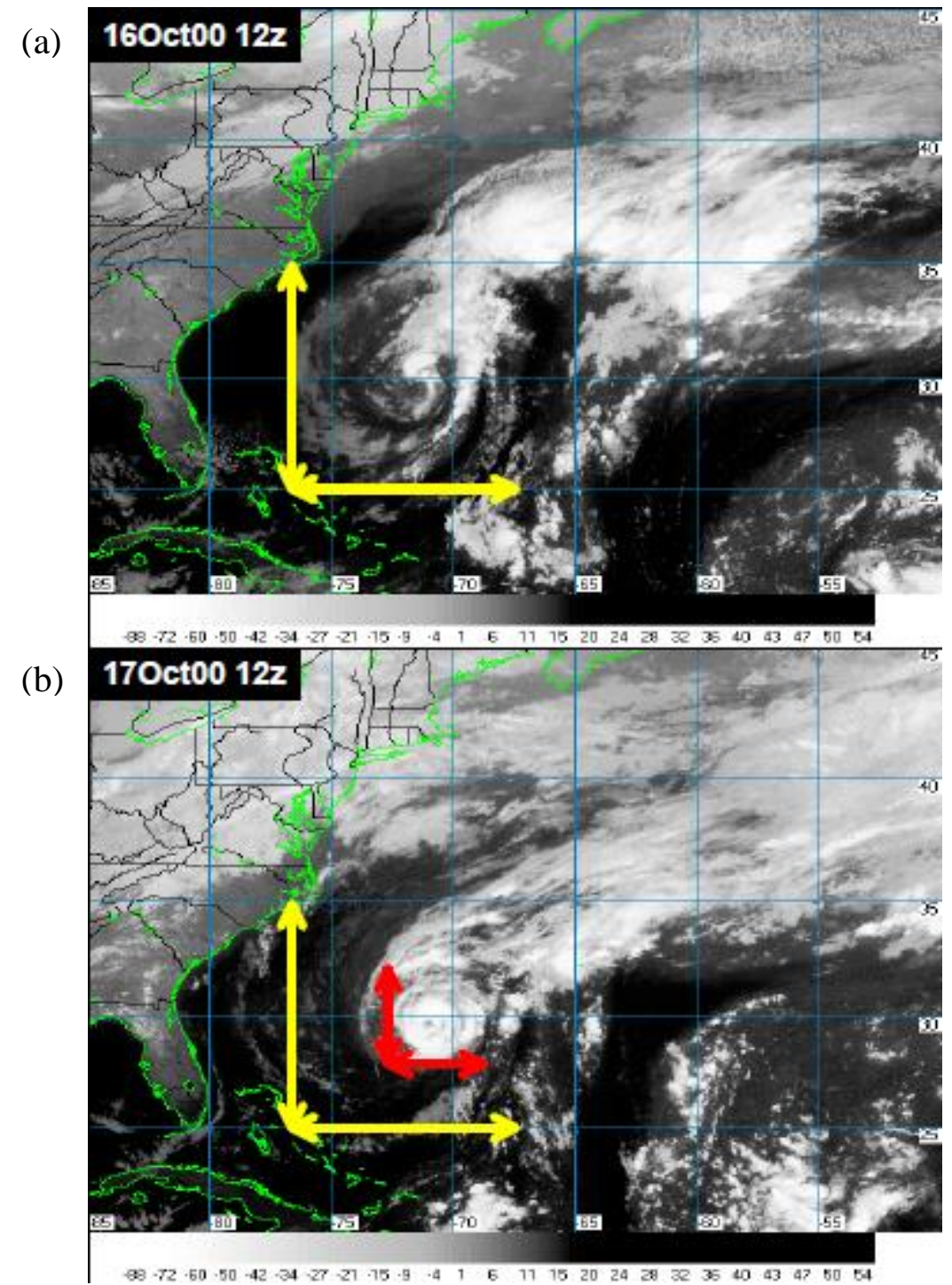

Fig. 1.4. Imagem de satélite do GOES-8 no canal IR do ciclone Michael na fase (a) subtropical e (b) tropical de seu ciclo de vida. As setas amarelas e vermelhas indicam a extensão das nuvens associadas à circulação ciclônica durante sua fase subtropical e tropical, respectivamente. Adaptado de Guishard (2006). 
Guishard (2006) e Evans e Guishard (2009) sugerem que a intensa atividade convectiva pode ocasionar a quebra de uma onda de Rossby de grande escala, levando à formação de baixas fechadas em altos níveis que favorecem a formação de ciclones subtropicais em superfície caso a TSM seja suficientemente alta e a camada limite instável. Segundo Davis e Bosart (2003), a quebra da onda de Rossby reduz a escala da onda em altos níveis, favorecendo a interação com um possível distúrbio de menor escala pré-existente em baixos níveis.

Braun (2009) realizou uma climatologia dos ciclones subtropicais sobre o Atlântico Sul e sobre a região do Mar da Tasmânia (costa leste da Austrália), e selecionou um ciclone subtropical de cada região para estudo de casos. As condições utilizadas para classificar um ciclone como subtropical foram semelhantes às condições impostas em Guishard (2006). Sobre o Atlântico Sul, Braun (2009) verificou que a frequiência de ocorrência destes sistemas também é baixa: em 51 anos (agosto de 1957 a dezembro de 2007), com a reanálise ERA-40 e dados GFS, foram encontrados somente 63 ciclones subtropicais, o que equivale a uma média de aproximadamente um ciclone por ano. No mesmo período, foram encontrados 111 ciclones subtropicais no Mar da Tasmânia. Os ciclones subtropicais se formaram sob cisalhamento vertical do vento horizontal de até $63,0 \mathrm{~m} \mathrm{~s}^{-1}$ e $56,0 \mathrm{~m} \mathrm{~s}^{-1}$, respectivamente, no Atlântico Sul e Mar da Tasmânia. Tais valores foram obtidos considerando a camada entre 900-300 hPa e uma caixa de $5,0^{\circ}$ centrada nos ciclones. Cabe ressaltar que para o Atlântico Norte, o máximo cisalhamento vertical observado em um caso de ciclone subtropical foi de 40,0 $\mathrm{m} \mathrm{s}^{-1}$; Braun (2009) argumenta que esta diferença nos valores do cisalhamento vertical entre os hemisférios pode ser atribuída às estações do ano em que ocorre o máximo da atividade ciclogenética subtropical: verão e outono para o Atlântico Norte e outono e inverno para o HS. Assim, uma vez que as correntes de jato mais intensas nos subtrópicos ocorrem no hemisfério de inverno, o cisalhamento vertical nesta estação também será maior.

Braun (2009) sugere um mecanismo alternativo para a formação de ciclones subtropicais, em que cadeias de montanhas na costa leste do continente (Cordilheira Australiana ou Grande Cordilheira Divisória no caso da região do Mar da Tasmânia e Serra da Mantiqueira no caso do Atlântico Sul) e correntes oceânicas em direção aos pólos (Corrente Leste Australiana e Corrente do Brasil) forneceriam uma forçante topográfica que favoreceria a ciclogênese a sotavento (em inglês, lee cyclogenesis). Conseqüientemente, em um ambiente de TSM suficientemente elevada e/ou intensa advecção quente em baixos níveis, pode ocorrer o desenvolvimento de um ciclone subtropical. A ciclogênese a sotavento é o desenvolvimento em escala sinótica de circulação atmosférica ciclônica a sotavento de uma montanha, devido à 
perturbação do escoamento zonal de oeste pela presença da montanha. No processo sugerido por Braun (2009), a forçante dinâmica precede a convecção intensa, ao contrário do mecanismo sugerido em Evans e Guishard (2009), onde a atividade convectiva é precursora de uma forçante dinâmica favorável em altos níveis.

No Pacífico norte-central, os ciclones subtropicais que ocorrem durante a estação fria (outubro-abril) recebem o nome de Kona lows (MORRISON e BUSINGER, 2001). Além de serem responsáveis por uma fração substancial do total de chuva de algumas regiões do Havaí (DAINGERFIELD 1921; RIEHL 1949), registros mostram que estes eventos também podem produzir grandes perdas devido às chuvas, ventos fortes, granizo, trovoadas e inundações (SCHROEDER 1977a,b; RAMAGE 1995; KODAMA e BARNES 1997; BUSINGER et al. 1998). Os Kona lows são sistemas de baixa pressão que se formam em latitudes subtropicais com núcleo frio e posteriormente se deslocam em direção ao Equador, desenvolvendo um núcleo quente raso e um campo de vento semelhante ao de ciclones tropicais (SIMPSON, 1952).

$\mathrm{Na}$ costa leste da Austrália, intensos ciclones se desenvolvem entre $25^{\circ} \mathrm{S}$ e $45^{\circ} \mathrm{S}$, tipicamente durante os meses de inverno. Embora raros (sua freqüência é de quase um por ano), são responsáveis por diversos danos, causando enchentes e ventos fortes. Sua previsão é difícil, já que estes ciclones são geralmente pequenos em seu estágio inicial e se desenvolvem muito rapidamente (HOLLAND et al. 1987).

Davis (2010) realizou simulações com um modelo baroclínico e investigou os ciclones que se formam em diferentes condições de jato do estado básico e diferentes valores de cisalhamento horizontal próximo à superfície. O autor propôs uma definição do ponto de vista dinâmico para os ciclones subtropicais que se formam em suas simulações úmidas idealizadas, que os distingue dos demais ciclones que se desenvolvem (extratropicais). Segundo a classificação de Davis (2010), os ciclones subtropicais apresentam: 1) baroclinia negligenciável; 2) alta influência do aquecimento por condensação e 3) profundo cisalhamento vertical entre $900 \mathrm{hPa}$ e $300 \mathrm{hPa}$, condição esta que os diferencia dos ciclones tropicais.

No CPS de Hart (2003), estrutura híbrida também é notada em ciclones que passam por processos de transição, sendo que a característica híbrida, isto é, núcleo quente em baixos níveis e frio em altos ocorre justamente durante a transição. Ciclones tropicais (extratropicais) que adquirem características extratropicais (tropicais) com o tempo são denominados ciclones de transição extratropical (tropical). Desta forma, no CPS a evolução dos ciclones de transição pode ser avaliada dentro de um contínuo. Imagens de satélite também representam uma 
ferramenta útil para identificar se um ciclone passou por processos de transição, uma vez que a distribuição de nuvens e precipitação é diferente em ciclones tropicais e extratropicais, conforme mencionado nos itens $1.2 \mathrm{~b}$ e $\mathbf{1 . 2 c}$.

Jones et al. (2003) sintetizam as principais características observadas durante transições extratropicais. Os autores destacam que tal transição costuma ocorrer em ciclones tropicais que se deslocam para latitudes mais altas, em diferentes condições atmosféricas, tais como: maior baroclinia e cisalhamento vertical do vento horizontal, maior gradiente meridional de umidade, menor TSM ou maiores gradientes de TSM e maior parâmetro de Coriolis. Além disso, também pode ocorrer que outro ciclone, com características extratropicais, ou um cavado na alta troposfera esteja próximo e interaja com o ciclone tropical. Tal processo ocorre, por exemplo, em ciclones de transição extratropical no Pacífico Sudoeste, com a aproximação de um cavado de latitudes médias (Sinclair, 2002). Jones et al. (2003) também destacam que durante a transição extratropical os ciclones ainda produzem vetos fortes e intensa precipitação, além de passarem a se deslocar mais rapidamente em comparação à fase tropical. Assim, a fase híbrida dos ciclones de transição não deve ser subestimada quanto ao grau de ameaça às atividades marítimas e/ou continentais.

Hart e Evans (2001) realizaram uma climatologia de ciclones de transição extratropical no Oceano Atlântico Norte, e verificaram que tais transições ocorrem em latitudes mais baixas (altas) no começo e no fim (no pico) da temporada de furacões.

Em março de 2004, o ciclone Catarina ganhou seu lugar na história como o primeiro ciclone de transição tropical documentado na bacia do Atlântico Sul (McTAGGART COWAN et al. 2006; VEIGA et al. 2008). A análise da estrutura tri-dimensional do Catarina através do Cyclone Phase Space (HART, 2003) indica que o sistema iniciou-se com certa assimetria térmica, mas logo realizou transição para um sistema simétrico (Fig. 1.5a). Além disso, o sistema iniciou-se com características híbridas, isto é, um núcleo quente em baixos níveis e frio em altos níveis, mas posteriormente tornou-se um sistema de núcleo quente em toda a troposfera (Fig. 1.5b) (GOZZO, 2011).

Segundo Pezza e Simmonds (2005), o cisalhamento vertical do vento horizontal (definido como a diferença do vetor de vento, em $\mathrm{m} \mathrm{s}^{-1}$, entre $200 \mathrm{hPa}$ e $850 \mathrm{hPa}$ ) climatológico na região do Atlântico Sul em que o ciclone Catarina se desenvolveu é de 25,8 $\pm 8,8 \mathrm{~m} \mathrm{~s}^{-1}$, valor demasiadamente alto para que tempestades puramente tropicais se desenvolvam. Entretanto, estes valores de cisalhamento não inibem o desenvolvimento de tempestades subtropicais (BRAUN, 2009). 
(a)

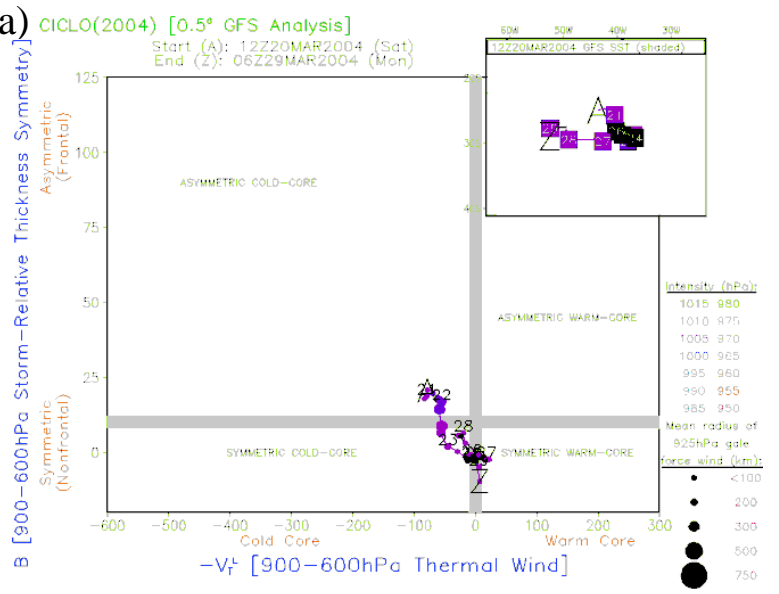

(b)

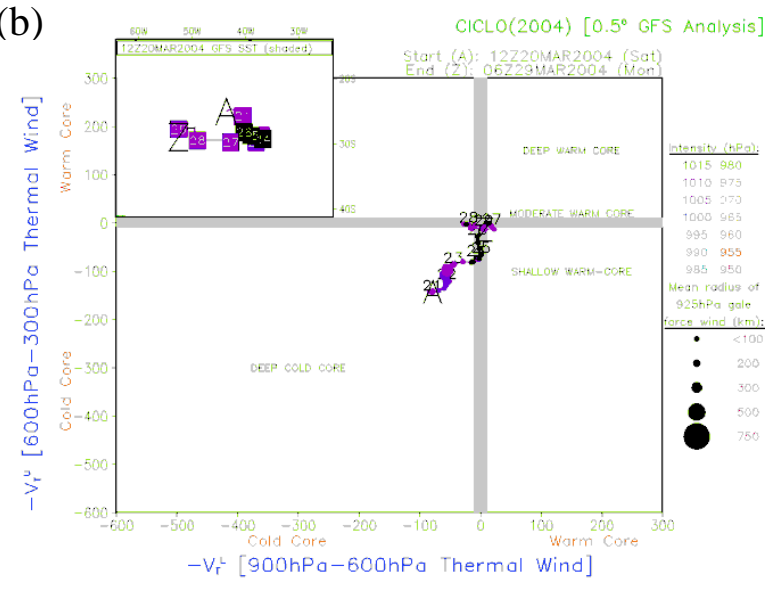

Fig. 1.5. Cyclone Phase Space (Hart, 2003) para o ciclone Catarina, ocorrido em março de 2004. Figura extraída de Gozzo (2011). 


\section{CAPÍTULO 2}

\section{Dados e metodologia}

\subsection{Dados}

Foram utilizados dados do NCEP, do NCEP FNL (final) Operational Model Global Tropospheric Analyses, e do TRMM (Tropical Rainfall Measuring Mission), além de imagens do satélite GOES-12 disponíveis no site do Centro de Previsão de Tempo e Estudos Climáticos do Instituto Nacional de Pesquisas Espaciais (CPTEC-INPE: www.cptec.inpe.br/). Utilizaram-se ainda imagens de satélite especiais obtidas por comunicação pessoal com o grupo responsável pelos produtos relacionados aos ciclones tropicais do NRL (United States Naval Research Laboratory).

As reanálises do NCEP (KALNAY et al. 1996) são utilizadas para muitas das previsões meteorológicas realizadas, tendo disponível no endereço (http://www.ncep.noaa.gov/) uma grande variedade de dados meteorológicos para longo período de tempo. Estes dados são freqüentemente utilizados pela comunidade científica, e possuem resolução espacial de $2,5^{\circ}$ de latitude e longitude em 17 níveis verticais de pressão (de 1000 a $10 \mathrm{hPa})$, e resolução temporal de 6 horas $(0,6,12$ e 18Z).

Os dados do NCEP FNL possuem resolução horizontal de $1,0^{\circ}$ de latitude por $1,0^{\circ}$ de longitude em 26 níveis verticais de pressão (de 1000 a $10 \mathrm{hPa}$ ) e em quatro horários por dia $(0,6,12$ e 18Z). Os dados FNL são as condições iniciais para o modelo global do NCEP denominado GFS. A série temporal de dados disponíveis tem início em julho de 1999 e pode ser acessada pelo endereço (http://dss.ucar.edu).

Os dados do TRMM possuem resolução horizontal de $0,25^{\circ}$ de latitude por $0,25^{\circ}$ de longitude e representam o acumulado diário de precipitação em $\mathrm{mm}$ dia $^{-1}$. Tais dados são gerados através de um algoritmo denominado 3B-42, que utiliza dados de infravermelho e micro-ondas de alta qualidade e estimativas dos erros médios quadráticos associados, além do uso indireto de dados de postos pluviométricos (HUFFMAN et al. 2007; PONTES DA SILVA, 2011). No presente trabalho, os dados de precipitação do TRMM são analisados do ponto de vista qualitativo. 


\subsection{Algoritmo para rastreamento dos ciclones}

Existem basicamente dois diferentes métodos para identificar a presença e evolução de um ciclone: o método subjetivo, no qual é realizada uma análise visual dos campos de diversas variáveis atmosféricas; e o método objetivo, no qual as regiões de baixa pressão são identificadas a partir de algoritmos, baseados nas características físicas conhecidas que uma região de escoamento ciclônico possui.

Este trabalho utilizou um algoritmo de rastreamento de ciclones inicialmente desenvolvido por Sugahara (2000) e posteriormente modificado por Reboita (2008), no qual os ciclones são identificados a partir de máximos de vorticidade ciclônica. Os campos da componente vertical de vorticidade relativa são calculados pelo algoritmo a partir das componentes horizontais do vento. Tanto Sugahara (2000) quanto Reboita (2008) utilizaram dados de vento em 10 metros de altura e com resolução espacial de $2,5^{\circ}$ por $2,5^{\circ}$ para efetuar o rastreamento dos centros ciclônicos. Entretanto, o presente trabalho utilizou campos de vento em $925 \mathrm{hPa}$ com resolução de $1,0^{\circ}$ de latitude por $1,0^{\circ}$ de longitude.

Estudos como os de Le Marshall e Kelly (1981) e Lambert (1988) mostraram que, no HS, a identificação objetiva de ciclones através de mínimos de pressão localiza a maioria dos centros ciclônicos ao sul de $60^{\circ} \mathrm{S}$. De acordo com Sinclair (1994), grande parte dos distúrbios ciclônicos em latitudes médias não é detectada através deste método pois os mínimos locais de pressão desaparecem devido aos intensos gradientes meridionais de pressão que se sobrepõem à circulação ciclônica. Assim, algoritmos de rastreamento de ciclones baseados em mínimos de pressão possuem maior habilidade em identificar sistemas mais intensos, como os que ocorrem em latitudes mais próximas dos pólos. Sinclair (1994) mostrou que a procura por máximos de vorticidade ciclônica ao invés de mínimos de pressão permite identificar melhor a atividade ciclônica nas latitudes entre $40^{\circ} \mathrm{S}$ e $60^{\circ} \mathrm{S}$.

Os resultados obtidos pelo método da vorticidade são, portanto, mais consistentes com as observações de satélites e com a experiência sinótica geral (SINCLAIR, 1997). Uma vez que a vorticidade relativa mede a rotação das parcelas de fluido, o uso desta variável no rastreamento dos ciclones é ideal para identificar o início de distúrbios com circulação ciclônica associada, mas que ainda não apresentam uma isóbara fechada (MURRAY e SIMMONDS, 1991a; SINCLAIR, 1994; REBOITA et al. 2010). Entretanto, a intensidade da vorticidade depende da resolução horizontal dos dados, pois quanto menor for o espaçamento de grade, maior será o valor do módulo da vorticidade. Por esta razão, o limiar de vorticidade 
usado para detectar os ciclones pode variar de acordo com o espaçamento de grade utilizado (REBOITA, 2008).

No algoritmo desenvolvido por Sugahara (2000), a busca pelo centro dos sistemas ciclônicos no HS (HN) é feita da seguinte forma: (1) Inicialmente, identificam-se os mínimos (máximos) relativos de vorticidade, ou seja, localizam-se os pontos cujo valor da vorticidade é menor (maior) que nos 24 pontos de grade vizinhos, devendo inclusive ser menor (maior) ou igual a um limiar previamente especificado. (2) Identificadas as coordenadas do mínimo local de vorticidade, esta posição é transferida para o tempo seguinte, servindo como um referencial para a busca da nova posição do centro do ciclone. (3) Ao encontrar esta nova posição, calcula-se a velocidade de deslocamento, que auxiliará na estimativa inicial da posição aproximada do sistema no próximo tempo, posição esta que servirá como o novo referencial para a procura do mínimo de vorticidade. Encontrada esta nova posição, o algoritmo repete os procedimentos iniciais, sendo que as demais posições futuras são sempre calculadas a partir da estimativa da velocidade de deslocamento do sistema sempre entre os dois últimos intervalos de tempo consecutivos.

Destaca-se que a vorticidade relativa é suavizada pelo método de Cressman (CRESSMAN, 1959; SINCLAIR, 1997), a fim de eliminar centros espúrios de vorticidade e reduzir ruídos das zonas de cisalhamento alongadas (REBOITA et al. 2010). Este método suaviza o valor de cada ponto de grade a partir de todos os pontos vizinhos localizados a uma distância menor que um raio constante pré-estabelecido (utilizou-se $r_{0}=500 \mathrm{~km}$ ). Posteriormente, os dados são interpolados para uma grade espacial de $0,3571^{\circ}$ por $0,3571^{\circ}$ através de uma função polinomial bicúbica (MURRAY e SIMMONDS, 1991a; SUGAHARA, 2000). Sugahara (2000) menciona que esta interpolação para uma grade de resolução maior, ao invés do rastreamento apenas na grade original, pode resultar em uma diferença por volta de $100 \mathrm{~km}$ na posição central do ciclone rastreado. Tal interpolação é feita somente nas regiões ao entorno do ciclone.

Neste trabalho, foram utilizados dois diferentes limiares de vorticidade para efetuar o rastreamento: $-1,0 \times 10^{-5} \mathrm{~s}^{-1}$ e $-2,5 \times 10^{-5} \mathrm{~s}^{-1}$. Ao aplicar este algoritmo para a região subtropical do Atlântico Sul, os resultados fornecidos são: 1) a data e horário de ocorrência, 2) a posição (latitude e longitude) e 3) a vorticidade relativa do centro dos sistemas, sendo que os dois primeiros itens serão utilizados no Cyclone Phase Space - CPS (HART, 2003). 


\subsection{Algoritmo para avaliar a estrutura dos ciclones}

O Cyclone Phase Space é um diagrama desenvolvido por Hart (2003) para avaliar a estrutura tri-dimensional dos ciclones, a partir de parâmetros que medem a assimetria térmica e a variação vertical dos gradientes de altura geopotencial (variação esta que é análoga ao vento térmico) em cada tempo do ciclo de vida dos sistemas. Com o CPS é possível inferir a natureza dos ciclones (tropicais, extratropicais ou híbridos), uma vez que os tipos de estruturas são classificados pela simetria, pelo fortalecimento da anomalia de temperatura e pela profundidade vertical (HART, 2003). Atualmente, os códigos do CPS encontram-se disponíveis na home page do pesquisador, em (http://moe.met.fsu.edu/ rhart/software.php).

Os três parâmetros do CPS utilizados na identificação das fases do ciclone são: simetria térmica ou de espessura do ciclone $(B)$, vento térmico em baixos níveis $\left(-\left|V_{T}^{L}\right|\right)$ e vento térmico em altos níveis $\left(-\left|V_{T}^{U}\right|\right)$, todos obtidos a partir dos campos de altura geopotencial.

O parâmetro $B$ (expressão 2.1) pode ser entendido como um gradiente horizontal de temperatura e indica, portanto, se a estrutura do sistema é ou não inclinada. Em outras palavras, este parâmetro identifica se o ciclone possui natureza frontal (extratropical) ou não frontal (tropical). $B$ é calculado a partir da diferença de espessura da camada, entre $900 \mathrm{hPa}$ e $600 \mathrm{hPa}$, em dois semicírculos que constituem a região do ciclone, como esquematizado na Fig. 2.1.

$$
B=h\left(\left.\overline{Z_{600 h P a}-Z_{900 h P a}}\right|_{R}-\left.\overline{Z_{600 h P a}-Z_{900 h P a}}\right|_{L}\right)
$$

Na equação (2.1), $Z$ é a altura geopotencial, $h$ é igual a +1 no HN e -1 no HS, e $R$ e $L$ referem-se, respectivamente, aos semicírculos direito e esquerdo do ciclone. Estes semicírculos possuem raio de $500 \mathrm{~km}$ e são definidos de acordo com o movimento do distúrbio. Tem-se que em todos os estágios de um ciclone tropical a temperatura é similar nos dois semicírculos e portanto $B \sim 0(-10 \mathrm{~m}<B<10 \mathrm{~m})$. Já no caso de um ciclone extratropical, haverá um lado quente e outro frio (ao menos nos estágios iniciais), o que implica em uma grande diferença de espessura entre os semicírculos, e deste modo o módulo de $B$ atinge valores grandes e varia ao longo do ciclo de vida do ciclone (Fig. 2.1). 
(a)

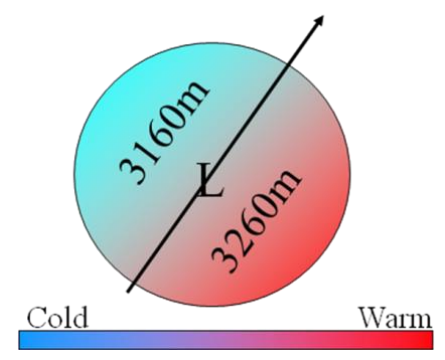

(b)

\section{Ciclone \\ Tropical \\ convencional: \\ $B \approx 0$}
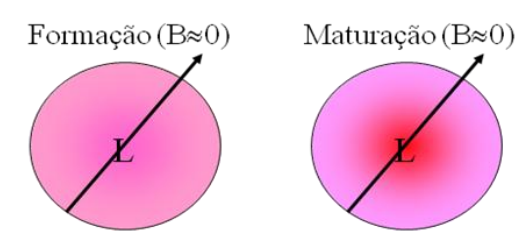

Decaimento $(\mathrm{B} \approx 0)$

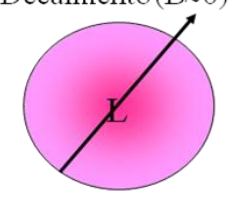

Desenvolvimento $(B>>0) \quad$ Mature $(B>0)$

\section{Ciclone}

Extratropical

convencional:

$B$ varia
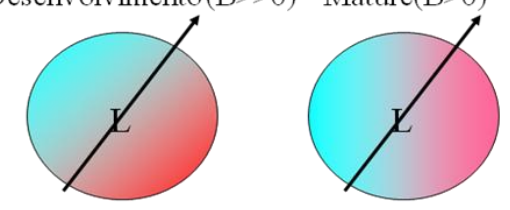

Oclusão $(\mathrm{B} \approx 0)$

Fig. 2.1. Esquematização para o $\mathrm{HN}$ : (a) Semicírculos de raio $500 \mathrm{~km}$ que compreendem a região do ciclone analisada pelo CPS e (b) valores esperados do parâmetro $B$ para diferentes estágios de um ciclone tropical convencional (topo) e de um ciclone extratropical convencional (abaixo). Na figura, $L$ indica a posição do centro do sistema de baixa pressão e a barra que delimita os semicírculos é definida de acordo com o movimento do distúrbio. Adaptado de (http://moe.met.fsu.edu/cyclonephase/index.html)

Os parâmetros do vento térmico são definidos como uma mudança no gradiente de altura geopotencial entre diferentes níveis de pressão:

$$
\begin{aligned}
& -\left|V_{T}^{L}\right|=\left.\frac{\partial\left(Z_{\max }-Z_{\min }\right)}{\partial \ln p}\right|_{900} ^{600} \\
& -\left|V_{T}^{U}\right|=\left.\frac{\partial\left(Z_{\max }-Z_{\min }\right)}{\partial \ln p}\right|_{600} ^{300}
\end{aligned}
$$

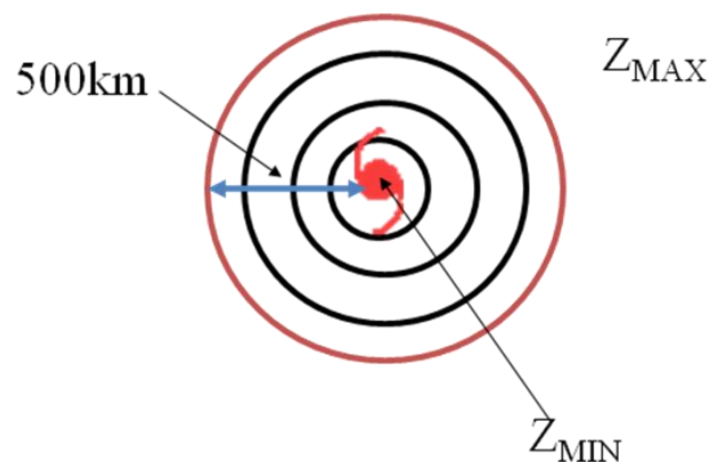

Fig. 2.2. Esquematização das localizações de $Z_{\max }$ e $Z_{\text {min }}$ para um dado nível de pressão. Adaptado de (http://moe.met.fsu.edu/cyclonephase/index.html).

Nas equações (2.2) e (2.3), os índices $L$ e $U$ denotam respectivamente as camadas entre $900-600 \mathrm{hPa}$ e $600-300 \mathrm{hPa}$, e $Z_{\max }$ e $Z_{\min }$ correspondem à altura geopotencial, respectivamente, na borda e no centro do círculo de raio de $500 \mathrm{~km}$ centrado no ciclone (Fig. 2.2). Tem-se que o perfil vertical de $\Delta Z=\left(Z_{\text {max }}-Z_{\text {min }}\right)$ é proporcional ao vento térmico. Para um evento de núcleo quente, tem-se que a perturbação da altura é maior em baixos níveis, isto é, decresce verticalmente, e então $-\left|V_{T}\right|>0$; já para um evento de núcleo frio 
ocorre o inverso: a perturbação da altura é maior em altos níveis, isto é, aumenta com a altura, e assim $-\left|V_{T}\right|<0$.

A Tabela 2.1 resume os valores esperados dos parâmetros do CPS para os três tipos de ciclones. Nota-se que os sistemas ciclônicos subtropicais são híbridos por possuírem características tanto tropicais quanto extratropicais.

Tabela 2.1. Valores esperados dos parâmetros do CPS para ciclones tropicais, subtropicais e extratropicais. Baseado em Guishard (2006).

\begin{tabular}{|c|c|c|c|}
\hline Tipo de ciclone & $\boldsymbol{B}$ (metros) & $-\left|\boldsymbol{V}_{\boldsymbol{T}}^{\boldsymbol{L}}\right|$ & $-\left|\boldsymbol{V}_{\boldsymbol{T}}^{\boldsymbol{U}}\right|$ \\
\hline Tropical & $-10<\mathrm{B}<10$ & $>>0$ & $>>0$ \\
Subtropical & Varia, mas não adquire & $>-10$ & $<10$ \\
Extratropical & valores grandes & $<0$ & $<<0$ \\
\hline
\end{tabular}

A principal saída do algoritmo do CPS é gráfica, apresentando o parâmetro $B$ versus $-\left|V_{T}^{L}\right|$ e $-\left|V_{T}^{U}\right|$ versus $-\left|V_{T}^{L}\right|$ (Fig. 2.3). De acordo com a posição e a trajetória para cada tempo do ciclo de vida do ciclone, é possível inferir visualmente o tipo de ciclone, usando como referência a Tabela 2.1. Além disso, os códigos fornecidos na home page do pesquisador Hart possibilitam a análise de apenas um ciclone por vez.
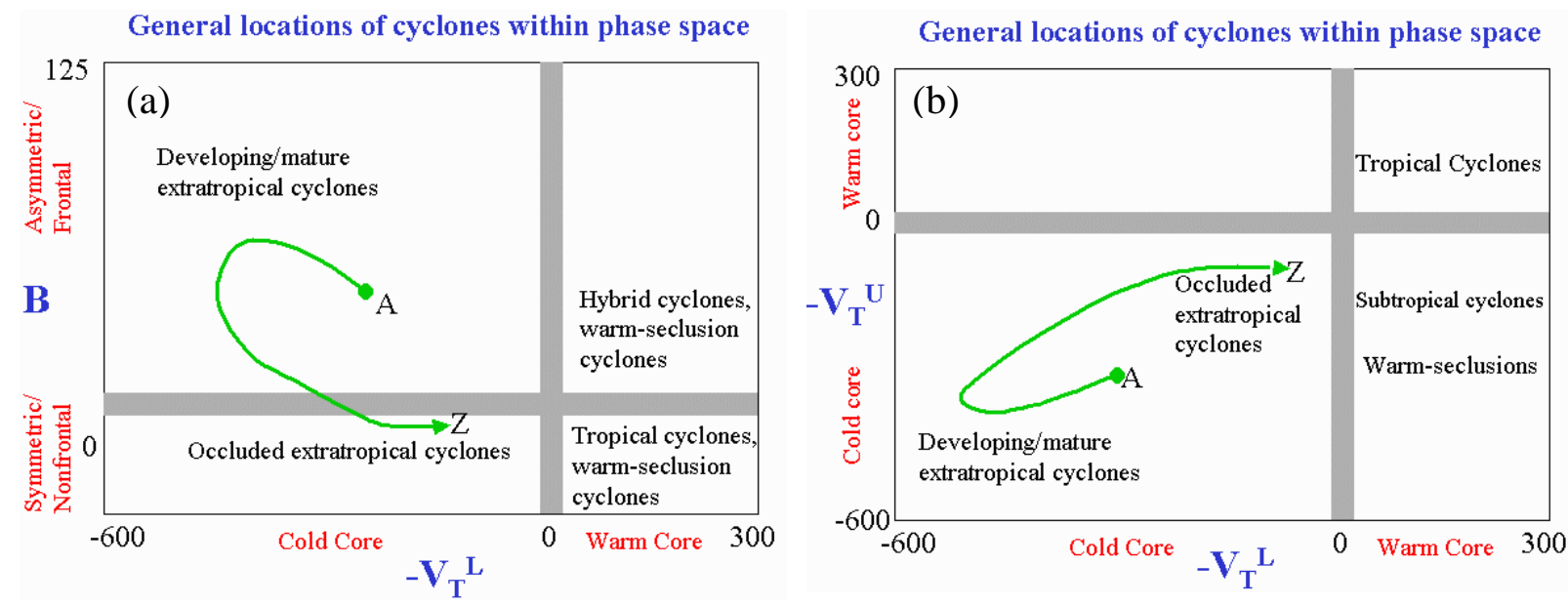

Fig. 2.3. Exemplo das saídas gráficas do CPS, para um caso idealizado de um ciclone extratropical (trajetória em verde). (a) parâmetro $B$ versus $-\left|V_{T}^{L}\right|$ e (b) $-\left|V_{T}^{U}\right|$ versus $-\left|V_{T}^{L}\right|$. Adaptado de (http://moe.met.fsu.edu/cyclonephase/index.html).

\subsection{Automatização do rastreamento e do CPS}

Para viabilizar a aplicação do CPS para todos os ciclones identificados no Oceano Atlântico Subtropical durante um longo período de tempo, desenvolveu-se um novo algoritmo em Shell cuja função é automatizar o processo que até então deveria ser feito manualmente e 
individualmente para cada ciclone. Esta automatização inicia o algoritmo de rastreamento de máximos de vorticidade ciclônica e fornece as informações de cada ciclone identificado ao CPS, armazenando os resultados finais em arquivos individuais para cada ciclone. As principais informações que devem ser fornecidas ao algoritmo de automatização são a data (ano e mês) inicial e final do período em que se deseja realizar o rastreamento, além de informações a respeito da área a ser rastreada e do limiar de vorticidade a ser utilizado. A automatização foi feita para os dados FNL e inclui algumas etapas conforme descrito a seguir.

Primeiramente, é necessário criar um arquivo com os dados em formato apropriado ao algoritmo de rastreamento. Para isso, utiliza-se um script do GrADS (GrADS script) que lê os dados FNL e copia as variáveis necessárias para um novo arquivo binário. Estas variáveis são a pressão reduzida ao nível médio do mar (PNMM) e as componentes zonal e meridional do vento no nível em que se deseja efetuar o rastreamento (no caso, $925 \mathrm{hPa}$ ). Destaca-se que este GrADS script recorta as variáveis apenas para uma área previamente estabelecida do HS, apesar dos dados FNL originais possuírem informações de todo o globo. A área recortada abrange uma região um pouco maior que a região em que os ciclones foram rastreados, conforme esquematizado na Fig. 2.4. Isto é necessário para não perder o rastreamento nas bordas da região, uma vez que o algoritmo utiliza diferenças finitas centrada no espaço para calcular a vorticidade relativa.

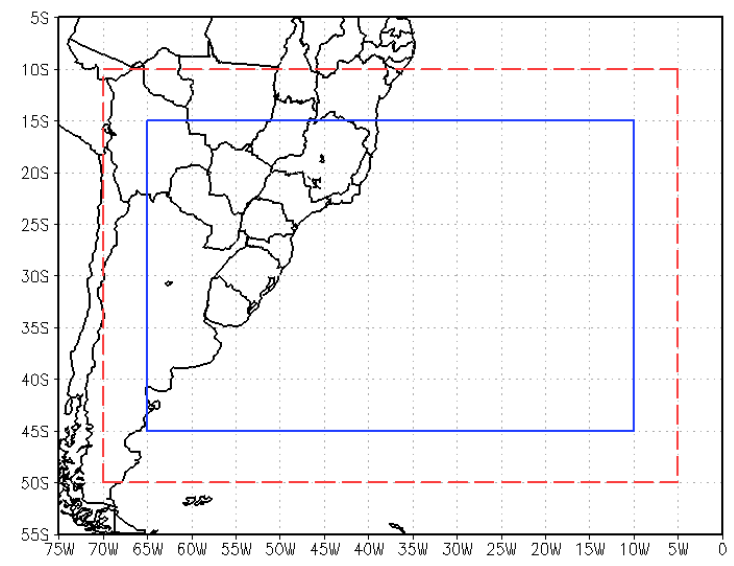

Fig. 2.4. Região na qual foi realizado o rastreamento dos máximos de vorticidade ciclônica (área do contorno azul), e região dos dados de entrada fornecidos ao algoritmo de rastreamento (área do pontilhado vermelho).

A saída do algoritmo de rastreamento consiste de um único arquivo que contém as informações de todos os ciclones rastreados, em sequiência cronológica. A automatização, por sua vez, lê este arquivo de saída e copia as informações de cada ciclone para um novo arquivo texto denominado stormtrack, que é então fornecido ao CPS juntamente com o arquivo 
descritor dos dados FNL originais. Ressalta-se que o arquivo stormtrack contém informações de apenas um ciclone por vez, sendo que as informações de cada ciclone rastreado são atualizadas na sequiência cronológica, ao término de cada rodada do CPS. Além disso, o arquivo descritor dos dados originais também é atualizado para cada diferente ciclone, pois os dados fornecidos ao CPS devem corresponder exatamente ao tempo de duração do ciclone, isto é, não devem ser fornecidos dados referentes a períodos prévios ou posteriores aos quais cada ciclone foi rastreado.

Após cada execução do CPS, o algoritmo de automatização copia as saídas para um novo diretório e as renomeia com a identificação (número em ordem crescente) de cada ciclone, para que os resultados posteriores não sejam sobrepostos sobre os anteriores. Ao total, são armazenados quatro arquivos para cada ciclone: a tabela com as informações do rastreamento (data, latitude, longitude e pressão central), as duas saídas gráficas do CPS e a saída correspondente do CPS em forma de tabela.

Este processo foi aplicado para todos os distúrbios ciclônicos identificados no Atlântico Subtropical nos anos de 2008 e 2009. Decidiu-se por realizar o rastreamento também para março de 2010, pois neste mês ocorreu um ciclone subtropical com deslocamento e características anômalas próximo à costa brasileira, que despertou a atenção da mídia na época.

A automatização desenvolvida neste trabalho também contribuiu com o projeto “Ciclones Subtropicais no Atlântico Sul: Aspectos Climáticos, Sinóticos e Dinâmicos", coordenado pela Profa. Dra. Rosmeri Porfírio da Rocha da Universidade de São Paulo e financiado pelo $\mathrm{CNPq}$ (Proc. 558121/2009-8). O projeto visa a elaboração de uma climatologia de ciclones subtropicais no Atlântico Sul, a partir dos parâmetros de saída do CPS.

\subsection{Identificação dos ciclones híbridos}

Com a automatização dos algoritmos de rastreamento e do diagrama de fase do ciclone, foi necessário elaborar um novo algoritmo para identificar nas tabelas de saída do CPS quais dos ciclones rastreados apresentaram estrutura hibrida. Neste trabalho, este algoritmo foi desenvolvido em Shell e os valores limítrofes foram semelhantes aos de Guishard (2006): $-\left|V_{T}^{L}\right|>-10$ e $-\left|V_{T}^{U}\right|<10$ (Tabela 2.1). Inicialmente, para que um ciclone fosse considerado como subtropical, considerou-se que as ambas as condições deveriam ser satisfeitas simultaneamente por um período mínimo de 24 horas, que é inferior 
ao de 36 horas adotado por Guishard (2006) para identificar ciclones subtropicais na bacia do Atlântico Norte. Entretanto, uma vez que a definição de limiares é subjetiva, adotou-se o limiar de 24 horas com o intuito de incluir sistemas híbridos de mais curta duração.

O algoritmo desenvolvido lê os parâmetros do vento térmico de cada ciclone rastreado e em cada tempo de seu ciclo de vida, e identifica quais os ciclones cujos parâmetros satisfizeram as condições estabelecidas. Dentre os resultados encontrados, foi possível selecionar alguns eventos para serem estudados no presente trabalho.

É importante destacar que os sistemas identificados não eram necessariamente híbridos durante todo o seu ciclo de vida, isto é, poderiam ser observadas estruturas extratropicais durante alguma fase de seu ciclo.

\subsection{Análises sinóticas}

Para a análise sinótica dos ciclones subtropicais selecionados, foram analisadas as seguintes variáveis meteorológicas: PNMM, vorticidade relativa (VR) em $925 \mathrm{hPa}$ e altura geopotencial em $500 \mathrm{hPa}$; temperatura e vento horizontal em $925 \mathrm{hPa}$; e linhas de corrente e isotacas em $200 \mathrm{hPa}$. Os níveis foram escolhidos de forma a representarem desde a baixa troposfera até níveis superiores, viabilizando, portanto, a análise da estrutura tri-dimensional da atmosfera na região de atuação dos sistemas.

A análise sinótica dos ciclones selecionados foi elaborada a partir dos dados NCEP FNL (que possuem maior resolução espacial), e considerou todo o período de atuação de cada sistema.

\subsection{Balanço de calor}

A primeira lei da termodinâmica é válida tanto para sistemas em equilíbrio termodinâmico quanto para sistemas em não-equilíbrio (HOLTON, 2004). A lei afirma que $a$ mudança da energia interna de um sistema é igual à diferença entre o calor adicionado ao sistema e o trabalho feito pelo sistema. Para um sistema que não está em equilíbrio, isto é, que não está em repouso, a primeira lei pode ser derivada como:

$$
c_{p} \frac{D T}{D t}-\alpha \frac{\partial p}{\partial t}=J
$$

Onde $c_{p}$ é o calor específico à pressão constante $\left(1004 \mathrm{~J} \mathrm{~K}^{-1} \mathrm{~kg}^{-1}\right), T$ é a temperatura do ar, $p$ é a pressão atmosférica, $\alpha$ é o volume específico, e $J=\partial H / \partial T$ é a taxa de 
aquecimento diabático, onde $H$ representa a soma dos processos radiativos, liberação de calor latente, calor sensível ou transporte turbulento, ou seja, as fontes diabáticas de calor.

Para um sistema isobárico, a primeira lei pode ser escrita expandindo a derivada material na equação (2.4) e notando que $\partial p / \partial t=\omega$.

$$
\left(\frac{\partial T}{\partial t}+u \frac{\partial T}{\partial x}+v \frac{\partial T}{\partial y}\right)-S_{p} \omega=\frac{J}{c_{p}}
$$

Onde $u$ e $v$ representam respectivamente a componente zonal e meridional do vento, $\omega$ é a pseudo-velocidade vertical, e $S_{p}$ é o parâmetro de estabilidade estática no sistema isobárico, dado por:

$$
S_{p} \equiv \frac{R T}{c_{p} p}-\frac{\partial T}{\partial p}
$$

Onde $R$ é a constante dos gases. Rearranjando os termos em (2.5), a equação da termodinâmica na forma de balanço pode ser escrita como:

$$
\frac{\partial T}{\partial t}=-\vec{V}_{H} \cdot \vec{\nabla}_{p} T+S_{w}+F_{T}
$$

Sendo que:

$$
\begin{aligned}
& S_{w}=\omega \frac{R T}{c_{p} p}-\omega \frac{\partial T}{\partial p} \\
& F_{T}=\frac{1}{c_{p}} \frac{\partial H}{\partial t}
\end{aligned}
$$

Onde $\vec{V}_{H}$ representa o vento horizontal e $\vec{\nabla}_{p}$ é o operador nabla horizontal (calculado sobre uma superfície de pressão constante). Na equação (2.7), o termo do lado esquerdo representa a variação local de temperatura, e os termos do lado direito correspondem (do primeiro ao último, respectivamente) à advecção horizontal de temperatura, ao termo relacionado ao movimento vertical $S_{w}$ (soma do termo de expansão/compressão adiabática e da advecção vertical de temperatura) e ao resíduo do balanço de calor ou termo diabático. Conforme a equação (2.7), o resíduo foi suposto ser basicamente de origem diabática. Entretanto, é importante destacar que este resíduo também inclui efeitos da incerteza computacional e observacional (SINCLAIR, 1993)

Os resíduos das equações representam uma medida de toda a contribuição sub-grade (VIRJI, 1982) e podem ser considerados como fontes ou sorvedouros aparentes, contribuindo 
para as variações da propriedade. Contudo, os resíduos não podem ser calculados diretamente ou muitas vezes não estão explícitos na equação (DIAS PINTO, 2007).

Em coordenadas esféricas, a equação do balanço de calor torna-se:

$$
\frac{\partial T}{\partial t}=-\left(\frac{u}{a \cos \varphi} \frac{\partial T}{\partial \lambda}+\frac{v}{a} \frac{\partial T}{\partial \varphi}\right)-\omega\left(\frac{\partial T}{\partial p}-\frac{\alpha}{c_{p}}\right)+F_{T}
$$

Onde $\lambda$ é a longitude, $\varphi$ é a latitude e $a$ é o raio da Terra.

O balanço de calor aplicado aos sistemas ciclônicos auxilia no entendimento dos processos termodinâmicos presentes no ciclo de vida destes sistemas. A equação da termodinâmica indica que as mudanças locais da temperatura de uma parcela de ar são provocadas pela advecção de temperatura, pelos resfriamentos/aquecimentos adiabáticos devidos aos deslocamentos verticais e pelas fontes diabáticas de calor.

Riehl e Malkus (1958) foram um dos primeiros a estudar o papel da convecção profunda no balanço de calor da atmosfera. Seus resultados mostraram como as nuvens cumulus podem transportar calor latente liberado durante a condensação do vapor d'água para a alta troposfera. Segundo Aubert (1957), o calor liberado na coluna pode influenciar a evolução e desenvolvimento de diversos sistemas tropicais e extratropicais (AUBERT, 1957 apud DIAS PINTO, 2007).

\subsection{Balanço de vorticidade}

A vorticidade é uma propriedade cinemática que quantifica o "spin" local ou a rotação das parcelas de fluido (CARLSON, 1991), fazendo o papel análogo à velocidade angular para corpos sólidos (HOLTON, 2004). Matematicamente, a vorticidade é um vetor que representa duas vezes a rotação média em torno dos eixos $x, y$ e $z$ e é definida como:

$$
\vec{\omega}=\vec{\nabla} \times \vec{V}=\left(\frac{\partial w}{\partial y}-\frac{\partial v}{\partial z}\right) \vec{i}+\left(\frac{\partial u}{\partial z}-\frac{\partial w}{\partial x}\right) \vec{j}+\left(\frac{\partial v}{\partial x}-\frac{\partial u}{\partial y}\right) \vec{k}
$$

Em meteorologia dinâmica de grande escala, geralmente as análises concentram-se somente na componente vertical da vorticidade (HOLTON, 2004), uma vez que os movimentos de escala sinótica são aproximadamente horizontais e as componentes horizontais da vorticidade são de dez a cem vezes menores que a vertical (FEDOROVA, 2001). Assim, desprezando as componentes horizontais na equação (2.11) tem-se:

$$
\zeta=\overrightarrow{\mathrm{k}} \cdot(\vec{\nabla} \times \vec{V})=\left(\frac{\partial v}{\partial x}-\frac{\partial u}{\partial y}\right)
$$


A partir das componentes horizontais da equação do movimento no sistema $(x, y, p, t)$ para um fluido invíscido, podemos obter a tendência local da vorticidade relativa:

$$
\frac{\partial \zeta}{\partial t}=-\vec{V}_{H} \cdot \vec{\nabla}_{p} \zeta-\omega \frac{\partial \zeta}{\partial p}-v \beta-(\zeta+f) \vec{\nabla}_{p} \cdot \vec{V}_{H}+\frac{\partial \omega}{\partial y} \frac{\partial u}{\partial p}-\frac{\partial \omega}{\partial x} \frac{\partial v}{\partial p}+F_{\zeta}
$$

Onde $\zeta$ é a vorticidade relativa, $f$ é a vorticidade planetária e $\beta$ representa a variação meridional de vorticidade planetária. A quantidade $(\zeta+f)$ é denominada vorticidade absoluta da parcela, que é dada pela soma da vorticidade relativa do escoamento e da vorticidade que é transferida ao fluido devido ao movimento de rotação da Terra.

O termo do lado esquerdo da equação (2.13) refere-se à variação local de vorticidade relativa, enquanto que os termos do lado direito representam (do primeiro ao último, respectivamente) a advecção horizontal de vorticidade relativa, advecção vertical de vorticidade relativa, advecção meridional de vorticidade planetária, termo de divergência (ou estiramento do tubo de vórtice), termo de inclinação (ou de torção do tubo de vórtice) e resíduo da equação da vorticidade.

Em coordenadas esféricas, a equação (2.13) torna-se:

$$
\begin{aligned}
& \frac{\partial \zeta}{\partial t}=-\left(\frac{u}{a \cos \varphi} \frac{\partial \zeta}{\partial \lambda}+\frac{v}{a} \frac{\partial \zeta}{\partial \varphi}\right)-\omega \frac{\partial \zeta}{\partial p}-\frac{v}{a} \frac{\partial f}{\partial \varphi}-(\zeta+f) \vec{\nabla}_{p} \cdot \vec{V}_{H}- \\
& \left(\frac{1}{a} \frac{\partial \omega}{\partial \varphi} \frac{\partial u}{\partial p}-\frac{1}{a \cos \varphi} \frac{\partial \omega}{\partial \lambda} \frac{\partial v}{\partial p}\right)+F_{\zeta}
\end{aligned}
$$

Sendo que:

$$
\begin{aligned}
& \zeta=\frac{1}{a \cos \varphi} \frac{\partial v}{\partial \lambda}-\frac{1}{a} \frac{\partial u}{\partial \varphi} \\
& \vec{\nabla}_{p} \cdot \vec{V}_{H}=\frac{1}{a \cos \varphi} \frac{\partial u}{\partial \lambda}+\frac{1}{a} \frac{\partial v}{\partial \varphi}
\end{aligned}
$$

A advecção horizontal de vorticidade, isto é, o transporte de vorticidade de um local para outro pelo escoamento atmosférico, é importante especialmente em médios e altos níveis, nas regiões onde o escoamento e os gradientes são mais intensos. Além disso, quanto mais próximo de $0^{\circ}$ ou $180^{\circ}$ for o ângulo entre o vetor da velocidade do vento horizontal e o vetor do gradiente de vorticidade, maior é a advecção, uma vez que ela depende do cosseno do ângulo entre estes vetores. A advecção horizontal de vorticidade representa um mecanismo importante no deslocamento de sistemas de cristas e cavados em níveis elevados (HOLTON, 
2004), além de ser uma forçante para movimentos verticais, como pode ser verificado pela equação Omega do sistema quase-geostrófico (BLUESTEIN, 1993).
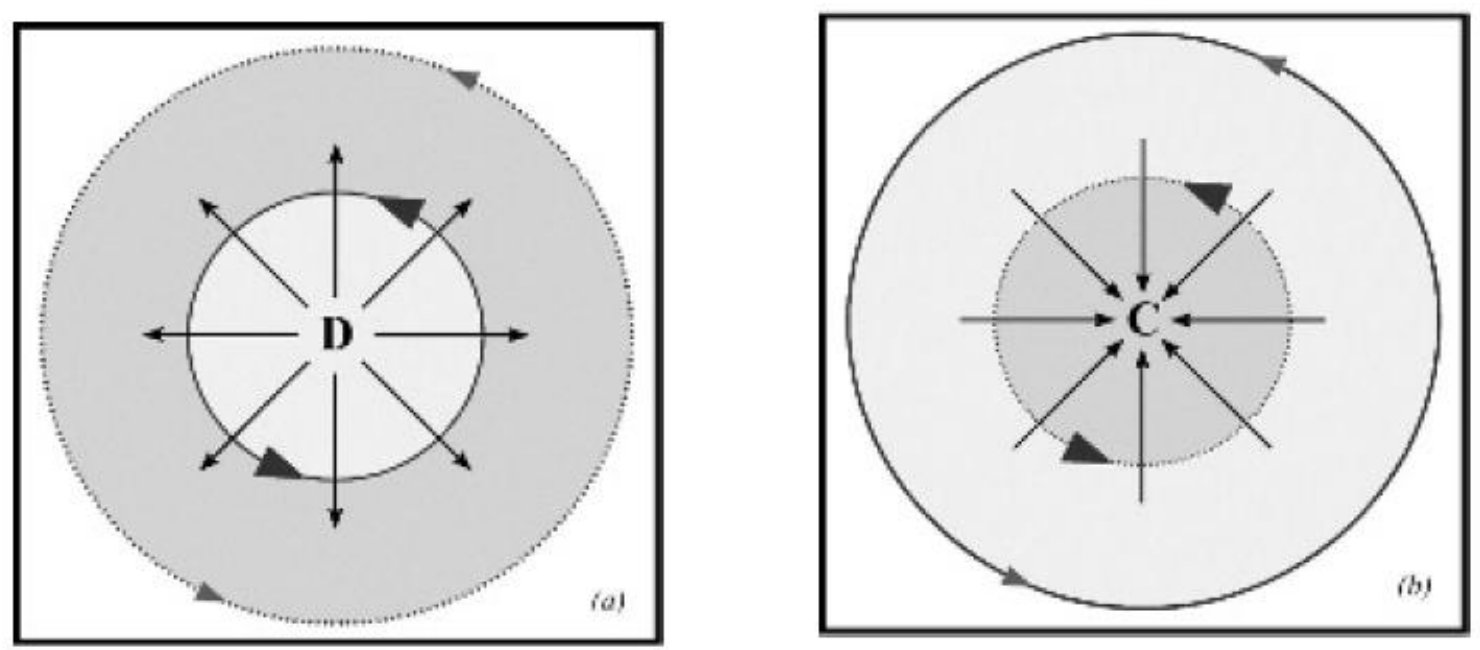

Fig. 2.5. Esquematização do efeito da divergência na vorticidade, para um fluido ciclônico no HN. A área que o fluido abrange num instante inicial é a colorida pelo tom de cinza claro, e a área após algum tempo é a colorida pelo tom de cinza escuro. (a) ilustra o efeito da divergência e (b) o efeito da convergência. Adaptado de Martin (2006).

O termo de divergência influencia as variações de vorticidade pelo estiramento e encolhimento da coluna de ar, ocasionados pela convergência e divergência de massa, respectivamente. A Fig. 2.5 foi adaptada de Martin (2006), e ilustra o efeito da divergência na tendência de vorticidade. Quando ocorre divergência, tem-se que a área do fluido aumenta com o tempo, e, conseqüentemente, a vorticidade se torna mais anticiclônica/menos ciclônica com o tempo. De forma análoga, quando ocorre convergência, a área do fluido diminui e a vorticidade passa a ser mais ciclônica.

Grotjahn (1996) utilizou composites do estágio maduro de 15 casos de ciclones extratropicais próximos à costa leste da Ásia, e investigou as distribuições, magnitudes e possíveis cancelamentos dos termos da equação da vorticidade. Seus resultados mostraram que, ao contrário do que é assumido, os termos da equação vorticidade que não estão presentes no sistema de equações do modelo quase-geostrófico (QG) não se cancelam de fato entre si, principalmente nos níveis mais próximos à superfície. Segundo Grotjahn (1996), modelos QG subestimam o crescimento e a amplitude dos sistemas ciclônicos, especialmente em baixos níveis.

Bjerkenss e Holmboe (1944) e Holmboe et al. (1945) mostraram que a divergência do escoamento em altos níveis é compensada pela convergência em níveis inferiores, representando, portanto, um fator importante para a formação e intensificação de sistemas ciclônicos. 
Para movimentos de escala sinótica, os termos de advecção vertical de vorticidade, advecção de vorticidade planetária e o termo de inclinação não influenciam tanto quanto os demais termos as variações locais de vorticidade. Por esta razão, tais termos são muitas vezes desprezados em trabalhos científicos que realizam o balanço de vorticidade.

Para que o termo de inclinação contribua para as tendências de vorticidade, é necessário a existência de cisalhamento vertical do vento horizontal e gradientes de movimento vertical. Fisicamente, este termo representa a translação de vorticidade orientada horizontalmente em componente vertical. Segundo Reed e Sanders (1953) e Carlson (1991), o termo de inclinação é importante em fenômenos de frontogênese. Grotjahn (1996) mostrou que este termo também pode ser importante em alguns níveis e períodos de ciclogêneses.

De forma geral, o balanço de vorticidade consiste em avaliar os termos na equação da vorticidade (VIRJI, 1982). Caso a soma desses termos estiver em "imbalanço", isto é, caso o termo residual não for zero, significa que existem outros processos dinâmicos que estão contribuindo para as tendências de vorticidade, mas que não estão explícitos na equação (DIAS PINTO, 2007).

Holton e Colton (1972) foram pioneiros em investigar o balanço de vorticidade, e concentraram o estudo do balanço no nível de 200 hPa sobre a região monçônica asiática durante o verão no HN (junho-agosto). Seus resultados sugeriram que o transporte vertical de vorticidade pela convecção é um mecanismo responsável pelo rápido decaimento da vorticidade em altos níveis.

Bonatti et al. (2004) utilizaram o balanço de vorticidade para investigar o ciclone Catarina ocorrido em março de 2004. Segundo os autores, o termo de estiramento da vorticidade relativa, e o de estiramento da vorticidade planetárica, foram determinantes para a propagação do evento para leste.

\subsection{Descrição espacial dos termos}

A distribuição espacial dos termos do balanço de calor foi feita para três diferentes níveis verticais de pressão $(925,500$ e $300 \mathrm{hPa})$, enquanto que para a equação do balanço de vorticidade verificou-se a distribuição espacial em dois níveis (925 e $300 \mathrm{hPa}$ ). Os campos foram elaborados a partir dos dados NCEP, e foram analisados durante todo o período de atuação de cada sistema.

No presente trabalho, cada termo das equações do balanço de calor e vorticidade foram calculados em algoritmo desenvolvido em Fortran, utilizando diferenças finitas centradas no tempo e no espaço. 


\subsection{Perfis verticais médios}

Para avaliar a contribuição de cada termo das equações em toda a coluna vertical e em cada estágio do ciclone, foram realizadas médias simples em caixas de $10^{\circ}$ de latitude por longitude, centradas na baixa em superfície. Esta análise foi feita com os dados NCEP, e equivale, portanto, à média de 25 pontos de grade.

Um dos ciclones selecionados teve curta duração e permaneceu atuando sobre a mesma região desde seu início até sua dissipação. Neste caso, as médias dos perfis verticais médios foram efetuadas para uma caixa fixa no espaço. Já o segundo ciclone selecionado teve longa duração e se deslocou consideravelmente de posição ao longo de sua trajetória. Assim, para este caso, a caixa na qual foram efetuadas as médias dos termos das equações variava de posição em cada tempo, de acordo com a posição central do ciclone em cada instante.

Como exemplo de trabalho que utilizou metodologia semelhante, destaca-se o estudo de Morrison e Businger (2001), que analisou o perfil vertical de alguns termos do balanço de vorticidade, utilizando médias em uma coluna com raio de aproximadamente $275 \mathrm{~km}$ centrada em um ciclone subtropical em superfície, que ocorreu próximo ao Havaí no Pacífico Norte central.

Sinclair (1993) e Sinclair e Revell (2000) também utilizaram perfis verticais médios do balanço de calor e vorticidade para determinar os principais processos termodinâmicos e dinâmicos de ciclones. Entretanto, nestes trabalhos os autores utilizam um sistema semilagrangeano se movendo com velocidade C (que é a velocidade de deslocamento do ciclone), em que a taxa de variação temporal $\partial / \partial \mathrm{t}$ é substituída por $\partial / \partial \mathrm{t}-\mathrm{C} \cdot \vec{\nabla}$ (SINCLAIR e ELSBERRY, 1986; SINCLAIR e CONG, 1992). Segundo Sinclair e Revell (2000), tal metodologia tem como objetivo separar os efeitos advectivos associados ao movimento do sistema dos processos relacionados à sua intensificação.

Em Sinclair (1993), os perfis verticais do balanço de calor e vorticidade foram utilizados para investigar um ciclone nomeado Patsy, que fez transição de tropical para extratropical. Os resultados mostraram que o termo de divergência foi o principal responsável por manter a estrutura ciclônica em baixos níveis na fase tropical, enquanto que a advecção de vorticidade ciclônica predominou em altos níveis na fase extratropical. Quanto aos processos termodinâmicos, o termo que mais contribuiu para o aquecimento durante o desenvolvimento tropical foi o termo diabático, que atuou de forma a contrabalancear o resfriamento imposto pelo termo relacionado ao movimento vertical $\mathrm{Sw}$. 


\section{CAPÍtULO 3}

\section{Resultados - Ciclones rastreados e selecionados}

\subsection{Ciclones rastreados}

A Fig. 3.1 resume a quantidade de ciclones rastreados no Atlântico Subtropical durante 2008, 2009 e março de 2010, além de indicar as respectivas quantidades de sistemas híbridos encontrados. Verifica-se que, em todos os períodos, a quantidade de eventos identificados pelo limiar mais intenso $\left(-2,5 \times 10^{-5} \mathrm{~s}^{-1}\right)$ equivale a menos da metade da quantidade rastreada pelo menos intenso $\left(-1,0 \times 10^{-5} \mathrm{~s}^{-1}\right)$. Este resultado é compatível com o esperado, uma vez que os limiares ciclônicos mais intensos filtram apenas os eventos mais intensos, desconsiderando sistemas mais fracos.

(a)

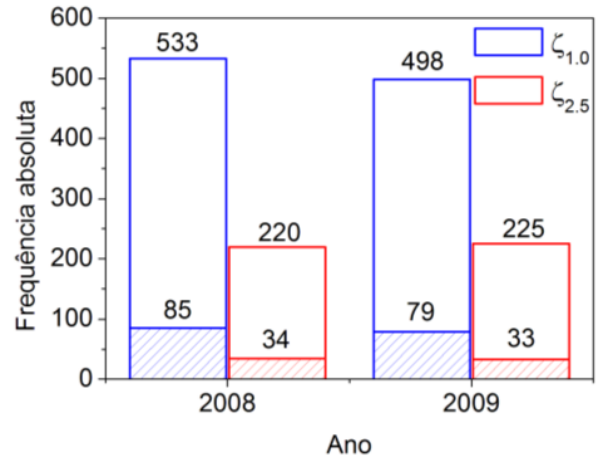

(b)

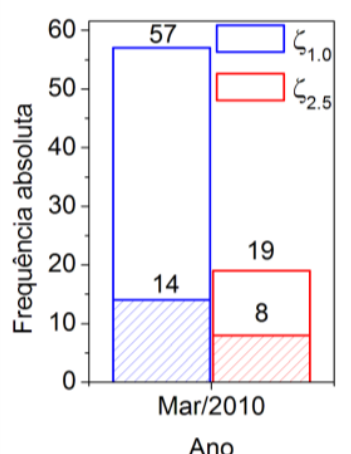

Fig. 3.1. Ocorrência (a) anual (para 2008 e 2009) e (b) mensal (para março de 2010) dos ciclones em parte da região subtropical do Atlântico Sul, encontrados através do algoritmo que rastreia máximos de vorticidade ciclônica com limiar de $-1,0 \times 10^{-5} \mathrm{~s}^{-1}$ (azul) e $-2,5 \times 10^{-5}$ $\mathrm{s}^{-1}$ (vermelho). As barras preenchidas referem-se aos sistemas híbridos encontrados.

Contudo, a quantidade total de distúrbios encontrados é muito alta e não condiz com resultados prévios como os de Reboita et al. (2010). Ao comparar subjetivamente as trajetórias rastreadas e os campos de PNMM e vorticidade em $925 \mathrm{hPa}$, constatou-se que este número elevado deve-se ao fato de que, em alguns casos, existe mais que um núcleo de vorticidade associado a uma mesma região de baixa pressão. As intensidades destes diferentes núcleos em um mesmo ciclone podem variar entre si, apesar da pressão ser semelhante em toda a região (SINCLAIR, 1994; REBOITA et al. 2010). Além disso, pode ocorrer de alguns núcleos de PNMM e vorticidade se desprenderem do núcleo principal, originando um novo sistema secundário que posteriormente se une novamente ao núcleo principal. A Fig. 3.2 ilustra exemplos destas situações para um ciclone principal ocorrido em março de 2010 
(trajetória em azul), cujo rastreamento objetivo de máximos de vorticidade ciclônica contabilizou outros dois diferentes distúrbios (trajetórias em vermelho e em roxo). Na figura, as três trajetórias apresentam padrões semelhantes; a trajetória do ciclone rastreado a partir das 12 UTC do dia 06/03/10 (vermelho) depois de algumas horas se sobrepõe à do ciclone principal, o que indica que ou este evento apresentou mais de um núcleo de vorticidade em algum momento de seu ciclo de vida, ou um segundo sistema independente se originou próximo à região e posteriormente foi absorvido pelo sistema principal.

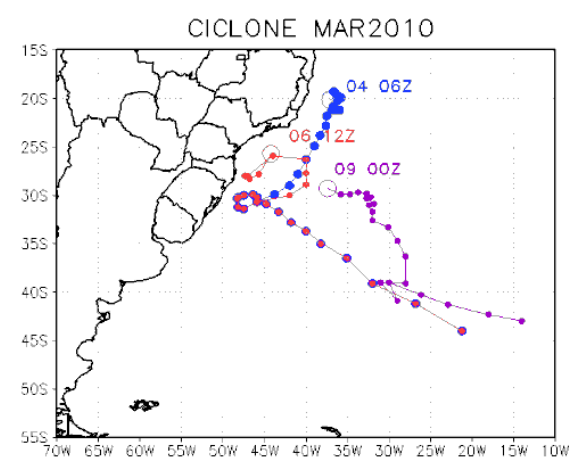

Fig. 3.2. Trajetórias da posição central de três ciclones de março de 2010, obtidas pelo algoritmo que rastreia máximos de vorticidade ciclônica, com limiar de $-1,0 \times 10^{-5} \mathrm{~s}^{-1}$. Cada ciclone está representado por uma cor diferente, e o círculo sem preenchimento indica a posição inicial do sistema.

A utilização dos dados FNL de resolução espacial $1,0^{\circ}$ x $1,0^{\circ}$ também influi no alto número de ciclones rastreados, uma vez que quanto maior a resolução, mais ruidoso será o campo de vorticidade relativa, e assim um número maior de núcleos distintos são obtidos. Reboita (2008) utilizou este mesmo algoritmo e o limiar de $-1,5 \times 10^{-5} \mathrm{~s}^{-1}$ para rastreamento de ciclones no Atlântico Sul durante dez anos e encontrou uma média de 278,7 \pm 11,1 ciclones por ano. Entretanto, estes resultados foram obtidos com os dados de reanálise do NCEP, que possuem resolução espacial de $2,5^{\circ}$ x $2,5^{\circ}$, que é menor do que a resolução espacial do FNL.

É importante ressaltar que o algoritmo de rastreamento encontrou diversos núcleos de vorticidade que não estavam associados a nenhuma região bem definida de baixa pressão, e assim algumas das trajetórias rastreadas não representam um ciclone com isóbara fechada. Em alguns casos, um núcleo de vorticidade correspondente a um cavado era rastreado, e contabilizado como um sistema independente. Também pode ocorrer de diferentes núcleos de vorticidade estarem muito próximos entre si, e o rastreamento pular de um núcleo para outro, acarretando na descontinuidade do rastreamento. 
O elevado número total de ciclones rastreados reflete na quantidade de sistemas híbridos encontrados (barras preenchidas). A expectativa é que o número de sistemas subtropicais seja significativamente menor que o mostrado na Fig. 3.1. Conforme citado no Capítulo 1, Braun (2009) obteve que eventos subtropicais no Atlântico Sul são menos freqüentes. Desta forma, foi necessário analisar subjetivamente cada caso de evento híbrido encontrado, buscando verificar se as trajetórias dos núcleos de máximos de vorticidade ciclônica correspondiam de fato a um sistema ciclônico com isóbaras fechadas. Esta análise utilizou a PNMM e linhas de corrente em baixos níveis na região de cada sistema híbrido identificado no processo objetivo. A partir desta análise subjetiva, identificou-se um número bem menor de sistemas ciclônicos híbridos em parte do Atlântico Subtropical.

É importante destacar que o processo de automatização também classificou como híbridos alguns casos de ciclones extratropicais que passaram por períodos de seclusão quente. Portanto, para uma climatologia de ciclones subtropicais será necessário incluir um filtro que exclua estes casos. Além disso, diversos ciclones extratropicais que atingiram a oclusão também foram identificados por apresentar estrutura híbrida no fim do seu ciclo de vida. Isto ocorreu pois os sistemas extratropicais convencionais acabam muitas vezes por atingir uma estrutura verticalmente empilhada no fim de seu ciclo de vida, implicando em baixos valores do parâmetro $B$. Além disso, com a oclusão, a estrutura fria em baixos níveis enfraquece, e em muitos casos o vento térmico $-\left|V_{T}^{L}\right|$ atinge valores neutros, deixando de ser tão intensamente negativo como nas fases anteriores do ciclo de vida dos sistemas extratropicais.

\subsection{Distúrbios híbridos selecionados}

Dentre os eventos híbridos identificados, dois foram selecionados para análise neste trabalho: um de abril de 2009 e outro de março de 2010. A Fig. 3.3 mostra as trajetórias destes eventos híbridos, enquanto que a Tabela 3.1 resume as datas de início e fim de cada sistema, conforme os campos de PNMM e o algoritmo que rastreia núcleos de vorticidade relativa.

Cabe destacar que as trajetórias obtidas pelo algoritmo de rastreamento (azul) apresentam boa concordância com as trajetórias obtidas pela inspeção visual dos campos de PNMM (preto). Isto indica que o algoritmo utilizado é válido para rastrear corretamente o deslocamento dos distúrbios ciclônicos, apesar de também rastrear outros núcleos secundários 
de vorticidade ou perturbações que não estão associadas a um sistema ciclônico com isóbara fechada.
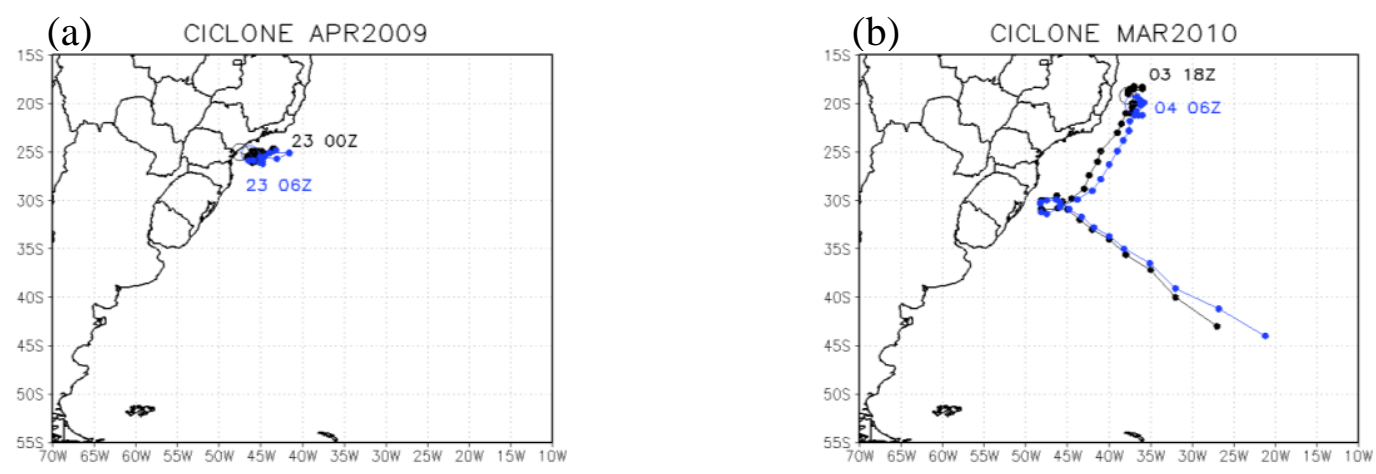

Fig. 3.3. Trajetória (indicada a cada $6 \mathrm{~h}$ ) da posição central do ciclone subtropical ocorrido em a) abril de 2009 e b) março de 2010. A trajetória em preto foi obtida pela inspeção visual dos campos de PNMM, e a trajetória em azul refere-se à rastreada pelo algoritmo de Sugahara (2000), com limiar de $-1,0 \times 10^{-5} \mathrm{~s}^{-1}$.

O ciclone de abril de 2009 se formou próximo à costa sul de São Paulo às 00 UTC do dia 23, e permaneceu praticamente estacionário sobre a região até às 12 UTC do dia 25 (Fig. 3.3a). Já o ciclone de março de 2010 durou mais, tendo um ciclo de vida de quase de UTC dias. O sistema começou em latitudes subtropicais, por volta de $19^{\circ} \mathrm{S}$, próximo à costa do sul da Bahia e Espírito Santo, e então apresentou deslocamento anômalo para sudoeste até atingir as proximidades da costa sul do país, passando posteriormente a se deslocar para sudeste (Fig. 3.3b).

Tabela 3.1. Datas de início e fim de cada distúrbio selecionado, obtidas através da inspeção visual dos campos de PNMM e do rastreamento pelos núcleos de VR com limiar de $-1.0 \mathrm{x}$ $10^{-5} \mathrm{~s}^{-1}$.

\begin{tabular}{|c|c|c|c|c|}
\hline \multirow{2}{*}{ Ciclone } & \multicolumn{2}{|c|}{ Início } & \multicolumn{2}{|c|}{ Fim } \\
\hline & PNMM & VR & PNMM & VR \\
\hline APR2009 & 00 UTC - 23/04/2009 & 06 UTC - 23/04/2009 & 12 UTC - 25/04/2009 & 06 UTC - 26/04/2009 \\
\hline MAR2010 & 18 UTC - 03/03/2010 & 06 UTC - 04/03/2010 & 00 UTC - 13/03/2010 & 06 UTC - 13/03/2010 \\
\hline
\end{tabular}

A Fig. 3.4 mostra os diagramas de fase de cada ciclone selecionado, construído a partir das posições obtidas no rastreamento visual dos campos de PNMM. Para o ciclone de abril de 2009, verifica-se que $-\left|V_{T}^{L}\right|$ é positivo e $-\left|V_{T}^{U}\right|$ é negativo durante todo o ciclo de vida do evento, indicando que o sistema se originou e se dissipou apresentando estrutura híbrida (Fig. 3.4b). O parâmetro $B$ também não atingiu valores intensos, porém os pontos da 
Fig. 3.4a estão distribuídos no quadrante superior direito, o que classifica o sistema como de núcleo quente assimétrico em baixos níveis. Entretanto, o CPS deste mesmo ciclone conforme rastreado pelo algoritmo de máximos de vorticidade ciclônica (figuras não mostradas) indica que o sistema possuiu um núcleo quente simétrico (quadrante inferior direito na Fig. 3.4a). Isto indica a alta dependência do diagrama de fase do ciclone com as latitudes e longitudes centrais do sistema rastreado. Destaca-se que o fato de o ciclone apresentar uma estrutura frontal fraca no CPS obtido da PNMM não o desclassifica como um ciclone híbrido ou subtropical; Guishard (2006) utilizou como "ciclone garoto propaganda" um evento subtropical ocorrido na bacia do Atlântico Norte, cujos valores de $B$ no diagrama de fase também indicavam uma natureza fraca assimétrica, semelhante ao ciclone de abril de 2009 deste trabalho.

(a)

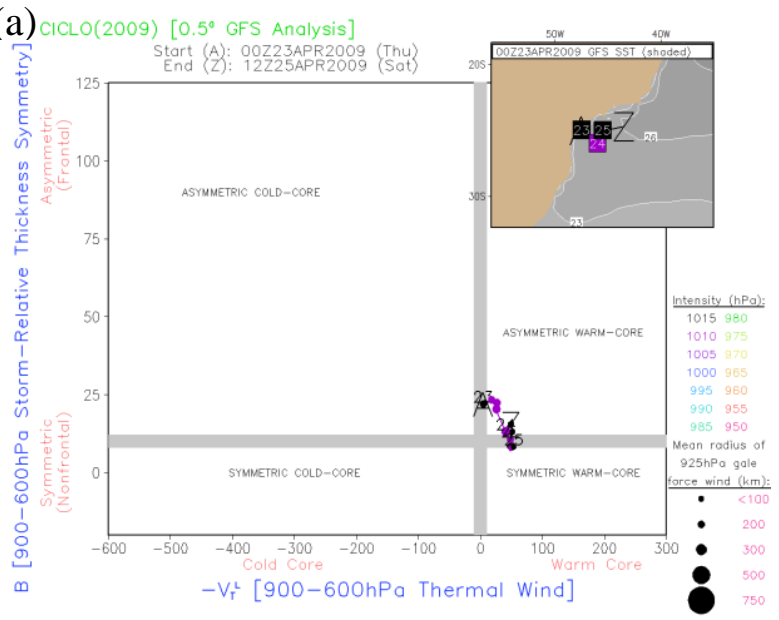

(c)

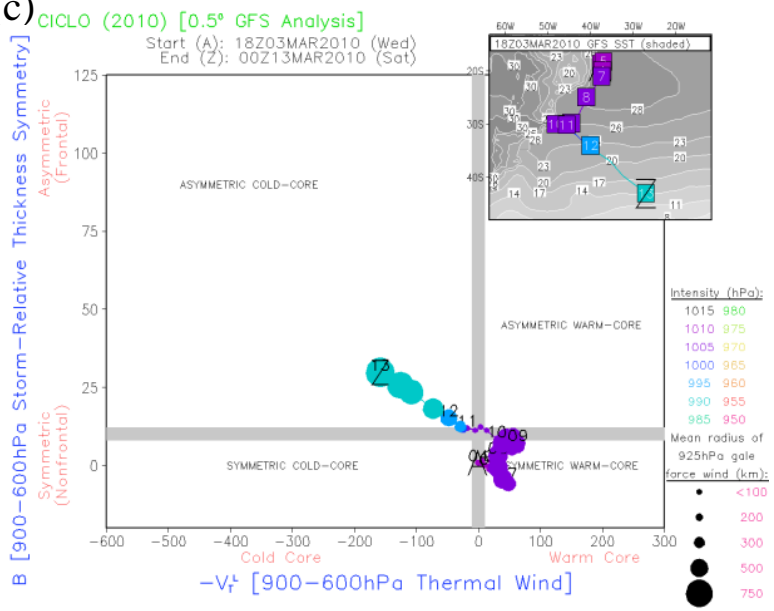

(b)

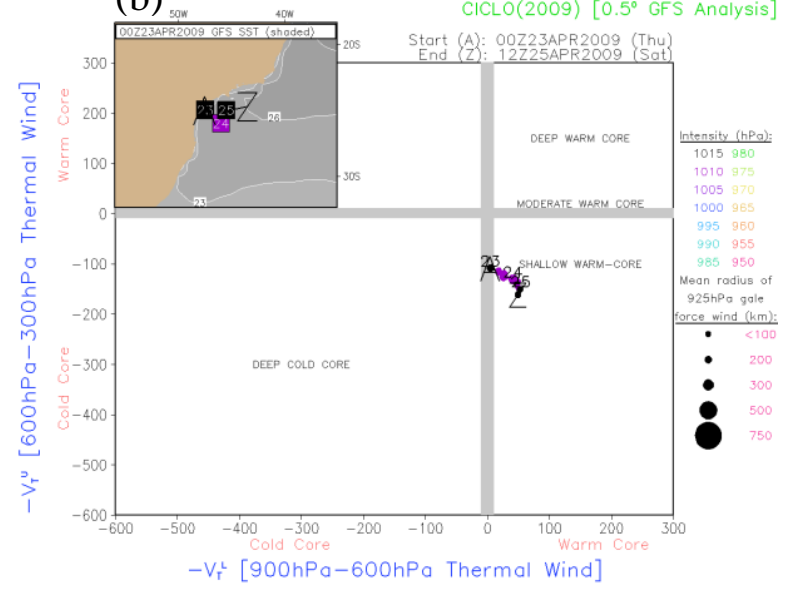

(d)

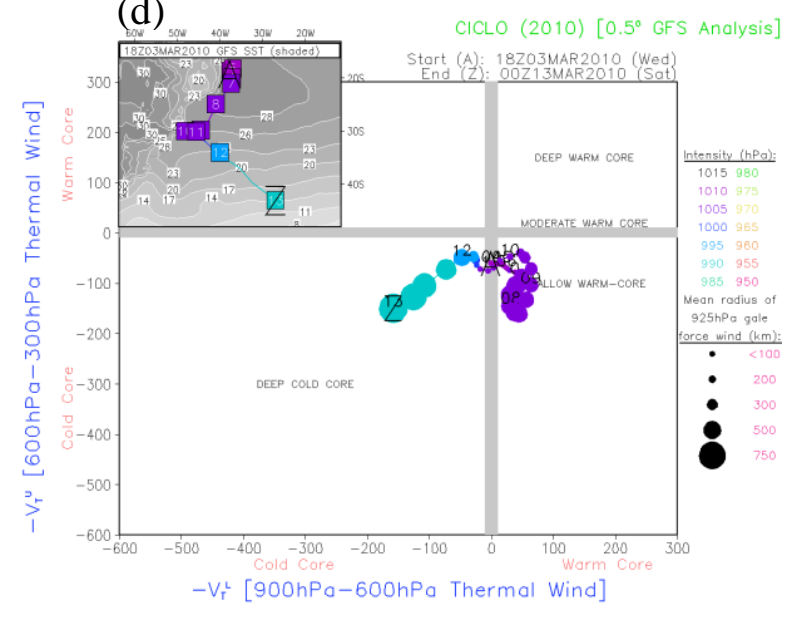

Fig. 3.4. Cyclone Phase Space para o ciclone de (a)-(b) abril de 2009 e (c)-(d) março de 2010. O algoritmo foi iniciado com o rastreamento visual dos campos de PNMM.

O CPS para o ciclone de março de 2010 mostra que, desde seu início até às 00 UTC do dia 11, o sistema apresentava estrutura híbrida com núcleo quente em baixos níveis e frio em 
altos níveis (Fig. 3.4d). Neste período, o parâmetro $B$ não atingiu valores elevados, indicando que o sistema manteve-se simétrico, isto é, sem características frontais (Fig. 3.4c). Esta evolução do diagrama de fase condiz com a evolução esperada de um ciclone subtropical. A partir das 06 UTC do dia 11, nota-se um rápido crescimento do parâmetro de assimetria térmica e um contínuo decréscimo do vento térmico em baixos níveis, indicando que o sistema passou por uma transição e tornou-se extratropical, com características frontais. 


\section{CAPÍTULO 4}

\section{Resultados - Ciclone de abril de 2009}

\subsection{Discussão sinótica}

Foram selecionados quatro diferentes tempos do ciclo de vida do ciclone de abril de 2009 (Fig. 4.1), para análise de sua evolução sinótica e dinâmica. Para auxiliar na referência, cada estágio recebeu uma diferente denominação: (i) início (23 de abril às 00Z), (ii) maduro (23 de abril às 12Z), (iii) enfraquecimento (24 de abril às 12Z) e (iv) dissipação (25 de abril às 12Z). O início refere-se ao tempo em que a primeira isóbara fechada aparece em superfície, enquanto no estágio maduro o sistema atinge a menor pressão em superfície. Por fim, o ciclone atinge os estágios de enfraquecimento e dissipação. A Fig. 4.1 mostra que a mínima pressão central foi de $1010,5 \mathrm{hPa}$, ou seja, o ciclone apresentou fraca intensidade.

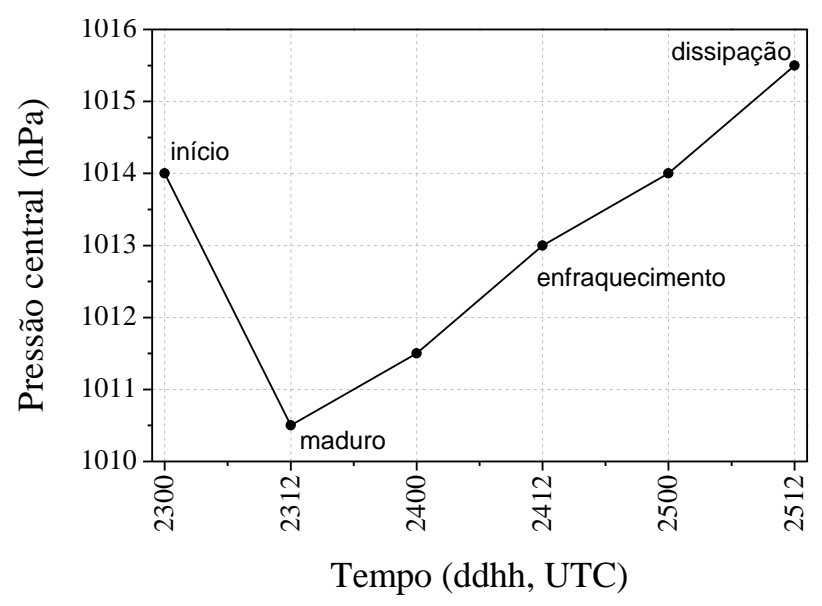

Fig. 4.1. Pressão central (hPa) do ciclone em superfície. Os estágios do ciclo de vida do ciclone de abril de 2009 (início, maduro, enfraquecimento, dissipação) estão identificados e marcados na figura.

O painel superior da Fig. 4.2 mostra a intensidade do vento e a VR ciclônica em 925 hPa máxima e média ao longo do período de atuação do ciclone. Desde o início de seu desenvolvimento até o enfraquecimento, o vento máximo observado na região do ciclone em superfície em $925 \mathrm{hPa}$ teve intensidade por volta de $20,0 \mathrm{~m} \mathrm{~s}^{-1}$, ou seja, este ciclone produziu ventos fortes. A partir deste tempo, a máxima velocidade observada cai para $15,0 \mathrm{~m} \mathrm{~s}^{-1}$. Quanto à VR, o sistema se iniciou com mínima VR de $-3,0 \times 10^{-5} \mathrm{~s}^{-1}$, e intensificou-se até -4,0 x $10^{-5} \mathrm{~s}^{-1}$ às 12 UTC do dia 24 (enfraquecimento), começando a perder intensidade a partir de então. O painel inferior da Fig. 4.2 mostra os perfis verticais do vento máximo e da VR ciclônica máxima. Tem-se que os ventos mais intensos ocorreram em altos níveis desde o 
início do sistema até às 00 UTC do dia 24 , com valores excedendo $50,0 \mathrm{~m} \mathrm{~s}^{-1}$. De forma similar, os mínimos valores de VR, que representam máximos de vorticidade ciclônica, ocorreram em altos níveis com pico de $-10,0 \times 10^{-5} \mathrm{~s}^{-1}$ no estágio maduro.

(a)

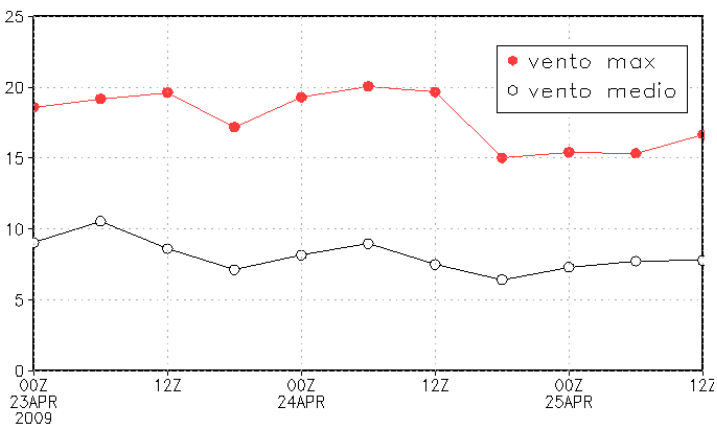

(c)

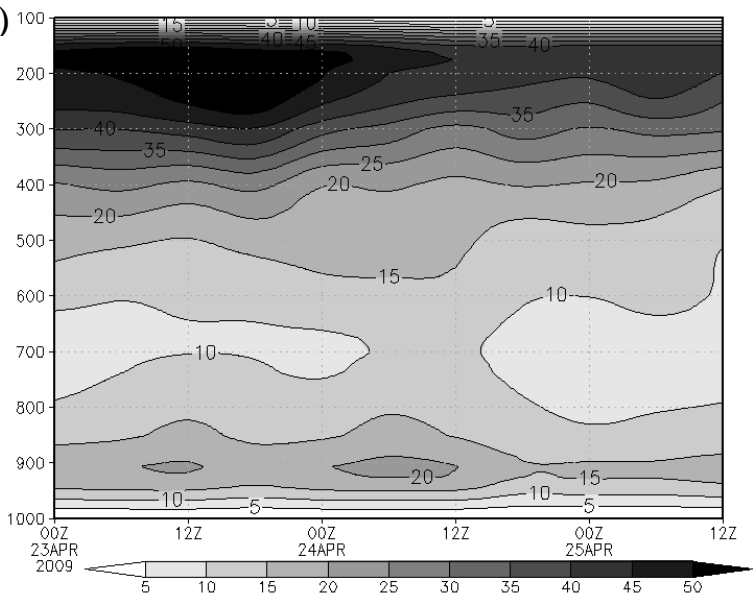

(b)

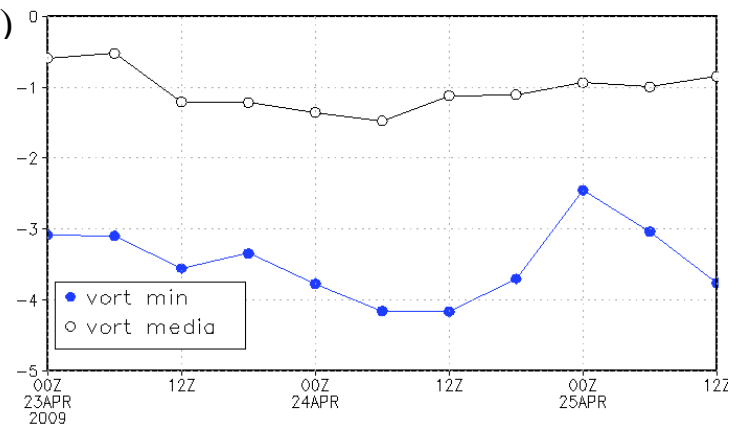

(d)

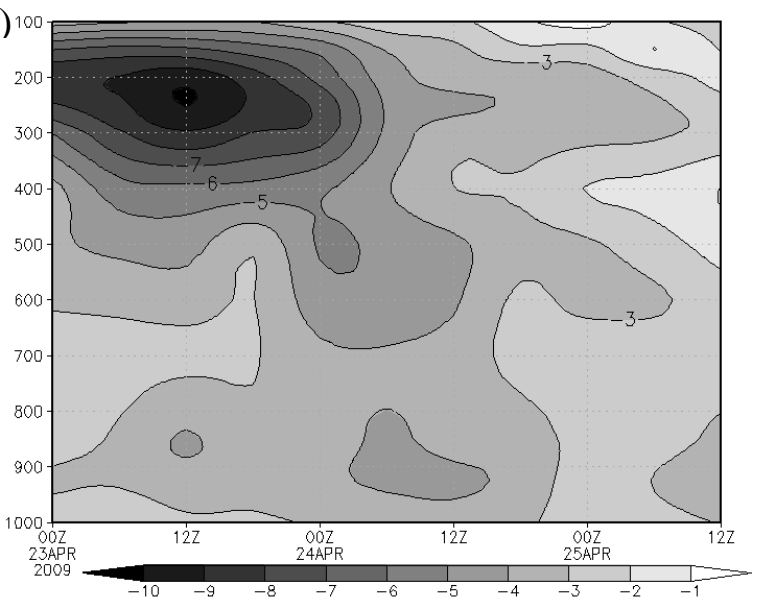

Fig. 4.2. (a) Intensidade média e máxima do vento em $925 \mathrm{hPa}\left(\mathrm{m} \mathrm{s}^{-1}\right)$, (b) VR média e mínima em $925 \mathrm{hPa}\left(10^{-5} \mathrm{~s}^{-1}\right)$ e perfil vertical (c) do vento máximo $\left(\mathrm{m} \mathrm{s}^{-1}\right)$ e (d) da VR mínima $\left(10^{-5} \mathrm{~s}^{-1}\right)$ na região de atuação do ciclone de abril de 2009. A análise foi feita com os dados do NCEP e considerando os pontos de grade dentro de uma caixa de $10^{\circ} \times 10^{\circ}$ centrada no ciclone em superfície.

No estágio inicial (Fig. 4.3), verifica-se uma pequena região com isóbara fechada de 1014,0 hPa próxima à costa do sul do estado de São Paulo, indicando o início do ciclone subtropical. O eixo do cavado invertido em superfície está orientado na direção noroestesudeste, e a vorticidade ciclônica em $925 \mathrm{hPa}$ associada ao sistema é fraca. A sudeste do ciclone atua um anticiclone com $1026,0 \mathrm{hPa}$, centrado em aproximadamente $35,0^{\circ} \mathrm{S}$ e $37,5^{\circ} \mathrm{W}$. Neste estágio, ainda não existe um núcleo circular bem marcado de temperatura elevada sobre a região do ciclone. Em níveis médios, o cavado associado orienta-se na direção sudestenoroeste e situa-se a sudoeste da baixa em superfície. Neste dia, já é possível identificar uma banda de nebulosidade sobre o leste do cavado em médios e altos níveis. Em altos níveis, a posição do jato e o respectivo cisalhamento horizontal do vento sobre a região do ciclone é 
importante na geração de vorticidade ciclônica (efeito da vorticidade por cisalhamento que tende a rotacionar as parcelas).
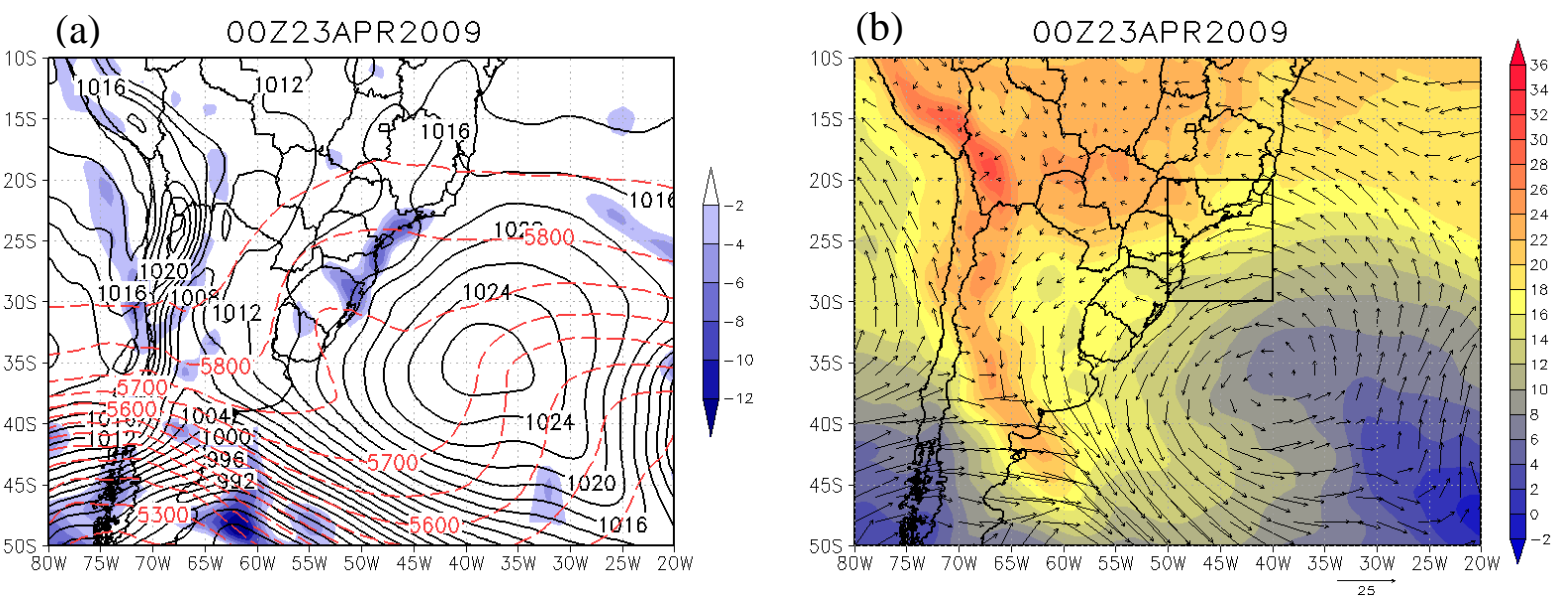

(c)

OOZ23APR 2009
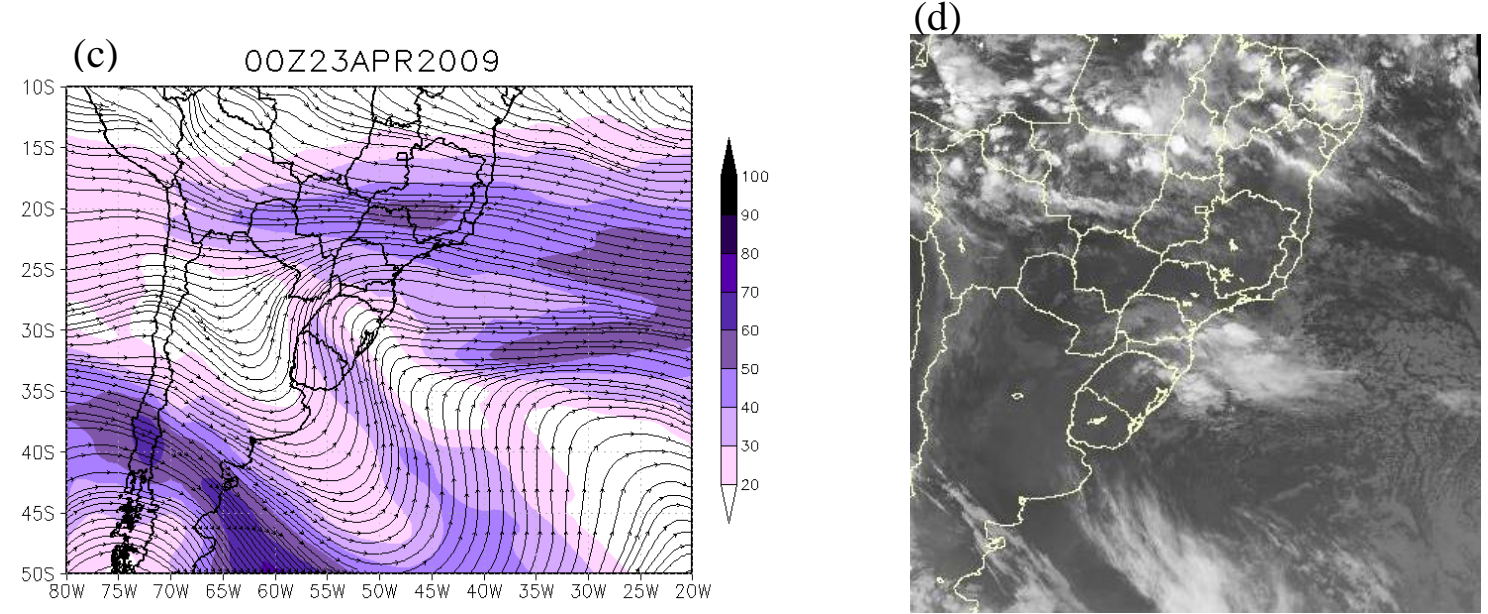

Fig. 4.3. 00 UTC do dia 23/04/2009 (início): (a) PNMM (hPa, linha preta), altura geopotencial em $500 \mathrm{hPa}$ (metros geopotencial, pontilhado vermelho) e VR em $925 \mathrm{hPa}\left(10^{-5}\right.$ $\left.\mathrm{s}^{-1}\right)$; (b) temperatura $\left({ }^{\circ} \mathrm{C}\right.$, sombreado) e vento horizontal ( $\mathrm{m} \mathrm{s}^{-1}$, vetor) em $925 \mathrm{hPa}$; (c) linhas de corrente e isotacas ( $\mathrm{m} \mathrm{s}^{-1}$, sombreado) em $200 \mathrm{hPa}$; (d) imagem de satélite no canal do IR.

Passadas apenas 12 horas, no estágio maduro (Fig. 4.4), o ciclone atinge sua menor pressão em superfície, chegando a 1010,5 $\mathrm{hPa}$. A posição central da isóbara fechada em superfície está deslocada levemente para sudeste, em comparação à posição do estágio anterior. Em $925 \mathrm{hPa}$, a circulação ciclônica está mais forte, sendo que os ventos à sudeste e ao sul do ciclone são intensos. A partir deste estágio, a região ciclônica passa a apresentar um núcleo aproximadamente circular de temperaturas mais quentes em baixos níveis, caracterizando, portanto, um sistema de núcleo quente nos níveis próximos à superfície. $\mathrm{O}$ campo de altura geopotencial em $500 \mathrm{hPa}$ mostra dois núcleos de baixa desprendida à sudoeste do ciclone em superfície. Em 200 hPa não há a configuração de um VCAN (Vórtice Ciclônico de Altos Níveis), porém o eixo do cavado está agora orientado na direção norte-sul. 
A nebulosidade associada ao ciclone ocupa uma área maior em seu setor oceânico. A partir deste estágio, a pressão central do sistema começa a aumentar até a sua dissipação.

(a)

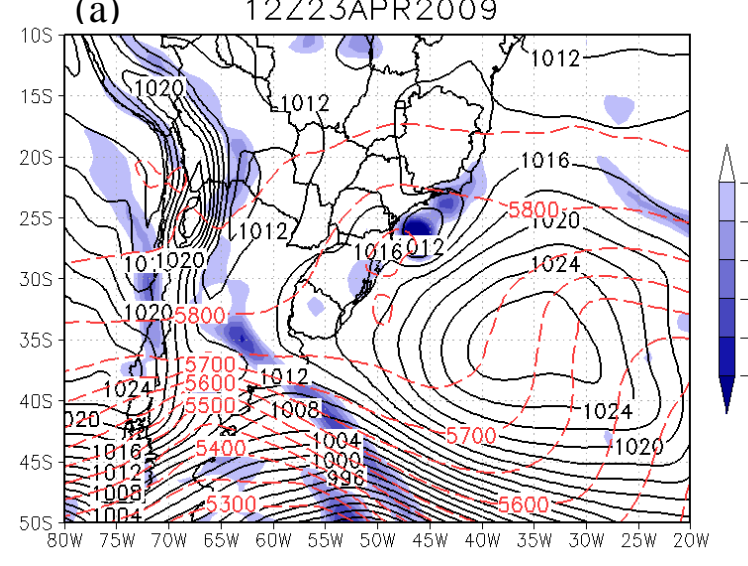

(c)

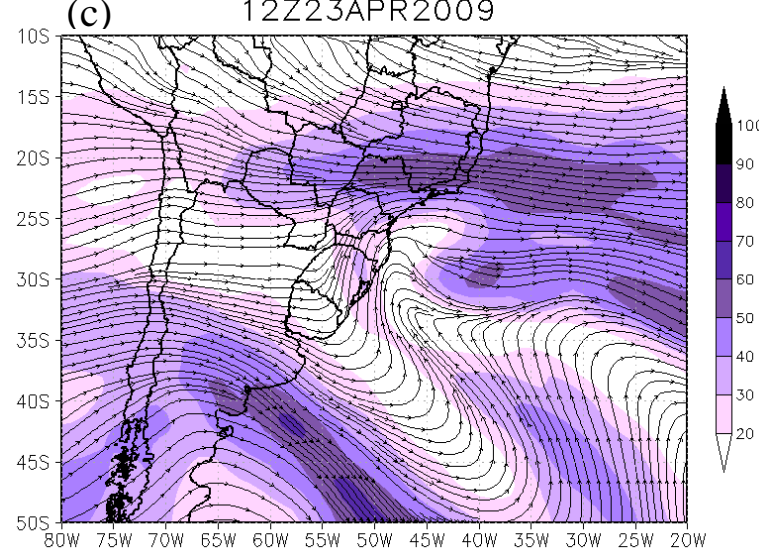

(b)
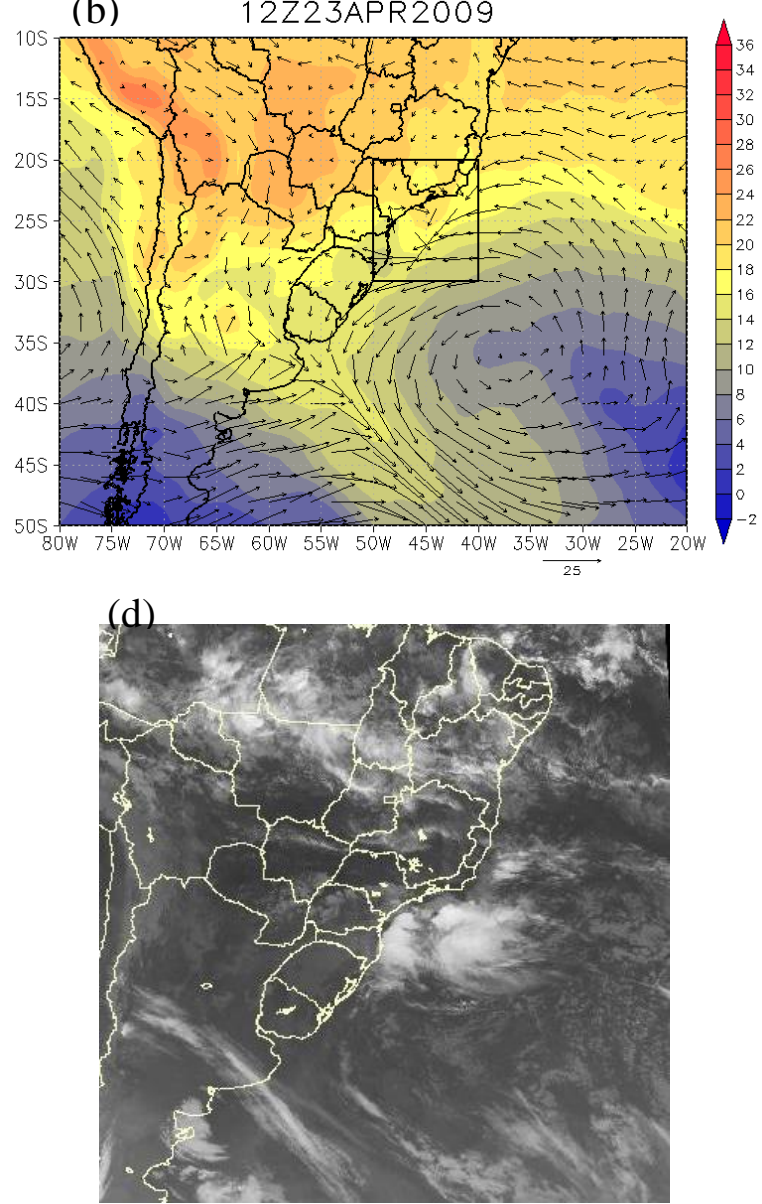

Fig. 4.4. Idem à Fig. 4.3, mas para o dia 23/04/2009 às 12 UTC (maduro).

No estágio de enfraquecimento (Fig. 4.5), a pressão central do sistema aumenta para 1013,0 hPa, enquanto que a vorticidade ciclônica em baixos níveis permanece intensa. Em $500 \mathrm{hPa}$, a baixa desprendida já está desconfigurada, porém ainda atua um cavado sobre a região do ciclone em superfície. Observa-se também uma crista posicionada à sudeste do cavado em níveis médios, que está associada ao anticiclone cuja posição central em superfície está localizada por volta de $32,5^{\circ} \mathrm{W}$ e $35,0^{\circ} \mathrm{S}$. Tal sistema anticiclônico atua como um 'bloqueio', contribuindo para o não deslocamento do ciclone subtropical para regiões mais a leste no Atlântico. Ressalta-se ainda que, neste estágio, o escoamento em $200 \mathrm{hPa}$ é bastante zonal e não se identifica nenhum cavado associado ao sistema, apesar de ainda existir VR ciclônica devido ao cisalhamento meridional do vento zonal. A imagem de satélite mostra grande área de nebulosidade a leste do ciclone em superfície. 
Após 24 horas, no estágio de dissipação (Fig. 4.6), o sistema de baixa pressão é identificado somente nos níveis mais próximos à superfície, sendo que nem em médios nem em altos níveis são observados cavados associados ao sistema. Nesta fase de dissipação, a nebulosidade organiza-se em banda alongada orientada na direção sudoeste-nordeste e localizada à leste da circulação ciclônica em superfície.
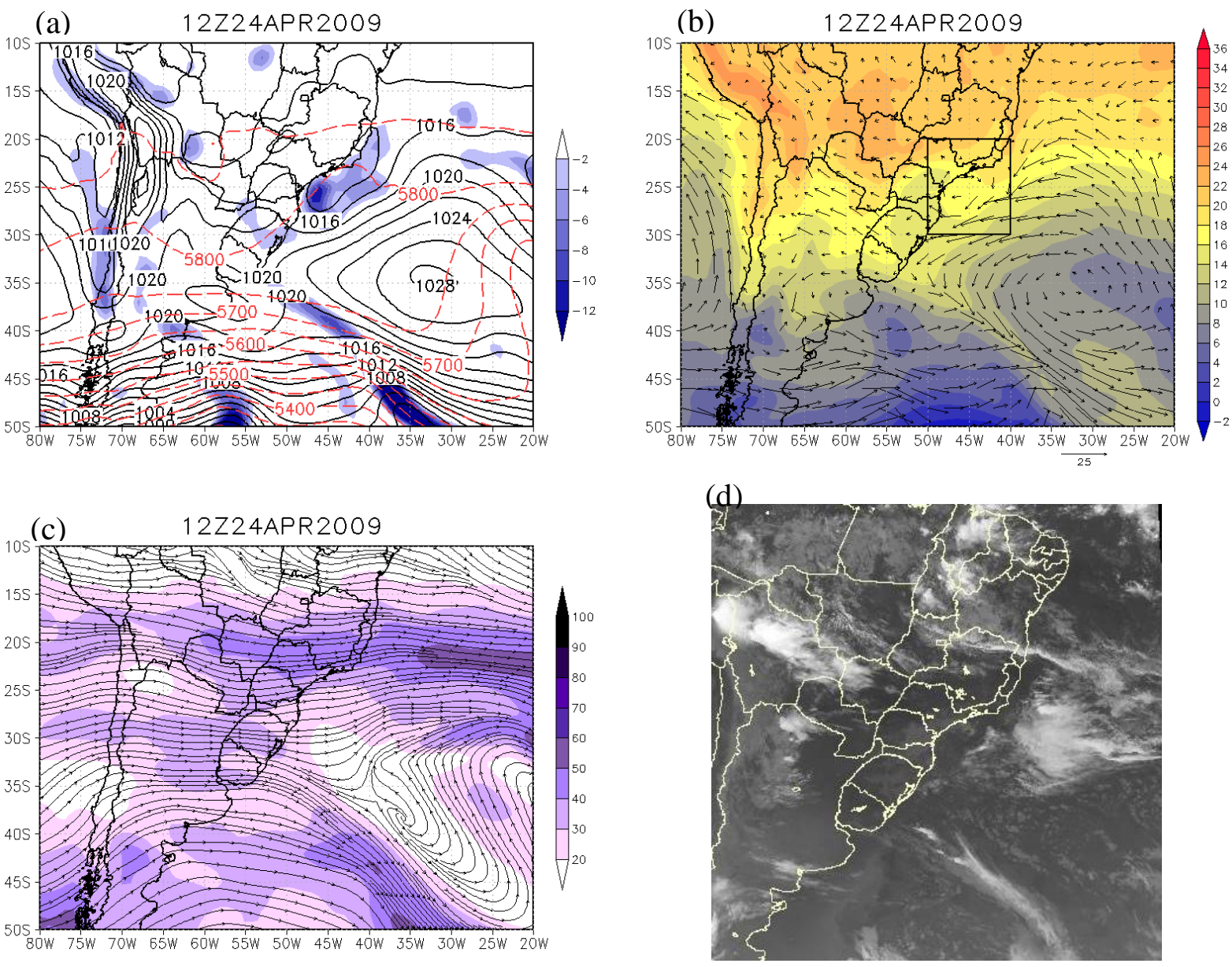

Fig. 4.5. Idem à Fig. 4.3, mas para o dia 24/04/2009 às 12 UTC (enfraquecimento). 
(a)
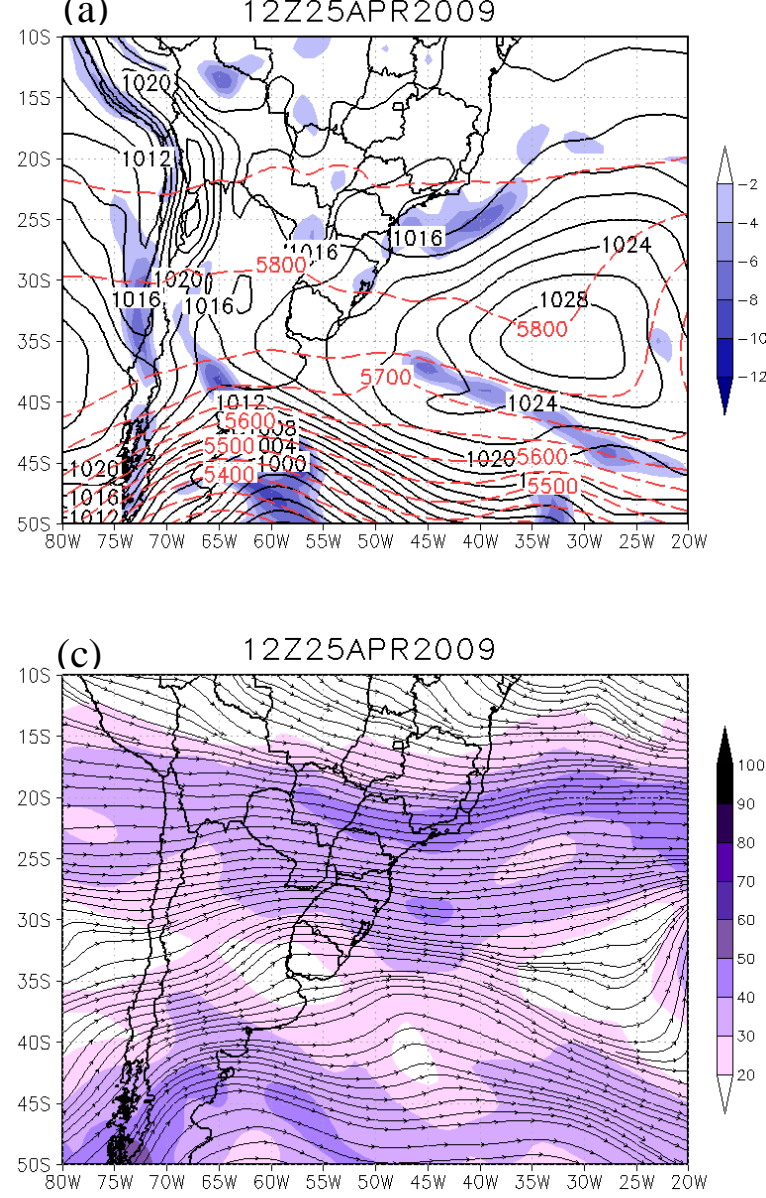

(b)
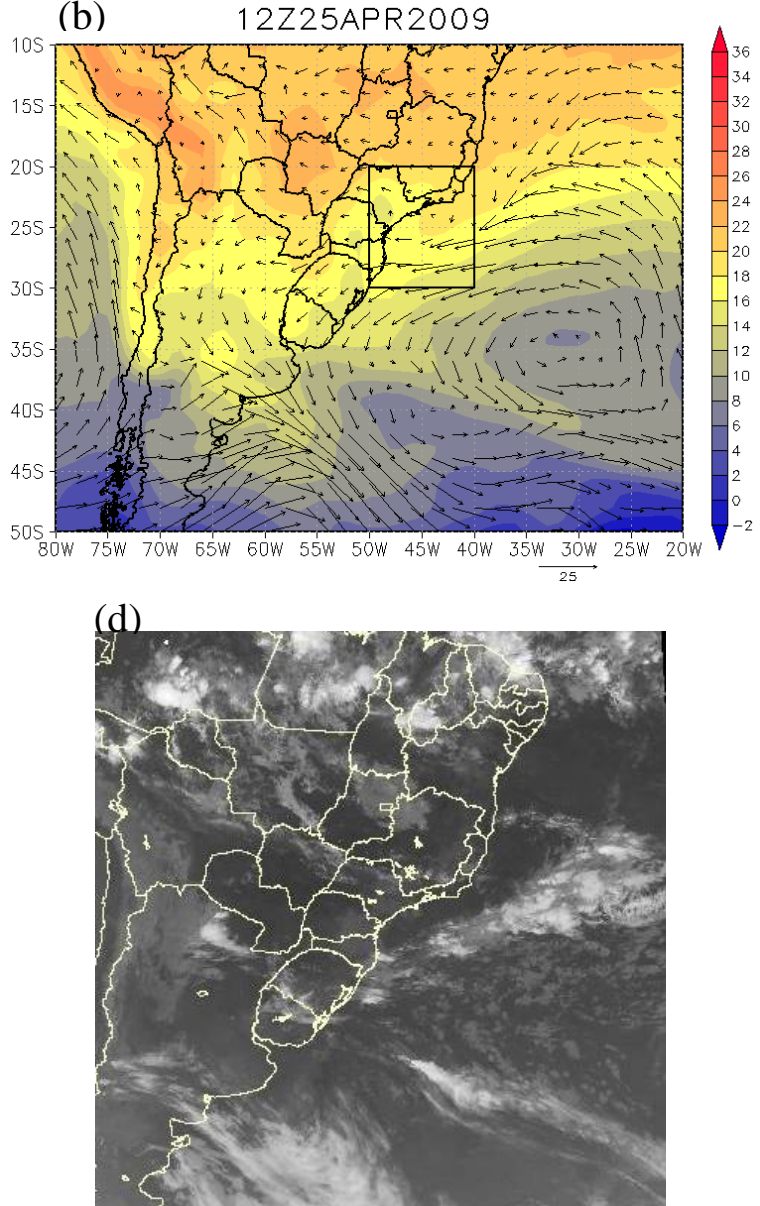

Fig. 4.6. Idem à Fig. 4.3, mas para o dia 25/04/2009 às 12 UTC (dissipação).

Os campos de precipitação diária (Fig. 4.7) mostram uma ampla área com chuva intensa na região do ciclone de abril de 2009 no dia 23 (Fig. 4.7a), que engloba os estágios de início e maduro. A precipitação associada a este ciclone atingiu não apenas a região marítima, mas também considerável parte das regiões costeiras dos estados de São Paulo, Paraná e Santa Catarina. É importante ressaltar que acumulados de precipitação intensa nesta região afetam negativamente diversas atividades portuárias e de navegação, e a chuva sobre o continente pode causar enchentes e desabamentos.

No dia 24 (Fig. 4.7b), o acumulado de precipitação na área do ciclone em superfície ainda é elevado, porém não tanto quanto o do dia anterior. A chuva neste dia ocorre principalmente em uma ampla região alongada na direção nordeste-sudoeste, e sobre o continente a precipitação se concentra sobre o Rio de Janeiro e norte da costa de São Paulo. No dia 25 (Fig. 4.7c) ainda existe uma banda de acumulado de precipitação orientada na direção nordeste-sudoeste, porém os acumulados são menos intensos e a banda de precipitação está mais deslocada para leste no oceano. Todos os campos de precipitação são 
compatíveis com a nebulosidade observada através das imagens de satélite (Figs. 4.3d, 4.4d, 4.5d e 4.6d).
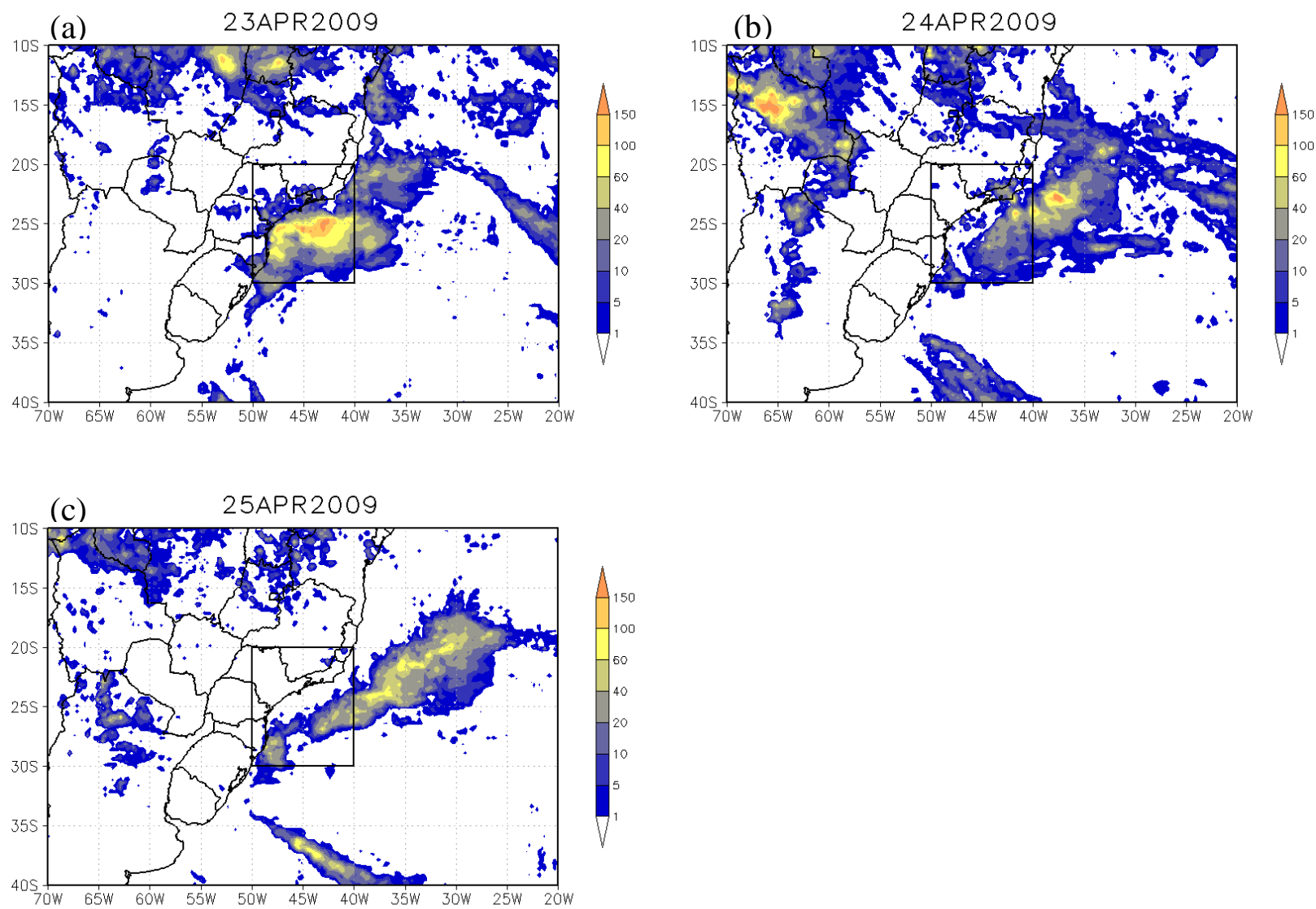

Fig. 4.7. Precipitação acumulada diária $\left(\mathrm{mm} \mathrm{dia}^{-1}\right)$ para cada dia de atuação do ciclone de abril de 2009: dia (a) 23 (início e maduro), (b) 24 (enfraquecimento) e (c) 25 (dissipação). A caixa de $10^{\circ} \times 10^{\circ}$ em cada figura está centralizada no ciclone em superfície às 12 UTC de cada dia.

A Fig. 4.8 apresenta os campos de temperatura e vento em $200 \mathrm{hPa}$. Quanto à distribuição de temperatura em altos níveis, os estágios de início e maduro apresentam uma similaridade: a região a oeste do ciclone em superfície possui uma área de temperaturas mais elevadas, que está cercado por temperaturas mais frias tanto a leste quanto à oeste (Figs. 4.8a e 4.8b). O ramo de temperaturas mais elevadas está localizado aproximadamente sobre a região do cavado de altos níveis, que pode ser identificado nas figuras através dos vetores de vento em $200 \mathrm{hPa}$. Tal distribuição de temperatura e vento deve favorecer advecção quente em altos níveis sobre a região do ciclone. Nos dias seguinte, durante o estágio de enfraquecimento e dissipação (Figs. 4.8c e 4.8d), não existe mais uma área de temperaturas mais elevadas a oeste do ciclone em superfície, as ondulações meridionais do escoamento em $200 \mathrm{hPa}$ perdem amplitude e o escoamento torna-se mais zonal. 

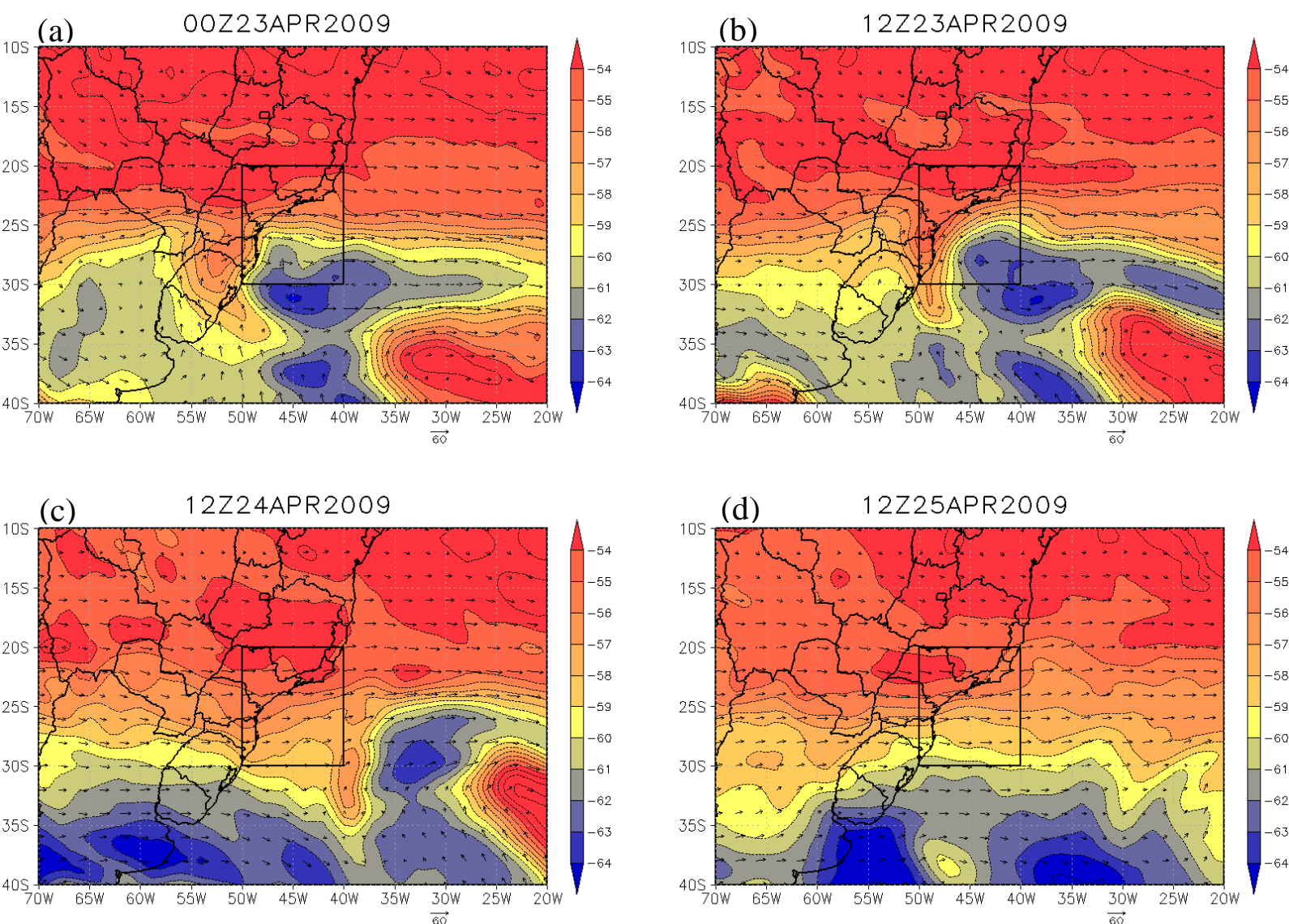

Fig. 4.8. Temperatura $\left({ }^{\circ} \mathrm{C}\right.$, sombreado) e vento $\left(\mathrm{m} \mathrm{s}^{-1}\right)$ em $200 \mathrm{hPa}$, para as (a) 00 UTC do dia 23 (início), (b) 12 UTC do dia 23 (maduro), (c) 12 UTC do dia 24 (enfraquecimento) e (e) 12 UTC do dia 25 (dissipação) de abril de 2009.

\subsection{Descrição espacial dos termos}

Nas figuras dos campos espaciais dos termos do balanço de calor e vorticidade (Figs. 4.9 a 4.13), a posição do centro do ciclone em superfície em cada instante é representada por um ponto preto.

\section{a. Balanço de calor}

A distribuição espacial dos termos do balanço de calor em $925 \mathrm{hPa}$ (Fig. 4.9) mostra que, em algumas regiões, o termo diabático atua de forma a contrabalancear as variações de temperatura causadas pela advecção horizontal. Por exemplo, no estágio inicial (Fig. 4.9a), existem dois núcleos de advecção fria próximos à posição central do ciclone em superfície: um ao sul e outro mais afastado no oceano a leste do sistema. Neste mesmo estágio, no campo do termo residual, verifica-se que nestas duas regiões existem núcleos contribuindo para o aumento de temperatura. Entretanto, este padrão de resposta do termo diabático à advecção horizontal de temperatura não ocorre em todas as regiões e estágios. 
Ambos os estágios de início e maduro do sistema (Fig. 4.9a,b) apresentam uma tendência de aquecimento nas regiões a leste do sistema em superfície, sendo que a taxa de aquecimento no estágio maduro é maior. Em contrapartida, durante o enfraquecimento (Fig. 4.9c) existe um núcleo de tendência de resfriamento à leste da posição central do ciclone, ocasionado por processos diabáticos e processos relacionados ao movimento vertical (termo $\mathrm{Sw})$.

(a)
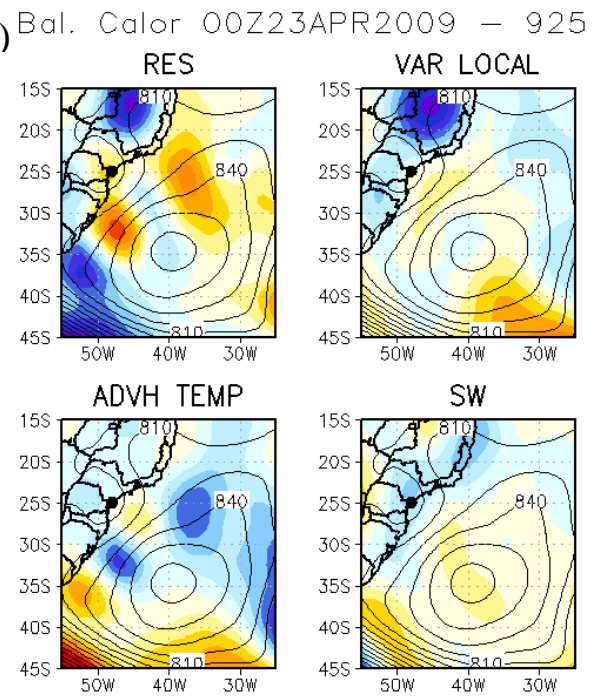

(c)
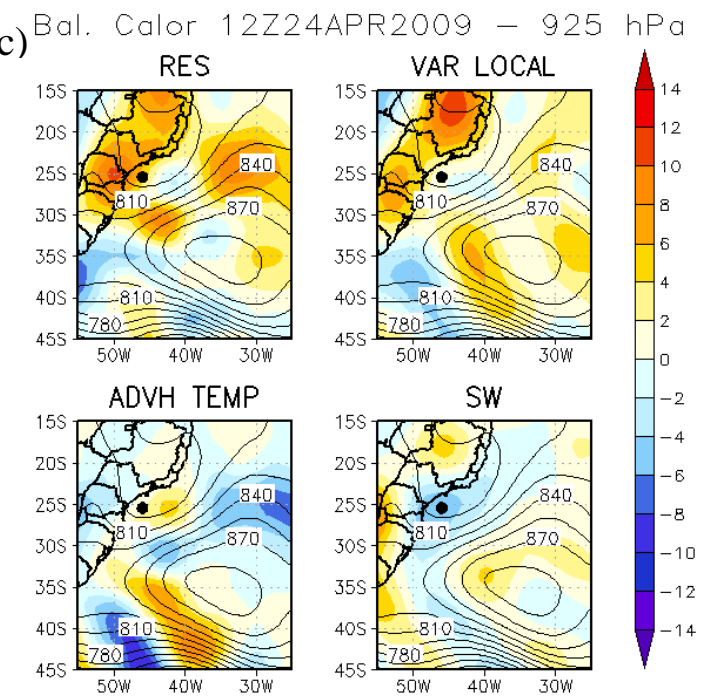

(b)

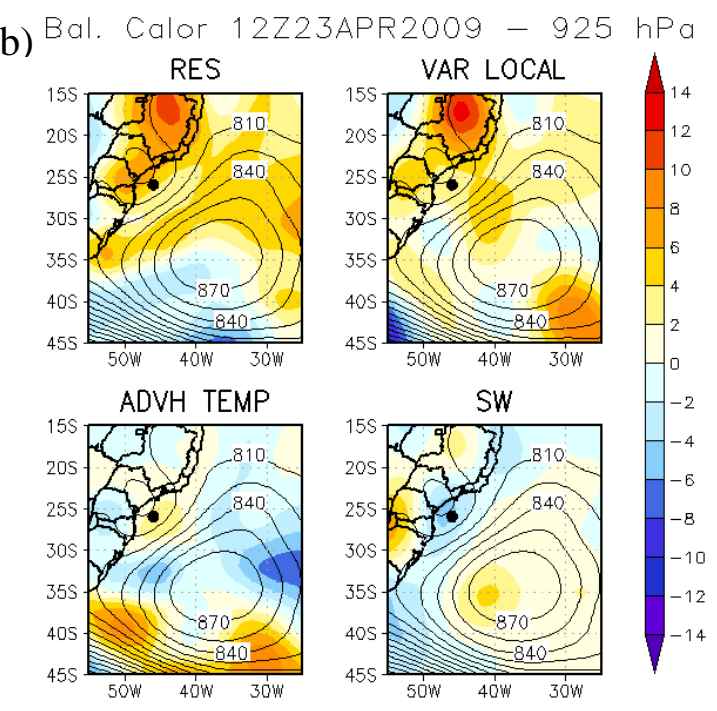

(d)

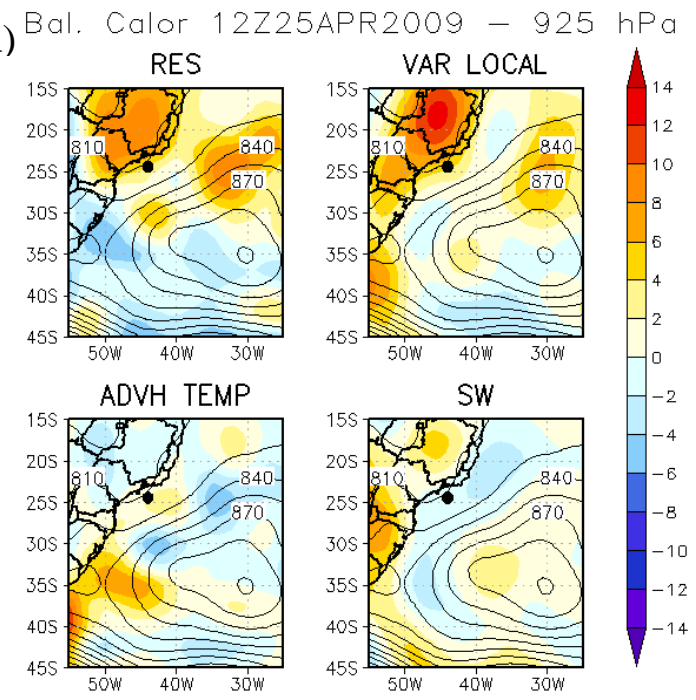

Fig. 4.9. Altura geopotencial (linhas contínuas, metros geopotencial) e termos do balanço de calor (sombreado; termo diabático, variação local, advecção horizontal e termo relacionado ao movimento vertical Sw, $\mathrm{K} \mathrm{dia}^{-1}$ ) em $925 \mathrm{hPa}$ para as (a) $00 \mathrm{UTC}$ do dia 23 (início), (b) 12 UTC do dia 23 (maduro), (c) 12 UTC do dia 24 (enfraquecimento) e (e) 12 UTC do dia 25 (dissipação).

Em todos os estágios mostrados na Fig. 4.9 existe advecção quente a leste do sistema em superfície, sobre o oceano, e advecção fria ao oeste, sobre o continente. Este padrão de advecção é promovido pela circulação ciclônica. Tal circulação transporta ar mais quente de latitudes menores para latitudes maiores, na porção leste, e transporta ar mais frio de latitudes 
maiores para latitudes menores, na porção oeste. Em todos os estágios também existe um núcleo de advecção fria ao sul do ciclone, provavelmente relacionado ao extenso sistema de alta pressão que atuava no Atlântico. É importante notar que a advecção quente associada a este ciclone subtropical é fraca (por volta de 2 a $4 \mathrm{~K} \mathrm{dia}^{-1}$ ) e menor do que tipicamente se observa em ciclones extratropicais.

Em 925 hPa (Fig. 4.9), o termo relacionado ao movimento vertical contribui em todos os estágios para a diminuição de temperatura sobre as regiões próximas à atuação do ciclone. Isto é uma resposta aos movimentos ascendentes associados ao sistema. De forma geral, os movimentos ascendentes ocasionam: 1) aquecimento pela advecção vertical de temperatura; e 2) resfriamento pelo processo de expansão adiabática. Como em geral a taxa de resfriamento adiabática é mais intensa que a da advecção vertical, o saldo final do termo $\mathrm{Sw}$ nas regiões de ascendência é negativo, ou seja, contribui para tendências de resfriamento.

A distribuição espacial dos termos do balanço de calor em 500 hPa (Fig. 4.10) mostra uma forte associação das regiões de intenso aquecimento diabático com as regiões de nebulosidade associada ao sistema subtropical. Este aquecimento diabático em níveis médios resulta do aquecimento da atmosfera devido à liberação de energia durante a condensação do vapor d’água. Este processo está diretamente associado à convecção, que por sua vez desenvolve-se quando os movimentos verticais são ascendentes. Esta relação pode ser entendida ao notar que o termo diabático se relaciona ao termo $\mathrm{Sw}$ nas regiões de nebulosidade, onde o termo diabático possui sinal oposto ao termo $\mathrm{Sw}$ : núcleos de aquecimento diabático são também núcleos de resfriamento pelo termo $\mathrm{Sw}$.

A relação descrita também ocorre em 300 hPa (Fig. 4.11): em altos níveis, o termo diabático atua se opondo às variações de temperatura causadas pelo termo Sw. Entretanto, é importante ressaltar que esta relação não ocorre em baixos níveis.

Em 300 hPa (Fig. 4.11), a região a leste do cavado em altos níveis apresenta tendência de resfriamento durante os estágios inicial e maduro. 
(a) Bal. Calor O0Z23APR2009 - $500 \mathrm{hPa}$
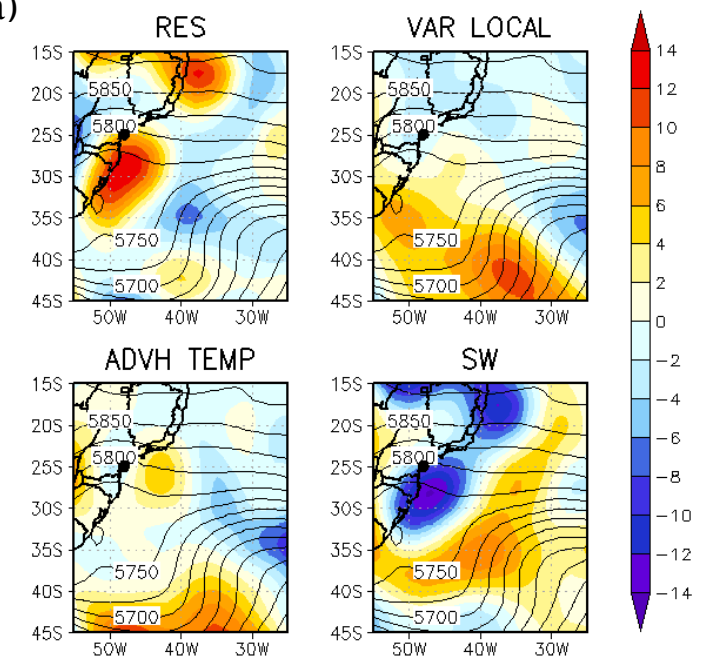

(c)
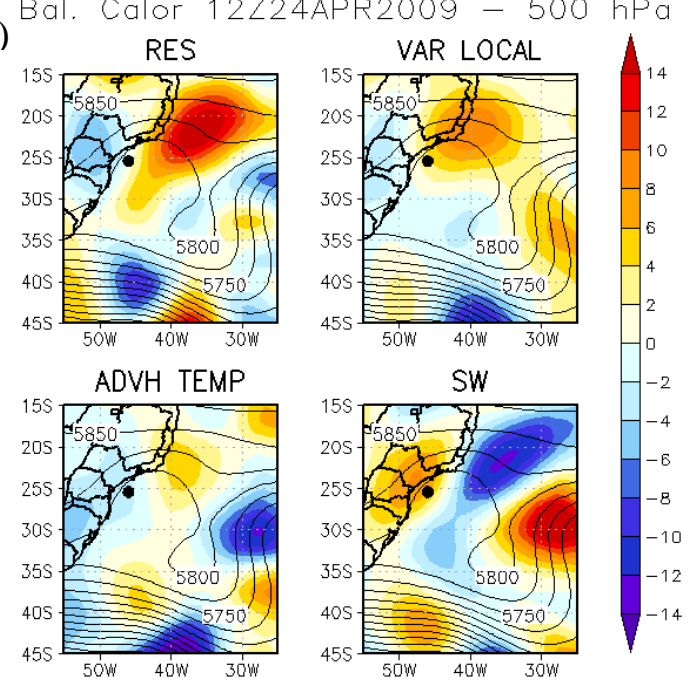

(b) Bal. Calor 12Z23APR2009 - $500 \mathrm{hPa}$
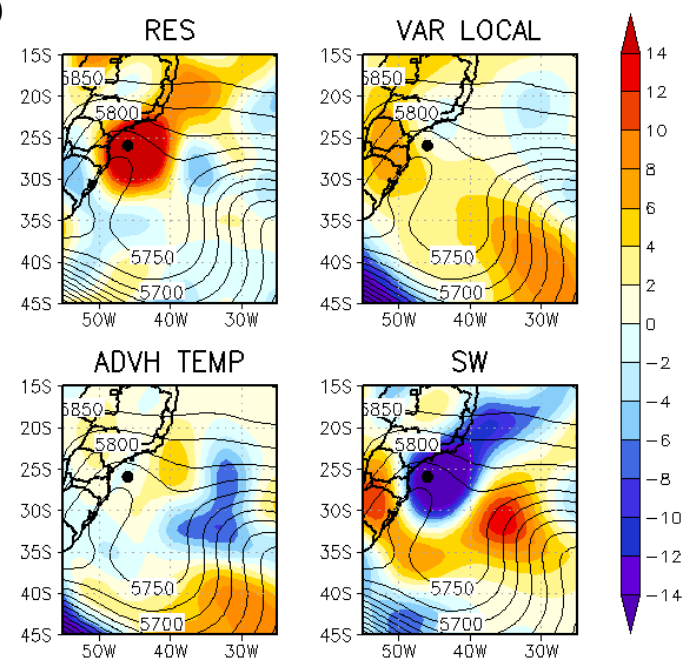

(d)
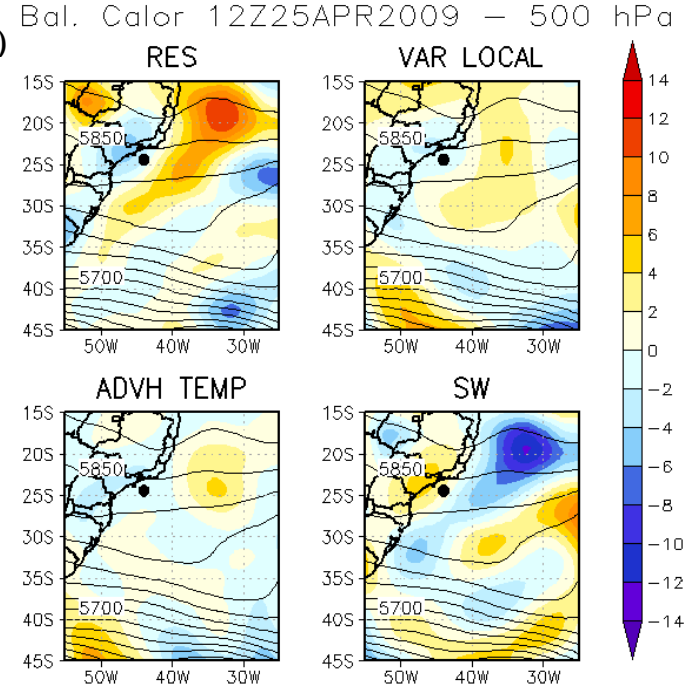

Fig. 4.10. Idem à Fig. 4.9, mas para $500 \mathrm{hPa}$. 

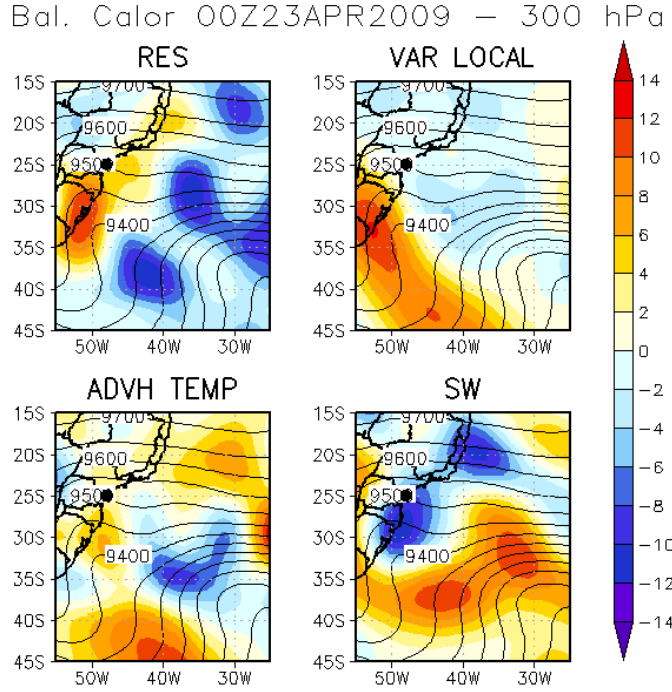

(c)

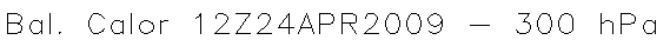

(c)
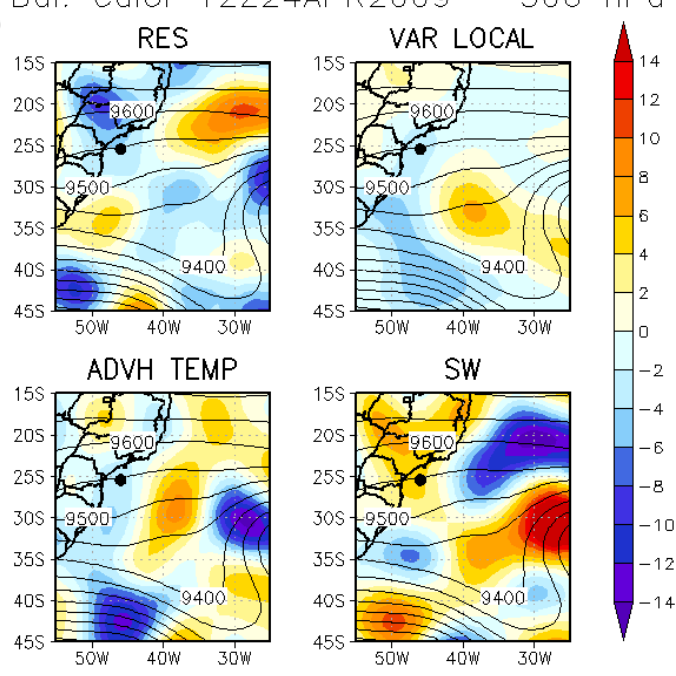

(b)

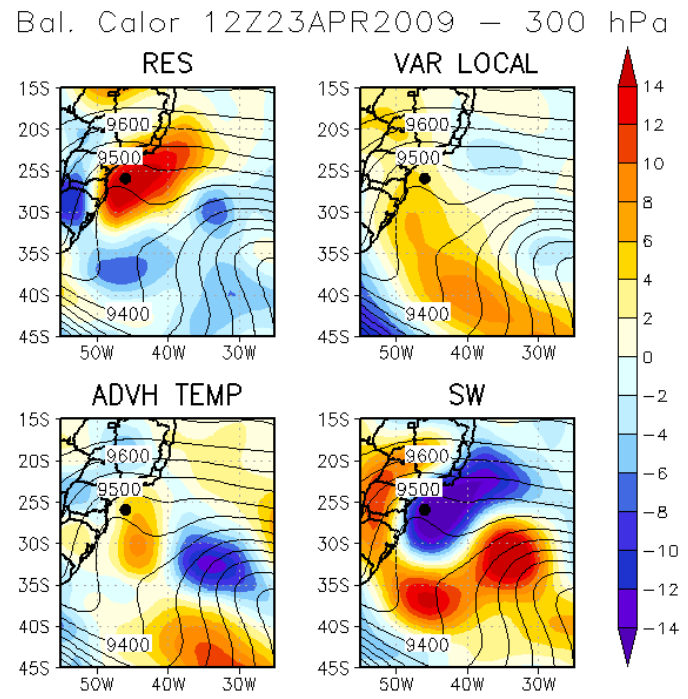

(d)
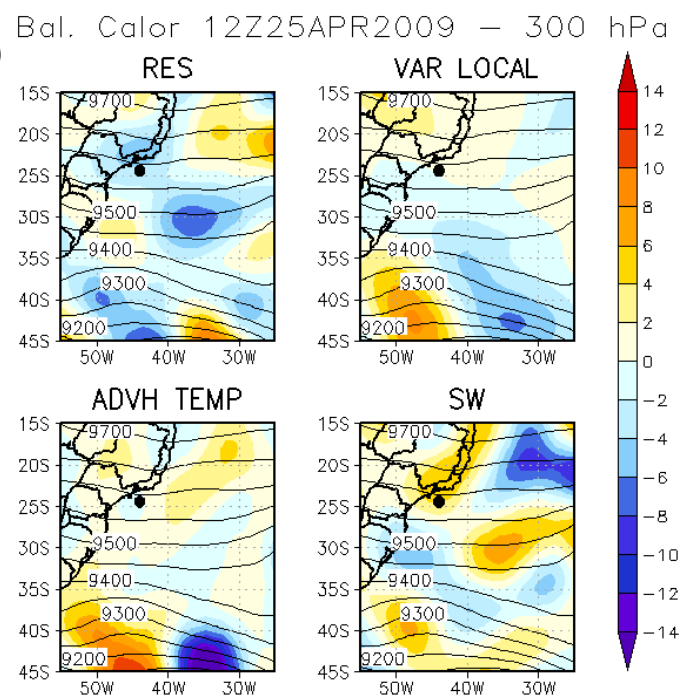

Fig. 4.11. Idem à Fig. 4.9, mas para $300 \mathrm{hPa}$.

\section{b. Balanço de vorticidade}

A distribuição espacial dos termos do balanço de vorticidade em 925 hPa (Fig. 4.12) mostra que os dois primeiros estágios do ciclone apresentam tendência de aumento da vorticidade ciclônica sobre a região do ciclone em superfície, indicando a intensificação do sistema. No estágio maduro, o núcleo de intensificação de VR ciclônica concentra-se na porção leste da posição central do sistema.

Em todos os estágios, existem contribuições para o aumento da vorticidade ciclônica sobre o sistema devidas ao termo de divergência. Isto é um reflexo da convergência produzida pelo ciclone, que promove os movimentos ascendentes. No estágio de dissipação, a convergência ocorre ligeiramente afastada da posição central do sistema, na porção leste/nordeste, provavelmente sendo responsável pela organização dos campos de 
nebulosidade e chuva. Sobre o centro do sistema e em sua porção oeste, a dissipação apresenta o termo de divergência contribuindo para vorticidade anticiclônica.

Em todos os estágios, ocorre advecção de vorticidade anticiclônica a leste do ciclone, sendo que advecção horizontal ciclônica ocorre nas partes central e oeste do sistema.

(a)
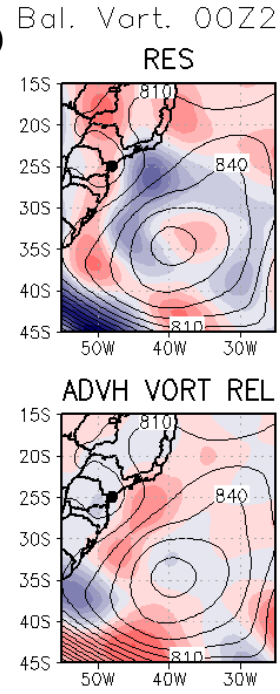

(c)
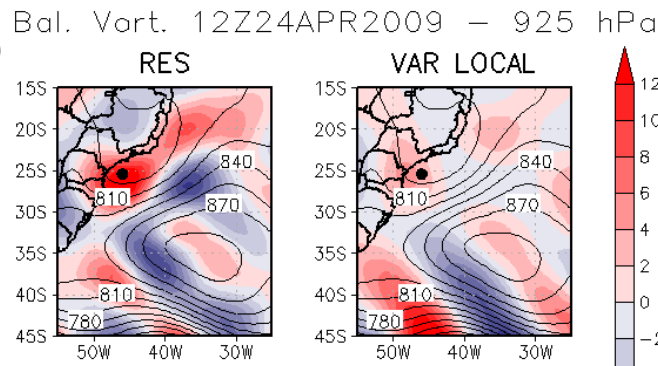

ADVH VORT REL

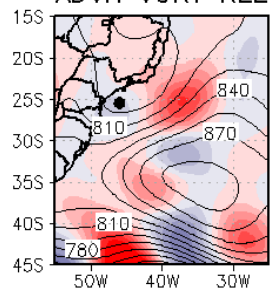

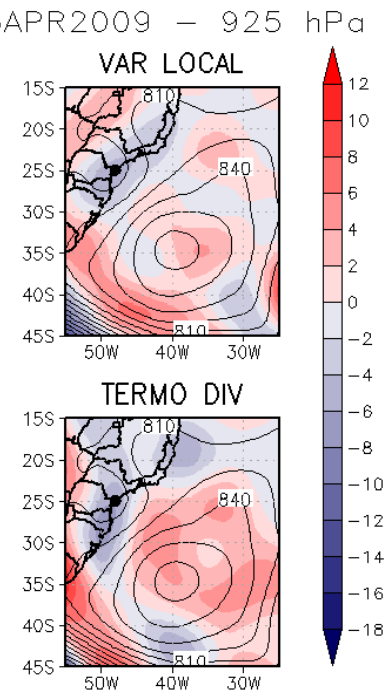

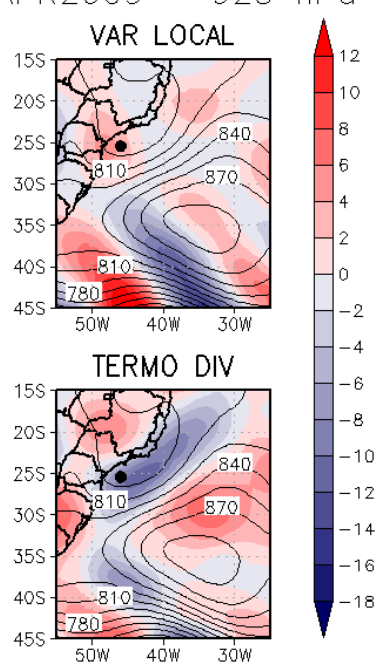

(b)

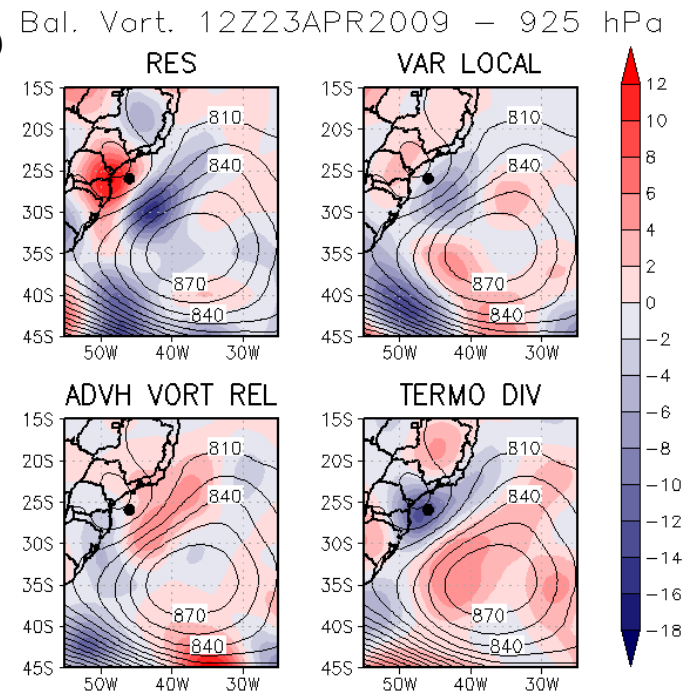

(d)

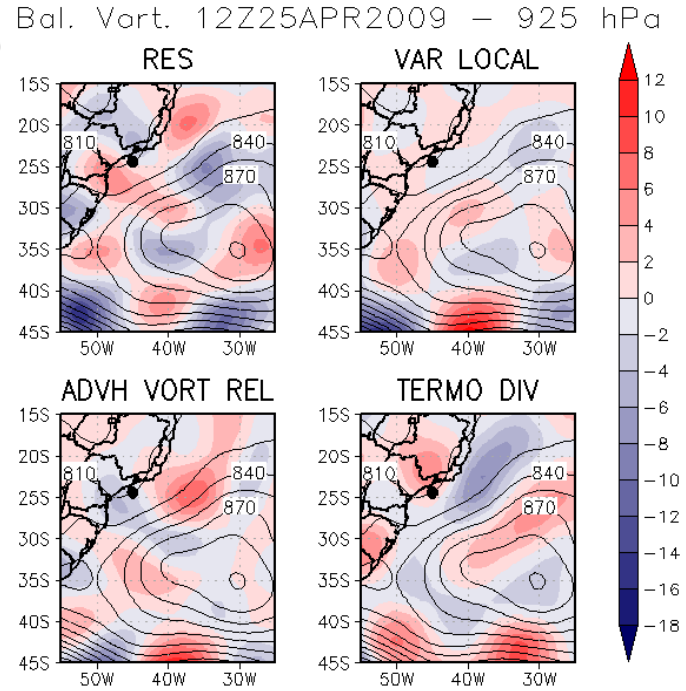

Fig. 4.12. Altura geopotencial (linhas contínuas, metros geopotencial) e termos do balanço de vorticidade (sombreado; resíduo, variação local, advecção horizontal e termo de divergência, $10^{-10} \mathrm{~s}^{-2}$ ) em $925 \mathrm{hPa}$ para as (a) 00 UTC do dia 23 (início), (b) 12 UTC do dia 23 (maduro), (c) 12 UTC do dia 24 (enfraquecimento) e (e) 12 UTC do dia 25 (dissipação).

Em altos níveis (Fig. 4.13), a intensidade dos termos da equação da vorticidade é consideravelmente maior que nos níveis próximos à superfície, uma vez que o escoamento e os gradientes são mais intensos. Nos estágios inicial e maduro, a tendência local de vorticidade na região acima do ciclone em superfície é ciclônica. Esta tendência possui influência dos termos residual e de advecção horizontal. Ressalta-se que a região do ciclone em superfície está localizada a leste do cavado em altos níveis, sendo portanto uma região 
onde se espera ocorrência de advecção horizontal de VR ciclônica em $300 \mathrm{hPa}$. Além disso, à leste do cavado em $300 \mathrm{hPa}$, o termo residual atua de forma a destruir as tendências anticiclônicas produzidas pelo termo de divergência. Tais tendências anticiclônicas do termo de divergência indicam que neste nível ocorre divergência do vento, associada aos movimentos ascendentes no ciclone.

Nos dois estágios finais do ciclone, a variação local de vorticidade em 300 hPa sobre o sistema é anticiclônica, uma vez que o cavado superior está completamente desconfigurado.

(a)
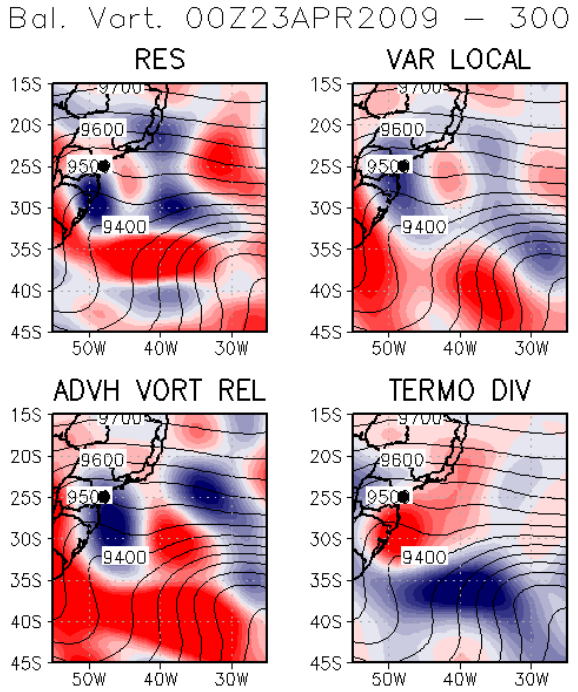

(c)
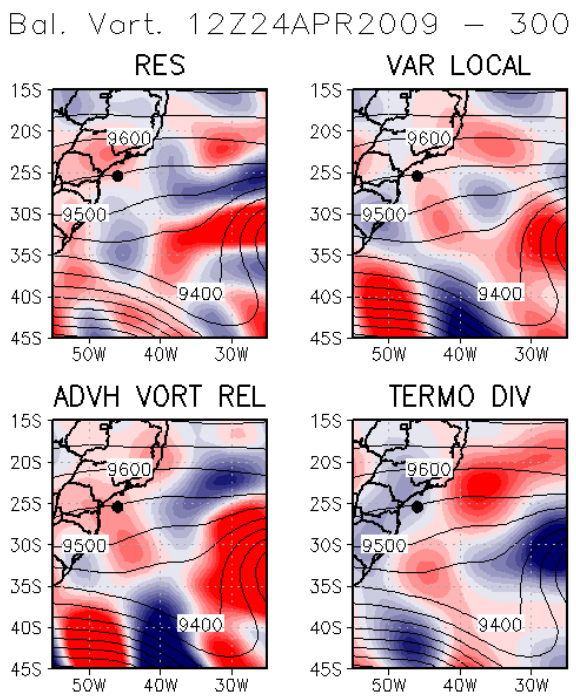

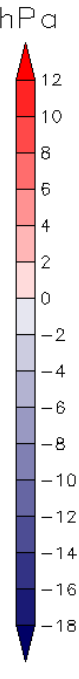

(b)

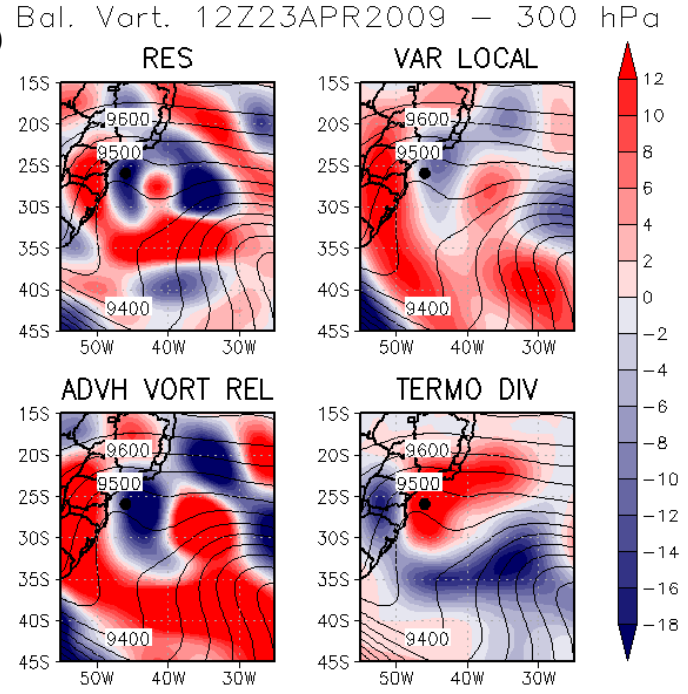

(d)
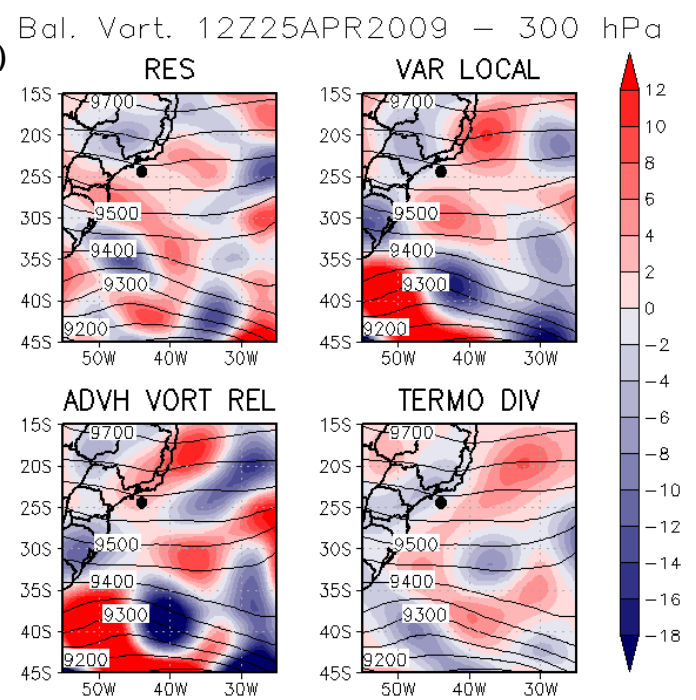

Fig. 4.13. Idem à Fig. 4.12, mas para 300 hPa. 


\subsection{Associação entre os campos residuais}

Reed e Johnson (1974) investigaram o perfil vertical do resíduo da equação da vorticidade em regiões de cristas e cavados de ondas de leste no HN. Os resultados do trabalho mostraram que, na região do cavado, ou seja, na região de maior atividade convectiva, o resíduo atua como um sumidouro de VR ciclônica em baixos níveis, e como uma fonte em altos níveis.

No presente trabalho, os campos espaciais dos resíduos do balanço de calor e de vorticidade foram analisados e comparados, buscando verificar se os resultados obtidos por Reed e Jonhson (1974) são válidos para as regiões de maior atividade convectiva associadas aos ciclones subtropicais aqui investigados.

Para o ciclone de abril de 2009, apenas em 300 hPa e em algumas regiões dos estágios inicial e maduro foi possível verificar associações entre os campos residuais das equações da termodinâmica e da vorticidade. Estas associações referem-se a semelhanças entre as regiões de intensa atividade convectiva e as regiões de intenso resíduo do balanço de VR.

No estágio inicial, existe um núcleo de atividade convectiva na região do cavado em altos níveis, localizado ao sul do ciclone em superfície. Tal atividade convectiva é responsável pela tendência de aquecimento em $300 \mathrm{hPa}$ devido ao termo diabático da equação da termodinâmica (Fig. 4.14a). Nesta mesma região, existe um núcleo de tendência de aumento de vorticidade ciclônica devido ao termo residual; assim, seguindo o mesmo raciocínio de Reed e Jonhson (1974), nesta região a convecção explicaria o "imbalanço" de vorticidade, sendo responsável pelo resíduo de vorticidade atuando como fonte de VR ciclônica em altos níveis.

No estágio maduro também havia uma região em altos níveis na qual a convecção explicaria parte do "imbalanço" de vorticidade observado: sobre o ciclone em superfície, localizado no leste do cavado em $300 \mathrm{hPa}$, o resíduo do balanço de vorticidade atua como fonte de vorticidade ciclônica (Fig. 4.14b). Ao analisar o resíduo do balanço de calor, esta região apresenta intensa atividade convectiva.

Entretanto, nota-se que a atividade convectiva que ocorre durante o estágio maduro se estende por uma região maior que aquela de resíduo ciclônico de vorticidade. Nestes locais em que os "imbalanços" de vorticidade não podem ser explicados pela convecção, sugere-se que a vorticidade residual que resultaria dos efeitos da convecção foi compensada por outro processo que também pode ocasionar tendências de VR. Além disso, sugere-se que a convecção possa ocasionar "imbalanços" de vorticidade de uma forma mais distribuída na 
coluna atmosférica e no espaço em que atua, da mesma forma que a divergência relacionada aos movimentos verticais nunca está concentrada apenas em uma região ou nível da atmosfera. Tal hipótese é reforçada pelo fato de que as associações entre os campos residuais ocorrem apenas nas regiões em que duas condições são satisfeitas:

- A distribuição espacial do termo de divergência deve estar relacionada à distribuição espacial do termo residual da equação da vorticidade (regiões delimitadas pelo círculo preto no painel inferior da Fig. 4.14);

- A distribuição espacial do termo $\mathrm{Sw}$ deve estar relacionada à distribuição espacial do termo residual da equação da termodinâmica (regiões delimitadas pelo círculo preto no painel superior da Fig. 4.14).

$\mathrm{Na}$ região em $300 \mathrm{hPa}$ em que existe atividade convectiva, porém não existe um "imbalanço" considerável de vorticidade, o termo de divergência não está associado ao resíduo de vorticidade, isto é, o termo de divergência não é o processo dinâmico que mais contribui para o resíduo observado de vorticidade.

(a)

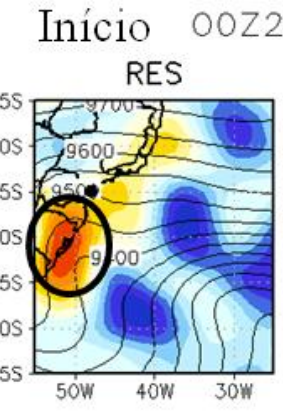

RES

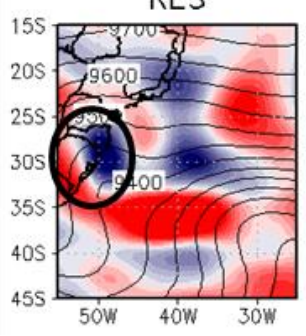

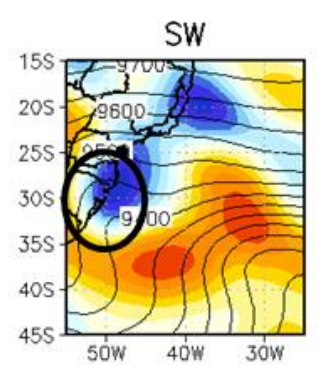

TERMO DIV

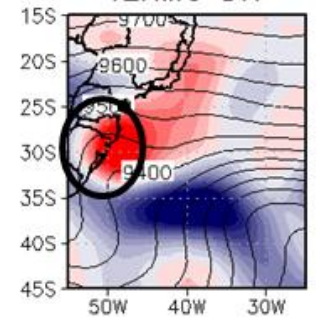

(b)

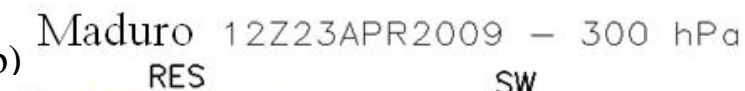

Fig. 4.14. Altura geopotencial (linhas contínuas, metros geopotencial) e termos diabático e Sw do balanço de calor (sombreado; painel superior; tons em amarelo indicam aquecimento, e tons em azul claro indicam resfriamento, $\mathrm{K} \mathrm{dia}^{-1}$ ) e termos residual e de divergência do balanço de vorticidade (sombreado; painel inferior; tons em vermelho indicam diminuição de vorticidade ciclônica, e tons em azul escuro indicam aumento de vorticidade ciclônica, $10^{-10}$ $\mathrm{s}^{-2}$ ) em $300 \mathrm{hPa}$ para (a) 00 UTC do dia 23/04/2009 (início) e (b) 12 UTC do dia 23/04/2009 (maduro). A posição central do ciclone em superfície é marcada pelo ponto preto, e os círculos pretos delimitam as regiões em que foram observadas associações entre os campos residuais (ver o texto para mais detalhes). 


\subsection{Perfis verticais médios}

A seguir são apresentados os perfis verticais médios calculados com os dados NCEP. Além dos perfis de cada termo das equações do balanço de calor e vorticidade, calcularam-se também os perfis de VR, divergência e Omega. Ressalta-se que, no caso deste ciclone, que permaneceu estacionário sobre a mesma região, a caixa utilizada nos cálculos manteve-se fixa no espaço.

\section{a. Vorticidade, divergência e Omega}

Na Fig. 4.15 são apresentados os perfis verticais médios de VR, divergência e Omega, centrados no ciclone em superfície entre 23 e 25 de abril de 2009. Na figura, cada cor indica um diferente estágio do ciclo de vida do ciclone.

O perfil vertical de VR (Fig. 4.15a) mostra que em $200 \mathrm{hPa}$ ocorrem os máximos valores de vorticidade ciclônica e anticiclônica durante, respectivamente, os estágios maduro e de dissipação. O estágio da dissipação destaca-se por apresentar vorticidade anticiclônica, embora pouco intensa e somente nos níveis acima de $300 \mathrm{hPa}$. Além disso, os estágios inicial e de dissipação apresentam vorticidade ciclônica média pouco intensa na baixa e média troposfera. Em altos níveis, o estágio inicial apresenta um pico de VR ciclônica em 200 hPa, similar ao pico do estágio maduro, porém menos intenso. Isto ocorre devido à aproximação do cavado de níveis superiores para a região do ciclone em superfície. Ambos os estágios de início e maduro são marcados por um acentuado aumento com a altura da VR ciclônica, desde a superfície até o nível de $200 \mathrm{hPa}$, nível acima do qual passa a ocorrer o decréscimo com a altura. Este pico de VR ciclônica em 200 hPa não ocorre durante o enfraquecimento, uma vez que neste estágio o cavado em altos níveis já enfraqueceu, conforme mostram as linhas de corrente em 200 hPa (Fig. 4.5c). Destaca-se ainda que, durante a dissipação, em toda a coluna a VR média ciclônica é menos intensa comparada ao estágio de enfraquecimento.

No perfil médio de divergência (Fig. 4.15b), tem-se que os estágios inicial e maduro apresentam um padrão bem definido de convergência em baixos e divergência em altos níveis. No estágio de enfraquecimento, predomina divergência em níveis médios, na camada entre $850 \mathrm{hPa}$ e $400 \mathrm{hPa}$, enquanto picos de convergência são observados em $1000 \mathrm{hPa}$ e em $200 \mathrm{hPa}$. É importante ressaltar que a convergência em altos níveis implica em movimentos descendentes, o que contribui para a desintensificação dos sistemas ciclônicos. No estágio de dissipação o padrão de convergência/divergência enfraquece em toda a coluna atmosférica, com valores médios próximos de zero. 

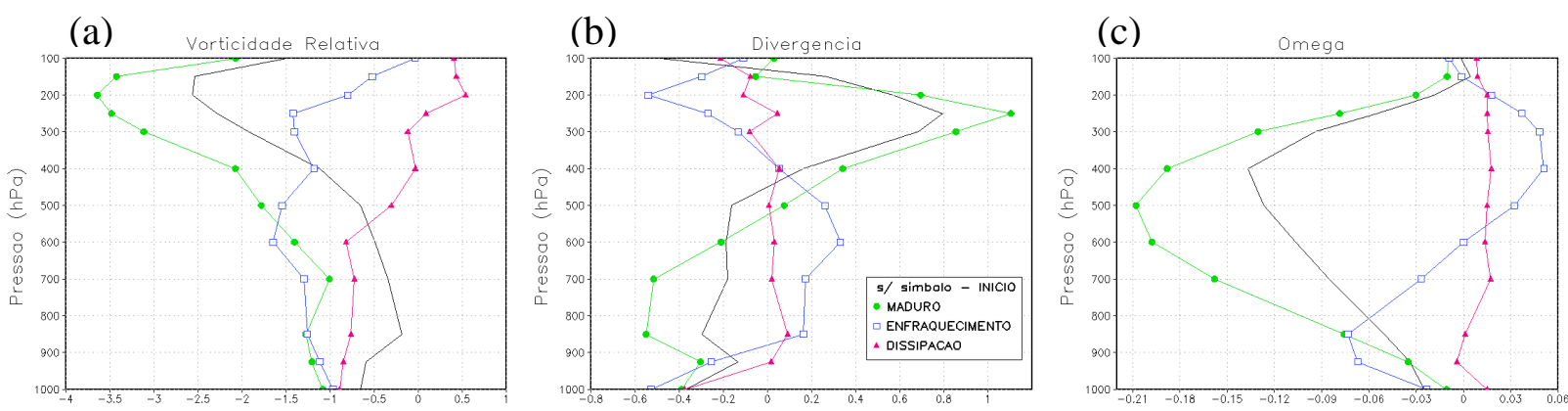

Fig. 4.15. Perfis verticais médios de (a) VR $\left(10^{-5} \mathrm{~s}^{-1}\right)$, (b) divergência $\left(10^{-5} \mathrm{~s}^{-1}\right)$ e (c) pseudovelocidade vertical Omega $\left(\mathrm{Pa} \mathrm{s}^{-1}\right)$, centrados no ciclone em superfície de abril de 2009. Cada cor representa um diferente estágio do sistema.

Para o perfil vertical de Omega (Fig. 4.15c), valores negativos indicam movimentos ascendentes, enquanto valores positivos indicam movimentos descendentes. Destaca-se que a fase madura do ciclone caracteriza-se por intensa atividade convectiva, quando os movimentos ascendentes mais intensos nas imediações do ciclone em superfície ocorrem em níveis médios, com pico em $500 \mathrm{hPa}$. No estágio inicial também predominam movimentos ascendentes na troposfera, porém não tão intensos quanto no estágio maduro. Durante o enfraquecimento, o movimento vertical é ascendente da superfície até $600 \mathrm{hPa}$ e descendente nos níveis superiores. O estágio de dissipação diferencia-se dos demais por apresentar subsidência em toda a camada atmosférica, embora os valores sejam pouco intensos.

\section{b. Balanço de calor}

A Fig. 4.16 mostra os perfis verticais médios dos termos do balanço de calor. Quanto à variação local de temperatura (Fig. 4.16a), o estágio inicial apresenta tendência de resfriamento em $925 \mathrm{hPa}$ e em níveis médios, com pico negativo em $600 \mathrm{hPa}$. De forma geral, todos os estágios posteriores apresentam tendências positivas de temperatura em superfície e em médios níveis, indicando o aquecimento da coluna ao longo do ciclo de vida do ciclone.

Analisando a distribuição na vertical dos termos médios de advecção horizontal de temperatura (Fig. 4.16b), verifica-se que no estágio maduro ocorrem advecções quentes mais intensas desde a superfície até níveis médios, enquanto que, em níveis superiores, a máxima advecção quente ocorre no estágio inicial, com pico em $200 \mathrm{hPa}$ de 5,0 $\mathrm{K} \mathrm{dia}^{-1}$. O estágio de enfraquecimento é o único que apresenta advecção fria em altos níveis, sendo que nos níveis médios e inferiores os valores médios são próximos de zero. Por fim, durante a dissipação, o perfil vertical médio mostra fraca advecção de temperatura em toda a coluna. 
Nos perfis médios de advecção vertical de temperatura e do termo adiabático (Figs. 4.16c e 4.16d) nota-se um claro padrão de oposição entre os termos, sendo que nos níveis em que ocorre advecção vertical positiva (negativa) de temperatura, o termo adiabático é negativo (positivo). Isto ocorre pois as parcelas ao subirem (descerem) se expandem (comprimem) adiabaticamente, o que contribui para a diminuição (aumento) da temperatura. Em contrapartida, no geral, os movimentos ascendentes (descendentes) na troposfera advectam o ar mais quente (frio) dos níveis inferiores (superiores) para os níveis acima (abaixo), contribuindo para o aumento (diminuição) da temperatura. Destes processos termodinâmicos, tem-se que as contribuições do termo adiabático são sempre maiores, como pode ser visto na Fig. 4.16e, onde o termo relacionado ao movimento vertical $(\mathrm{Sw})$ representa a soma da advecção vertical de temperatura e do termo adiabático.

No perfil vertical de $\underline{\mathrm{Sw}}$ (Fig. 4.16e), nota-se que o estágio maduro apresenta as maiores contribuições para a tendência de diminuição da temperatura em toda a coluna acima de $850 \mathrm{hPa}$. Esta configuração é uma resposta aos intensos movimentos ascendentes observados neste período (Fig. 4.15c). O estágio inicial também apresenta intensas contribuições para diminuição da temperatura em praticamente toda a troposfera sobre o ciclone em superfície, entretanto os valores são menores que durante o período maduro. No estágio de enfraquecimento ocorrem contribuições para diminuição e aumento de temperatura, respectivamente, nos níveis abaixo e acima de 600 hPa. Já durante a dissipação, a subsidência observada (Fig. 4.15c) faz com que Sw contribua para o aumento de temperatura, embora com valores menores.

Comparando-se os perfis verticais médios de Sw e do termo diabático (Figs. 4.16e e 4.16f), nota-se que de forma geral, estes termos comportam-se de forma oposta, ou seja, à medida que um contribui para as tendências positivas (negativas) de temperatura, o outro contribui negativamente (positivamente). Isto ocorre pois o termo diabático está diretamente relacionado aos processos convectivos e de aquecimento ou resfriamento da atmosfera através de calor sensível e latente. A relação de oposição é mais clara nos médios e altos níveis da atmosfera, enquanto que, próximo à superfície, esta relação nem sempre ocorre, ou seja, o resíduo da equação da termodinâmica não atua de forma a cancelar parcialmente as variações de temperatura causadas pelo termo $\mathrm{Sw}$. 
(a)

Variacao Local

(b) ADV. Horiz. Temp.

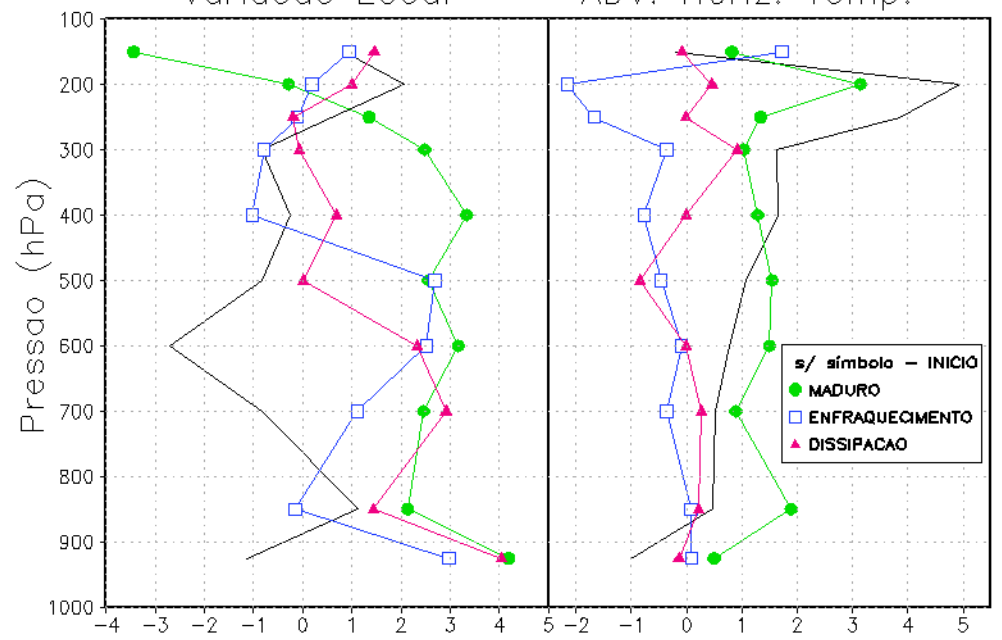

(c) ADV. Vert. Temp.

(d) Termo Adiabatico

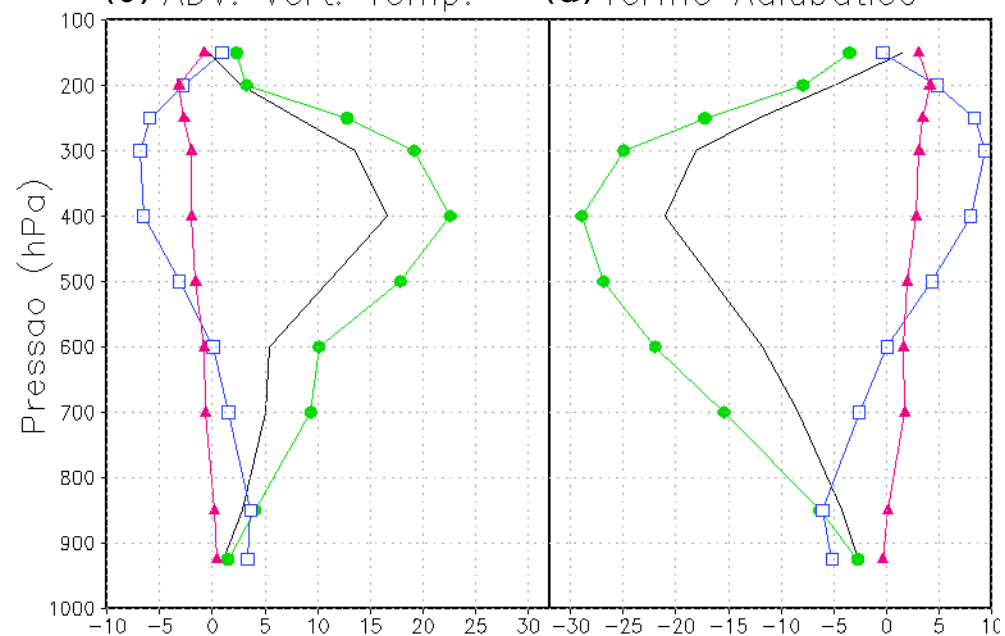

(e)

(f) Termo Diabatico

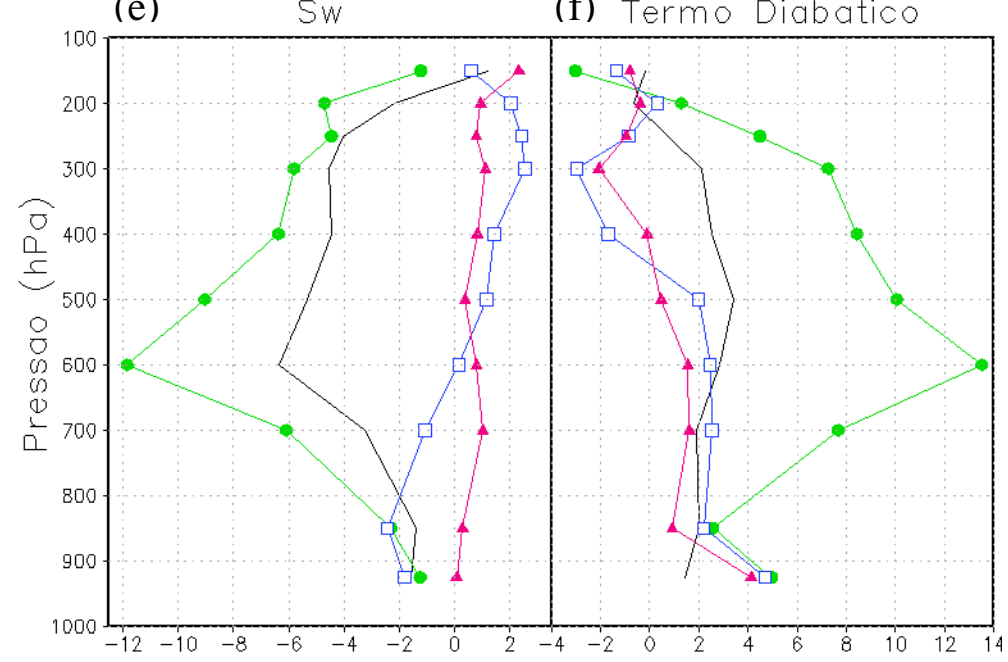

Fig. 4.16. Perfil vertical médio na área em torno do ciclone em superfície (a) da variação local de temperatura $\left(\mathrm{K} \operatorname{dia}^{-1}\right)$, (b) da advecção horizontal de temperatura ( $\left.\mathrm{K} \mathrm{dia}^{-1}\right)$, (c) da advecção vertical de temperatura $\left(\mathrm{K} \mathrm{dia}^{-1}\right),(\mathrm{d})$ do termo adiabático $\left(\mathrm{K} \mathrm{dia}^{-1}\right)$, (e) do termo relacionado ao movimento vertical $\left(\mathrm{K} \mathrm{dia}^{-1}\right)$ e (f) do resíduo da equação da termodinâmica ( $\mathrm{K}$ $\left.\mathrm{dia}^{-1}\right)$, para cada estágio do ciclone de abril de 2009 . 
No geral, o termo residual da equação da termodinâmica atua contribuindo para as tendências de aumento de temperatura na região de atuação do ciclone (Fig. 4.16f), principalmente nos níveis próximos a superfície e níveis médios. No estágio maduro, a contribuição do termo diabático para o aquecimento é mais intensa, chegando a atingir pico de 14,0 K dia ${ }^{-1}$ em $600 \mathrm{hPa}$. Em altos níveis, nos estágios de enfraquecimento e dissipação, o termo diabático contribui para tendências de diminuição da temperatura, com picos de resfriamento em $300 \mathrm{hPa}$.
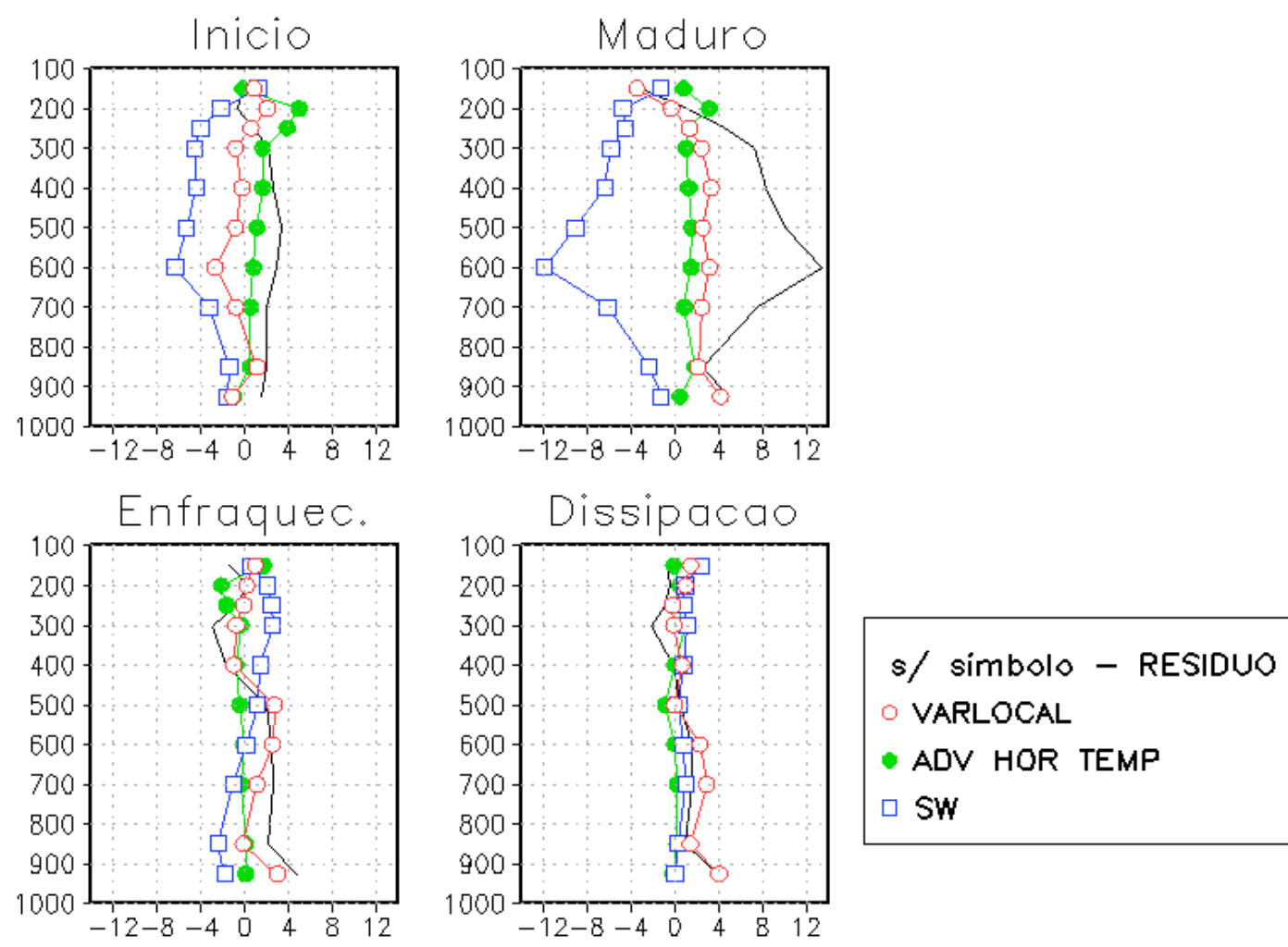

Fig. 4.17. Perfil vertical dos termos de maior contribuição do balanço de calor (resíduo ou termo diabático, variação local de temperatura, advecção horizontal de temperatura e termo relacionado ao movimento vertical $\mathrm{Sw}, \mathrm{K} \mathrm{dia}^{-1}$ ), para cada estágio do ciclo de vida do ciclone de abril de 2009.

A Fig. 4.17 mostra os mesmos perfis verticais apresentados na Fig. 4.16, porém todos os termos da equação da termodinâmica estão juntos, para cada diferente estágio do ciclone. Nesta figura fica evidente o padrão de oposição entre os termos Sw e diabático, especialmente em médios e altos níveis. Destacam-se também os picos de advecção quente em $200 \mathrm{hPa}$ nos estágios de início e maduro, respectivamente de 5,0 $\mathrm{K} \mathrm{dia}^{-1}$ e 3,0 $\mathrm{K} \mathrm{dia}^{-1}$. Tal perfil vertical do termo de advecção horizontal de temperatura, em que ocorrem picos de advecção quente em altos níveis, também foi observado em ciclogêneses extratropicais no trabalho de Sinclair e Revell (2000). Considerando um perfil idealizado de advecção horizontal de temperatura para 
ciclones extratropicais, a advecção quente (fria) que ocorre a leste (oeste) do cavado decresce com a altura, e assim $\partial A_{T} / \partial z<0\left(\partial A_{T} / \partial z>0\right)$. Holton (2004) argumenta que tal decréscimo com a altura deve-se ao fato de que, nos níveis acima de $500 \mathrm{hPa}$, os gradientes de temperatura são mais fracos e as isotermas são freqüentemente paralelas às linhas de altura.

Desde a fase madura até a fase de dissipação, o aquecimento em 925 hPa (Fig. 4.17) pode ser atribuído aos processos turbulentos de transferência de calor sensível do oceano para a atmosfera. Tal padrão é similar ao encontrado por Iwabe e da Rocha (2009) para ciclones secundários.

\section{c. Balanço de vorticidade}

A Fig. 4.18 apresenta os perfis verticais médios dos termos do balanço de vorticidade. Quanto ao termo de variação local de vorticidade relativa (Fig. 4.18a), o início do sistema apresenta os maiores valores de tendência de vorticidade ciclônica na média e na alta troposfera. Apenas neste estágio as tendências médias são ciclônicas em todos os níveis de pressão. O pico de tendência ciclônica neste dia ocorre em $250 \mathrm{hPa}$. O estágio maduro também apresenta tendências ciclônicas em quase toda a coluna atmosférica, entretanto os valores são menores do que no estágio inicial, exceto nos níveis abaixo de $700 \mathrm{hPa}$. Tendência de vorticidade anticiclônica ocorre durante os períodos finais de atuação do sistema, nos estágios de enfraquecimento e dissipação.

A advecção horizontal de vorticidade relativa (Fig. 4.18b) é fraca em baixos e médios níveis em todos os estágios, o que está associado à presença de circulação ciclônica 'fechada' (gradientes de VR quase perpendiculares ao vetor vento). Durante a dissipação, a advecção média de VR mantém-se próxima de zero em toda a troposfera acima do ciclone em superfície. Entretanto, durante ambos os estágios de início e maduro, intensos valores de advecção horizontal de VR ciclônica ocorrem em altos níveis, com picos em 200 hPa. Isto reflete a aproximação do cavado em níveis superiores. Em contrapartida, durante o enfraquecimento ocorrem picos de advecção de VR anticiclônica em altos níveis, o que deve estar associado ao enfraquecimento do cavado em altos níveis.

O perfil vertical médio do termo de divergência (Fig. 4.18c) mostra que este termo contribui para as tendências locais ciclônicas de VR durante os estágios de início e maduro, desde os níveis mais baixos até $500 \mathrm{hPa}$, enquanto nos demais níveis contribui para tendências anticiclônicas. Ressalta-se ainda que o estágio maduro apresenta picos ciclônicos e anticiclônicos mais intensos, respectivamente em $850 \mathrm{hPa}$ e $250 \mathrm{hPa}$. Durante o período de 
enfraquecimento, observa-se valores anticiclônicos do termo de divergência desde 850 até $400 \mathrm{hPa}$, sendo que em $925 \mathrm{hPa}$ e acima de $400 \mathrm{hPa}$ contribui para tendências ciclônicas. O estágio de dissipação apresenta valores médios do termo de divergência muito próximos de zero em toda a coluna vertical acima do ciclone.

O termo residual da equação da vorticidade (Fig. 4.18d) atua em função principalmente do termo de divergência, ou seja, o resíduo é mais/menos intenso nos estágios e nas regiões em que o termo de divergência também é mais/menos intenso. Ressalta-se ainda que os dois termos atuam inversamente, o que significa que o resíduo atua destruindo a vorticidade gerada pelos efeitos do termo de divergência. Portanto, é importante analisar a equação da termodinâmica, já que a convecção pode ser uma forçante para os "imbalanços" de vorticidade, uma vez que o termo residual está relacionado principalmente ao termo de divergência, que por sua vez relaciona-se aos movimentos verticais.

A advecção vertical de vorticidade relativa (Fig. 4.18e) contribui para as tendências anticiclônicas em altos níveis durante o estágio maduro, com pico de $3,0 \times 10^{-10} \mathrm{~s}^{-2}$ em 250 $\mathrm{hPa}$. Um pico secundário de advecção anticiclônica ocorreu durante o estágio inicial, em 300 hPa. Quanto à influência deste termo para as tendências de vorticidade durante os outros estágios, nota-se que o perfil vertical médio não apresenta padrões importantes.

A advecção de vorticidade planetária (Fig. 4.18f) mostra tendências opostas à advecção horizontal de vorticidade relativa (Fig. 4.18b), especialmente durante os estágios inicial e de enfraquecimento em altos níveis. Entretanto, é importante ressaltar que estes dois termos nem sempre apresentam tendências exatamente opostas, uma vez que o sinal de sua contribuição depende do cosseno do ângulo entre o vetor vento e os gradientes de vorticidade relativa e planetária. Assim, existem situações no escoamento real (não idealizado) em que ambos os vetores do gradiente podem formar um ângulo menor que $90^{\circ} \mathrm{com}$ o vetor vento. Destaca-se ainda que, nos níveis mais próximos à superfície, a advecção de vorticidade planetária contribui somente para tendências anticiclônicas em todos os estágios.

O termo de inclinação (Fig. 4.18g) contribui para tendências locais ciclônicas de vorticidade durante o estágio maduro em altos níveis, de forma a contrabalancear as variações de vorticidade causadas pela advecção vertical de VR. 
(a) Variacao Local

(b)ADV. Horiz. Vort. Rel

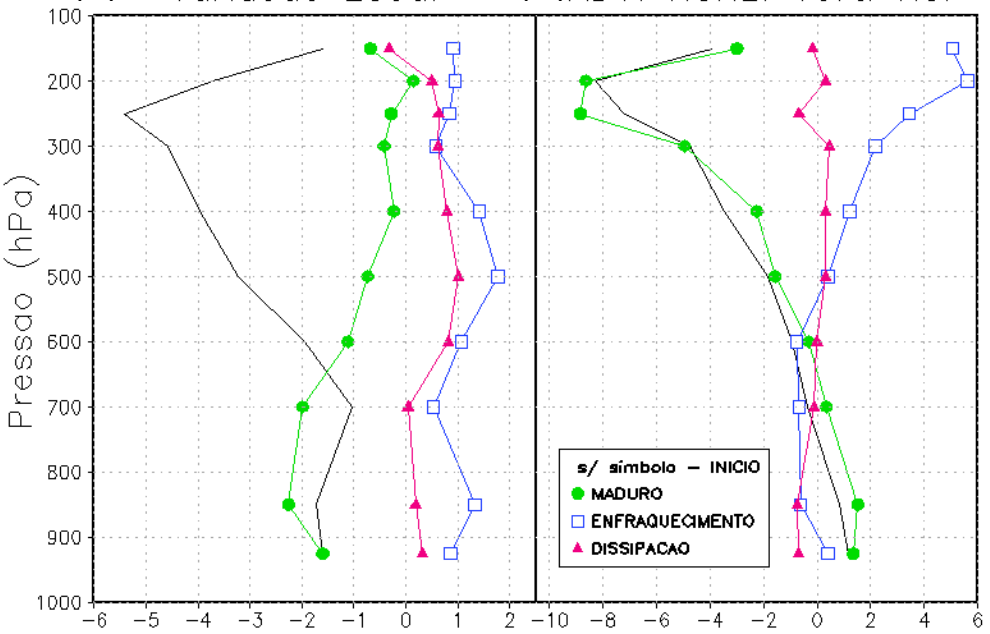

(c) Termo Divergencia (d) Residuo Bal. Vort.

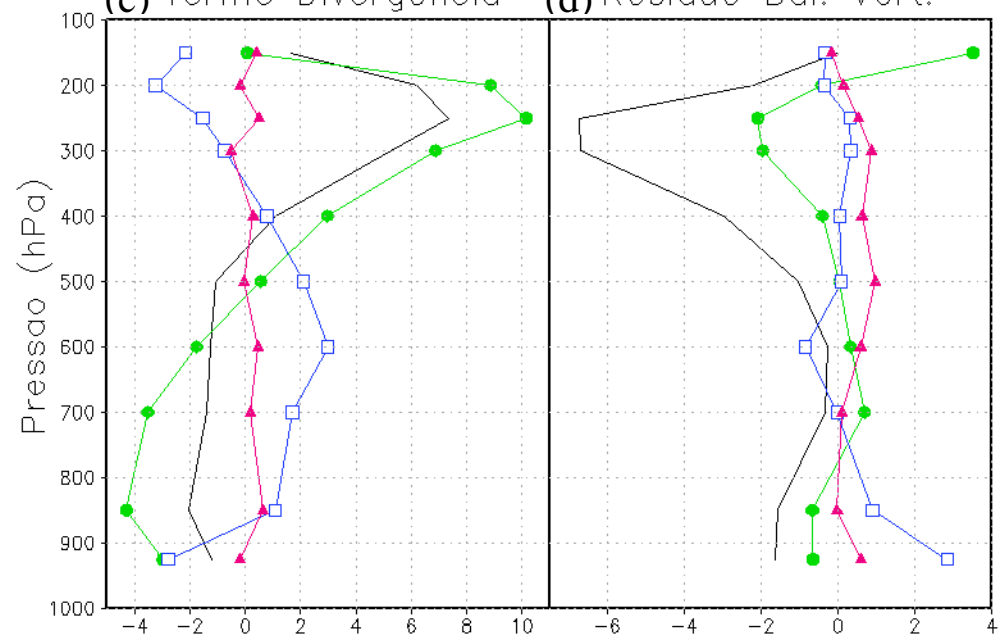

(e)ADV. Vert. Vort. Rel. (f) ADV. Vort. Planetaria

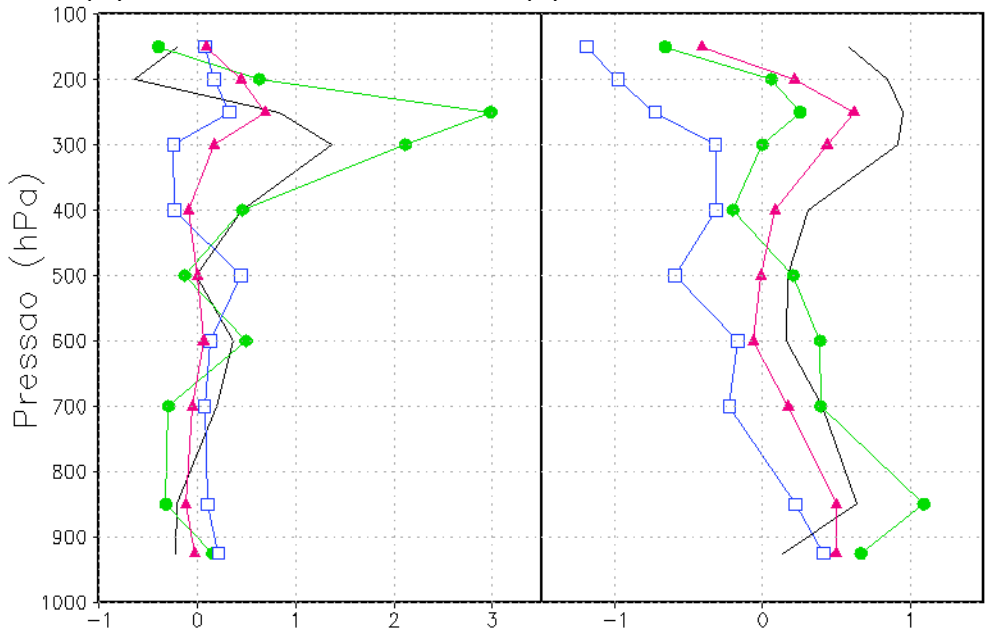

(g) Termo Inclinacao

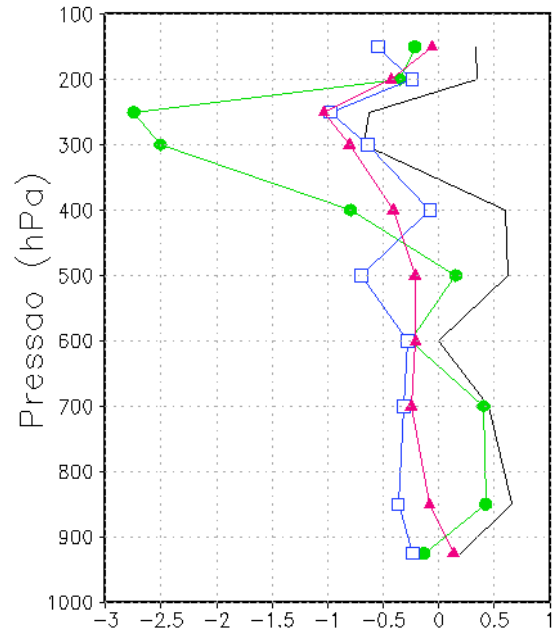

Fig. 4.18. Perfil vertical médio na área em torno do ciclone em superfície (a) da variação local de vorticidade relativa $\left(10^{-10} \mathrm{~s}^{-2}\right)$, (b) da advecção horizontal de vorticidade relativa $\left(10^{-10} \mathrm{~s}^{-2}\right)$, (c) do termo de divergência $\left(10^{-10} \mathrm{~s}^{-2}\right)$, (d) do resíduo do balanço de vorticidade $\left(10^{-10} \mathrm{~s}^{-2}\right)$, (e) da advecção vertical de vorticidade relativa $\left(10^{-10} \mathrm{~s}^{-2}\right.$ ), (f) da advecção de vorticidade planetária $\left(10^{-10} \mathrm{~s}^{-2}\right)$ e $(\mathrm{g})$ do termo de inclinação $\left(10^{-10} \mathrm{~s}^{-2}\right)$, para cada estágio do ciclone de abril de 2009. 
Na Fig. 4.19, tem-se o perfil vertical médio do resíduo da equação da vorticidade (linhas em preto), para cada estágio definido do ciclone. $\mathrm{Na}$ figura, as linhas em azul representam o resíduo calculado desprezando-se os termos de menor contribuição (advecção vertical de vorticidade relativa, advecção de vorticidade planetária e termo de inclinação), que são freqüentemente desprezados em diversos trabalhos que analisam o balanço de vorticidade. Analisando a Fig. 4.19, pode-se inferir que, em termos qualitativos, desprezar estes termos não altera significativamente a distribuição vertical média do resíduo. Contudo, verifica-se que, em toda a coluna no estágio inicial e da superfície até $500 \mathrm{hPa}$ do estágio maduro, desprezar estes termos resulta em valores do termo residual menos ciclônicos, o que significa que, nestas situações, estes termos contribuem para as tendências anticiclônicas de vorticidade. Nos estágios de enfraquecimento, observa-se que desprezar os termos implica em valores do termo residual mais ciclônicos, especialmente em altos níveis.
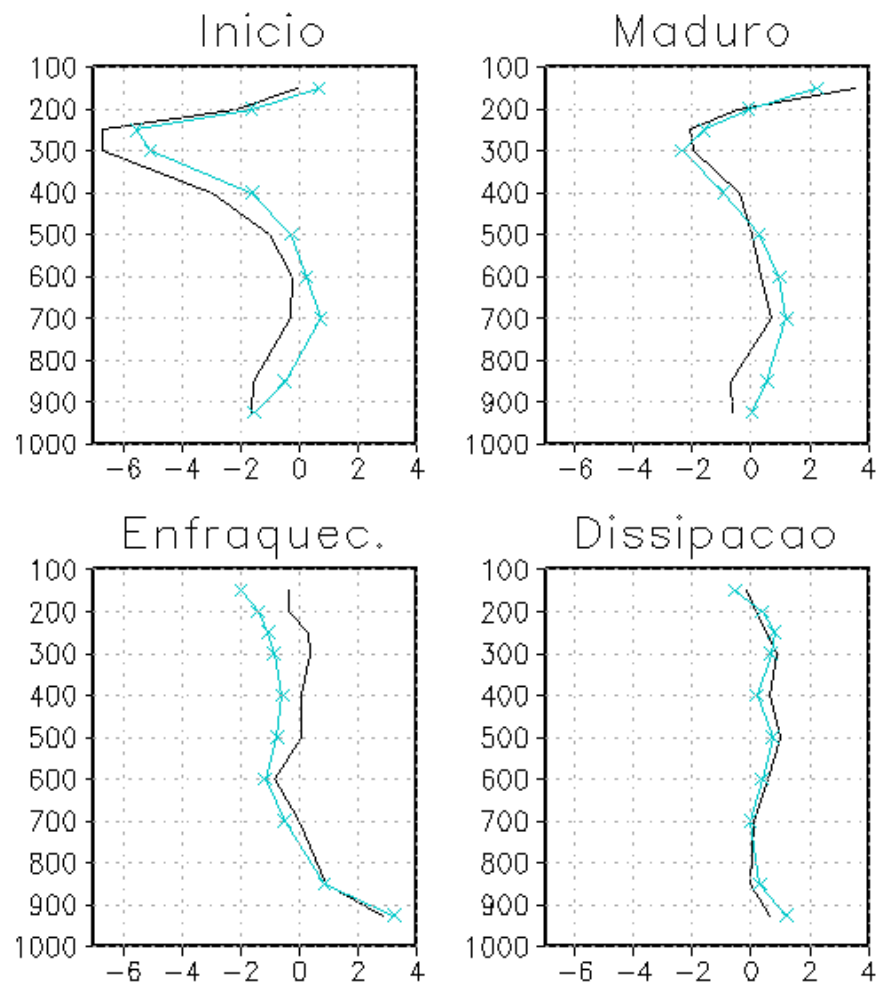

Fig. 4.19. Perfil vertical do resíduo do balanço de vorticidade $\left(10^{-10} \mathrm{~s}^{-2}\right.$, preto) e do resíduo calculado desprezando-se os termos de menor contribuição $\left(10^{-10} \mathrm{~s}^{-2}\right.$, azul), para cada estágio do ciclone de abril de 2009. 


\section{CAPÍtULO 5}

\section{Resultados - Ciclone de março de 2010}

\subsection{Discussão sinótica}

Foram selecionados cinco diferentes tempos do ciclo de vida do ciclone (Fig. 5.1), a fim de ilustrar os aspectos mais notáveis da evolução dinâmica do sistema. Para auxiliar na referência, os cinco estágios receberam diferentes denominações: (i) início (04 de março às 12Z), (ii) intensificação 1 (07 de março às 12Z), (iii) maduro (09 de março às 12Z), (iv) enfraquecimento (10 de março às 12Z) e intensificação 2 (11 de março às $12 Z$ ). O início refere-se ao horário a partir do qual a pressão central do sistema começa a decrescer, enquanto que durante a intensificação 1 a baixa em superfície começa a se deslocar para sudoeste. $\mathrm{O}$ horário quando o sistema atinge a menor pressão em superfície durante sua fase subtropical corresponde ao estágio maduro. O estágio de enfraquecimento é marcado por um aumento da pressão central do sistema, e durante a intensificação 2 ocorre novamente o aprofundamento do ciclone em superfície numa taxa máxima.

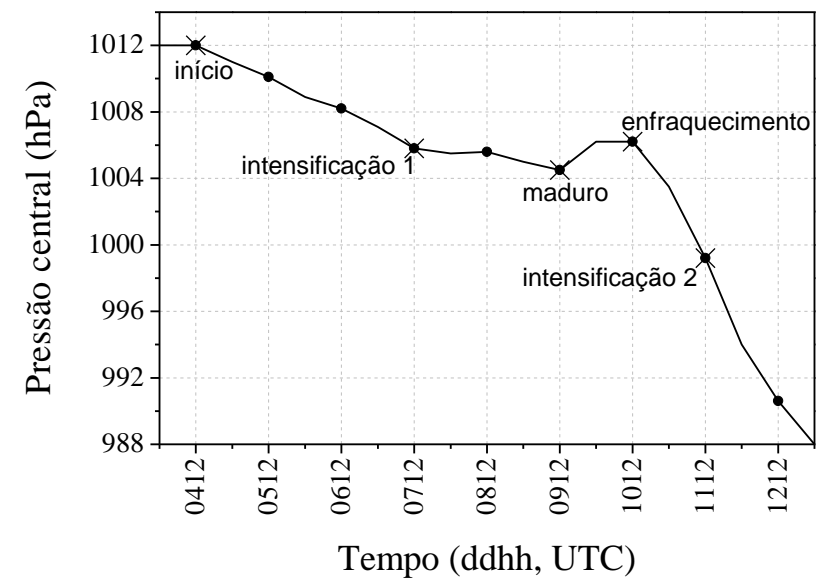

Fig. 5.1. Pressão central $(\mathrm{hPa})$ do ciclone em superfície. Os estágios do ciclo de vida do ciclone de março de 2010 (início, intensificação 1, maduro, enfraquecimento, intensificação 2) estão identificados e marcados na figura.

Em baixos níveis, os ventos máximos observados na região de atuação do sistema, isto é, dentro de uma caixa de $10^{\circ}$ de latitude por longitude, mantiveram-se entre 10 e $15 \mathrm{~m} \mathrm{~s}^{-1}$ nos estágios iniciais do desenvolvimento do ciclone, e atingindo picos por volta de $25 \mathrm{~m} \mathrm{~s}^{-1}$ entre às 12 UTC do dia 07 (intensificação 1) até às 12 UTC do dia 08. Após o estágio de intensificação 2, os ventos máximos em baixos níveis aumentam de intensidade novamente, chegando a $35 \mathrm{~m} \mathrm{~s}^{-1}$ às 00 UTC do dia 13 (Fig. 5.2a). Os mínimos valores de VR observados 
em $925 \mathrm{hPa}$ em todo o ciclo de vida do ciclone ocorrem às 12 UTC do dia $08\left(-7 \times 10^{-5} \mathrm{~s}^{-1}\right) \mathrm{e}$ às 00 UTC do dia $13\left(-10 \times 10^{-5} \mathrm{~s}^{-1}\right)$ (Fig. 5.2a). O perfil vertical da intensidade máxima do vento na região do ciclone mostra picos de $40 \mathrm{~m} \mathrm{~s}^{-1}$ às 00 UTC do dia 09 e $50 \mathrm{~m} \mathrm{~s}^{-1}$ às 00 UTC do dia 13 em altos níveis. A partir do dia 12, os ventos máximos aumentam de intensidade em toda a troposfera (Fig. 5.2c). Os mínimos valores de VR ocorrem entre às 12 UTC do dia 08 até às 00 UTC do dia 10 nos níveis mais elevados da atmosfera (Fig. 5.2d).

(a)

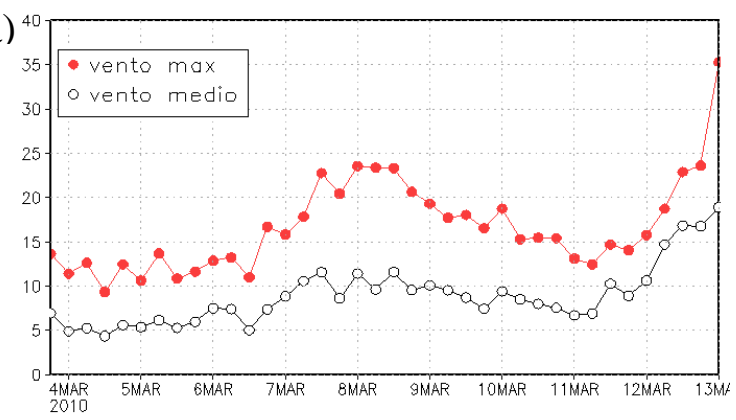

(c)

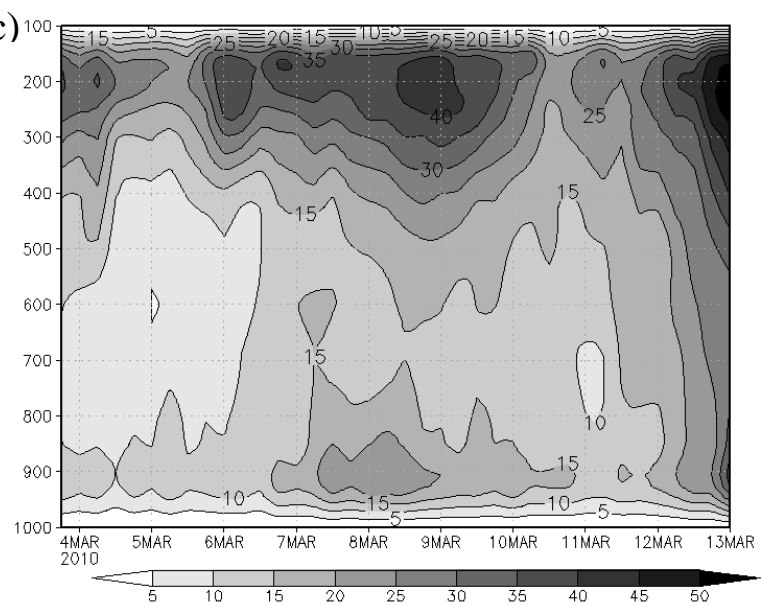

(b)

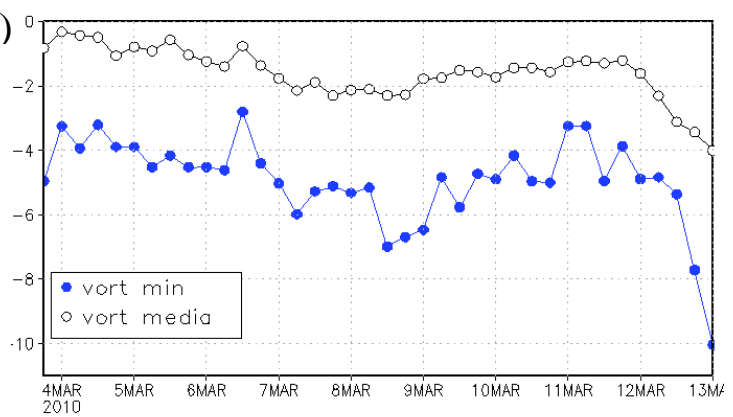

(d)

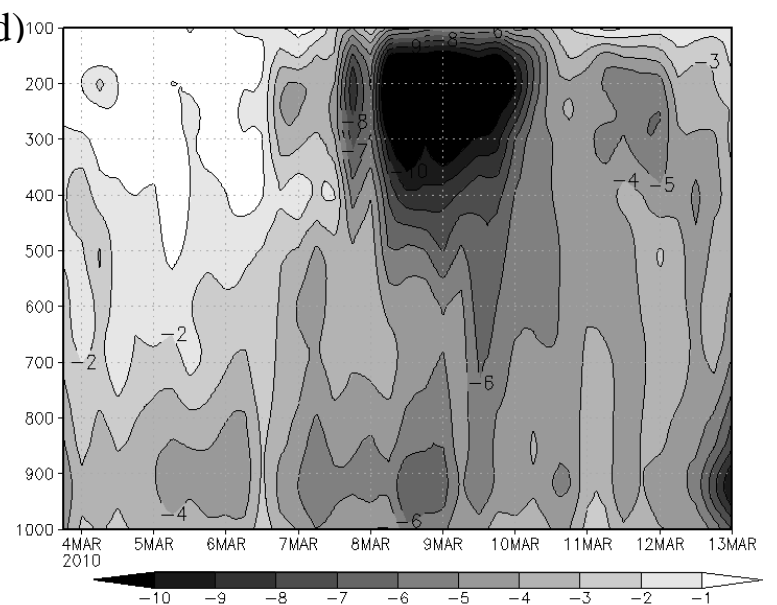

Fig. 5.2. (a) Intensidade média e máxima do vento em $925 \mathrm{hPa}\left(\mathrm{m} \mathrm{s}^{-1}\right)$, (b) VR média e mínima em $925 \mathrm{hPa}\left(10^{-5} \mathrm{~s}^{-1}\right)$ e perfil vertical (c) do vento máximo $\left(\mathrm{m} \mathrm{s}^{-1}\right)$ e (d) da VR mínima $\left(10^{-5} \mathrm{~s}^{-1}\right)$ na região de atuação do ciclone de março de 2010. A análise foi feita com os dados do NCEP e considerando os pontos de grade dentro de uma caixa de $10^{\circ} \times 10^{\circ}$ centrada no ciclone em superfície.

A trajetória do ciclone de março de 2010 foi bastante rara para a região, e assim o sistema passou a despertar o interesse inclusive de centros meteorológicos internacionais. Isto ocorreu pois alguns modelos numéricos de previsão do tempo indicavam que o ciclone se deslocaria atipicamente para sul nos próximos dias, podendo adquirir características de subtropical ou tropical. A comunidade meteorológica tornou-se ansiosa para observar se este sistema iria evoluir como o ciclone Catarina, ocorrido em março de 2004, que deslocou-se anomalamente para oeste em direção às regiões de baixo cisalhamento vertical do vento (McTAGGART-COWAN et al. 2006). O Catarina fez transição para tropical e foi o sistema 
de baixa pressão mais intenso e profundo observado até os dias de hoje próximo ao território brasileiro.

A Marinha dos Estados Unidos (United States Naval Research Laboratory - NRL) começou a monitorar o ciclone, designando-o como Invest 90Q. Segundo o glossário do National Hurricane Center (NHC), uma vez que um sistema recebeu esta designação, a coleta e processamento de dados especiais se iniciam em diversos sites governamentais e acadêmicos, incluindo o NRL. A letra no nome do Invest refere-se à região de localização do fenômeno (por exemplo, os eventos monitorados na base do oceano Atlântico Norte possuem a letra "L" em sua designação, enquanto que os do Pacífico Nordeste recebem a letra "E"). A letra "Q" foi utilizada pela primeira vez para este ciclone de 2010, referindo-se à região do oceano Atlântico Sul. O número no nome do Invest pode variar de 90 a 99, e é utilizado em seqüência e em ordem crescente a cada evento de cada região. O NHC também começou a monitorar o sistema, designando-o como Low SL90 ("SL" refere-se ao Atlântico Sul).

O ciclone recebeu destaque inclusive no site oficial da NASA (http://www.nasa.gov/). Segundo informações publicadas, no dia 10 às 14 UTC o Invest $90 Q$ localizava-se a uma distância aproximada de 180 milhas a leste de Porto Alegre, com ventos máximos sustentados próximos a 35 nós. Ressalta-se que ao pesquisar na internet sobre este ciclone, são encontradas diversas informações contraditórias, sendo que alguns sites afirmam que o sistema chegou a atingir a classificação de tempestade tropical. Entretanto, de acordo com informações obtidas por comunicação pessoal com o NRL, o NHC decidiu não classificar o Invest $90 Q$ como uma depressão ou tempestade tropical, pois o ciclone não atingiu a intensidade de vento ou estrutura necessária para ser classificado como tal.

Segundo a MetSul Meteorologia, instituição privada de Porto Alegre que realizou um acompanhamento detalhado do sistema em seu site (http://www.metsul.com/), alguns centros meteorológicos regionais e as empresas de Meteorologia do Rio Grande do Sul e Santa Catarina (Ciram/Epagri - Florianópolis/SC; Atmosfera Meteorologia - Pelotas/RS; Central RBS de Meteorologia - Porto Alegre/RS e Florianópolis/SC; Climaterra - São Joaquim/SC; Fundação de Apoio ao Desenvolvimento Rural - Florianópolis/SC), em uma decisão conjunta, nomearam o ciclone ocorrido de Anita. É importante ressaltar que a WMO não faz referência a nenhum centro meteorológico responsável pelo monitoramento de ciclones tropicais no Atlântico Sul, já que eventos desta natureza são pouco freqüentes na região. Assim sendo, o nome Anita não possui nenhum caráter oficial, e a decisão de utilizar este nome visa facilitar menções e discussões futuras. 
No estágio inicial (Fig. 5.3), existe uma isóbara fechada de 1012,0 hPa próxima à costa da Bahia e Espírito Santo, que se refere ao ciclone de março de 2010. Associado a este sistema, nota-se um cavado invertido raso com eixo orientado na direção sudoeste-nordeste, se estendendo até a costa do Rio de Janeiro. A sudeste do Anita atua outro ciclone, mais a leste no Atlântico, cujo eixo se estende na direção noroeste-sudeste, enquanto que ao sul há um anticiclone com 1028,0 $\mathrm{hPa}$, centrado em aproximadamente $40,0^{\circ} \mathrm{S}$ e $42,5^{\circ} \mathrm{W}$. Em altos níveis, nota-se um cavado de onda curta e raso sobre a região do Rio de Janeiro e do Espírito Santo. Neste dia, já se observa nebulosidade associada ao ciclone subtropical nas costas da Bahia e do Espírito Santo. Em latitudes mais altas $\left(\sim 40,0^{\circ} \mathrm{S}\right)$, tem-se outro ciclone na costa nordeste da Argentina e fechado desde a superfície até níveis médios da atmosfera. Em 500 hPa, o ciclone é aparente através do contorno fechado de altura geopotencial. Nota-se ainda a nebulosidade associada ao ciclone frontal que atua sobre a costa da Argentina.
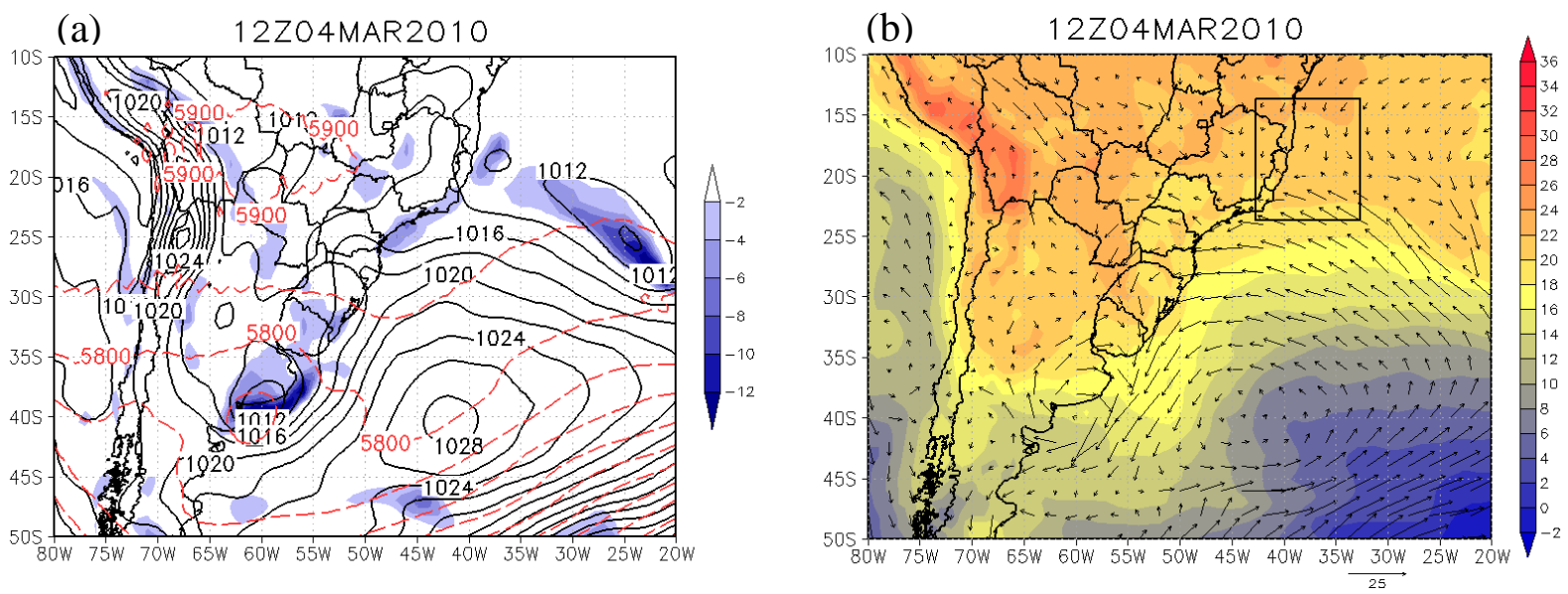

(d)
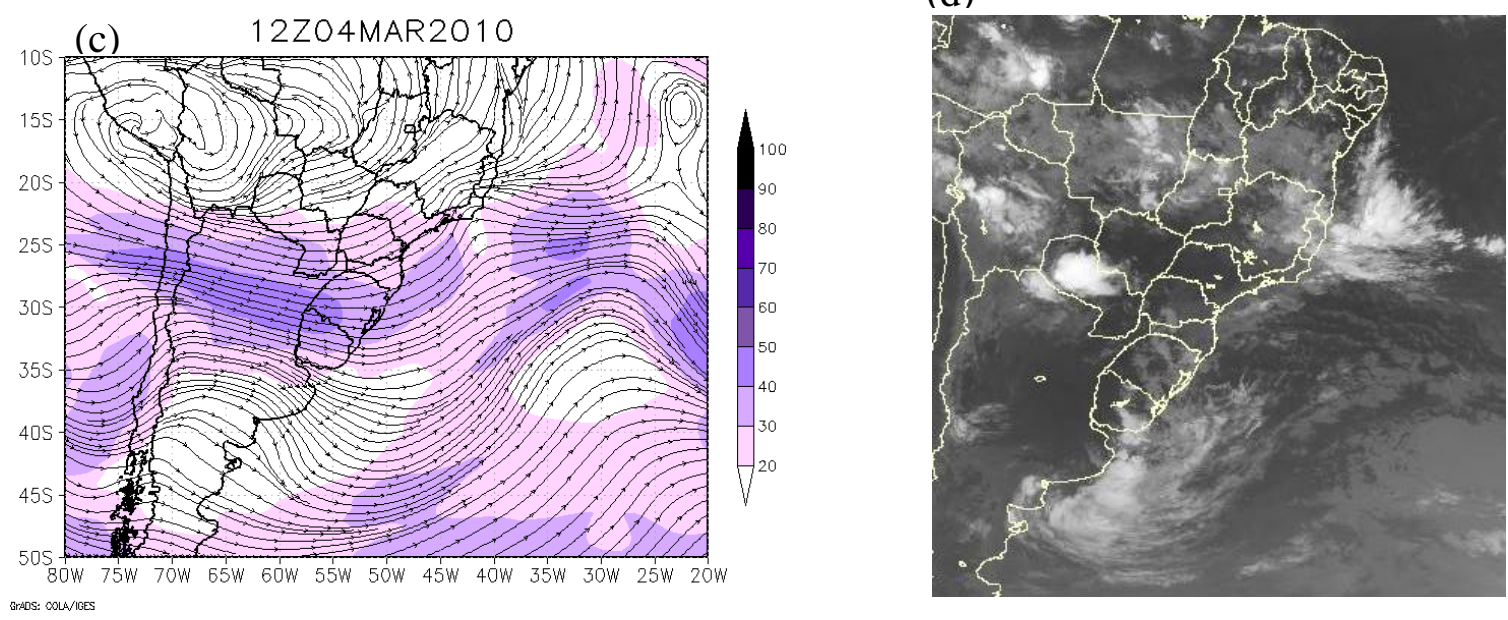

Fig. 5.3. 12 UTC do dia 04/03/2010 (início): (a) PNMM (hPa, linha preta), altura geopotencial em $500 \mathrm{hPa}$ (metros geopotencial, pontilhado vermelho) e VR em $925 \mathrm{hPa}\left(10^{-5} \mathrm{~s}^{-1}\right.$, sombreado); (b) temperatura $\left({ }^{\circ} \mathrm{C}\right.$, sombreado) e vento horizontal $\left(\mathrm{m} \mathrm{s}^{-1}\right.$, vetor) em $925 \mathrm{hPa}$; (c) linhas de corrente e isotacas ( $\mathrm{m} \mathrm{s}^{-1}$, sombreado) em $200 \mathrm{hPa}$ e (d) imagem de satélite no canal do IR. 

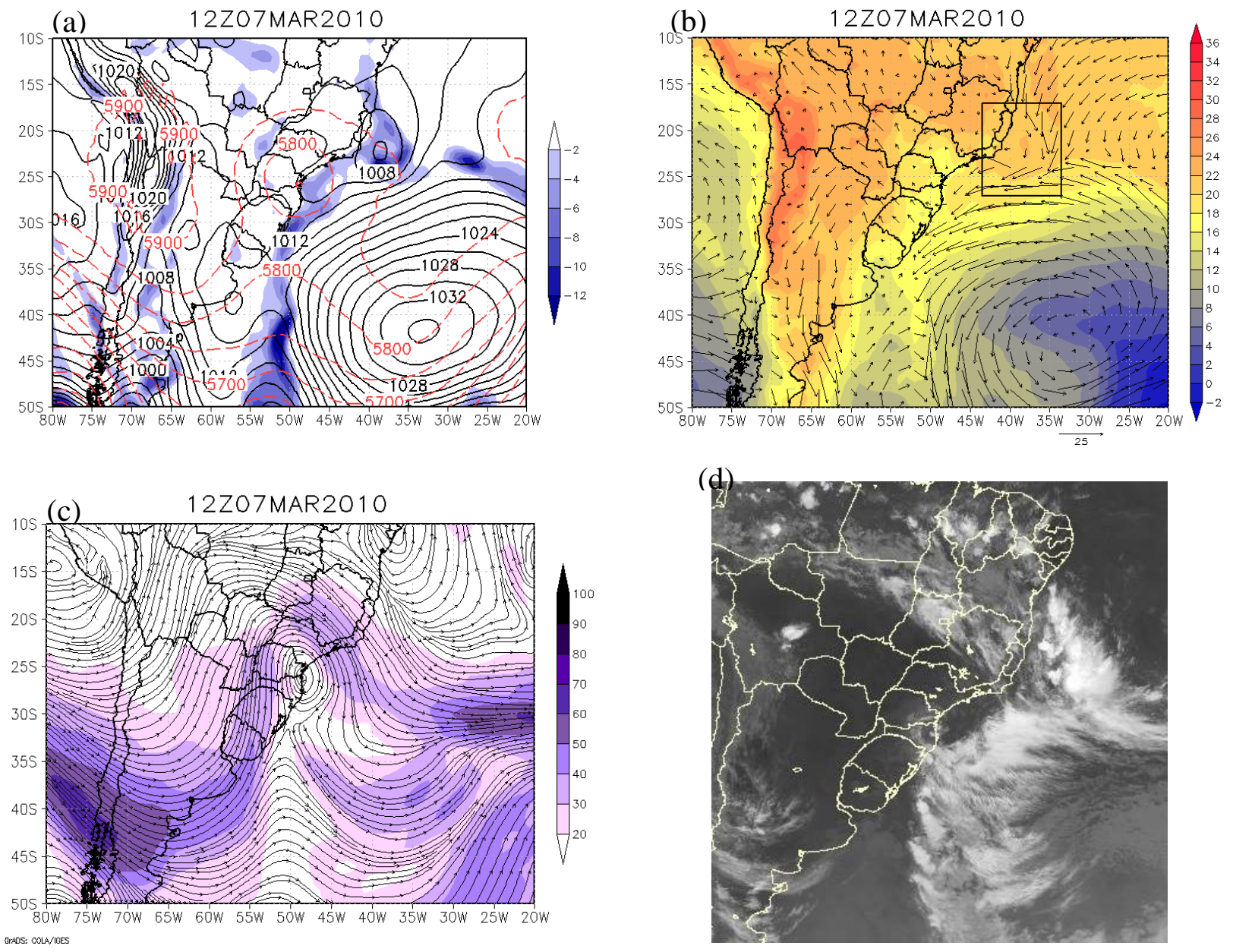

Fig. 5.4. Idem à Fig. 5.3, mas para o dia 07/03/2010 às 12 UTC (intensificação 1).

No horário da intensificação 1, (Fig. 5.4), o ciclone subtropical em superfície apresenta significativa intensificação, chegando a 1006,0 hPa, e seu núcleo se desloca para sudoeste. Um cavado invertido associado ao ciclone se estende para sudoeste, próximo à costa entre São Paulo e Paraná. Existe um núcleo aproximadamente circular de temperaturas mais quentes em $925 \mathrm{hPa}$ sobre a região de circulação ciclônica. Em $500 \mathrm{hPa}$, forma-se uma baixa desprendida, próximo de $25,0^{\circ} \mathrm{S}$ e $50,0^{\circ} \mathrm{W}$, à sudoeste do distúrbio subtropical em superfície. Em 200 hPa nota-se a configuração de um VCAN, praticamente acima da baixa desprendida em níveis médios. Com esta estrutura vertical da atmosfera, existe suporte dinâmico para a intensificação do ciclone em superfície, pois a região a leste do cavado em níveis médios favorece a convergência de massa em superfície, gerando movimentos ascendentes. Durante a intensificação 1, observa-se uma extensa faixa de nebulosidade sobre grande parte do Atlântico Oeste. Este padrão de nebulosidade é organizado, em parte, pelo ciclone extratropical da Argentina, que se deslocou para sudeste e cuja frente fria orienta-se na 
direção norte-sul em latitudes mais altas no oceano. Ressalta-se que, neste estágio, o Anita possui duas regiões de cavado em superfície: uma ao norte do núcleo de baixa, alongada sobre a costa da Bahia; e outra a sudoeste, até a região sul do Brasil.
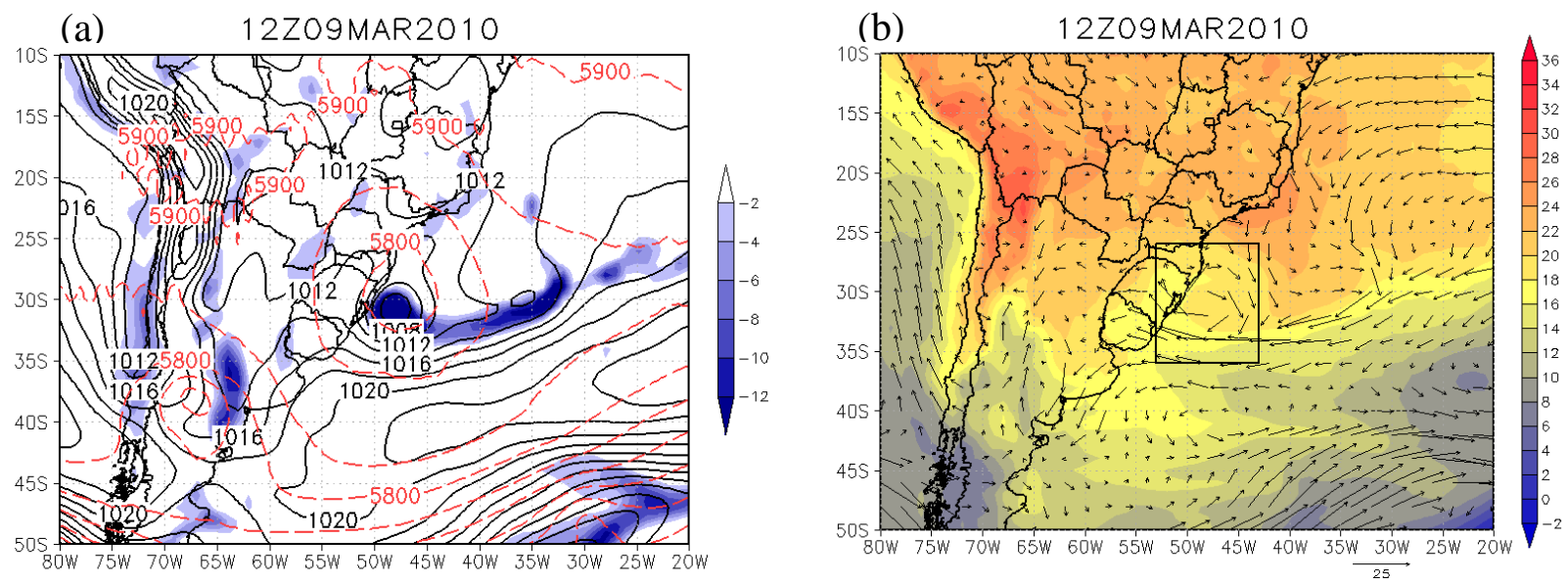

(d)
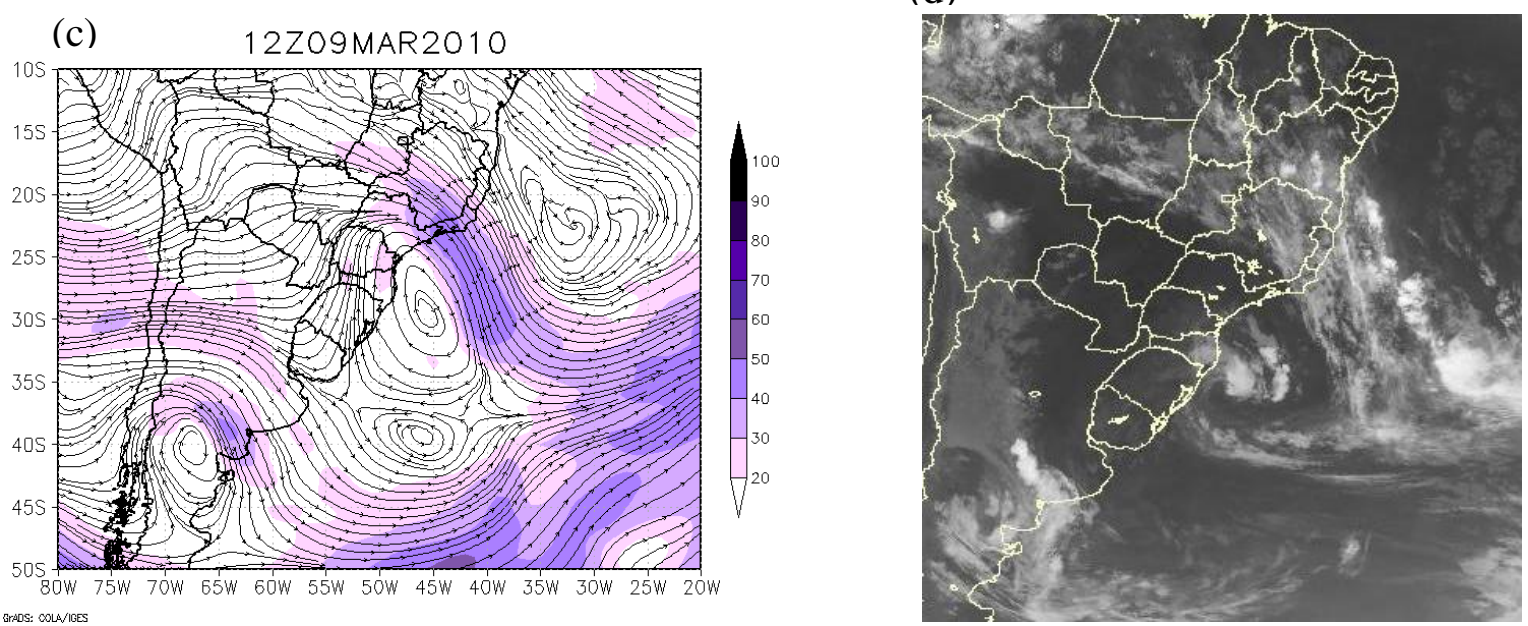

Fig. 5.5. Idem à Fig. 5.3, mas para o dia 09/03/2010 às 12 UTC (maduro).

Após 24 horas, no estágio maduro (Fig. 5.5), o ciclone subtropical se desloca rapidamente para sudoeste, posicionando-se a leste de Santa Catarina e Rio Grande do Sul, com pressão central de 1005,0 hPa. Verifica-se que, neste estágio, apesar de o ciclone estar posicionado sobre uma região circular de temperaturas quentes, a região a nordeste do ciclone, onde ele estava previamente posicionado, apresenta temperaturas mais elevadas. Em $850 \mathrm{hPa}$, há um núcleo com UR maior que $80 \%$ aproximadamente circular sobre toda a região do sistema (figura não mostrada). Em níveis médios, a baixa desprendida se desloca para sudeste, assim como o VCAN em $200 \mathrm{hPa}$. Assim, em níveis médios e altos, com as baixas desprendidas posicionadas sobre o ciclone em superfície, caracteriza-se o estágio barotrópico equivalente do sistema. Nesta fase, a nebulosidade na região do ciclone subtropical adquire 
aspecto de espiral, de forma semelhante ao que se observa nos ciclones extratropicais. Verifica-se ainda uma faixa de nebulosidade orientada na direção noroeste-sudeste, localizada a leste do VCAN em 200 hPa, onde o escoamento em altos níveis é bastante intenso.

No estágio de enfraquecimento (Fig. 5.6), o centro do ciclone subtropical em superfície se desloca lentamente para oeste, e sua pressão central aumenta para 1007,0 hPa. O núcleo desprendido que estava imerso no eixo do Anita se desacopla completamente e dá origem a um novo sistema ciclônico, que rapidamente se desloca para leste. Existe ainda a organização de um sistema ciclônico extratropical mais ao sul, na costa leste da Argentina, por volta de $40,0^{\circ} \mathrm{S}$ e $60,0^{\circ} \mathrm{W}$, e cuja frente se estende até o sul do Uruguai. Em $500 \mathrm{hPa}$, a baixa desprendida associada ao Anita ainda atua, mas começa a enfraquecer. Em $200 \mathrm{hPa}$, o VCAN se desloca para leste e também perde a intensidade, enquanto o cavado ao norte perde amplitude, comparado com o estágio anterior. A nebulosidade associada ao ciclone subtropical ainda ocupa uma grande área aproximadamente circular do oceano.

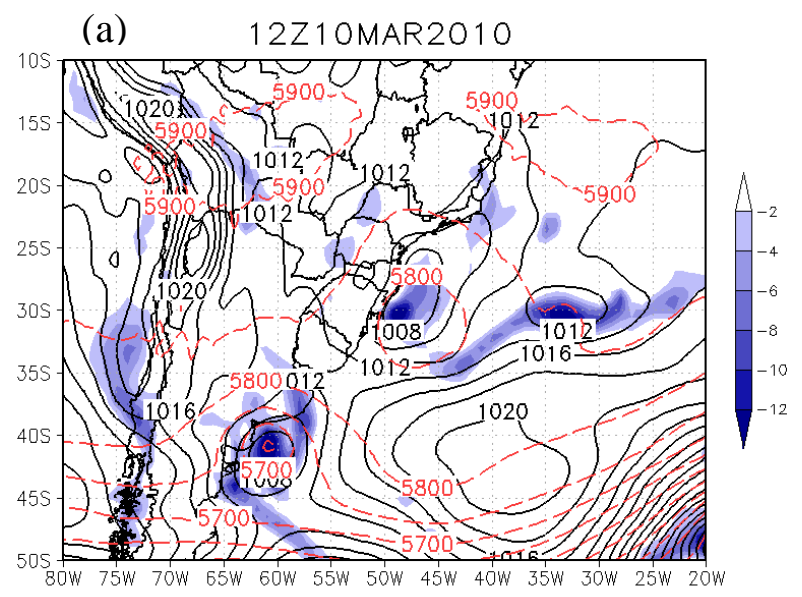

(c)

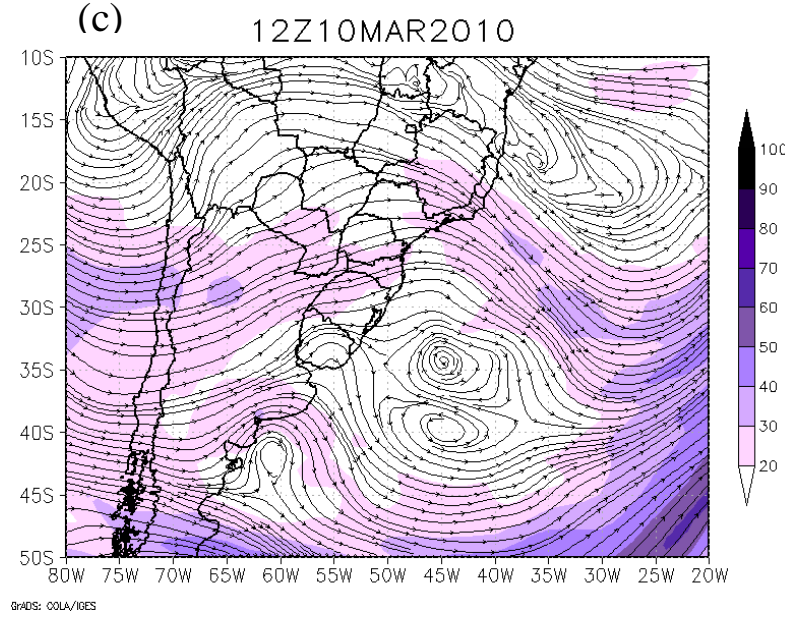

(b)

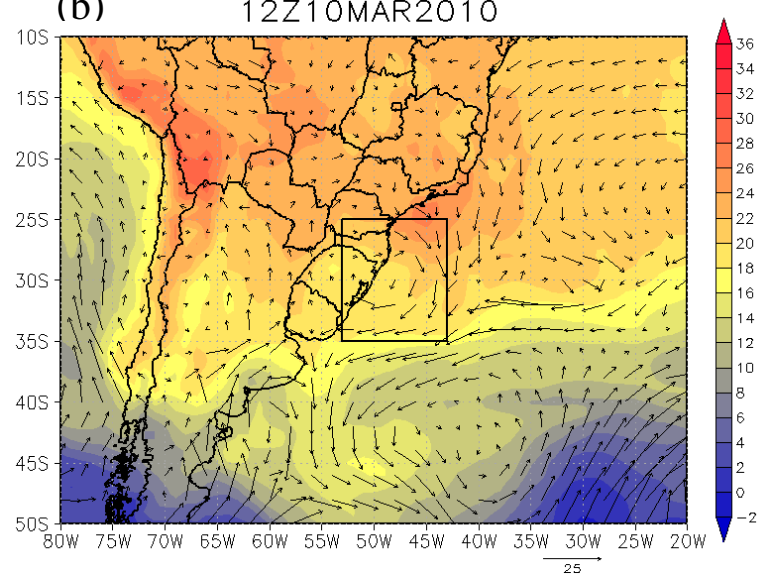

(d)

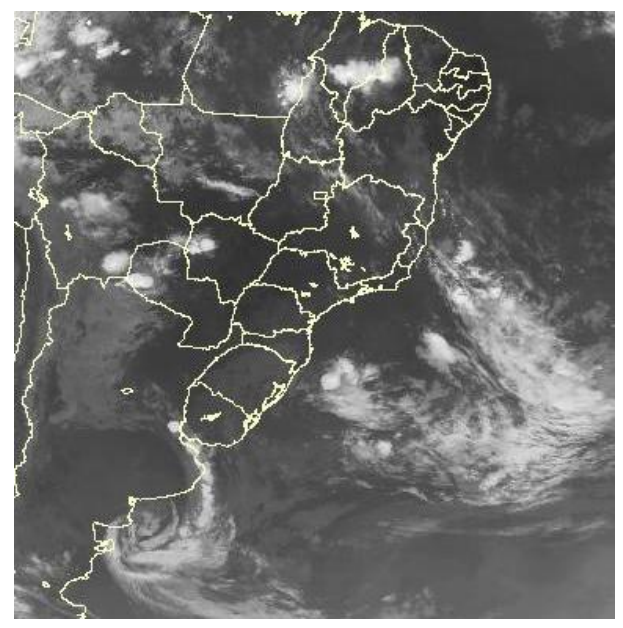

Fig. 5.6. Idem à Fig. 5.3, mas para o dia 10/03/2010 às 12 UTC (enfraquecimento). 
No estágio de intensificação 2 (Fig. 5.7), o centro do Anita enfim apresenta deslocamento para leste. Nota-se inclusive uma tendência de acoplamento com o ciclone extratropical da Argentina, embora ainda existam duas circulações ciclônicas distintas em baixos níveis. Neste dia, a baixa desprendida em 500 hPa está desconfigurada, bem como o VCAN em $200 \mathrm{hPa}$, restando apenas cavados na região. Quanto à nebulosidade, observam-se duas bandas distintas: uma mais ao sul, associada ao ciclone frontal na Argentina; e outra mais ao norte, ainda com características em espiral, associada ao Anita.

(a)

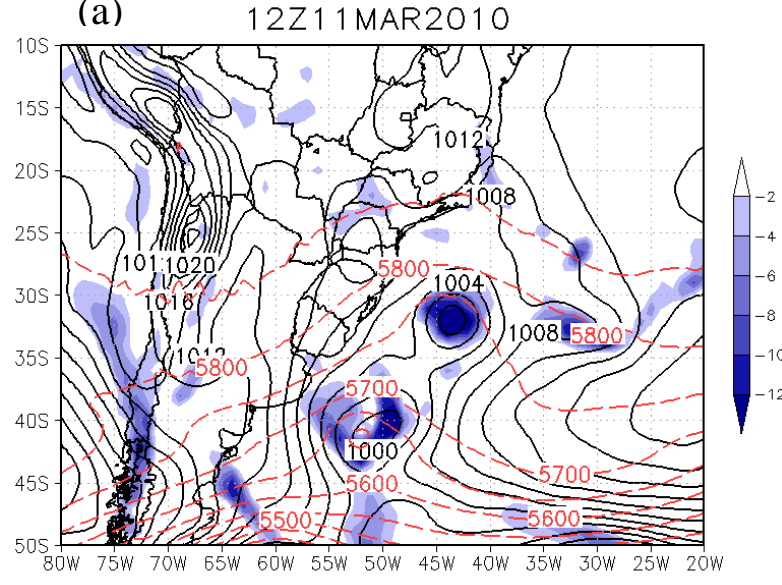

(c)

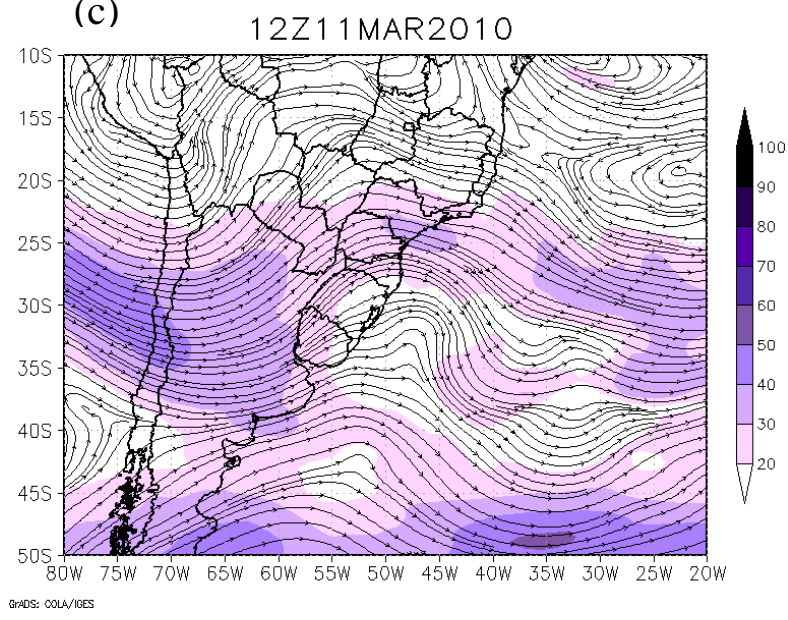

(b)

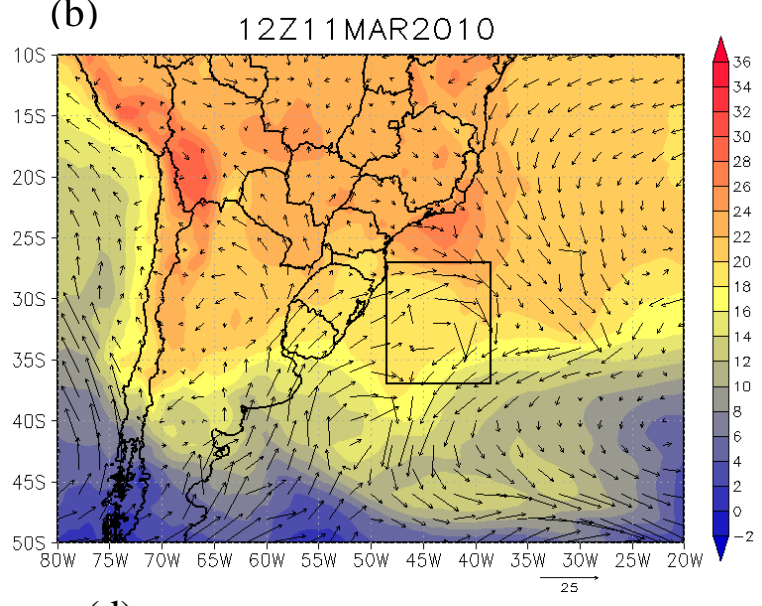

(d)

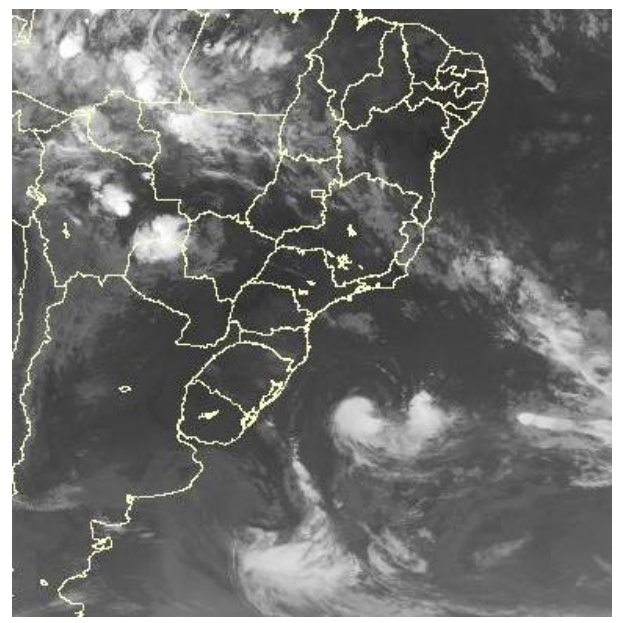

Fig. 5.7. Idem à Fig. 5.3, mas para o dia 11/03/2010 às 12 UTC (intensificação 2).

Passadas mais 24 horas, às 12 UTC do dia 12 (figuras não mostradas), o Anita se mescla completamente com o ciclone extratropical, e passa a se deslocar rapidamente para leste e em direção a latitudes mais altas, posicionando-se em aproximadamente $37,5^{\circ} \mathrm{S}$ e $37,0^{\circ} \mathrm{W}$. Nesta fase, o sistema, que era inicialmente subtropical, fez transição para extratropical, apresentando significativa intensificação em termos de pressão central, chegando a 991,0 hPa (Fig. 5.1). Contudo, seu núcleo já está completamente sobre o 
Atlântico, não afetando mais diretamente a região costeira brasileira. Em $850 \mathrm{hPa}$, existe uma grande circulação ciclônica associada, e em $500 \mathrm{hPa}$ existe um cavado raso com eixo inclinado para leste sobre o núcleo do ciclone em superfície.

A Fig. 5.8 mostra algumas imagens de satélite ampliadas na região do sistema. Estas imagens foram obtidas por comunicação pessoal com o grupo responsável pelos produtos relacionados aos ciclones tropicais do NRL. Esta figura ilustra desde um período anterior ao estágio maduro, até pouco depois do estágio de intensificação 2. Verifica-se que o aspecto em espiral das bandas de nebulosidade se inicia conforme o ciclone atinge o estágio maduro, sendo que existe uma faixa de nebulosidade sobre toda a região costeira do Rio Grande do Sul neste período (Fig. 5.8a e b). No dia do estágio de enfraquecimento, parte da nebulosidade associada ao ciclone se dissipa no setor oeste do sistema e sobre o continente, embora ainda exista bastante nuvens convectivas sobre a posição central do sistema em superfície (Fig. 5.8c). Por fim, na intensificação 2 , a extensão de nebulosidade do sistema aumenta e adquire novamente aspecto espiral (Fig. 5.8d)

(a)

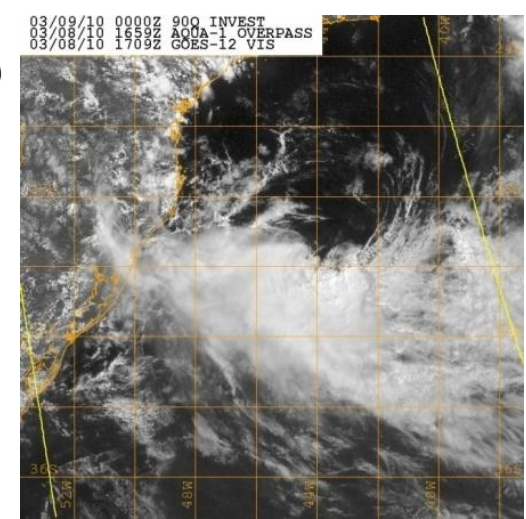

(c)

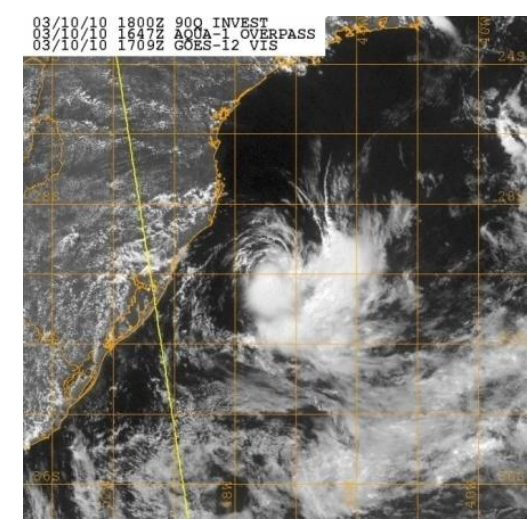

(b)

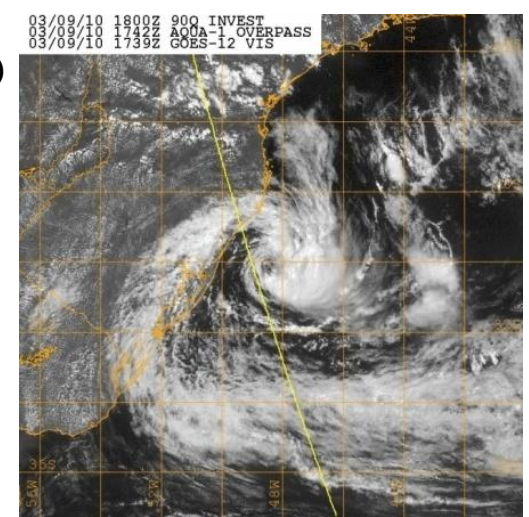

(d)

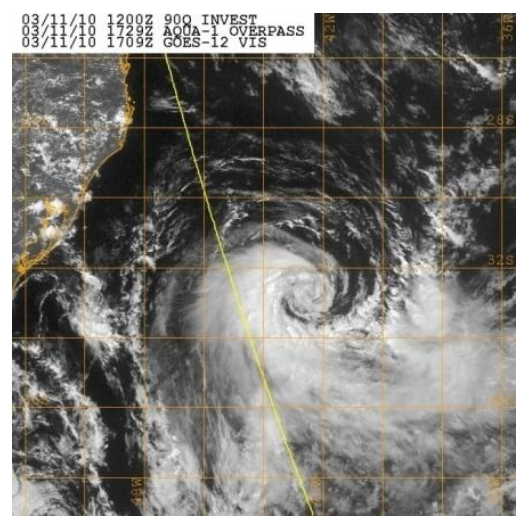

Fig. 5.8. Imagens de satélite no canal do visível sobre a região de atuação do ciclone, às (a) 17:09 UTC do dia 08, (b) 17:39 UTC do dia 09, (c) 17:09 UTC do dia 10 e (d) 17:09 UTC do dia 11. Fonte: comunicação pessoal com o grupo NRL. 

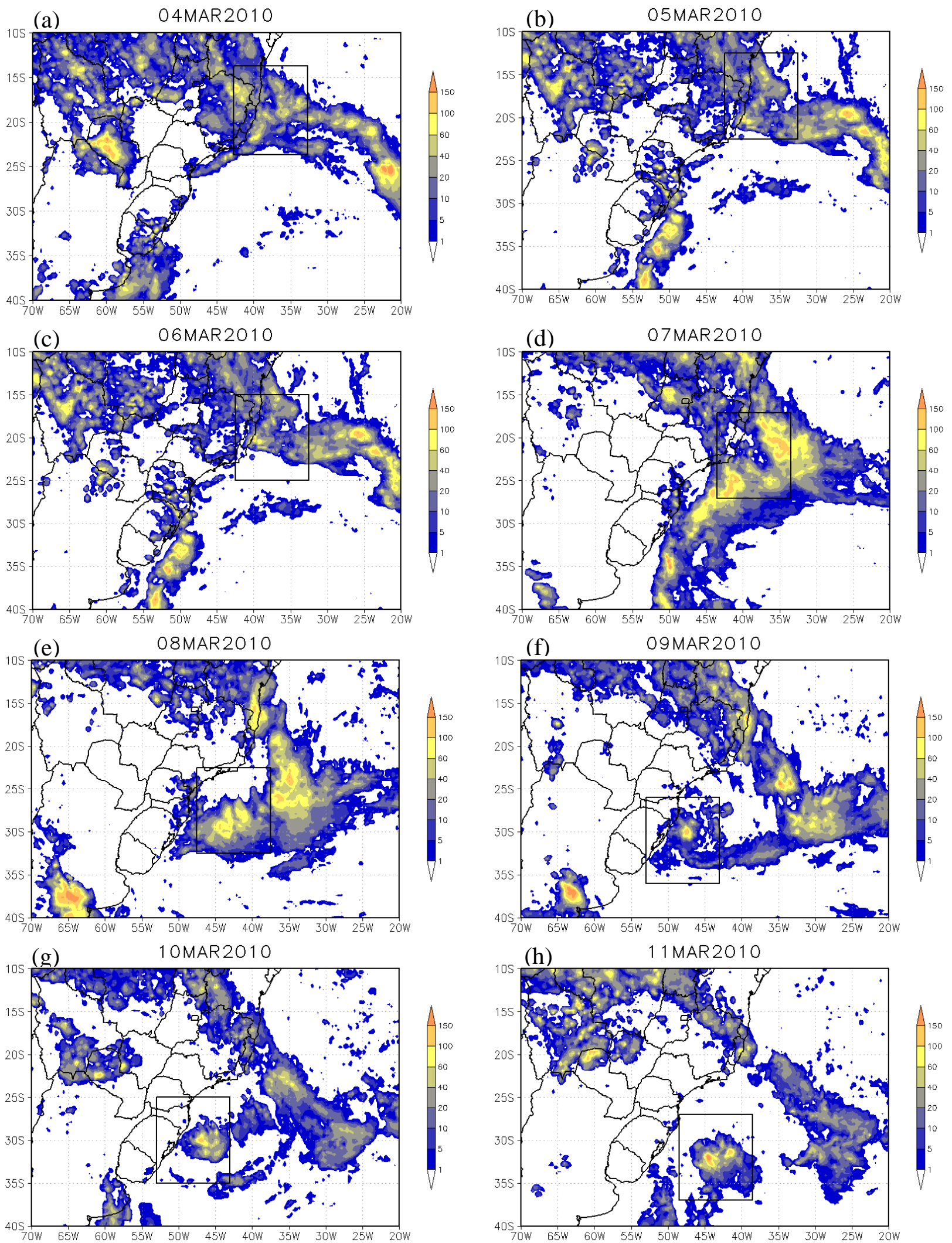

Fig. 5.9. Precipitação acumulada diária $\left(\mathrm{mm} \mathrm{dia}^{-1}\right)$ para cada dia de atuação do ciclone de março de 2010: dia (a) 04 (início), (b) 05, (c) 06, (d) 07 (intensificação 1), (e) 08, (f) 09 (maduro), (g) 10 (enfraquecimento) e (h) 11 (intensificação 2). A caixa de $10^{\circ} \times 10^{\circ}$ em cada figura está centralizada no ciclone em superfície às 12 UTC de cada dia. 
A Fig. 5.9 apresenta os campos de precipitação acumulada diária em parte do oceano Atlântico Sul Oeste e parte da América do Sul para cada dia de atuação do ciclone Anita. Nesta figura, as retas na cor preta demarcam a caixa de $10^{\circ}$ de latitude por $10^{\circ}$ de longitude centralizada no ciclone em superfície às 12 UTC de cada dia. Quanto à distribuição espacial qualitativa da chuva, tem-se que os campos de acumulado de precipitação estão de acordo com a nebulosidade observada nas imagens de satélite (Figs. 5.3d, 5.4d, 5.5d, 5.6d e 5.7d). Observa-se que, desde o dia 04 até o dia 07 (Figs 5.9a-d), a precipitação acumulada na região do ciclone não apresenta um padrão circular bem definido como ocorre nos próximos dias, de 08 a 11 de março (Figs 5.9e-h). Em todos os dias, tanto sobre o oceano quanto sobre o continente, existem intensos acumulados de chuva associados ao ciclone e as suas regiões de cavado em superfície.

A distribuição de temperatura em altos níveis no tempo do estágio de início (Fig. 5.10a) mostra um núcleo quente centrado sobre o sudoeste do Uruguai, ao norte do ciclone extratropical da Argentina que se estende fechado desde a superfície até níveis médios da atmosfera (Fig. 5.3a). Um outro núcleo de temperatura mais elevada também existe na região da costa de São Paulo, aonde posteriormente se desenvolve um extenso cavado em níveis altos e médios que se intensificam resultando na configuração de um VCAN e de um sistema fechado em 500 hPa (Figs. 5.4a e c). De acordo com Hirschberg e Fritsch (1991), na região de ondulação da tropopausa, a temperatura do ar em $200 \mathrm{hPa}$ é anomalamente mais quente e os gradientes de temperatura são intensos (IWABE, 2008).

No dia da intensificação (Fig. 5.10b), um núcleo de temperatura mais elevada em 200 hPa existe sobre a mesma região do VCAN posicionado próximo à costa do Paraná e Santa Catarina. No estágio maduro (Fig. 5.10c) uma extensa parte da atmosfera em altos níveis no oceano Atlântico Sul Subtropical parece estar relativamente mais aquecida, sendo que isotermas com temperaturas mais elevadas se estendem de latitudes mais baixas para sul. $\mathrm{Na}$ caixa de $10^{\circ}$ de latitude por $10^{\circ}$ de longitude centrada no ciclone em superfície, a parte a leste está mais aquecida que a parte a oeste. No dia 10, durante o estágio de enfraquecimento (Fig. 5.10d), toda a região sobre o ciclone em superfície apresenta temperaturas mais altas em altos níveis, sendo que tanto a oeste quanto a leste da caixa de $10^{\circ}$ por $10^{\circ}$ as temperaturas são relativamente mais frias. Neste dia, o núcleo quente de temperatura em $200 \mathrm{hPa}$ está posicionado por volta de $33,0^{\circ} \mathrm{S}$ e $45,0^{\circ} \mathrm{W}$, a sudeste da posição central do ciclone em superfície. Por fim, no tempo do estágio de intensificação 2 (Fig. 5.10e), temperaturas mais (menos) elevadas em altos níveis ocorrem ao norte (sul) do ciclone em superfície. 

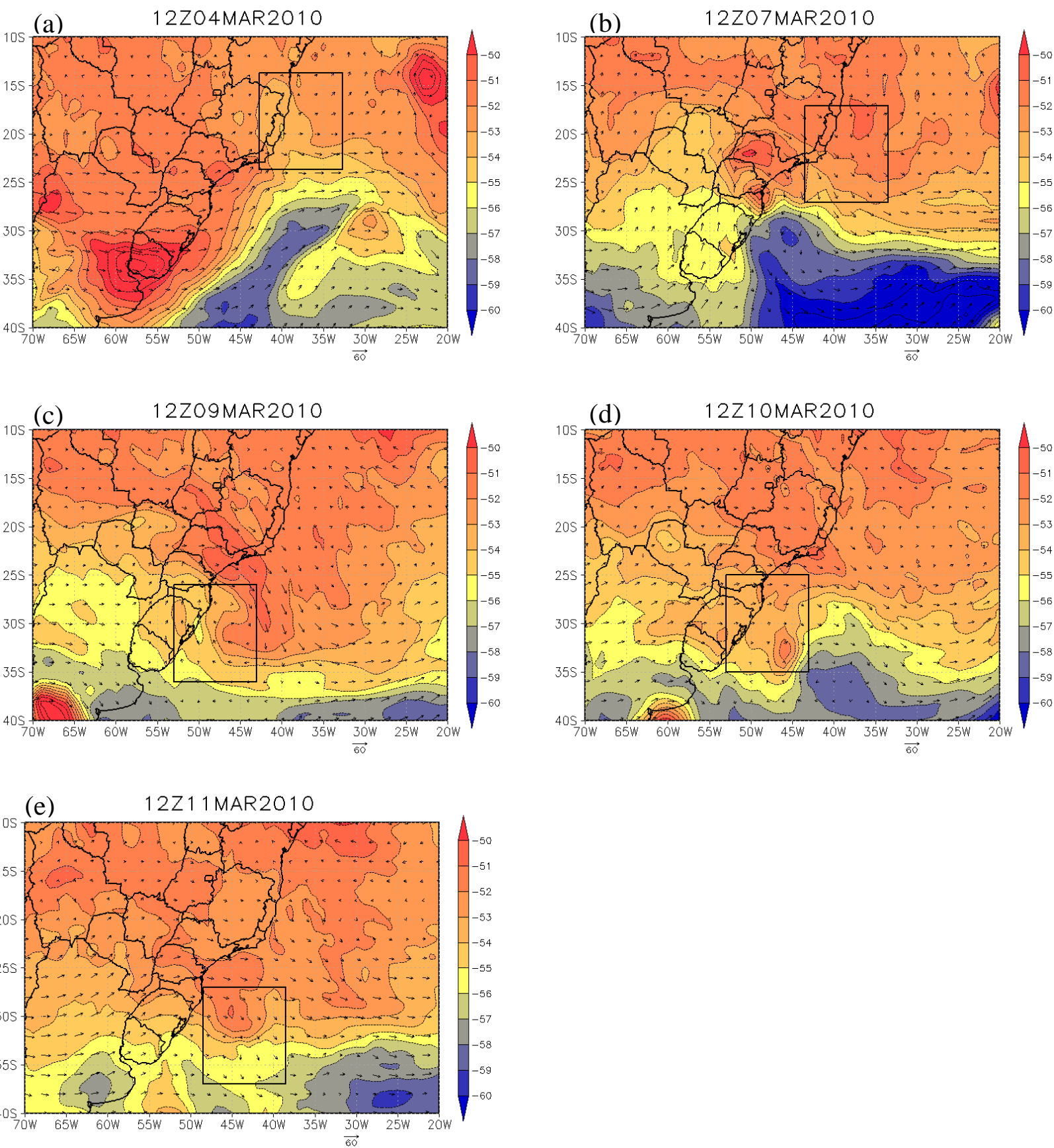

Fig. 5.10. Temperatura $\left({ }^{\circ} \mathrm{C}\right.$, sombreado) e vento $\left(\mathrm{m} \mathrm{s}^{-1}\right)$ em $200 \mathrm{hPa}$, para às 12 UTC do dia (a) 04 (início), (b) 07 (intensificação 1), (c) 09 (maduro), (d) 10 (enfraquecimento) e (e) 11 (intensificação 2) de março de 2010. 


\subsection{Descrição espacial dos termos}

\section{a. Balanço de calor}

Analisando a distribuição espacial em $925 \mathrm{hPa}$, tem-se que especificamente em ambos os estágios de intensificação (Figs. 5.11b e 5.11e), é possível verificar em algumas regiões próximas à área de atuação do ciclone uma forte associação entre o termo diabático e a advecção horizontal de temperatura, de modo que regiões de advecção quente (fria) correspondem às regiões de contribuição negativa (positiva) do termo diabático. Nos estágios inicial e de intensificação 1 (Figs. 5.11a e 5.11b), a advecção horizontal de temperatura fria ao sul do ciclone em superfície é uma resposta à atuação do anticiclone que atuava na região. Entretanto, destaca-se que na intensificação 1 existe um núcleo de advecção quente próximo à costa de SP, para onde o ciclone se desloca posteriormente. No estágio maduro (Fig. 5.11c), o setor sudeste do ciclone apresenta intensos valores de advecção quente, enquanto que no setor sudoeste ocorre advecção fria. Esta configuração mostra o transporte de ar mais quente (frio) de latitudes mais baixas (altas) para as latitudes mais altas (baixas), promovidos pela circulação ciclônica.

Lembrando que valores negativos do termo $\mathrm{Sw}$ representam o resfriamento através do processo de expansão adiabática, nota-se que, na intensificação 1 , o resfriamento produzido pelos movimentos ascendentes em toda a região da costa do Brasil é visível inclusive em 925 $\mathrm{hPa}($ Fig. 5.11b).

Comparando-se as imagens de satélite (Figs. 5.3d, 5.4d, 5.5d, 5.6d e 5.7d) com os campos do termo diabático da equação da termodinâmica em 500 hPa (Fig. 5.12), é possível observar uma relação entre as regiões de nebulosidade associadas ao ciclone e as regiões de contribuição positiva para a tendência de temperatura do termo diabático. Esta relação é melhor observada especialmente no estágio de intensificação 1 (Fig. 5.12d), onde existe uma extensa área de aquecimento devido ao resíduo da termodinâmica orientada na direção sudoeste-nordeste, da mesma forma que o padrão de cobertura de nuvens. Isto indica o aquecimento da atmosfera através da liberação de energia pela condensação do vapor d’água, processo esse diretamente associado à convecção.

É importante ressaltar que em médios e altos níveis (Figs. 5.12 e 5.13) o termo diabático da equação do calor atua claramente de forma oposta ao termo $\mathrm{Sw}$, ou seja, ele age para destruir as variações de temperatura causadas pelos processos adiabáticos e de advecção vertical de temperatura. Entretanto, em baixos níveis esta relação não ocorre, o que significa que o termo $\mathrm{Sw}$ não é o principal responsável pelo comportamento do termo residual da 
equação da termodinâmica. Especificamente em ambos os estágios de intensificação, é possível verificar em algumas regiões próximas à área de atuação do ciclone uma forte associação entre o termo diabático e a advecção horizontal de temperatura, de modo que regiões de advecção quente (fria) correspondem às regiões de contribuição negativa (positiva) do termo diabático.

Em 500 hPa (Fig 5.12) também fica visível que a advecção horizontal de temperatura não é tão intensa como nos níveis inferiores (Fig 5.11). 
(a)
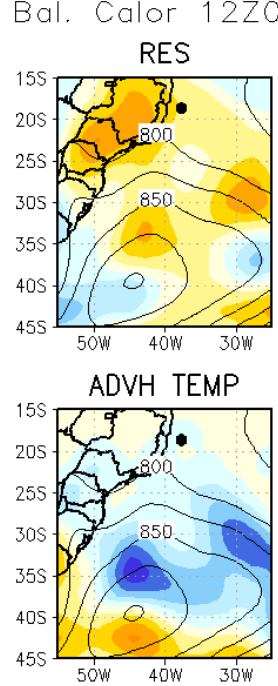

(c)
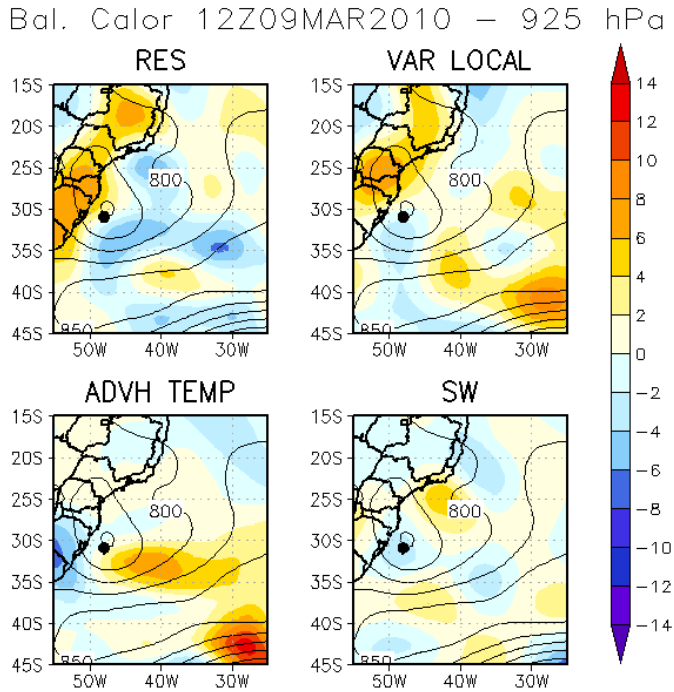
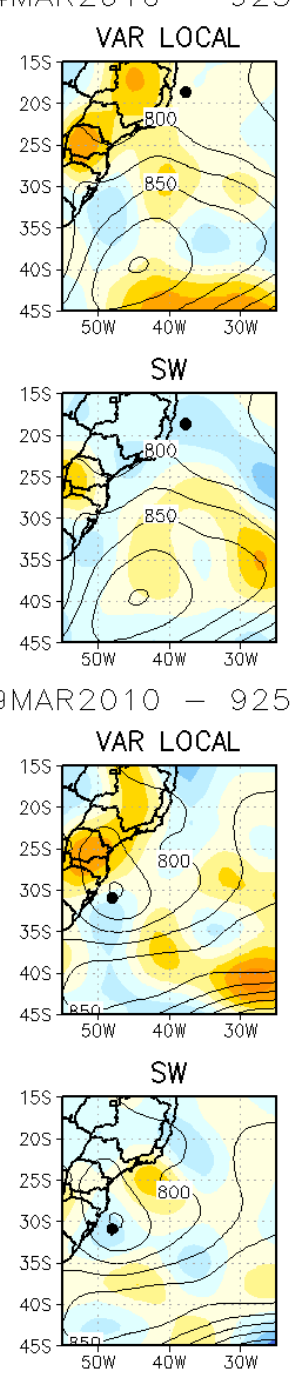

(b)
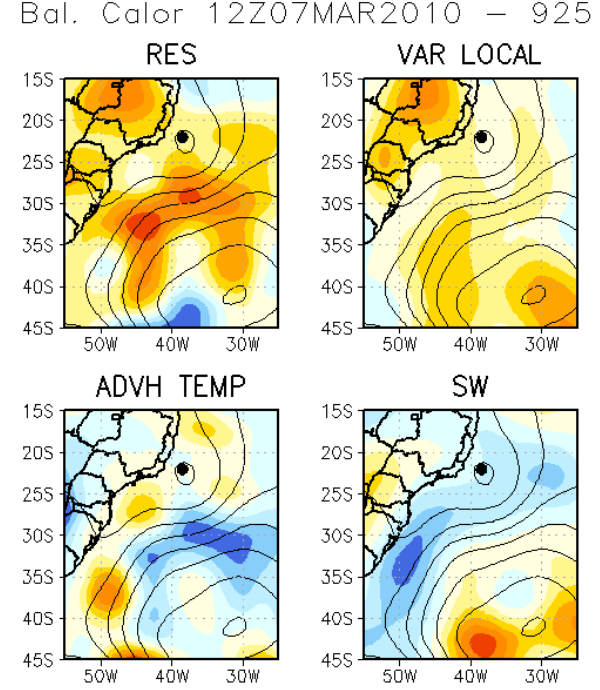

(d)
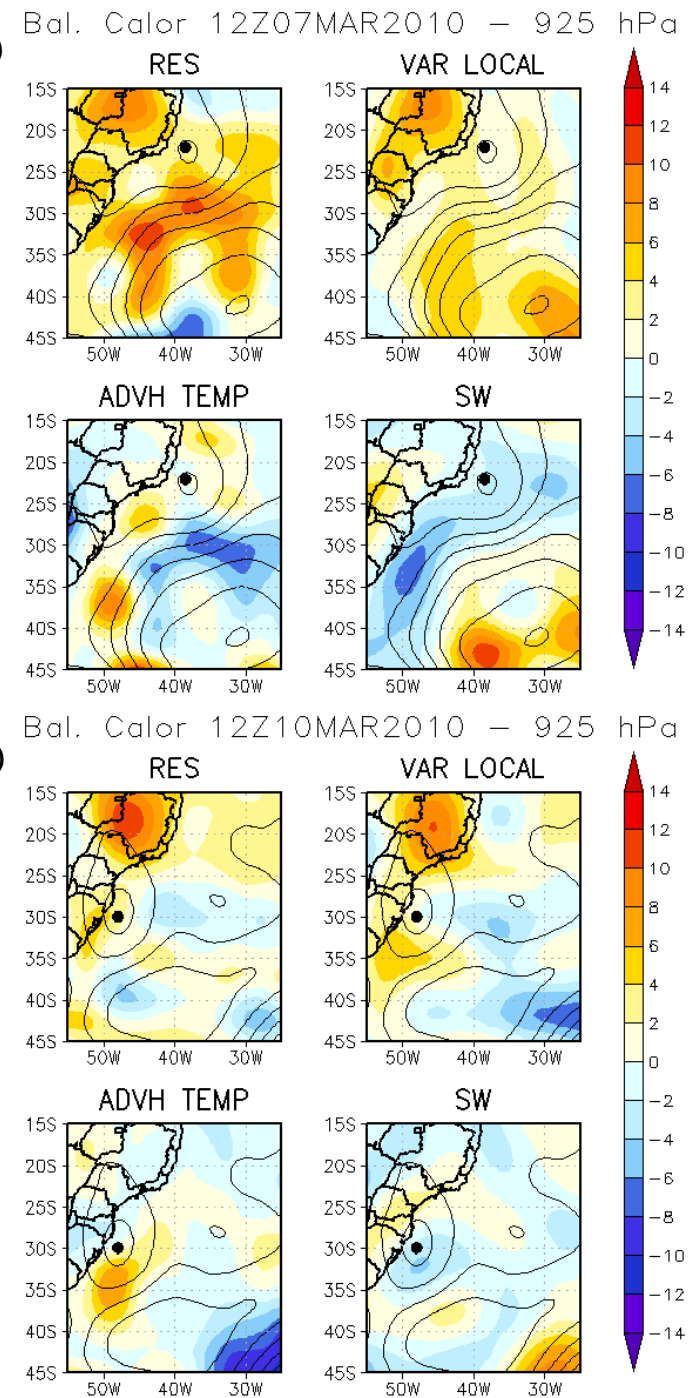

(e)
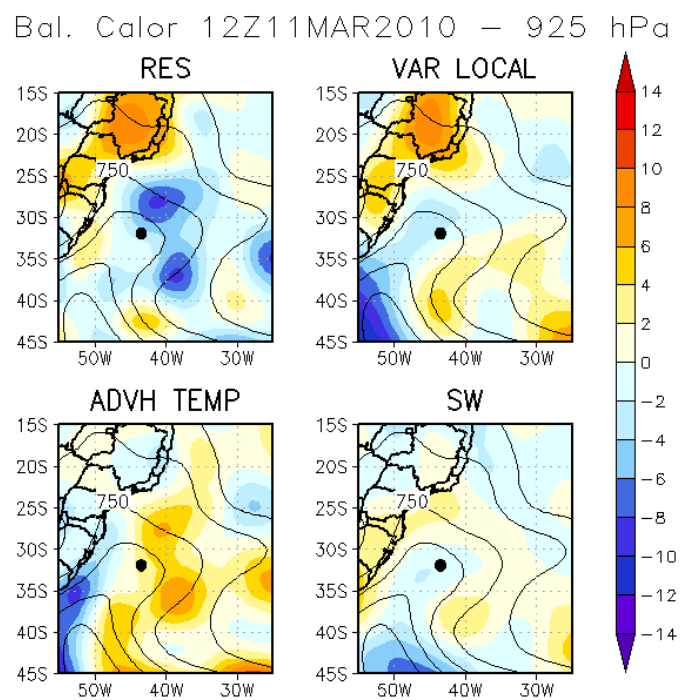

Fig. 5.11. Altura geopotencial (linhas contínuas, metros geopotencial) e termos do balanço de calor (sombreado; termo diabático, variação local, advecção horizontal e termo relacionado ao movimento vertical $\mathrm{Sw}, \mathrm{K} \mathrm{dia}^{-1}$ ) em $925 \mathrm{hPa}$ para às 12 UTC do dia (a) 04 (início), (b) 07 (intensificação 1), (c) 09 (maduro), (d) 10 (enfraquecimento) e (e) 11 (intensificação 2). 
(a) Bal. Calor 12Z04MAR2010 - $500 \mathrm{hPa}$
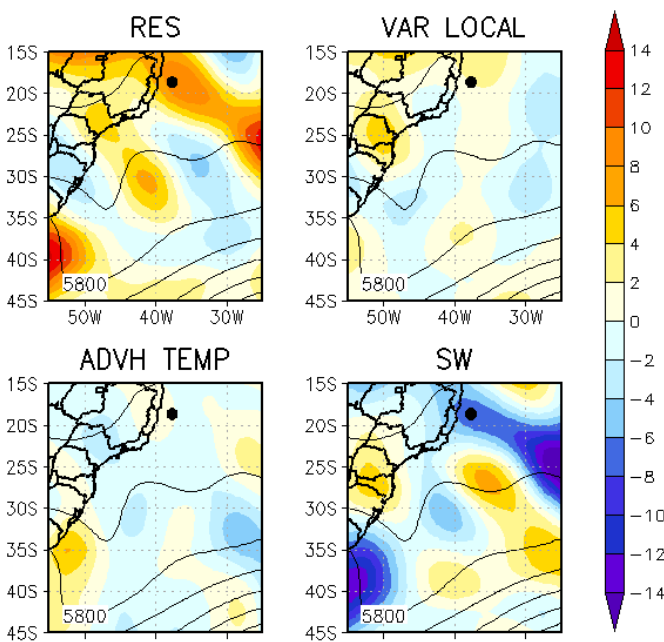

(c)
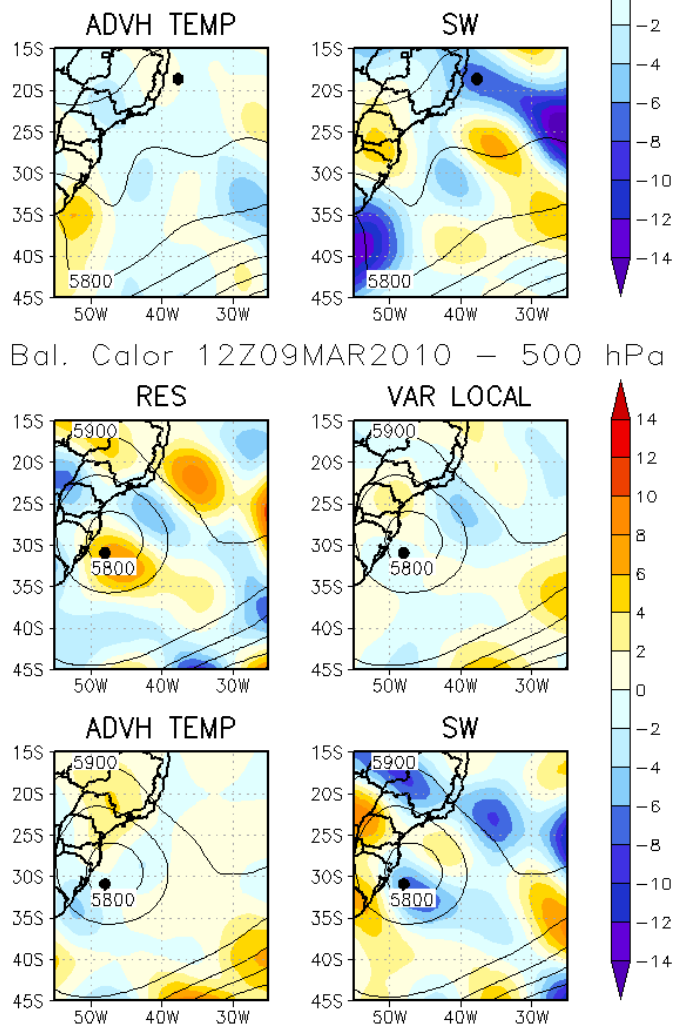

(e) Bal. Calor 12Z11MAR2010 - 500 hPa

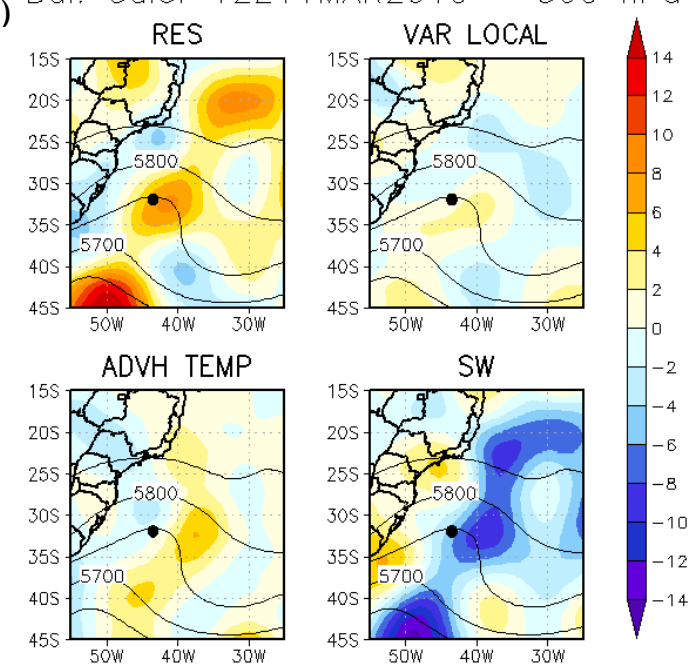

Fig. 5.12. Idem à Fig. 5.11, mas para $500 \mathrm{hPa}$. (b) Bal. Calor 12Z07MAR2010 - $500 \mathrm{hPa}$
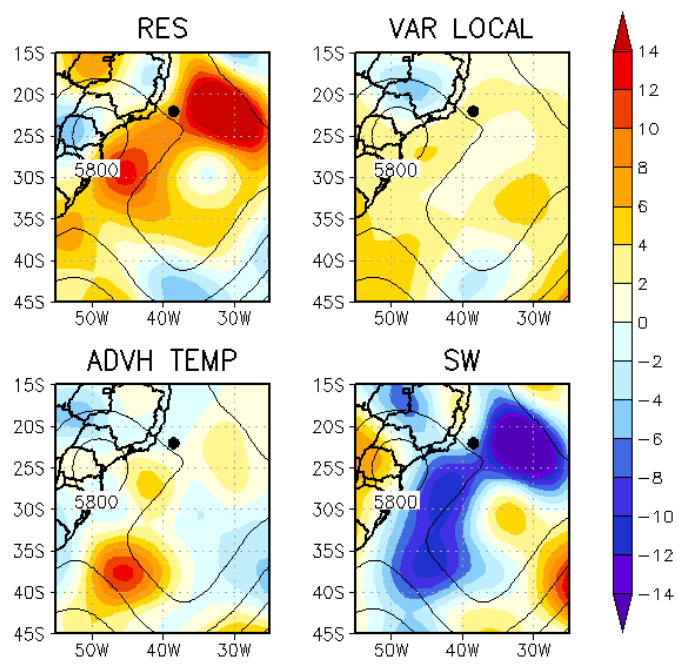

(d)
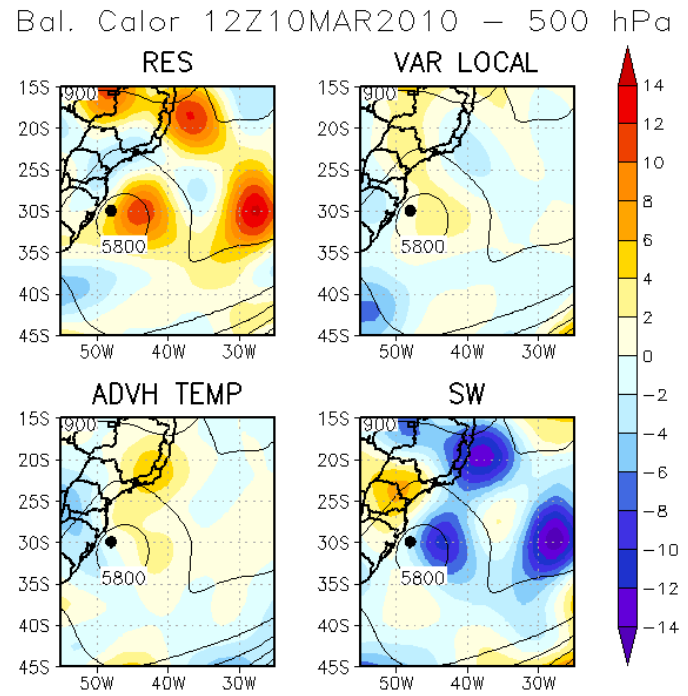
(a) Bal. Calor 12Z04MAR2010 - $300 \mathrm{hPa}$
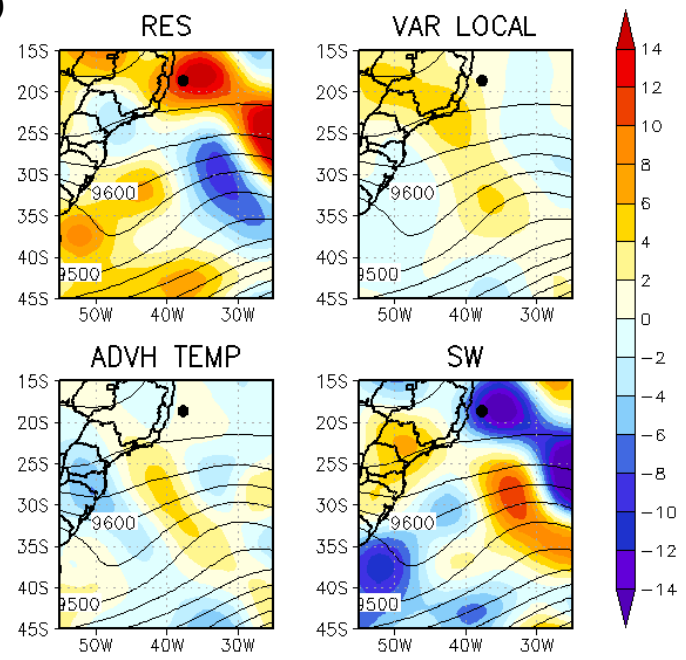

(c)
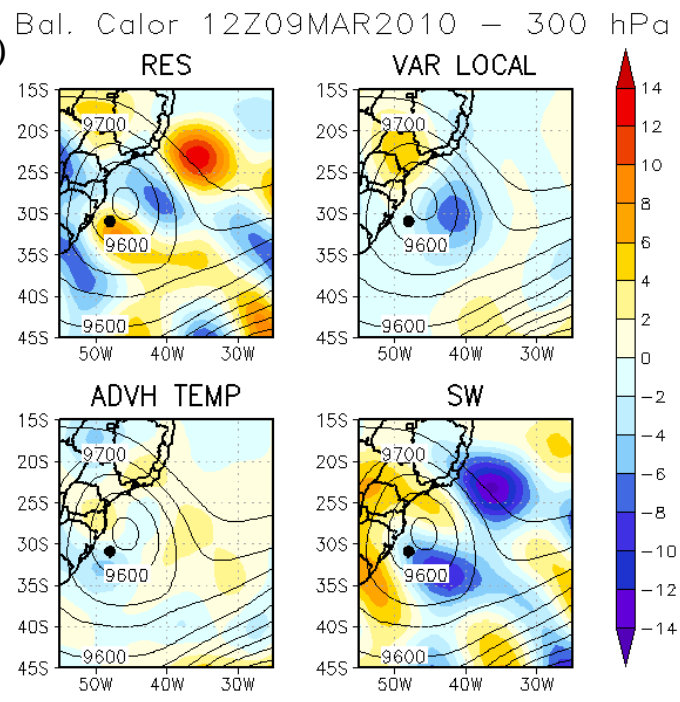

(e)
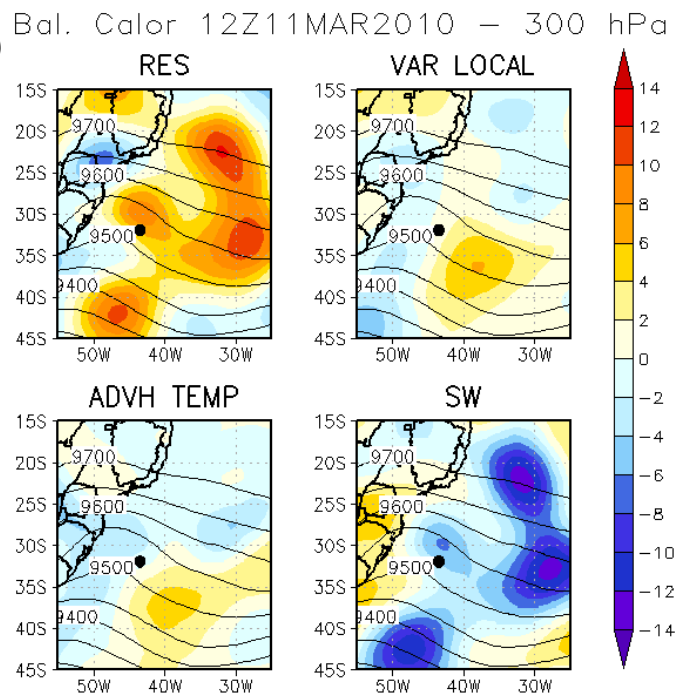

(b) Bal. Calor $12207 \mathrm{MAR} 2010$ - $300 \mathrm{hPa}$
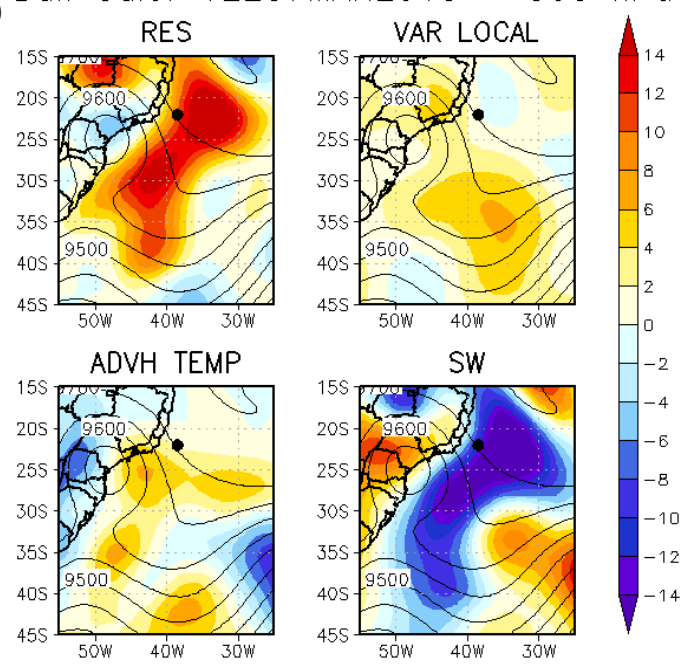

(d)
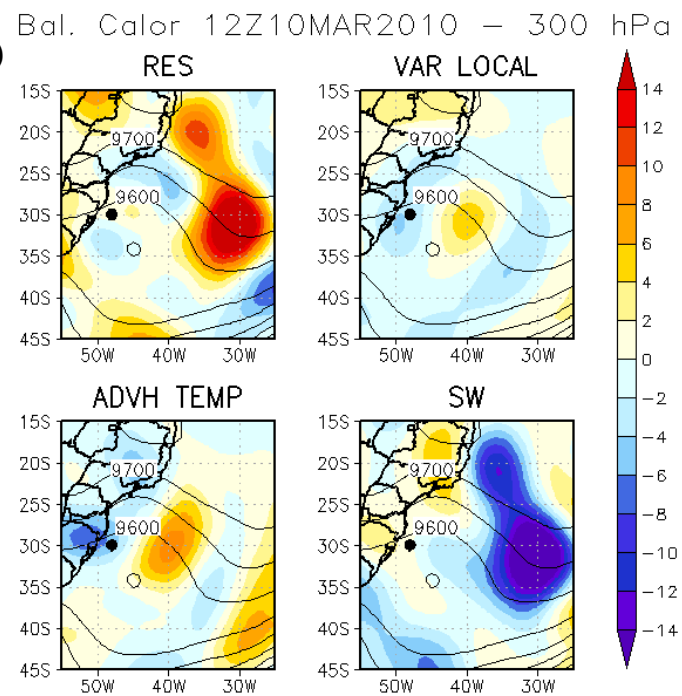

Fig. 5.13. Idem à Fig. 5.11, mas para 300 hPa. 


\section{b. Balanço de vorticidade}

As Figs. 5.14 e $\mathbf{5 . 1 5}$ apresentam os campos espaciais dos termos de maior contribuição do balanço de vorticidade, respectivamente para os níveis 925 e $300 \mathrm{hPa}$, e para cada estágio do ciclo de vida do ciclone de março de 2010.

No dia 04 (estágio de início), ainda não é possível ver nenhum contorno fechado de altura geopotencial associado à baixa fechada em superfície em nenhum dos níveis de pressão $(925,500$ e $300 \mathrm{hPa})$. Para o dia da intensificação 1, a partir do qual a baixa em superfície começa a se deslocar significativamente para sudoeste, observa-se um contorno fechado de geopotencial em $925 \mathrm{hPa}$ exatamente sobre a região do ciclone em superfície, indicando um maior aprofundamento do sistema. Em médios e altos níveis estabeleceu-se um ciclone com configuração barotrópica desde $500 \mathrm{hPa}$ até $300 \mathrm{hPa}$, centrado por volta de $25,0^{\circ} \mathrm{S}$ e $49,0^{\circ} \mathrm{W}$. Durante o estágio maduro, têm-se que o ciclone em superfície está alinhado com o ciclone em médios e altos níveis, caracterizando portanto uma configuração barotrópica equivalente em toda a coluna atmosférica. No período de enfraquecimento, o ciclone perde intensidade em todos os níveis, porém em 300 hPa esta desintensificação é mais abrupta, apresentando uma perceptível desorganização dos contornos de altura geopotencial. No segundo estágio de intensificação, o ciclone em médios e altos níveis está completamente desconfigurado, embora cavados ainda sejam verificados sobre a região do ciclone em superfície.

Para o estágio do início, e em $925 \mathrm{hPa}$ (Fig. 5.14a), verifica-se que toda a região próxima ao ciclone em superfície apresenta valores negativos do termo de divergência, com um núcleo principal na parte leste do centro do ciclone. Estes valores estão associados às configurações dinâmicas remanescentes do ciclone que estava atuando mais a leste no Atlântico, como foi visto na análise sinótica. Ressalta-se que valores negativos do termo de divergência implicam em convergência de massa na região. Verifica-se que a distribuição do termo de resíduo se comporta de forma semelhante à do termo de divergência, fato este que também é verificado através dos perfis verticais médios do ciclone (ver seção 5.4c). Os campos de advecção horizontal não apresentam valores intensos, exceto em $300 \mathrm{hPa}$ (Fig. 5.15a) onde a região ao sul do ciclone em superfície possui um núcleo bem definido de advecção horizontal negativa de vorticidade. O estágio inicial apresenta padrões de variação local da vorticidade similares em ambos os níveis estudados, com tendências positivas a sudeste do ciclone em superfície e negativas nas demais regiões ao redor do sistema.

No estágio de intensificação 1, nota-se que todos os termos do balanço de vorticidade em 925 hPa (Fig. 5.14b) apresentam valores mais intensos que o estágio inicial (Fig. 5.14a), 
em resposta à intensificação do escoamento associado ao ciclone. No dia 07, verifica-se ainda semelhanças quanto ao padrão de advecção horizontal de vorticidade nos três níveis, com valores negativos localizados sempre a sul da baixa em superfície. Em $925 \mathrm{hPa}$, isto ocorre devido ao cavado invertido no qual o sistema está imerso, que em conjunto com o padrão de circulação horária do ciclone transporta advecção negativa do eixo do cavado (orientado na direção noroeste-sudeste) para a região ao sul do sistema. Já em 300 hPa (Fig. 5.15b), a advecção negativa nesta região deve-se à configuração do ciclone que se estabeleceu em médio e altos níveis, cujo cavado está orientado na direção norte sul, e portanto a advecção horizontal negativa de vorticidade ocorre ao leste do cavado, região esta que coincide com o sul da baixa em superfície.

O termo de divergência apresenta dois núcleos de valores negativos durante o primeiro estágio de intensificação em $925 \mathrm{hPa}$ : um a leste do ciclone e outro a sudoeste, próximo às costas do Paraná e de Santa Catarina (Fig. 5.14b), região esta para a qual o ciclone se desloca futuramente. Nesta mesma região, o termo de divergência apresentava um núcleo intenso positivo em $300 \mathrm{hPa}$ (Fig. 5.15b), caracterizando assim uma situação em que existe divergência promovida pelo cavado em altos níveis e conseqüente convergência em superfície, o que favorece os movimentos ascendentes. Ainda durante o estágio de intensificação 1, o termo de resíduo em baixos níveis novamente parece se contrapor ao de divergência, intensificando-se (com sinal oposto) próximo às regiões onde o termo de divergência é mais ativo. Analisando o saldo final, tem-se que em $925 \mathrm{hPa}$ a variação local de vorticidade é negativa ao sul e positiva ao norte do ciclone em superfície (Fig. 5.14b), indicando uma situação favorável para o deslocamento do sistema para sul.

Para o estágio maduro, com o ciclone no estágio barotrópico equivalente, nota-se que o termo de divergência apresenta valores menos intensos em todos os níveis (Figs. 5.14c e 5.15c), em comparação ao estágio anterior de intensificação. Isto indica que, com o alinhamento dos centros de baixa pressão em toda a troposfera, o processo de convergência e divergência já não é tão eficiente.

Tanto o estágio maduro quando o estágio de enfraquecimento apresentam padrões semelhantes da advecção horizontal de vorticidade em $925 \mathrm{hPa}$, com núcleos negativos na porção sudeste e positivos na porção leste do ciclone (Figs. 5.14c e 5.14d). No estágio maduro em $300 \mathrm{hPa}$, o termo residual e o de advecção horizontal são os que mais parecem contribuir para os valores negativos da tendência local de vorticidade na região localizada a nordeste do ciclone (Fig. 5.15c). 
O estágio de enfraquecimento é caracterizado por ser o primeiro a apresentar variação local de vorticidade negativa a leste do ciclone em $925 \mathrm{hPa}$, o que contribui para que o centro do ciclone tenha um deslocamento para leste (Fig. 5.14d). Este tendência negativa nesta região ocorre principalmente devido ao termo residual e ao de divergência. Em $500 \mathrm{hPa}$ também havia tendência negativa a leste do cavado de níveis médios, contudo neste nível o termo de advecção horizontal também contribui com valores negativos a leste do ciclone (figura não mostrada). Em $300 \mathrm{hPa}$, onde o ciclone estava se desconfigurando, também há regiões de intensa variação local de vorticidade a leste do cavado de altos níveis, porém estes valores estão mais deslocados para leste no Atlântico (Fig. 5.15d), o que contribui para um deslocamento mais rápido para leste do sistema de cavado.

O estágio de intensificação 2 apresenta valores negativos intensos de advecção horizontal de vorticidade negativa ao sul e sudeste do ciclone em superfície em todos os níveis estudados (Figs. 5.14e e 5.15e). De forma semelhante ao verificado durante o primeiro estágio de intensificação, este segundo estágio apresenta intensos valores negativos do termo de divergência em 925 hPa e positivos em níveis médios e altos, caracterizando uma condição favorável aos movimentos ascendentes. Em baixos níveis, é o termo de divergência que mais parece contribuir para as variações locais negativas de vorticidade ao sul do ciclone em superfície (Fig. 5.14e), enquanto que em altos níveis esta contribuição nesta região vem principalmente dos termos de resíduo e de advecção horizontal (Fig. 5.15e). 
(a)
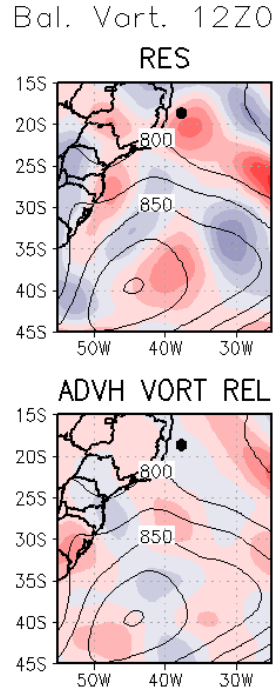

(c)
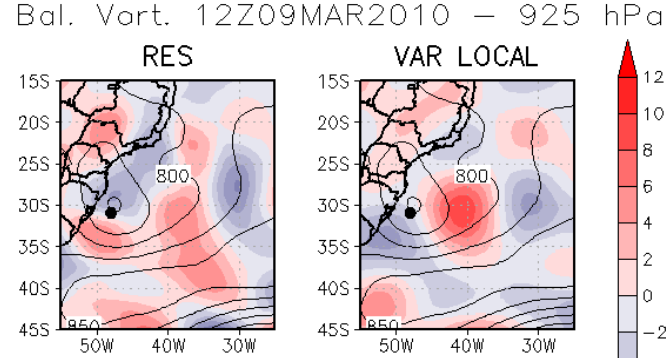

ADVH VORT REL
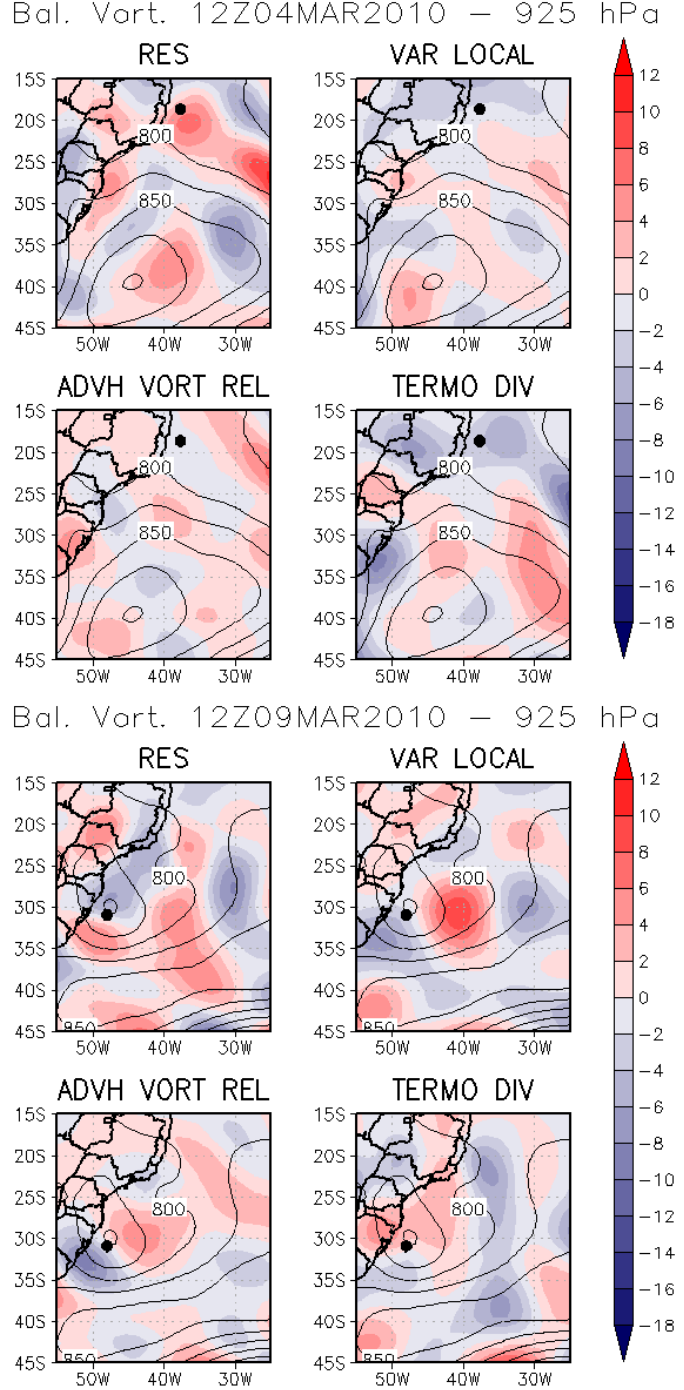

(e)
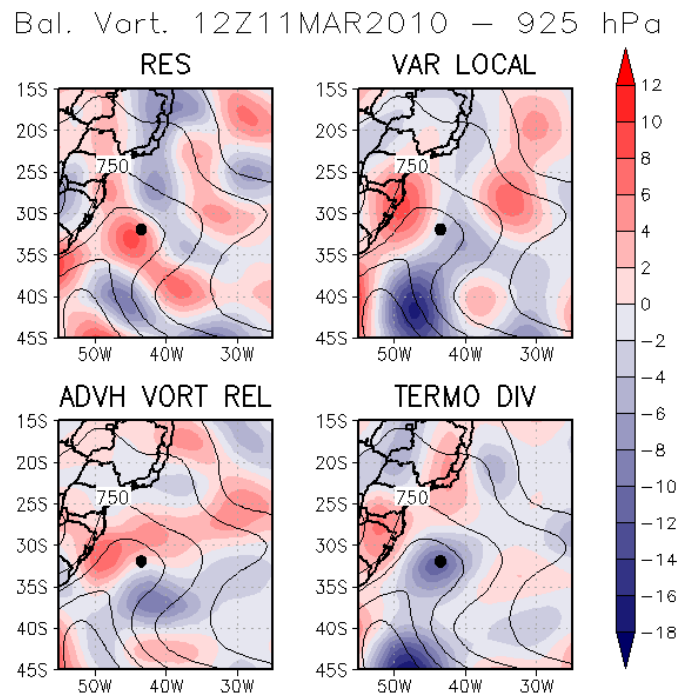

(b)
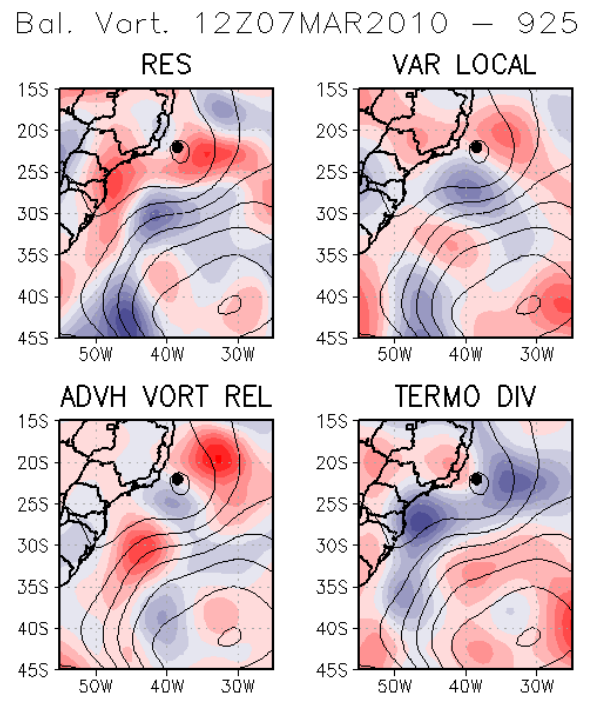

(d)
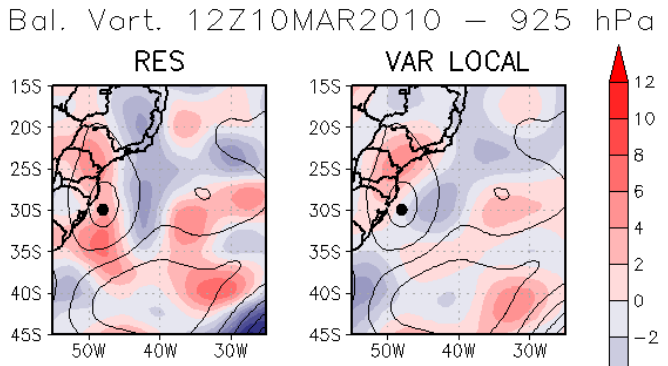

ADVH VORT REL
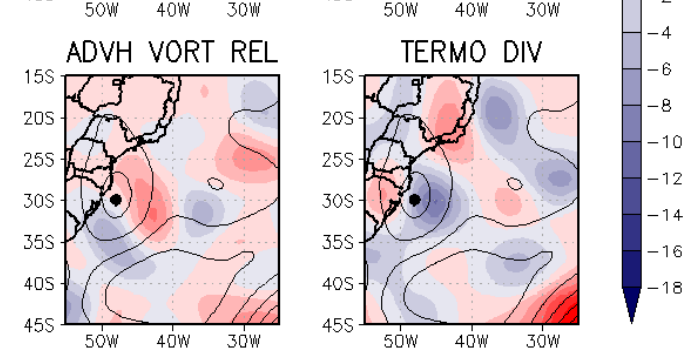

Fig. 5.14. Altura geopotencial (linhas contínuas, metros geopotencial) e termos do balanço de vorticidade (sombreado; resíduo, variação local, advecção horizontal e termo de divergência, $10^{-10} \mathrm{~s}^{-2}$ ) em $925 \mathrm{hPa}$ para às 12 UTC do dia (a) 04 (início), (b) 07 (intensificação 1), (c) 09 (maduro), (d) 10 (enfraquecimento) e (e) 11 (intensificação 2). 
(a) Bal. Vort. 12Z04MAR2010 - $300 \mathrm{hPa}$
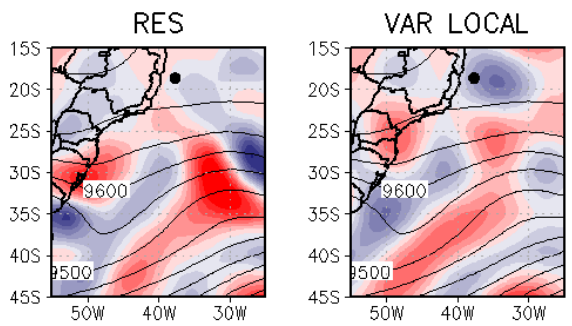

ADVH VORT REL
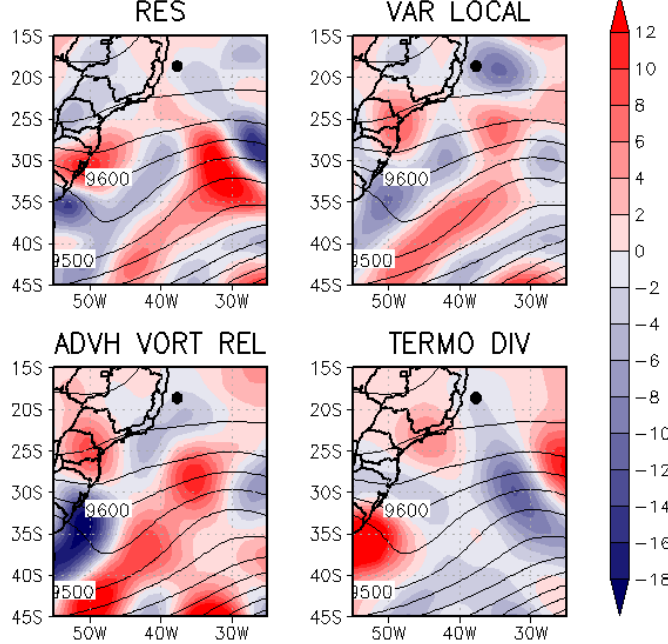

(c)
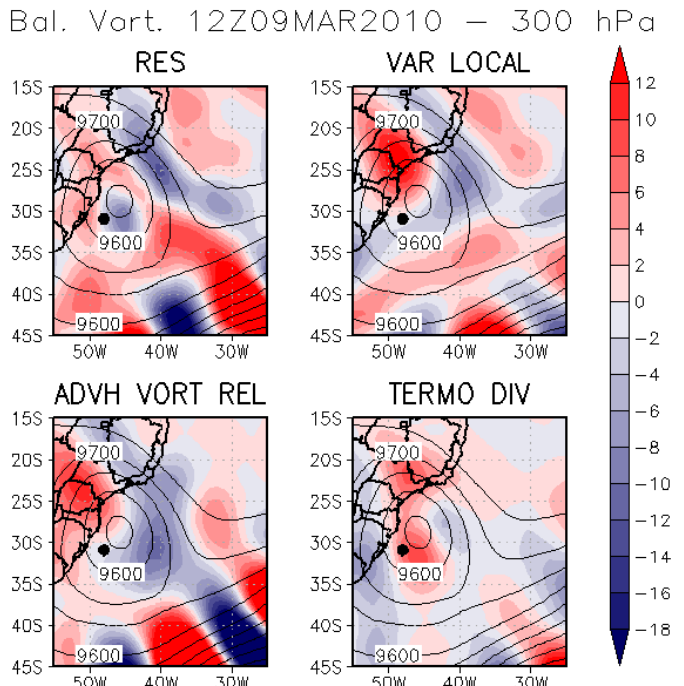

(e)
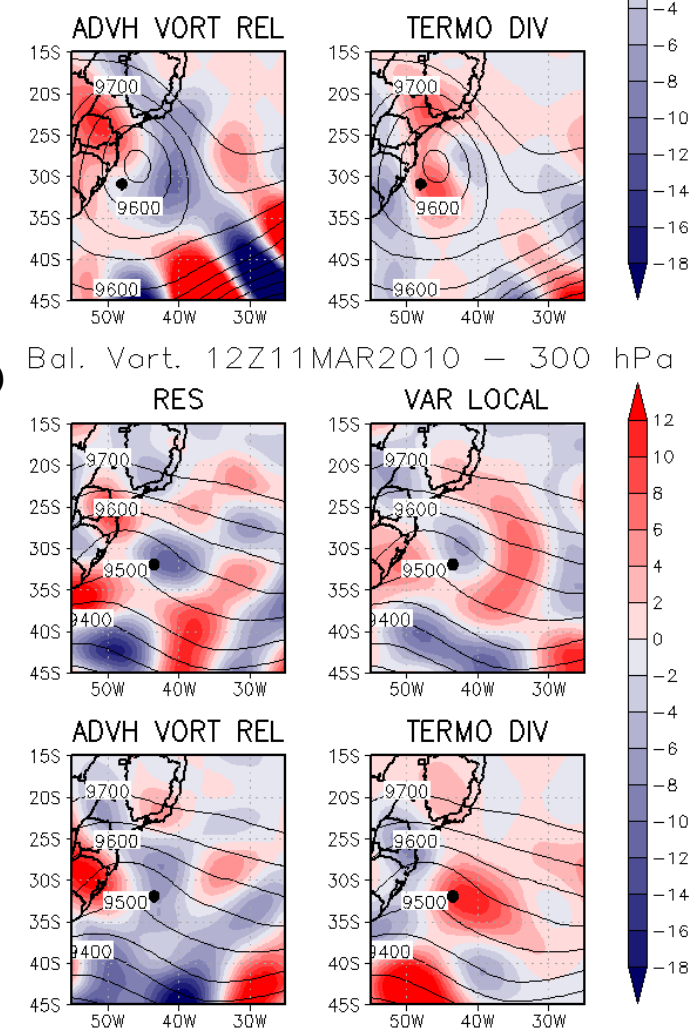

Fig. 5.15. Idem à Fig. 5.14, mas para $300 \mathrm{hPa}$.

hPa (b) Bal. Vort. 12Z07MAR2010 - $300 \mathrm{hPa}$
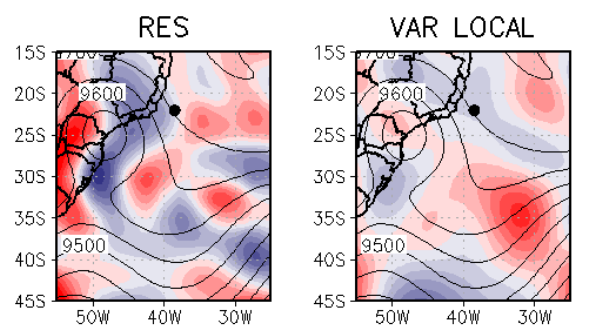

ADVH VORT REL
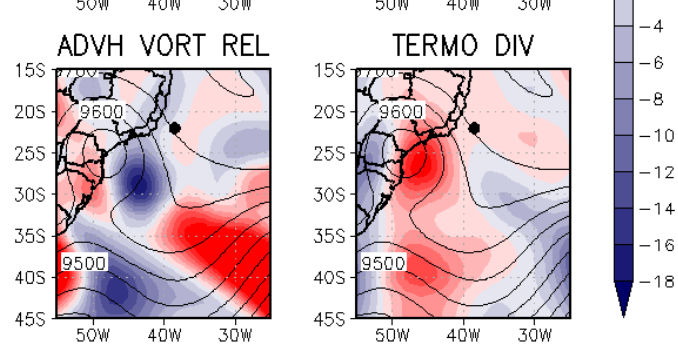

(d)
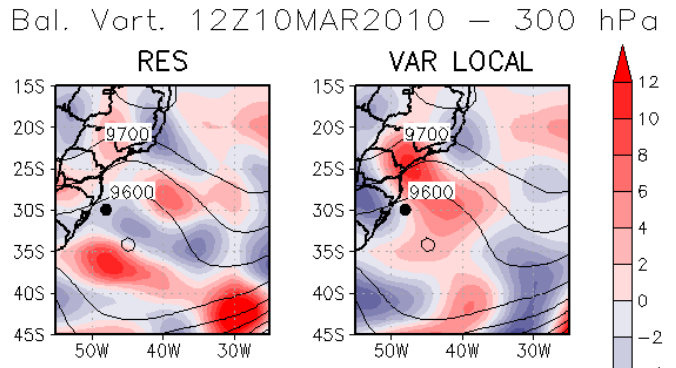

ADVH VORT REL
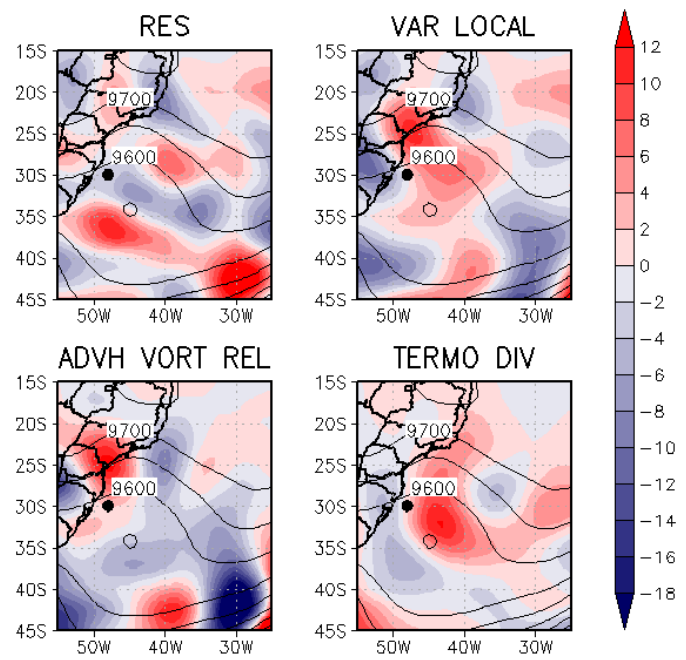


\subsection{Associação entre os campos residuais}

Da mesma forma que o observado no caso do ciclone de abril de 2009, para o ciclone de março de 2010 a relação entre a distribuição espacial do resíduo do balanço de vorticidade e o termo diabático do balanço de calor (que representa os processos convectivos) pode ser observada com maior clareza somente em $300 \mathrm{hPa}$ e somente em alguns estágios.

$\mathrm{Na}$ intensificação 2 e em $300 \mathrm{hPa}$ verificam-se duas diferentes regiões cujo termo residual da equação da vorticidade é negativo: uma sobre a área do ciclone em superfície, por volta de $30,0^{\circ} \mathrm{S}$ e $40,0^{\circ} \mathrm{W}$ e outra a sudoeste do sistema, associada com a região de nebulosidade do ciclone frontal que iria se mesclar ao ciclone Anita. Ao comparar este padrão com o do termo diabático da equação da termodinâmica, nota-se que as regiões de “imbalanço" mencionadas são também regiões de maior resíduo positivo da equação do calor (Fig 5.16c). Em 925, sobre a região de atuação do ciclone em superfície, existe um núcleo positivo do resíduo da equação da vorticidade (Fig 5.14e). Esta configuração estaria de acordo com a observada para os distúrbios estudados de Reed e Johnson (1974), em que em baixos níveis existe um sumidouro de vorticidade ciclônica e em altos níveis uma fonte.

A configuração descrita para o estágio de intensificação 2 também pode ser observada em outros estágios: no inicial, nota-se em $300 \mathrm{hPa}$ uma faixa negativa do resíduo da equação da vorticidade a sudeste do ciclone em superfície, orientada na direção noroeste-sudeste. No mesmo nível, no campo do termo diabático do calor, verifica-se uma faixa semelhante, mas de intensos valores positivos (Fig 5.16a). Em $925 \mathrm{hPa}$, o termo residual do balanço de vorticidade nesta faixa atua como um sumidouro (Fig 5.14a). No estágio maduro, em $300 \mathrm{hPa}$ também é possível verificar uma pequena região de oposição entre os resíduos das duas equações sobre a região do ciclone: "imbalanço" negativo do resíduo da equação da vorticidade e positivo da equação do calor (Fig. 5.16b). Isto significa que nestas regiões e estágios mencionados, a convecção pode explicar os substanciais resíduos de vorticidade observados.

É interessante e importante destacar o fato de que, nas regiões e estágios em que as relações entre os termos residuais de ambas as equações são observadas, o termo de divergência é o principal responsável pela configuração do campo do resíduo da equação da vorticidade (sendo que ambos atuavam com contribuições opostas). Em contrapartida, nas demais regiões e estágios em que as relações entre os resíduos não são observadas, o termo de divergência não é o processo dominante na influência do resíduo da equação da vorticidade. 
O fato descrito no parágrafo anterior está associado ao processo dinâmico relacionado com o termo de divergência: valores positivos do termo em $300 \mathrm{hPa}$ estão associados com divergência, que em altos níveis normalmente relaciona-se a movimentos ascendentes. Assim, quando o termo de divergência é o que mais influencia os "imbalanços" da equação da vorticidade, significa que estes “imbalanços” estão fortemente relacionados com os processos de movimentos verticais, que por sua vez estão relacionados à atividade convectiva.

Além disso, nas regiões em que as relações entre os termos residuais de ambas as equações são observadas, o termo relacionado ao movimento vertical $\mathrm{Sw}$ é o que mais contribui para o resíduo do balanço de calor, que representa os processos convectivos.

Desta forma, pode-se inferir que os processos convectivos possuem um papel fundamental nos "imbalanços" da tendência da vorticidade, especialmente em algumas regiões próximas à área de atuação do ciclone durante os estágios inicial, maduro e de intensificação 2. Nos demais estágios, a convecção provavelmente também deve influenciar os resíduos observados, porém talvez de forma mais distribuída na coluna atmosférica, da mesma forma que o campo de divergência do vento associado aos movimentos verticais também deve estar mais distribuído na coluna. Além disso, devem existir outros processos sub-grade que também não puderam ser resolvidos pelas variáveis de larga escala na equação, o que também explicaria a não verificação da relação entre as regiões de maiores resíduos das equações. 


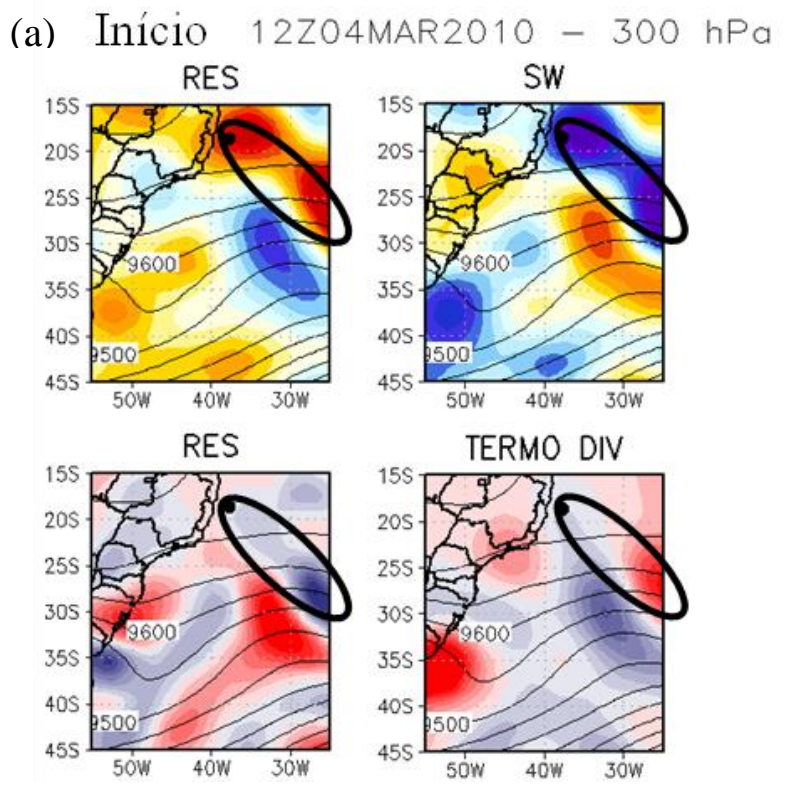

(b) Maduro 12Z09MAR2010 - $300 \mathrm{hPa}$
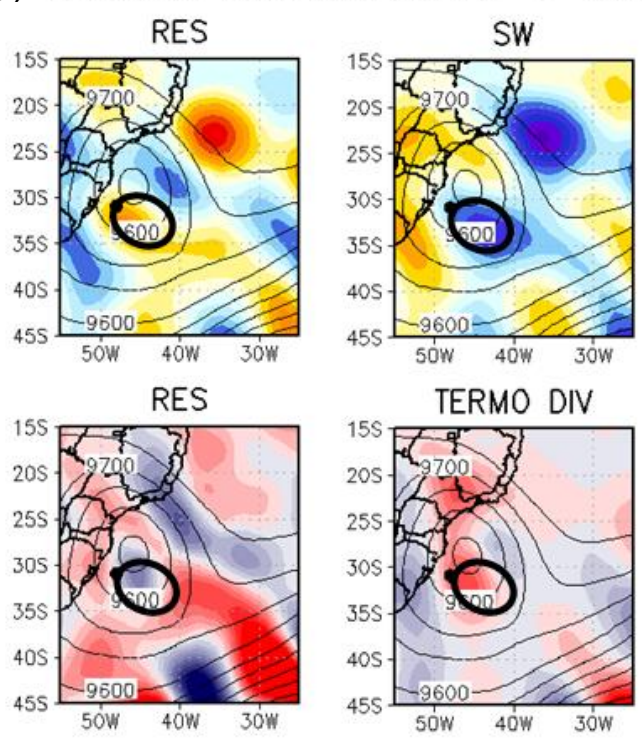

(c) Intensif. 2 12Z11MAR2010 - $300 \mathrm{hPa}$
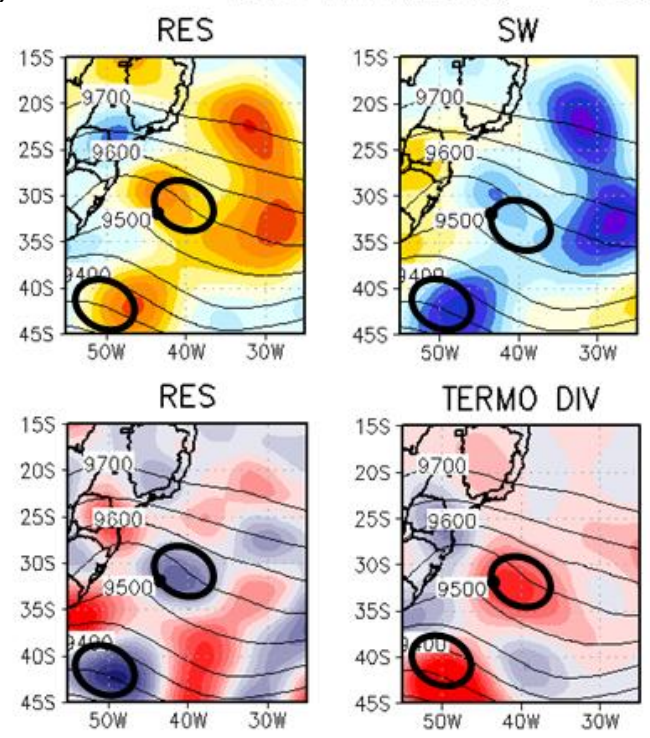

Fig. 5.16. Altura geopotencial (linhas contínuas, metros geopotencial) e termos diabático e Sw do balanço de calor (sombreado; painel superior; tons em amarelo indicam aquecimento, e tons em azul claro indicam resfriamento, $\mathrm{K} \mathrm{dia}^{-1}$ ) e termos residual e de divergência do balanço de vorticidade (sombreado; painel inferior; tons em vermelho indicam diminuição de vorticidade ciclônica, e tons em azul escuro indicam aumento de vorticidade ciclônica, $10^{-10} \mathrm{~s}^{-}$ ${ }^{2}$ ) em $300 \mathrm{hPa}$ para $12 \mathrm{UTC}$ de (a) 04/03/2010 (início), (b) 09/03/2010 (maduro) e (c) 11/03/2010 (intensificação 2). A posição central do ciclone em superfície é marcada pelo ponto preto, e os círculos pretos delimitam as regiões em que foram observadas associações entre os campos residuais (ver o texto para mais detalhes). 


\subsection{Perfis verticais médios}

A seguir são apresentados os perfis verticais médios. Além dos perfis de cada termo das equações do balanço de calor e vorticidade, calculou-se também os perfis de VR, divergência e Omega. Ressalta-se que, no caso do ciclone de março de 2010, a caixa variava de posição a cada tempo do ciclo de vida do sistema, acompanhando a posição central da baixa em superfície.

\section{a. Vorticidade, divergência e Omega}

A Fig. 5.17 mostra os perfis verticais médios de VR, divergência e Omega, centrados no ciclone em superfície de março de 2010. Da mesma forma que os perfis verticais do ciclone de abril de 2009, cada cor indica um diferente estágio de seu ciclo de vida.
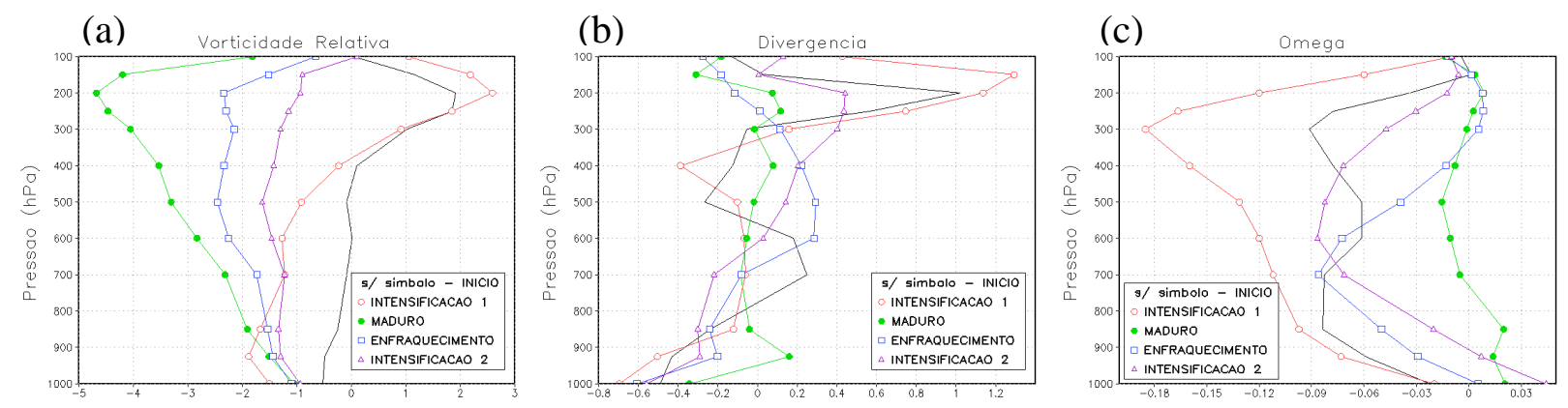

Fig. 5.17. Perfis verticais médios de (a) VR $\left(10^{-5} \mathrm{~s}^{-1}\right)$, (b) divergência $\left(10^{-5} \mathrm{~s}^{-1}\right)$ e (c) pseudovelocidade vertical Omega $\left(\mathrm{Pa} \mathrm{s}^{-1}\right)$, centrados no ciclone em superfície de março de 2010. Cada cor representa um diferente estágio do sistema.

Analisando o perfil vertical de VR (Fig. 5.17a), nota-se que no nível de $200 \mathrm{hPa}$ ocorrem os máximos valores de vorticidade anticiclônica e ciclônica em toda a camada atmosférica, referentes, respectivamente, aos estágios da intensificação 1 e maduro. Os estágios de início e de intensificação 1 apresentam vorticidade anticiclônica acima de aproximadamente $500 \mathrm{hPa}$, sendo que o estágio de início apresenta vorticidade ciclônica pouco intensa em baixos níveis. O estágio maduro é marcado por uma acentuada intensificação da vorticidade ciclônica com a altura, maximizando no nível de $200 \mathrm{hPa}$. A partir do nível de $850 \mathrm{hPa}$, este estágio apresenta os valores mais intensos de VR ciclônica. Em termos qualitativos, os estágios de enfraquecimento e de intensificação 2 não apresentam grandes diferenças quanto às taxas de variação com a altura, porém, durante o enfraquecimento, a VR ciclônica é mais fraca do que durante a intensificação 2 em toda a coluna. 
No perfil médio de divergência (Fig. 5.17b), nota-se que o estágio inicial e de intensificação 2 apresentam um padrão bem definido de convergência em baixos níveis e divergência em altos níveis, enquanto que nos estágios maduro e de enfraquecimento apresentam convergência em altos níveis. Durante a intensificação 1, a convergência em superfície é mais intensa.

Para o perfil vertical médio de Omega (Fig. 5.17c), valores negativos representam movimentos ascendentes, e valores positivos, movimentos descendentes. A fase de intensificação 1 caracteriza-se por atividade convectiva intensa, com forte movimento vertical médio ascendente nas imediações do ciclone. Entre o estágio maduro e de intensificação 2, têm-se um período em que, na média, ocorrem movimentos descendentes desde médios até altos níveis.

\section{b. Balanço de calor}

Quanto ao perfil vertical do termo de variação local de temperatura (Fig. 5.18a), temse que, de forma geral, os estágios inicial e de intensificação 1 apresentam as maiores tendências de aquecimento em altos e médios níveis, indicando um maior aquecimento da coluna neste período. Em particular, durante a intensificação 1, o aquecimento também é intenso na baixa troposfera (900-700 hPa). Em contrapartida, o estágio maduro caracteriza-se por apresentar tendências médias de resfriamento ou muito próximas de zero, com exceção do nível de $925 \mathrm{hPa}$, que apresenta tendência de aquecimento. Os picos negativos da fase madura ocorrem em $700 \mathrm{hPa}$ e em $250 \mathrm{hPa}$ e equivalem, respectivamente, a -1,3 $\mathrm{K} \mathrm{dia}^{-1}$ e $-1,8 \mathrm{~K} \mathrm{dia}^{-1}$. Destaca-se que em altos níveis, o estágio de enfraquecimento também apresenta forte tendência média de resfriamento. Contudo, em médios e baixos níveis, a tendência de aumento da temperatura continua intensa durante o enfraquecimento, e com valores semelhantes aos do período de intensificação 2 .

Nos níveis mais próximos à superfície, todos os estágios apresentam advecção horizontal média positiva de temperatura (Fig. 5.18b). Em médios e baixos níveis, durante a intensificação 2, as contribuições mais intensas para tendência de aquecimento devem-se ao termo de advecção horizontal, com pico em $925 \mathrm{hPa}$ de 3,3 $\mathrm{K} \mathrm{dia}^{-1}$. Já em altos níveis, a intensificação 1 apresenta as maiores advecções horizontais quentes de temperatura, com pico de 3,0 K dia ${ }^{-1}$ em $250 \mathrm{hPa}$. No estágio inicial, exceto por forte advecção quente em $150 \mathrm{hPa}$, os valores médios de advecção horizontal de temperatura são menores do que nos demais estágios. Ao atingir o estágio maduro, o ciclone é caracterizado por advecção quente (fria) 
abaixo (acima) de $600 \mathrm{hPa}$. Um perfil semelhante foi observado no estágio de enfraquecimento, exceto em $150 \mathrm{hPa}$, onde a advecção média quente é intensa.

Da mesma forma que o observado para o ciclone de abril de 2009, a distribuição na coluna dos termos médios de advecção vertical de temperatura e do termo adiabático para o ciclone de março de 2010 (Figs. 5.18c e 5.18d) mostra um claro padrão de oposição entre ambos os termos. Nos níveis em que ocorre advecção vertical quente (fria), o termo adiabático contribui para o resfriamento (aquecimento). Tal oposição ocorre devido à expansão (compressão) adiabática das parcelas ao subirem (descerem), e devido ao fato de que, no geral, os movimentos ascendentes (descendentes) na troposfera advectam o ar mais quente (frio) dos níveis inferiores (superiores) para os níveis acima (abaixo). Deste processo termodinâmico, as contribuições do termo adiabático são sempre mais intensas, como pode ser visto na Fig. 5.18e, onde o termo relacionado ao movimento vertical $(\mathrm{Sw})$ representa a soma da advecção vertical de temperatura e do termo adiabático.

Analisando o perfil vertical de $\underline{S_{w}}$ (Fig. 5.18e), nota-se que o estágio de intensificação 1 apresenta as maiores contribuições para a tendência de diminuição da temperatura em toda a coluna sobre o ciclone em superfície. Isto representa uma resposta dos intensos movimentos ascendentes observados neste período. Nos estágios maduro e de enfraquecimento, o termo Sw apresenta em altos níveis uma leve contribuição para o aumento da temperatura, que se deve ao predomínio de movimentos médios descendentes nestes níveis (Fig. 5.17c). Por esta mesma razão, o estágio maduro também apresenta valores positivos de $\mathrm{Sw}$ nos primeiros níveis próximos à superfície. Entretanto, destaca-se no estágio maduro uma menor contribuição do termo $\mathrm{Sw}$, sendo que os valores mostraram-se próximos a zero em praticamente todos os níveis. Ambos os estágios de enfraquecimento e de intensificação 2 apresentam tendência de aumento com a altura da contribuição de $\mathrm{Sw}$ para a diminuição de temperatura, desde a superfície até o nível de $600 \mathrm{hPa}$, sendo que diminuição com a altura ocorre nos níveis acima. Assim, nestes dois estágios têm-se picos de contribuições negativas do termo Sw na média troposfera.

O termo Sw e o termo diabático (Figs. 5.18e e 5.18f) comportam-se de forma oposta: à medida que um contribui para as tendências positivas (negativas) de temperatura, o outro contribui negativamente (positivamente). Como já discutido para o ciclone de abril de 2009, isto ocorre pois o termo diabático está diretamente relacionado aos processos de aquecimento ou resfriamento da atmosfera através de calor sensível e latente. A relação de oposição é mais clara nos médios e altos níveis da atmosfera, enquanto que, próximo à superfície, esta relação 
nem sempre ocorre, ou seja, o resíduo da equação da termodinâmica não atua de forma a cancelar parcialmente as variações de temperatura causadas pelo termo Sw.

No geral, o termo residual da equação da termodinâmica atua contribuindo para as tendências de aumento de temperatura na região de atuação do ciclone (Fig. 5.18f). Nos estágios inicial e de intensificação 1, isto ocorre em todos os níveis da atmosfera . O estágio maduro é o que apresenta novamente os valores menos intensos do termo residual, sendo que nos níveis de $850 \mathrm{hPa}$ e $700 \mathrm{hPa}$ e na camada compreendida entre 300 e $200 \mathrm{hPa}$ a contribuição é negativa, ou seja, de resfriamento. Nos estágios de enfraquecimento e intensificação 2, a contribuição média de aquecimento mostra-se mais significativa nos níveis médios da atmosfera. As tendências de aquecimento devido ao termo residual estão provavelmente associadas à evaporação da precipitação e ao overshooting do topo das nuvens (da ROCHA e CAETANO NETO, 2010).

A Fig. 5.19 mostra os mesmos perfis verticais apresentados na Fig. 5.18, porém todos os termos da equação da termodinâmica estão plotados juntos, para cada diferente estágio do ciclone. Nesta figura fica evidente o padrão de oposição entre os termos $\mathrm{Sw}$ e diabático, especialmente em médios e altos níveis. Destaca-se também que no estágio maduro, todos os termos médios estão pouco ativos na região de atuação do ciclone, em toda a estrutura vertical da atmosfera. Além disso, nota-se o pico de advecção quente em altos níveis no estágio de intensificação 1. Outra característica importante durante os estágios em que o ciclone estava em sua fase híbrida é que, em baixos níveis, a tendência de aquecimento é devida principalmente ao termo diabático, o que sugere que a atmosfera em baixos níveis está sendo aquecida pela contribuição de fluxos turbulentos próximos à superfície. Quando o ciclone está na fase de transição extratropical (estágio de intensificação 2), o sentido dos fluxos próximos à superfície se inverte e o termo diabático contribui para tendências de resfriamento de temperatura. 
(a) Variacao Local (b) ADV. Horiz. Temp.

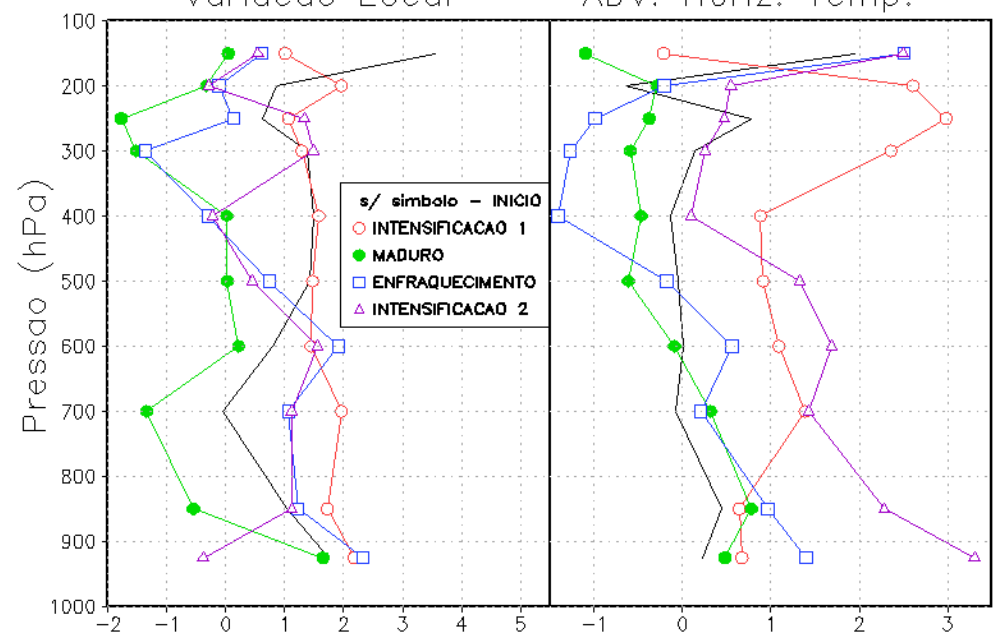

(c) ADV. Vert. Temp. (d) Termo Adiabatico
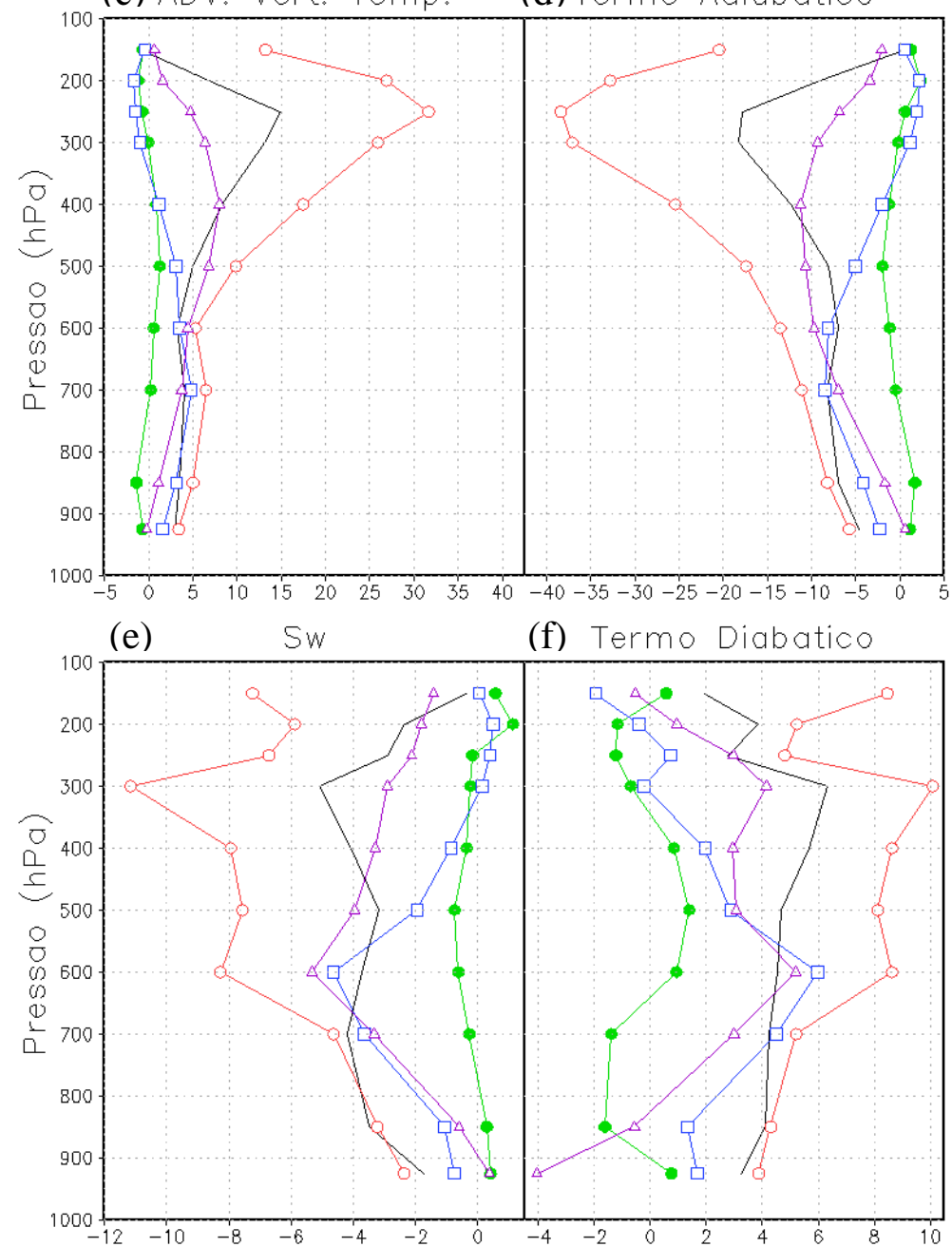

Fig. 5.18. Perfil vertical (a) da variação local de temperatura $\left(K \operatorname{dia}^{-1}\right)$, (b) da advecção horizontal de temperatura $\left(\mathrm{K} \mathrm{dia}^{-1}\right)$, (c) da advecção vertical de temperatura ( $\left.\mathrm{K} \mathrm{dia}^{-1}\right)$, (d) do termo adiabático $\left(\mathrm{K} \mathrm{dia}^{-1}\right)$, (e) do termo relacionado ao movimento vertical $\left(\mathrm{K} \mathrm{dia}^{-1}\right)$ e (f) do resíduo da equação da termodinâmica $\left(\mathrm{K} \mathrm{dia}^{-1}\right)$, para cada estágio do ciclo de vida do ciclone de março de 2010. 

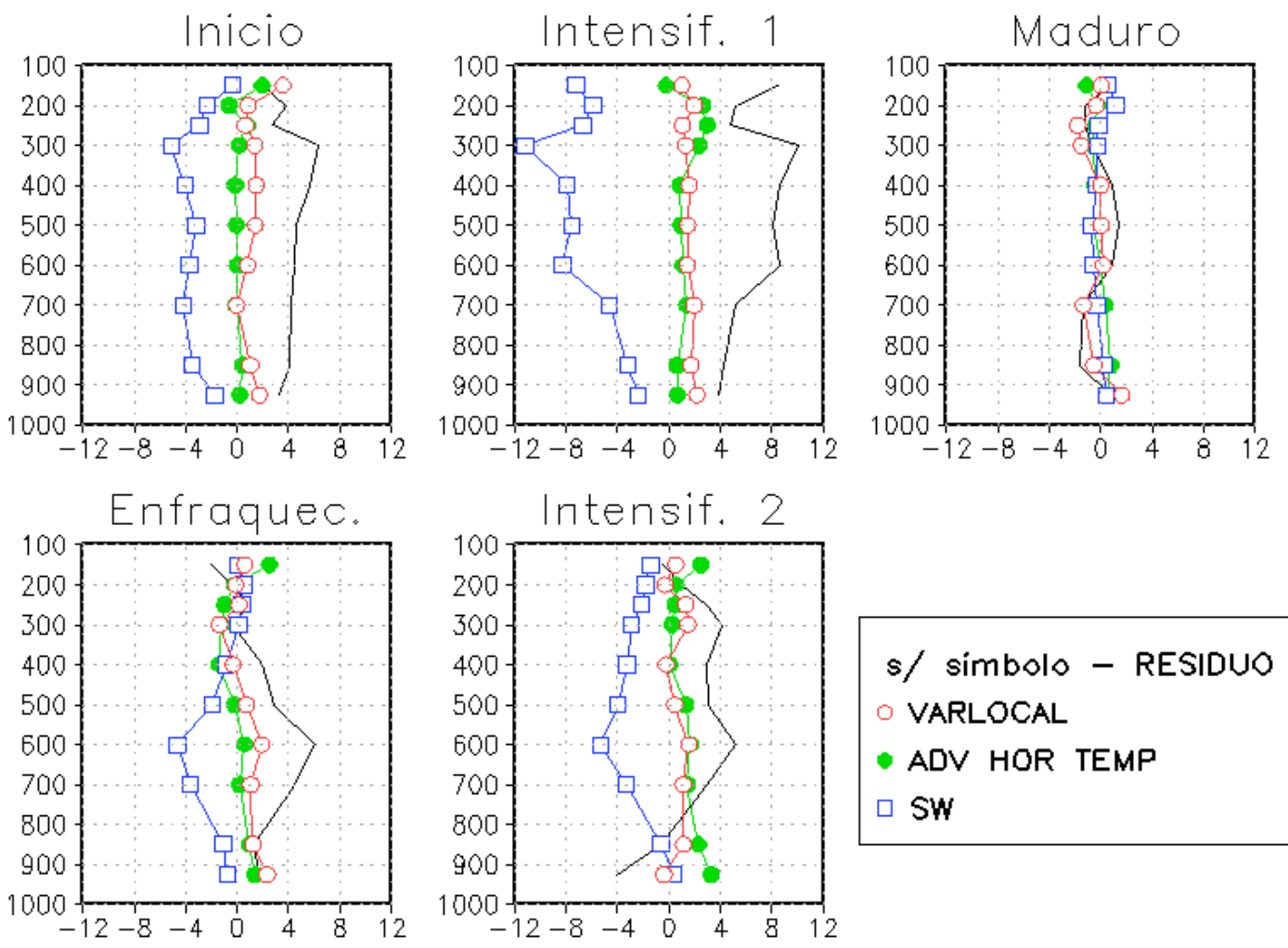

Fig. 5.19. Perfil vertical dos termos de maior contribuição do balanço de calor (variação local, resíduo, advecção horizontal de temperatura e termo relacionado ao movimento vertical, $\mathrm{K} \mathrm{dia}^{-1}$ ), para cada estágio do ciclo de vida do ciclone de março de 2010.

\section{c. Balanço de vorticidade}

A Fig. 5.20 apresenta os perfis verticais médios dos termos do balanço de vorticidade. Quanto ao termo de variação local de vorticidade relativa (Fig. 5.20a), tem-se que o início do sistema apresenta os maiores valores de tendência de vorticidade ciclônica na média e na alta troposfera. Em oposição, uma forte tendência de vorticidade anticiclônica ocorre durante o período de enfraquecimento em praticamente toda a coluna, exceto nos níveis abaixo de 700 hPa. Os perfis verticais de tendência da vorticidade durante os estágios de intensificação apresentam características bastante distintas. Enquanto na intensificação 1 a tendência de vorticidade ciclônica mais intensa encontra-se em altos níveis (máximo em 300 hPa), na intensificação 2 é encontrada abaixo de $500 \mathrm{hPa}$. Isto pode ser um indicativo de diferentes mecanismos físicos agindo para aumentar a vorticidade ciclônica do sistema. O estágio maduro apresenta tendência local ciclônica e anticiclônica respectivamente nos níveis abaixo e acima de $500 \mathrm{hPa}$, com valores não muito intensos, atingindo picos de vorticidade ciclônica de $-1,0 \times 10^{-10} \mathrm{~s}^{-2}$ em $850 \mathrm{hPa}$ e anticiclônica de $1,1 \times 10^{-10} \mathrm{~s}^{-2} \mathrm{em} 400 \mathrm{hPa}$.

A advecção horizontal de vorticidade relativa ciclônica é mais intensa durante ambos os estágios de intensificação (Fig. 5.20b), principalmente nos níveis mais elevados, onde o 
escoamento é mais intenso. Praticamente todos os estágios apresentam advecção horizontal de vorticidade pequena em níveis médios, com exceção da intensificação 2. No início, a advecção horizontal de vorticidade contribui pouco para a tendência ciclônica, exceto nos níveis mais elevados, com pico ciclônico de $-2,0 \times 10^{-10} \mathrm{~s}^{-2}$ em $200 \mathrm{hPa}$. estágio maduro também apresenta valores muito próximos de zero em quase toda a coluna, com picos de advecção horizontal ciclônica de $-1,0 \times 10^{-10} \mathrm{~s}^{-2}$ em $925 \mathrm{hPa}$ e anticiclônica de $1,0 \times 10^{-10} \mathrm{~s}^{-2}$ em $150 \mathrm{hPa}$. Durante o enfraquecimento, intensos valores de advecção horizontal de vorticidade relativa anticiclônica são observados em altos níveis, com pico de $3,6 \times 10^{-10} \mathrm{~s}^{-2}$ em $150 \mathrm{hPa}$.

Ao associar o perfil vertical médio de advecção horizontal de vorticidade relativa com o movimento vertical esperado pela equação Omega do sistema quase geostrófico (BLUESTEIN, 1993; TRENBERTH, 1978; MADDOX e DOSWELL, 1982; equação 5.1), é possível inferir que a variação vertical da advecção horizontal (Fig. 5.20b) explica parte substancial do movimento vertical (Fig. 5.17c). Isto é melhor observado nos níveis mais elevados e durante ambos os estágios de intensificação (estágio de enfraquecimento), quando a advecção horizontal de vorticidade ciclônica aumenta (diminui) com a altura. Através do primeiro termo do lado direito da equação Omega, tem-se que esta estrutura vertical contribui para movimentos ascendentes (descendentes), o que está de acordo com o campo de velocidade vertical da Fig. 5.17c. Na equação (5.1), o termo do lado esquerdo é proporcional à $-\omega$, e os termos do lado direito representam (da esquerda para a direita) a variação vertical da advecção de vorticidade absoluta e o laplaciano da advecção de temperatura ou espessura.

$$
\left(\nabla^{2}+\frac{\mathrm{f}_{0}^{2}}{\sigma} \frac{\partial^{2}}{\partial p^{2}}\right) \omega=-\frac{\mathrm{f}_{0}}{\sigma} \frac{\partial}{\partial p}\left[-\vec{V}_{g} \cdot \vec{\nabla}(\zeta+\mathrm{f})\right]+\frac{1}{\sigma} \nabla^{2}\left[\vec{V}_{g} \cdot \vec{\nabla}\left(-\frac{\partial \Phi}{\partial p}\right)\right]
$$

O perfil vertical médio do termo de divergência (Fig. 5.20c) mostra que este termo contribui para as tendências locais ciclônicas de vorticidade relativa durante os estágios de intensificação 1 e 2, desde os níveis mais baixos até respectivamente 400 e $700 \mathrm{hPa}$, sendo que nos demais níveis, a contribuição é para as tendências anticiclônicas. Estes são os únicos estágios do ciclo de vida do ciclone que apresentam apenas um nível de inversão do sinal desta contribuição. É importante notar que na intensificação 1, a tendência ciclônica devida ao termo de divergência ocupa uma coluna vertical mais profunda do que na intensificação 2, que apresenta um perfil mais clássico de desenvolvimento de ciclones extratropicais. Durante o período de enfraquecimento, o termo de divergência induz vorticidade ciclônica da superfície até $700 \mathrm{hPa}$ e acima de $250 \mathrm{hPa}$, sendo que toda a camada compreendida acima de 
700 até $250 \mathrm{hPa}$ apresenta valores anticiclônicos, com pico de 3,0 x $10^{-10} \mathrm{~s}^{-2} \mathrm{em} 400 \mathrm{hPa}$. No período maduro, a contribuição do termo de divergência para as tendências ciclônicas diminui, exceto em $150 \mathrm{hPa}$ que alcançou um pico ciclônico de $-4,2 \times 10^{-10} \mathrm{~s}^{-2}$. Contribuições para a tendência anticiclônica de vorticidade neste estágio ocorrem em $925 \mathrm{hPa}$ e na camada entre 400 e $200 \mathrm{hPa}$, com picos anticiclônicos em $250 \mathrm{hPa}$ de $2,9 \times 10^{-10} \mathrm{~s}^{-2}$. No período do início, toda a tendência de vorticidade ciclônica na Fig. 5.20a nos baixos níveis da atmosfera pode ser atribuída ao termo de divergência (Fig. 5.20c).

Em todos os estágios do ciclo de vida do ciclone, em baixos níveis, o termo de divergência contribui mais para as tendências locais ciclônicas de vorticidade, exceto no estágio maduro, quando o termo de advecção de vorticidade relativa apresenta as contribuições para tendência ciclônica mais intensas. Em altos níveis, a advecção horizontal de vorticidade contribui mais para as tendências locais ciclônicas durante os estágios de início e das intensificações 1 e 2. Em particular, durante a intensificação 2, toda a média e a alta troposfera experimentam intensa advecção horizontal ciclônica de vorticidade relativa.

Nota-se ainda que em todos os estágios, o termo residual da equação da vorticidade (Fig. 5.20d) atua em função principalmente do termo de divergência, ou seja, o resíduo é mais/menos intenso nos estágios e nas regiões em que o termo de divergência também é mais/menos intenso. Além disso, os dois termos atuam inversamente, o que significa que o resíduo atua destruindo a vorticidade gerada pelos efeitos do termo de divergência. Assim, conclui-se que o termo residual está relacionado ao termo de divergência, que por sua vez relaciona-se aos movimentos verticais. Portanto, é importante analisar a equação da termodinâmica, já que a convecção, que também está relacionada aos movimentos verticais, pode ser uma forçante para os "imbalanços" de vorticidade.

Quanto aos termos de menor contribuição para as variações locais de vorticidade (advecção vertical de vorticidade relativa, advecção de vorticidade planetária e termo de inclinação), têm-se que o termo de advecção vertical de vorticidade relativa (Fig. 5.20e) contribui mais para as tendências ciclônicas de vorticidade durante o estágio de intensificação 1, quando os movimentos verticais são mais intensos (Fig. 5.17c). Isto indica que neste estágio o transporte de vorticidade ciclônica para os níveis médios e altos da atmosfera é em parte relacionado aos efeitos da convecção. No estágio inicial, a advecção vertical de VR se tornou um termo dominante para a tendência local de vorticidade.

No geral, a advecção de vorticidade planetária (Fig. 5.20f) mostra tendências opostas à advecção horizontal de vorticidade relativa (Fig. 5.20b), embora com menos intensidade. Nos dois estágios de intensificação e especialmente em altos níveis, o termo de advecção de 
vorticidade planetária contribui para tendências anticiclônicas de vorticidade, contrapondo-se à advecção horizontal de VR ciclônica. Entretanto, é importante ressaltar que estes termos não apresentam tendências necessariamente opostas em todas as situações. Destaca-se ainda que os estágios de intensificação são os únicos nos quais o termo de advecção planetária contribui somente para tendências anticiclônicas em toda a coluna atmosférica. Este termo possui uma contribuição substancial para a tendência ciclônica em altos níveis na fase inicial do sistema.

O termo de inclinação (Fig. 5.20g) contribuiu menos para as tendências locais de vorticidade, com picos máximos anticiclônicos nos estágios inicial e de intensificação 1, e valores muito próximos de zero nos demais estágios.

A Fig. 5.21 mostra o perfil vertical médio do resíduo da equação da vorticidade (linhas em preto), para cada estágio do ciclone. Nesta figura, as linhas em azul representam o resíduo calculado desprezando-se os termos de menor contribuição (advecção vertical de vorticidade relativa, advecção de vorticidade planetária e termo de inclinação). Analisando os resultados, pode-se inferir que, em termos qualitativos, desprezar estes termos não altera significativamente a distribuição vertical média do resíduo. Contudo, verifica-se que em ambos os estágios de intensificação, desprezar estes termos resulta em termos residuais menos ciclônicos, o que significa que nestes estágios estes termos contribuem para as tendências anticiclônicas de vorticidade. Nos estágios do início e do enfraquecimento, observa-se que desprezar os termos levou a valores do termo residual menos ciclônicos e mais ciclônicos, respectivamente nas camadas inferiores e superiores da troposfera.

A Fig. 5.22 foi extraída do artigo de Reed e Johnson (1974), e mostra o perfil vertical do resíduo da equação da vorticidade para regiões de crista (contornos) e cavado (símbolos preenchidos) de composites de ondas de leste no HN. A região do cavado é a que possui a maior precipitação, e assim presume-se que também seja a de maior atividade convectiva. Os autores obtiveram que o resíduo atua como um sumidouro de vorticidade ciclônica nos baixos níveis, e como uma fonte nos altos níveis, e assim sugerem que os efeitos da convecção poderiam explicar os resíduos observados, através do transporte vertical de vorticidade. 
(a) Variacao Local (b)ADV. Horiz. Vort. Rel
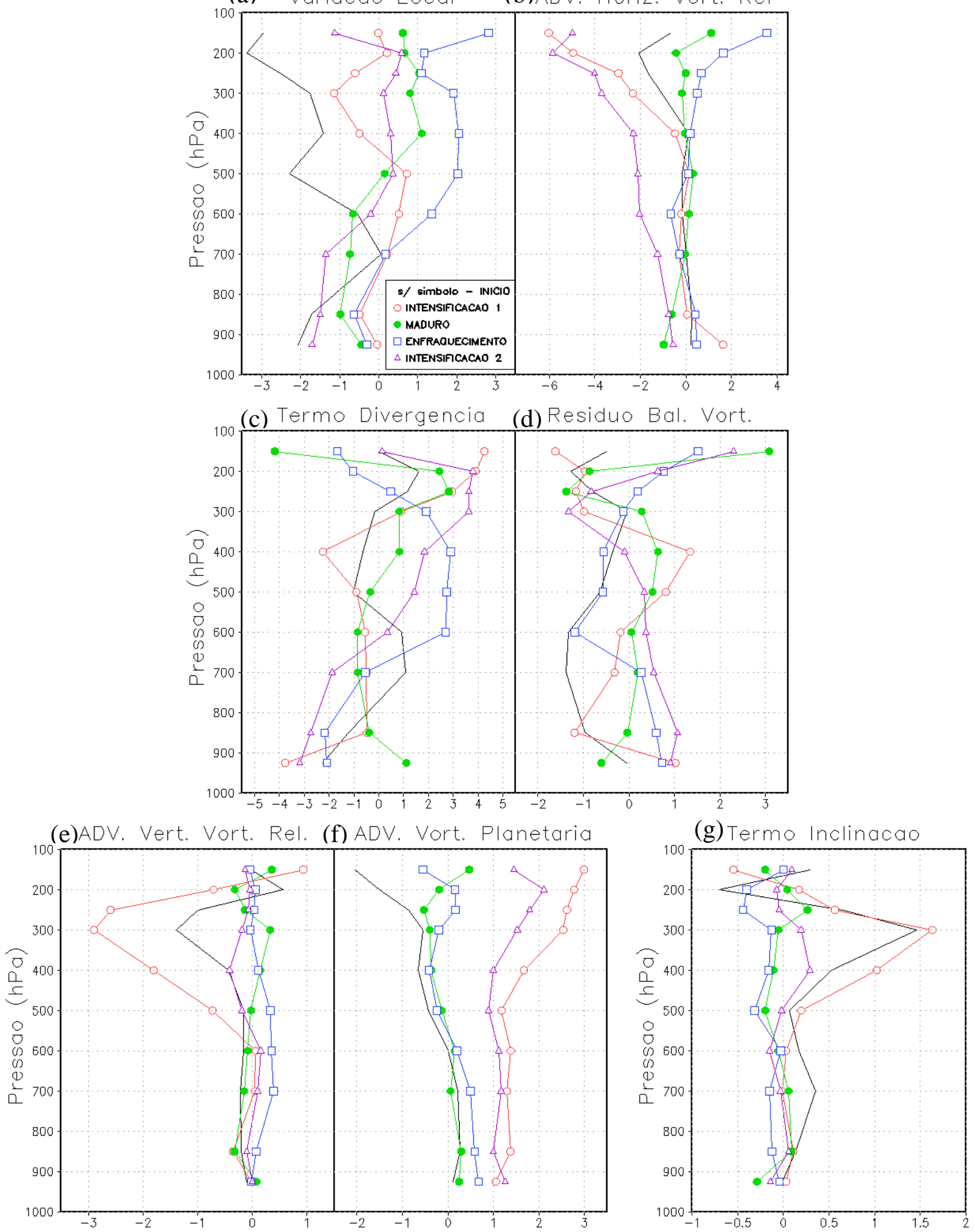

Fig. 5.20. Perfil vertical (a) da variação local de vorticidade relativa $\left(10^{-10} \mathrm{~s}^{-2}\right)$, (b) da advecção horizontal de vorticidade relativa $\left(10^{-10} \mathrm{~s}^{-2}\right)$, (c) do termo de divergência $\left(10^{-10} \mathrm{~s}^{-2}\right)$, (d) do resíduo do balanço de vorticidade $\left(10^{-10} \mathrm{~s}^{-2}\right)$, (e) da advecção vertical de vorticidade relativa $\left(10^{-10} \mathrm{~s}^{-2}\right)$, (f) da advecção de vorticidade planetária $\left(10^{-10} \mathrm{~s}^{-2}\right)$ e $(\mathrm{g})$ do termo de inclinação $\left(10^{-10} \mathrm{~s}^{-2}\right)$, para cada estágio do ciclo de vida do ciclone de março de 2010. 

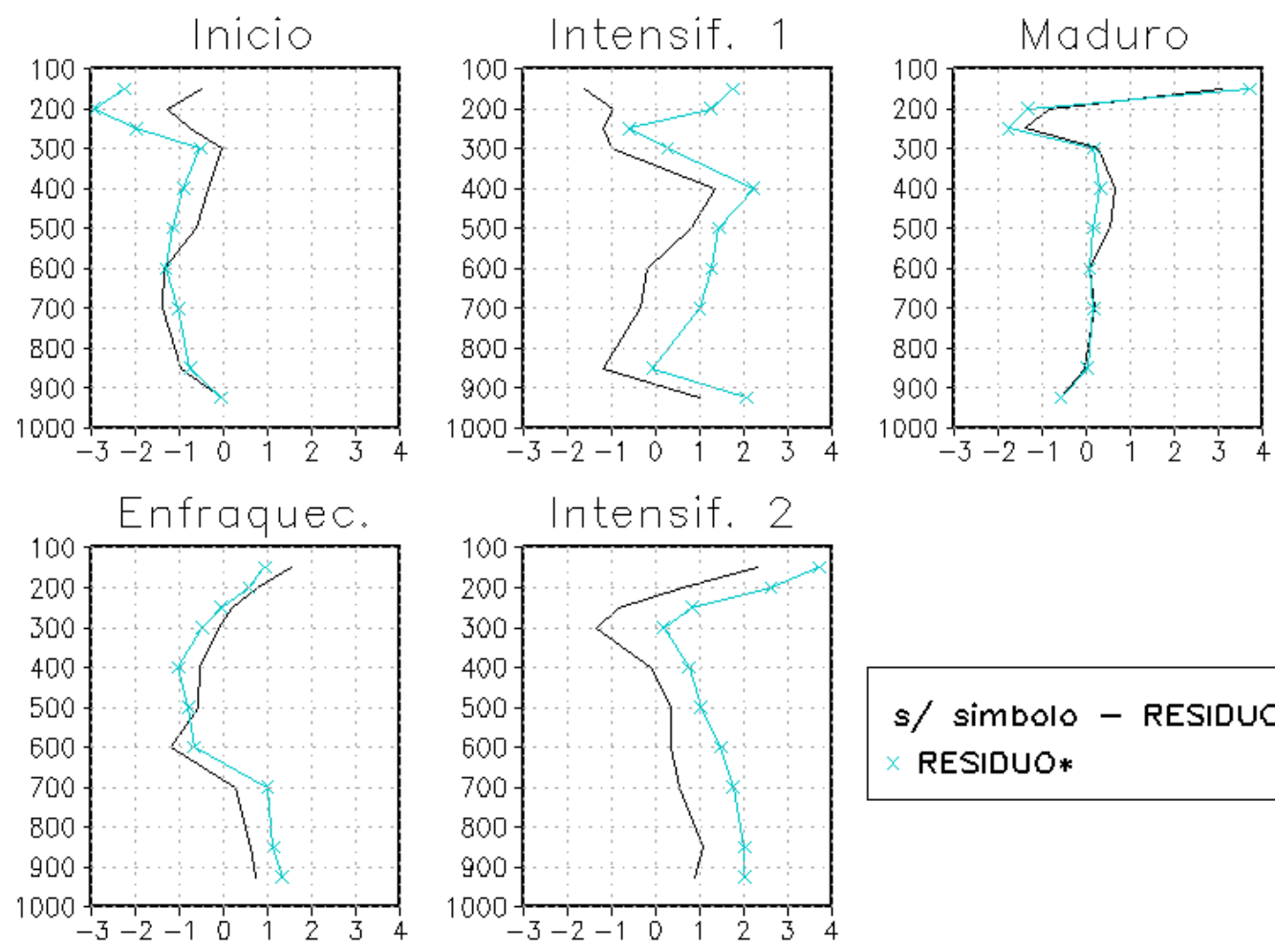

S/ Simbolo - RESIDUO
$\times$ RESIDUO*

Fig. 5.21. Perfil vertical do resíduo do balanço de vorticidade (preto, $10^{-10} \mathrm{~s}^{-2}$ ) e do resíduo calculado desprezando-se os termos de menor contribuição (advecção de vorticidade planetária, advecção vertical de vorticidade relativa e termo de inclinação - azul, $10^{-10} \mathrm{~s}^{-2}$ ), para cada estágio do ciclo de vida do ciclone de março de 2010.

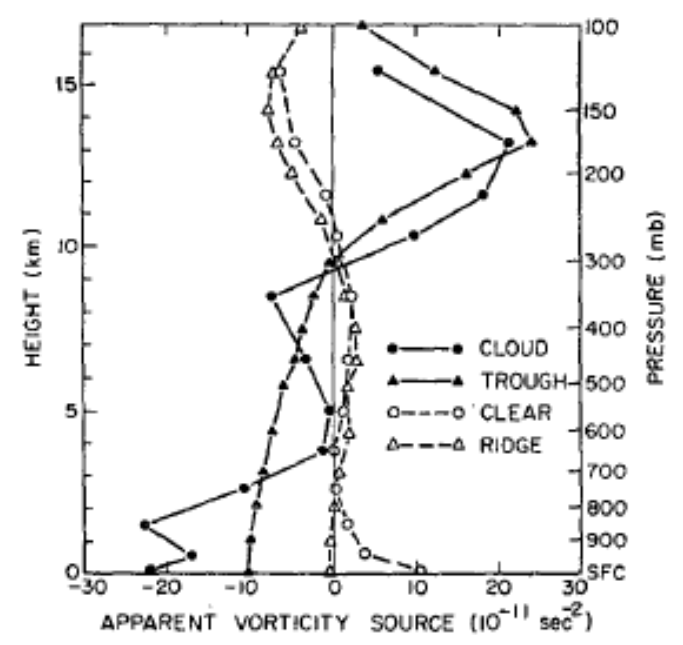

Fig. 5.22. Perfil vertical do resíduo do balanço de vorticidade para diferentes regiões de composites de ondas de leste (ver o texto para mais explicações). Figura extraída de Reed e Johnson (1974). 
Comparando-se os resultados do presente trabalho (Fig. 5.21) com o resultado de Reed e Johnson (1974) (Fig. 5.22), nota-se que o estágio de intensificação 2 apresenta um perfil vertical médio do termo residual semelhante, atuando como sumidouro na região convergente da baixa troposfera e como fonte na região divergente em altos níveis. É importante lembrar que um sumidouro de vorticidade ciclônica no HS (HN) é representado por valores positivos (negativos) de VR. 


\section{CAPÍTULO 6}

\section{Considerações finais}

\subsection{Sumário e conclusões gerais do trabalho}

As etapas iniciais desenvolvidas neste trabalho consistiram no processo de automatização do algoritmo de rastreamento (SUGAHARA, 2000) e do CPS (HART, 2003). Esta automatização possibilitou a análise dos diagramas de fase de todas as perturbações ciclônicas ocorridas no Atlântico Sul Subtropical durante um extenso período de tempo (mais de dois anos). Antes da automatização, esta análise era inviável, uma vez que os códigos do CPS disponíveis na home page do pesquisador Hart (2003) permitem a análise de apenas um ciclone por vez.

Os parâmetros do CPS proporcionais ao vento térmico $\left(-\left|V_{T}^{L}\right|\right.$ e $\left.-\left|V_{T}^{U}\right|\right)$ foram avaliados durante todo o ciclo de vida de cada ciclone rastreado durante os anos de 2008, 2009 e o mês de março de 2010, através de um algoritmo desenvolvido em Shell. Quando as condições impostas ocorreram por pelo menos quatro tempos consecutivos, o ciclone foi separado e identificado como híbrido. Este processo objetivo de identificação dos ciclones híbridos encontrou um número demasiadamente elevado de sistemas que não condiz com o esperado, uma vez que estudos anteriores verificaram que ciclones subtropicais no Atlântico Sul são pouco freqüentes (BRAUN, 2009). Realizou-se, portanto, uma análise subjetiva dos campos sinóticos de cada caso, e constatou-se que o processo de rastreamento de núcleos de vorticidade ciclônica superestimava a quantidade de ciclones. Isto ocorreu, em parte, devido à utilização dos dados FNL de resolução horizontal de $1,0^{\circ}$ por $1,0^{\circ}$, que resulta em campos de VR mais ruidosos. Entretanto, verificou-se que, apesar de identificar diversas trajetórias que não correspondem de fato a uma região ciclônica com isóbaras fechadas, o processo de automatização também identifica corretamente e de maneira precisa a trajetória dos ciclones principais que ocorreram na região.

Com isso, foi possível selecionar dois diferentes ciclones com estruturas híbridas para investigação: um de abril de 2009, próximo à região costeira de São Paulo, e outro de março de 2010, que despertou a atenção da mídia por sua trajetória e configuração atípicas. Cada ciclone selecionado foi investigado do ponto de vista sinótico, dinâmico e termodinâmico, sendo que as análises foram divididas nas seguintes etapas: 
- Realização da análise sinótica do evento, a partir de campos de variáveis meteorológicas sobre a região de atuação do sistema e em diferentes níveis de pressão;

- Análise dos campos espaciais de cada termo do balanço de calor e vorticidade sobre a região de atuação do sistema, e em diferentes níveis de pressão;

- Descrição dos perfis verticais médios de cada termo das equações do balanço de calor e vorticidade, além de perfis de VR, divergência e movimento vertical;

- Comparação entre os campos residuais do balanço de calor e do balanço de vorticidade, a fim de verificar se a atividade convectiva poderia ser responsável pelos “imbalanços” observados de VR.

Ambos os ciclones subtropicais analisados apresentaram fraco aprofundamento da pressão central, e provavelmente não seriam detectados em rastreamentos utilizando mínimos de pressão devido aos limiares normalmente utilizados. No entanto, a análise sinótica mostrou que, nos dois eventos, os ventos máximos no entorno dos ciclones superaram $15 \mathrm{~m} \mathrm{~s}^{-1}$ em 925 hPa por várias horas, além de terem sido responsáveis por chuva intensa no Oceano Atlântico, afetando a região costeira de vários estados da costa brasileira. Portanto, embora com fraca intensidade em termos de pressão central, estes sistemas apresentam impacto importante nas condições de tempo sobre o centro-leste do Brasil e o Atlântico Sul Oeste.

No caso do ciclone de abril de 2009, sua posição central em superfície permaneceu praticamente estacionária entre os dias 23 a 25 de abril. O distúrbio em superfície se originou a leste de um cavado em níveis superiores da atmosfera, o que sugere que o sistema ciclônico teve seu início disparado por forçante de altos níveis. Este sistema durou somente dois dias, sendo que, apenas 12 horas após o surgimento da primeira isóbara, o ciclone já atingiu sua menor pressão em superfície, passando então a enfraquecer até sua dissipação. Em níveis médios da atmosfera, no estágio maduro, uma baixa se desprendeu dentro do cavado em 500 hPa. Quando o cavado em altos níveis enfraqueceu, o sistema passou a se desintensificar em toda a coluna atmosférica.

Os perfis verticais médios deste ciclone de abril de 2009 mostraram que, os estágios inicial e maduro foram caracterizados por intensa VR ciclônica em altos níveis. Além disso, esses estágios apresentaram um padrão de convergência em baixos e divergência em altos níveis. A fase madura do sistema foi a que apresentou movimentos ascendentes mais intensos na média troposfera. 
O ciclone de março de 2010 formou-se no dia 4 às 12 UTC em superfície próximo à costa do Rio de Janeiro e Espírito Santo, e passou a se deslocar para sudoeste em direção à região onde havia um cavado em médios e altos níveis que fornecera suporte dinâmico. Este suporte dinâmico propiciava a convergência em baixos níveis e assim contribuía para a intensificação do sistema. Este ciclone teve longa duração (aproximadamente 8 dias) e apresentou deslocamento atípico para a região, tendo despertado a atenção de diversos centros meteorológicos e inclusive da mídia. O ciclone recebeu o nome Anita e apresentou dois diferentes estágios de intensificação: um durante sua fase híbrida e outro em sua fase de transição extratropical.

No dia 3 às 18Z, o Anita se formou com características subtropicais, e a partir do dia 11 às 06 UTC fez transição para extratropical no fim de seu ciclo de vida, quando se mesclou a um outro ciclone que atuava em latitudes médias. Os movimentos ascendentes foram máximos na região de atuação do sistema, especialmente no estágio de intensificação 1; entretanto, a partir do momento que o ciclone atingiu seu estado maduro, observaram-se movimentos descendentes em médios e altos níveis, sendo que movimentos ascendentes voltaram a ser observados somente na segunda intensificação.

Quanto às semelhanças observadas entre ambos os estágios de intensificação do ciclone de março de 2010, destaca-se a máxima advecção horizontal de VR ciclônica em altos níveis na região de atuação do ciclone em superfície. Além disso, durante as intensificações, a soma dos termos de menor contribuição da equação da vorticidade foi máxima em toda a coluna atmosférica, contribuindo para as tendências anticiclônicas de vorticidade. Verificouse ainda que o estágio maduro caracterizou-se por apresentar os menores valores dos termos das equações em todos os níveis. O estágio de enfraquecimento foi o primeiro que apresentou um núcleo bem definido de variação local da vorticidade relativa no setor leste do ciclone em superfície, o que propiciou enfim o seu deslocamento para leste no Atlântico. Esta configuração deveu-se principalmente do termo de divergência e do termo residual.

Os dois ciclones analisados apresentaram, ao menos em algum tempo de sua fase subtropical, um pico de advecção quente em altos níveis. Para o ciclone de abril de 2009, o pico de advecção quente ocorreu em $200 \mathrm{hPa}$ durante o estágio inicial e maduro, enquanto que para o ciclone de março de 2010 ocorreu em 250 hPa no estágio de intensificação 1.

A magnitude da advecção horizontal de temperatura em baixos níveis para ambos os ciclones subtropicais mostrou-se menos intensa que a obsevada tipicamente em ciclones de latitudes médias. Além disso, durante a fase híbrida dos ciclones, o termo diabático era positivo em baixos níveis, e era o termo responsável pelas tendências de aquecimento em 
baixos níveis. Durante a fase de transição extratropical do ciclone de março de 2010, o sentido dos fluxos em superfície se inverteu e o termo diabático passou a contribuir para tendências de resfriamento em baixos níveis.

Para ambos os ciclones investigados neste trabalho, observou-se uma forte relação entre as áreas de nebulosidade e as áreas de maior aquecimento diabático em médios níveis, evidenciando o aumento da temperatura devido aos efeitos da liberação de calor latente pela condensação do vapor d’água. Além disso, em médios e altos níveis, o termo diabático atuou de forma a contrabalancear as variações de temperatura causadas pelo termo relacionado ao movimento vertical Sw (termo adiabático e de advecção vertical de temperatura). Contudo, nos níveis mais próximos à superfície esta relação não ocorreu.

$\mathrm{Na}$ busca de uma explicação física para as regiões em que ocorrem os maiores “imbalanços”, alguns estudos indicam que a convecção pode ser responsável pelos intensos resíduos observados. Entretanto, no presente trabalho, a relação entre as regiões de resíduos das equações da vorticidade e da termodinâmica foi verificada somente no nível de $300 \mathrm{hPa}$ e somente em alguns estágios. Constatou-se ainda que esta relação ocorre apenas nas regiões em que são satisfeitas as seguintes condições:

1) O resíduo da equação da vorticidade deve atuar de forma a contrabalancear as tendências de vorticidade impostas pelo termo de divergência (o que explica o fato de que as relações foram verificadas em $300 \mathrm{hPa}$, já que neste nível o campo de divergência do vento possui uma alta correspondência ao campo de movimento vertical - regiões de divergência são regiões de movimento ascendente - que por sua vez está relacionado aos efeitos da convecção);

2) As contribuições para as variações de temperatura devidas aos processos diabáticos devem ser opostas às contribuições do termo relacionado ao movimento vertical Sw (Isto explica o fato de que as relações entre as regiões de resíduos das equações não foram verificadas em $925 \mathrm{hPa}$, já que neste nível o campo de divergência também corresponde bem ao campo de movimento vertical - regiões de convergência são regiões de movimento ascendente - contudo o termo diabático não se opõe claramente ao termo $\mathrm{Sw}$ ).

Assim, em $300 \mathrm{hPa}$, foram encontradas algumas regiões em que os processos convectivos poderiam explicar os "imbalanços" observados de vorticidade. Entretanto, é importante ressaltar que a convecção provavelmente também é responsável pelos resíduos do balanço de vorticidade mesmo nas regiões e nos níveis em que não foi observada uma relação direta entre os campos residuais. Nestes casos, sugere-se que a convecção influencia as 
variações locais de vorticidade de uma forma mais distribuída na coluna atmosférica, assim como a divergência associada aos movimentos ascendentes pode se dar de forma mais distribuída ao longo da troposfera, sem estar concentrada somente em alguns níveis.

\subsection{Sugestões para pesquisas futuras}

A automatização do algoritmo de rastreamento de ciclones e do CPS pode servir como uma útil ferramenta para a realização de climatologias de ciclones, não só subtropicais, mas também extratropicais ou tropicais. Além disso, seria interessante ter uma base de dados mais ampla de ciclones que passaram por processos de transição, como o ciclone de março de 2010, e de ciclones que passaram por seclusão quente no Atlântico Sul. Com uma climatologia de cada tipo de sistema, seria possível identificar quais são as regiões e épocas preferenciais de ocorrência de cada classe de ciclone.

Além disso, seria interessante utilizar composites de diversos ciclones subtropicais no Atlântico Sul e identificar quais são as condições sinóticas, dinâmicas e termodinâmicas médias associadas ao desenvolvimento destes sistemas, buscando encontrar características nos perfis verticais dos termos das equações dos balanços de calor e vorticidade que diferenciem os ciclones subtropicais dos ciclones tropicais e extratropicais. 


\section{REFERÊNCIAS BIBLIOGRÁFICAS}

ALLABY, M. Atmosphere. A Scientific History of Air, Weather, and Climate. Facts On File, 258 pp, 2009.

AUBERT, E. F. On the release of latent heat as a factor in large scale atmospheric motion. Journal of Meteorology, v. 14, p. 527-542, 1957.

BENGTSSON, L.; HODGES, K. I.; ESCH, M.; KEENLYSIDE, N.; KORNBLUEH, L.; LUO, J.-J.; YAMAGATA, T. How may tropical cyclones change in a warmer climate? Tellus, v. 59A, p. 539-561, 2007.

BEVEN, J. L. II. A study of three "hybrid" storms. In: $22^{\text {nd }}$ CONFERENCE ON HURRICANES AND TROPICAL METEOROLOGY, Fort Collins, CO. American Meteorological Society, p. 645-646, 1997.

BJERKNES, J. On the Structure of Moving Cyclones. Geof. Publ., v. 1(2), p. 1-8, 1919.

BJERKNESS, J. e HOLMBOE, J. On the Theory of Cyclones. Journal of Meteorology, v. 1, p. 1-22, 1944.

BJERKNESS, J. e SOLBERG, H., 1922: Life Cycles of Cyclones and Polar Front Theory of Atmospheric Circulation. Geofys. Publ. v. 3(1), 3-18.

BLUESTEIN, H. Synoptic-Dynamic Meteorology in Midlatitudes: Principles of Kinematics and Dynamics. Oxford University Press, New York, vol. 1, 431 pp., 1993.

BONATTI, J. P.; RAO, V. B.; DA SILVA DIAS, P. L. Estudo observacional da propagação para leste do fenômeno Catarina e sua simulação com modelo global de alta resolução. In: XIII CONGRESSO BRASILEIRO DE METEOROLOGIA, Fortaleza, Brasil, 2004. 29 ago. a 03 set. Anais... CD-ROM, 16 p., 2004.

BRAND, S. The effects on a tropical cyclone of cooler surface waters due to upwelling and mixing produced by a prior tropical cyclone. Journal of Applied Meteorology, v. 10, p. 865874, 1971.

BRAUN, A. A comparison between South Atlantic and Tasman Sea subtropical storms, 2009. 140 f. Dissertação (Mestrado em Meteorologia) - Departamento de Meteorologia Pennsylvannia State University, State College, PA, 2009.

BUSINGER, T.; BIRCHARD, Jr.; KODAMA, K.; JENDROWSKI, P. A.; WANG, J. A bow echo and severe weather associated with a kona low in Hawaii. Weather and Forecasting, 13, p. 576-591, 1998.

CARLSON, T. Mid-Latitude Weather Systems. Harper-Collins Academia, 507 pp., 1991. 
CAVAlCANTI, I. F. A.; FERREIRA, N. J.; SILVA, M. G. A. J.; DIAS, M. A. F. S. Tempo e clima no Brasil. São Paulo: Oficina de Textos, 463 pp, 2009.

CHARNEY, J. G. The Dynamics of Long Waves in a Baroclinic Westerly Currents. Journal of Meteorology, v. 4(5), p. 135-162, 1947.

CHARNEY, J. G. e ELIASSEN, A. On the growth of hurricane depression. Journal of Atmospheric Sciences, v. 21, p. 68-75, 1964.

CRESSMAN, G. P. An operational objective analysis system. Monthly Weather Review, v. 7(10), p. 367-374, 1959.

da ROCHA, R. P. e CAETANO NETO, E. S. The role of convective parameterization in the simulation of a cyclone over the South Atlantic. Atmósfera (México), v. 23, p. 1-23, 2010.

DAINGERFIELD, L. H. Kona storms. Monthly Weather Review, v. 49, p. 327-328, 1921.

DAVIS, C. A. Simulations of subtropical cyclones in a baroclinic channel model. Journal of the Atmospheric Sciences, v. 67, p. 2871-2892, 2010.

DAVIS, C. A. e BOSART, L. F. Baroclinically Induced Tropical Cyclogenesis. Monthly Weather Review, v. 131, p. 2730-2747, 2003.

DIAS PINTO, J. R. Análise da Dinâmica de um Ciclone no Leste do Sudeste do Brasil através do Balanço de Vorticidade, 2007. Relatório final de atividades FAPESP, 2007.

EADY, E. T. Long Waves and Cyclones Waves. Tellus, v. 1(3), p. 35-52, 1949.

EMANUEL, K. A. The maximum intensity of hurricanes. Journal of the Atmospheric Sciences, v. 45, p. 1143-1155, 1988.

EVANS, J. L. e GUISHARD, M. P. Atlantic Subtropical Storms. Part I: Diagnostic Criteria and Composite Analysis. Monthly Weather Review, v. 137, p. 2065-2080, 2009.

FEDOROVA, N. Meteorologia Sinótica. Editora e Gráfica Universitária- UFPel, Pelotas, v. 2, $242 \mathrm{pp}, 2001$.

FITZROY, R. The Weather Book: A Manual of Practical Meteorology. 2nd ed. Longman, Green, Longman, Roberts and Green, London, 463 pp, 1863.

GAN, M. A.; RAO, V. B. Surface cyclogenesis over South America. Monthly Weather Review, v. 119, p. 1293-1303, 1991.

GLICKMAN, T. Glossary of Meteorology. Second edition, American Meteorological Society, CD-ROOM, 2000. 
GOZZO, L. F. Simulação numérica da influência dos fluxos de superfície em ciclones na costa leste do sul do Brasil, 2010, 121 f. Dissertação (Mestrado em Meteorologia), Departamento de Ciências Atmosféricas do Instituto de Astronomia, Geofísica e Ciências Atmosféricas, Universidade de São Paulo, São Paulo, 2010.

GOZZO, L. F. Ciclones subtropicais sobre o Atlântico Sul: climatologia dinâmica e potencial para transição tropical. Relatório de atividades do doutorado, 2011. Instituto de Astronomia, Geofísica e Ciências Atmosféricas da Universidade de São Paulo, 2011.

GRAY, W. M. Hurricanes: their formation, structur e, and likely role in the tropical cyclone. Meteorology over the Tropical Oceans. D. B. Shaw, Ed., Roy. Meteor. Soc., 155-218, 1979.

GROTJAHN, R. Vorticity Equation Terms for Extratropical Cyclones. Monthly Weather Review, v. 124, p. 2843-2858, 1996.

GUISHARD, M. P. Atlantic Subtropical Storms: Climatology and Characteristics, 2006. 158 f. Tese PhD (Doutorado). Departamento de Meteorologia - Pennsylvannia State University, State College, PA, 2006.

GUISHARD, M. P.; NELSON, E. A.; EVANS, J. L.; HART, R. E.; O’CONNELL, D. G. Bermuda subtropical storms. Meteorology and Atmospheric Physics, v. 97, p. 239-253, 2007.

GUISHARD, M. P.; Evans, J. L.; Hart, R. E. Atlantic Subtropical Storms. Part II: Climatology. Journal of Climate, v. 22, p. 3574-3594, 2009.

HAKIM, G. J. Cyclogenesis. Encyclopedia of Atmospheric Science. Edited by James R. Holton, Judith A. Curry and John A. Pyle, Academic Press, San Diego, v. 6, p. 589-594, 2003.

HART, R. E. A cyclone phase space derived from thermal wind and thermal asymmetry. Monthly Weather Review, v. 131, p. 585-616, 2003.

HART, R. E. e EVANS, J. L. A climatology of the extratropical transition of Atlantic tropical cyclones. Journal of Climate, v. 14, 546-564, 2001.

HIRSCHBERG, P. A. e FRITSCH, J. M. Tropopause undulations and the development of extratropical cyclones, Part I: Overview and observations from a cyclone event. Monthly Weather Review, v. 119, p. 496-517, 1991.

HOLLAND, G. J.; LYNCH, A. H.; LESLIE, L. M. Australian east-coast cyclones. Part I: Synoptic overview and case study. Monthly Weather Review, v. 115, p. 3024-3036, 1987.

HOLLAND G. J. The maximum potential intensity of tropical cyclones. Journal of Atmospheric Sciences, v. 54, p. 2519-2541, 1997. 
HOLMBOE, J.; FORSYTHE, G. E.; GUSTIN, W. Dynamic Meteorology. John Wiley \& Sons, Inc., New York, N.Y., 378 pp, 1945.

HOLTON, J. R., 2004: An Introduction to Dynamic Meteorology. Elsevier Academic Press, New York, 4th Edition, 535 pp, 2004.

HOLTON, J. R. e COLTON, D. E. A diagnostic study of the vorticity balance at $200 \mathrm{mb}$ in the tropics during the Northern summer. Journal of Atmospheric Sciences, v. 29(9), p. 1124-1128, 1972.

HOSKINS, B. J. e HODGES, K. I. A New on Southern Hemisphere Storm Tracks. Journal of Climate, v. 18, p. 4108-4129, 2005.

HUFFMAN, G. J.; ADLER, R. F.; BOLVIN, D. T.; GU, G.; NELKIN, E. J.; BOWMAN, K. P.; STOCKER, E. F.; WOLFF, D. B. The TRMM Multi-satellite Precipitation Analysis: Quasi-Global, Multi-Year, Combined-Sensor Precipitation Estimates at Fine Scale. Journal of Hydrometeorology, v. 8, p. 33-55, 2007.

IWABE, C. M. N. Intrusão Estratosférica Associada com Ciclogêneses na Costa Sul do Brasil: uma Análise Utilizando o Conceito de Vorticidade Potencial, 2008. $106 \mathrm{f}$. Dissertação (Mestrado em Meteorologia), Departamento de Ciências Atmosféricas do Instituto de Astronomia, Geofísica e Ciências Atmosféricas, Universidade de São Paulo, São Paulo, 2008.

IWABE, C. M. N.; DA ROCHA, R. P. An event of stratospheric air intrusion and its associated secondary surface cyclogenesis over the South Atlantic Ocean. Journal of Geophysical Research, v. 114, p. 1-15, 2009.

JONES, S. C., e co-autores. The Extratropical Transition of Tropical Cyclones: Forecast Challenges, Current Understanding, and Future Directions. Weather and Forecasting, v. 18, p. 1052-1092, 2003.

KALNAY, E.; KANAMITSU, M.; KISTLER, R.; COLLINS, W.; DEAVEN, D.; GANDIN, L.; IREDELL, M.; SAHA, S.; WHITE, G.; WOOLLEN, J.; ZHU, Y.; LEETMAA, A.; REYNOLDS, B.; CHELLIAH, M.; EBISUZAKI, W.; HIGGINS, W.; JANOWIAK, J.; MO, K.C.; ROPELEWSKI, C.; WANG, J.; ROY JENNE; DENNIS JOSEPH. The NCEP/NCAR 40-Year Reanalysis Project. Bulletin of the American Meteorological Society, v. 77, p. 437-471, 1996.

KODAMA, K. R. e BARNES, G. M. Heavy rain events over the south-facing slopes of Hawaii: Attendant conditions. Weather and Forecasting, v. 12, p. 347-367, 1997.

LAMBERT, S. J. A cyclone climatology of the Canadian Climate Centre general circulation model. Journal of Climate, v. 1, p. 109-115, 1988. 
Le MARSHALL, J. F. e KELLY, G. A. M. A January and July climatology of the Southern Hemisphere based on daily numerical analyses 1973-77. Aust. Meteor. Mag., v. 29, p. 115$123,1981$.

LIM, E.-P. e SIMMONDS, I. Southern Hemisphere winter extratropical cyclone characteristics and vertical organization observed with the ERA-40 reanalysis data in 19792001. Journal of Climate, v. 20, p. 2675-2690, 2007.

MADDOX, R. A. e DOSWELL, C. A. An Examination of Jet Stream Configurations, $500 \mathrm{mb}$ Vorticity Advection and Low-Level Thermal Advection Patterns During Extended Periods of Intense Convection. Monthly Weather Review, v. 110, p. 184-197, 1982.

MARKS, F. D. Hurricanes. Encyclopedia of Atmospheric Science. Edited by James R. Holton, Judith A. Curry and John A. Pyle, Academic Press, San Diego, v. 6, p. 942-966, 2002.

MARTIN, J. E. Mid-Latitude Atmospheric Dynamics - A First Course. Wiley, 324 pp, 2006.

McTAGGART-COWAN, R.; BOSART, L.; DAVIS, C. A.; ATALLAH, E. H.; GYAKUM, J. R.; EMANUEL, K. A. Analysis of Hurricane Catarina (2004). Monthly Weather Review, v. 134, p. 3029-3053, 2006.

MORRISON, I. e BUSINGER, S. Synoptic Structure and Evolution of a Kona Low. Weather and Forecasting, v. 16, p. 81-98, 2001.

MURRAY, R. J. e SIMMONDS, I. A numerical scheme for tracking cyclone centers from digital data. Part I: Development and operation of the scheme. Aust. Meteor. Mag., v. 39, p. 155-166, 1991a.

MURRAY, R. J. e SIMMONDS, I. A numerical scheme for tracking cyclone centers from digital data. Part II: Application to January and July general circulation model simulations. Aust. Meteor. Mag., v. 39, p. 167-180, 1991b.

NEIMAN, P. J. e SHAPIRO, M. A. The Life Cycle of an Extratropical Marine Cyclone. Part I: Frontal- Cyclone Evolution and Thermodynamic Air-Sea Interaction Monthly Weather Review, v. 121, p. 2153-2176, 1993.

PALMÉN, E. e NEWTON, C. W. Atmospheric Circulation Systems: Their Structure and Physical Interpretation. New York: Academic Press, 603 p, 1969.

PETTERSSEN, S. Weather analysis and forecasting, Vol. I: Motion and motion systems. New York, McGraw Hill Book Co. Inc. 428 pp, 1956.

PETTERSSEN, S. e SMEBYE, S. J. On the development of extratropical cyclones. Quarterly Journal of the Royal Meteorological Society, v. 97(414), p. 457-482, 1971. 
PEZZA, A. B. e SIMMONDS, I. The First South Atlantic Hurricane: Unprecedented Blocking, Low Shear and Climate Change. Geophysical Research Letters, v. 32, L15712, DOI: 10.1029/2005GL023390, 2005.

PONTES DA SILVA, B. F. Contribuição dos Distúrbios Ondulatórios de Leste para a chuva no Leste do Nordeste do Brasil: evolução sinótica média e simulações numéricas, 2011. 123 f. Dissertação (Mestrado em Meteorologia), Departamento de Ciências Atmosféricas do Instituto de Astronomia, Geofísica e Ciências Atmosféricas, Universidade de São Paulo, São Paulo, 2011.

RADINOVIC, D. On the development of orographic cyclones. Quarterly Journal of the Royal Meteorological Society, v. 112, p. 927-951, 1986.

RAMAGE, C. S. Forecasters guide to tropical meteorology: AWS TR 240 updated. AWS/TR95/001, Air Weather Service, U.S. Air Force. 392 pp., 1995. [Disponível em AWSTL, 859 Buchanan St., Scott AFB, IL 62225.]

REBOITA, M. S. Ciclones Extratropicais sobre o Atlântico Sul: Simulação Climática e Experimentos de Sensibilidade, 2008. 294 f. Tese (Doutorado em Meteorologia), Departamento de Ciências Atmosféricas do Instituto de Astronomia, Geofísica e Ciências Atmosféricas, Universidade de São Paulo, São Paulo, 2008.

REBOITA, M. S.; da ROCHA, R. P.; AMBRIZZI, T.; SUGAHARA, S. South Atlantic Ocean Cyclogenesis Climatology Simulated by Regional Climate Model (RegCM3). Climate Dynamics, 10.1007/s00382-009-0668-7, 2010.

REED, R. J. e JOHNSON, R. H. The vorticity budget of synoptic scale wave disturbance in the Tropical western Pacific. Journal of Atmospheric Sciences, v. 31, p. 1784-1790, 1974.

REED, R. J., e SANDERS, F. An investigation of the development of a mid-tropospheric frontal zone and its associated vorticity field. Journal of Atmospheric Sciences, v. 10, p. 338-349, 1953.

RIEHL, H. Some aspects of Hawaiian rainfall. Bulletin of the American Meteorological Society, v. 30, p. 167-187, 1949.

RIEHL, H. e MALKUS, J.S. On the heat balance in the equatorial trough zone. Geophysica, v. 6, p. 503-538, 1958.

SCHROEDER, T. A. Meteorological analysis of an Oahu flood. ccc, v. 105, p. 458-468, 1977a. 1977b.

Hawaiian waterspouts and tornadoes. Monthly Weather Review, v. 105, p. 1163-1170,

SCHULTZ, D. M. Reexamining the cold conveyor belt. Monthly Weather Review, v. 129, p. 2205-2225, 2001. 
SHAPIRO, M. A. e KEYSER, D. Fronts, jet streams and the tropopause. Extratropical Cyclones, The Erik Palmén Memorial Volume, C. W. Newton and E. O. Holopainen, Eds., Amer. Meteor. Soc., 167-191, 1990.

SHAW, W. N. Forecasting Weather. Van Nostrand, 380 pp, 1911.

SIMPSON, R. H. Evolution of the Kona storm: A subtropical cyclone. Journal of Meteorology, v. 9, p. 24-35, 1952.

SINCLAIR, M. R. Synoptic-Scale Diagnosis of Extratropical Transition of a Southwest Pacific Tropical Cyclone. Monthly Weather Review, v. 121, p. 941-960, 1993.

An Objective Cyclone Climatology for the Southern Hemisphere. Monthly Weather Review, v. 122, p. 2239-2256, 1994.

—. Reply. Monthly Weather Review, v. 124, p. 2615-2618, 1996.

Objective Identification of Cyclones and Their Circulation Intensity, and Climatology. Weather and Forecasting, v. 12, p. 595-612, 1997.

e CONG, X. Polar air stream cyclogenesis in the Australasian region: A composite study using ECMWF analyses. Monthly Weather Review, v. 120, p. 1950-1972, 1992.

- e ELSBERRY, R. L. A diagnostic study of baroclinic disturbances in polar air streams. Monthly Weather Review, v. 114, p. 1957-1983, 1986.

—, e REVELL, M. J. Classifications and Composites Diagnosis of Extratropical Cyclogenesis Events in Southwest Pacific. Monthly Weather Review, v. 128, p. 1089-1105, 2000.

- Extratropical transition of southwest Pacific tropical cyclones. Part I: Climatology and mean structure changes. Monthly Weather Review, v. 130, p. 590-609, 2002.

STRETEN, N. A. e TROUP, A. J. A synoptic climatology of satellite observed cloud vortices over the Southern Hemisphere. Quarterly Journal of the Royal Meteorological Society, v. 99, p. 56-72, 1973.

SUGAHARA, S. Variação Anual da Frequiência de Ciclones no Atlântico Sul. In: XI CONGRESSO BRASILEIRO DE METEOROLOGIA - II ENCONTRO BRASILEIRO DE INTERAÇÃO OCEANO-ATMOSFERA, Rio de Janeiro, out. 2000.

TALJAARD, J. J. Development, distribution and movement of cyclones and anticyclones in the Southern Hemisphere during IGY. Journal of Applied Meteorology, v. 6, p. 973-987, 1967. 
TRENBERTH, K. E. On the interpretation of the diagnostic quasi-geostrophic w-equation. Monthly Weather Review, v. 106, p. 131-137, 1978.

UPPALA, S.; KALLBERG, P.; HERNANDEZ, A.; SAARINEN, S.; FIORINO, M.; LI, X.; ONOGI, K.; SOKKA, N.; ANDRAE, U.; BECHTOLD, V. D. C. ERA-40: ECMWF 45-year reanalysis of the global atmosphere and surface conditions 1957-2002. ECMWF Newsletter, v. 101, p. 2-21, 2004.

van LOON, H. A. Climatological Study of the Atmospheric Circulation in the Southern Hemisphere during the IGY, Part I: July 1957 - 31 March 1958. Journal of Applied Meteorology, v. 4, p. 479-491, 1965.

VEIGA, J. A. P.; PEZZA, A. B.; SIMMONDS, I.; SILVA DIAS, P. An analysis of the environmental energetics associated with the transition of the first South Atlantic hurricane, Geophys. Res. Lett., v. 35, L15806, doi:10.1029/2008GL034511, 2008.

VIRJI, H. An estimate of summertime tropospheric vorticity equation budget over South America. Monthly Weather Review, v. 110, p. 217-224, 1982.

WORLD METEOROLOGICAL ORGANIZATION. Technical Document \#94 Tropical Cyclone Programme Report No. TCP-30 Regional Association IV (North America, Central America and the Caribbean) Hurricane Operational Plan 2005 Edition, 2005.

WU, G. e LAU, N.-C. A GCM simulation of the relationship between tropical-storm formation and ENSO. Monthly Weather Review, v. 120, p. 958-977, 1992. 